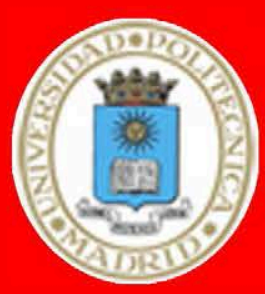

UNIVERSIDAD POLITÉCNICA DE MADRID

ESCUELA TÉCNICA SUPERIOR DE INGENIEROS DE MINAS Y ENERGÍA

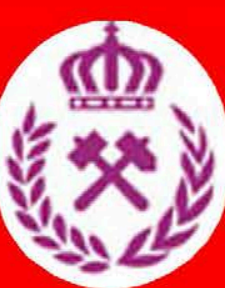

\title{
ENVIRONMENTAL RISKS ASSOCIATED WITH FLOWBACK AND PRODUCED WATERS IN SHALE GAS PROJECTS
}

TESIS DOCTORAL

\section{MA LANTING}

Doctorado en Investigación, Modelización y Análisis del Riesgo en el Medio Ambiente 



\section{ACKNOWLEDGEMENTS}

I would like to thank my advisors Juan F. Llamas and Antonio Hurtado for providing me the opportunity to start my Ph.D. thesis in Universidad Politécnica de Madrid. Although they always being busy, they could find time to offer me professional and financial support.

I would like to express my sincerely appreciation to my tutors - Sonsoles and Fernando in CIEMAT. I spent majority time in CIEMAT with them, they were not only my advisor who helped me to solve the academic issues, to modify my papers and posters that enlightening my academic career. But also they gave me lots of supports in normal life, they helped me finished almost all administrative papers that could let me do not bothering by these stuffs. As a foreigner, no matter how little thing is, they explained many times until I understand completely. Muchas gracias a ustedes.

The research for this paper was financially supported by CTM2014-59828-R project (Ministerio de Economía y Competitividad, Spain).

I would like to extend my thanks to my professors in UPM (Maria Jesús, Marcelo, Luis, etc.,) who gave me a hand and colleagues (Julio, Rocio, Natalia, Irene, etc.,) for having such a good time with them.

I would like to specially thank my parents for always encouraging. I love you.

感谢父母，感谢导师们无私的支持与帮助，谢谢！ 


\section{TABLE OF CONTENTS}

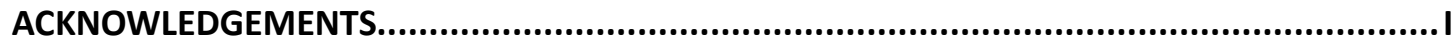

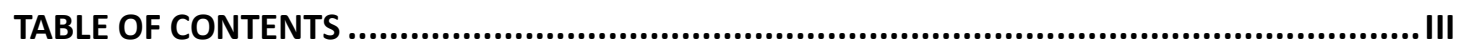

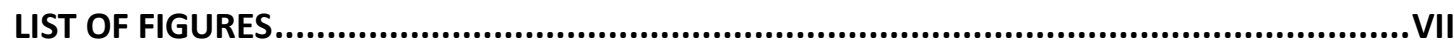

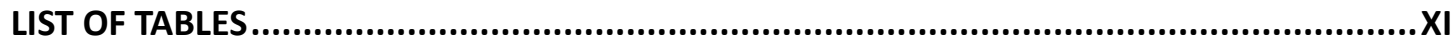

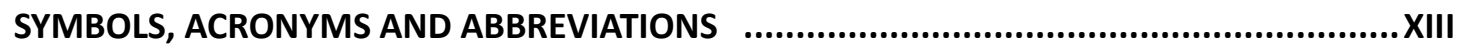

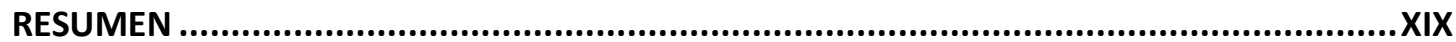

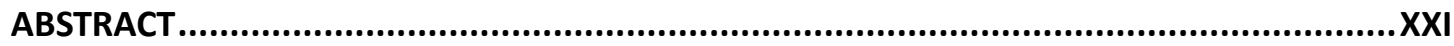

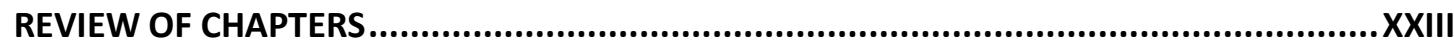

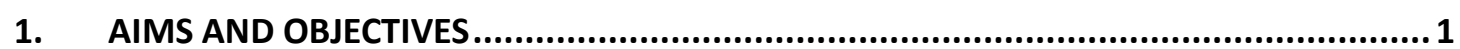

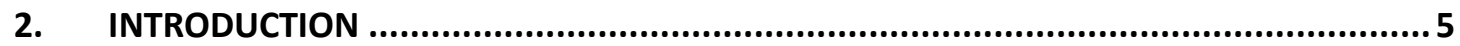

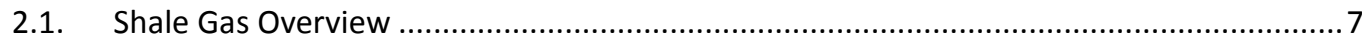

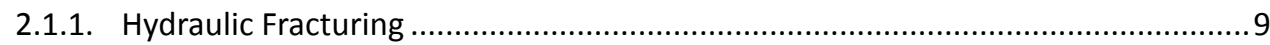

2.1.2. Two perspectives: USA and Europe .............................................................16

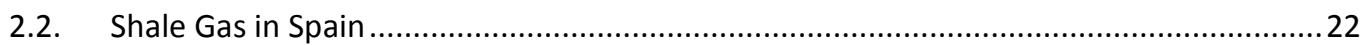

2.3. Unintended consequences of unconventional gas operations: Environmental risk .........33

2.3.1. Water Contamination Pathways............................................................... 40

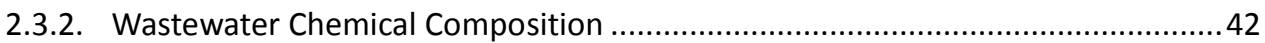

2.4. Underground Transport Processes ...................................................................... 47

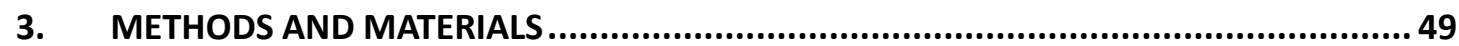

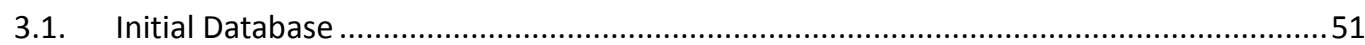

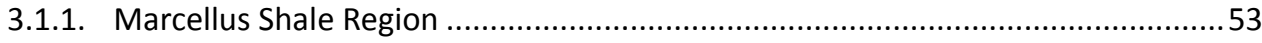


3.2. Description of Transport Phenomena of Reactive Solutes in Soil 58

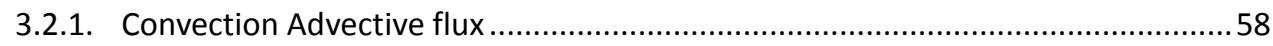

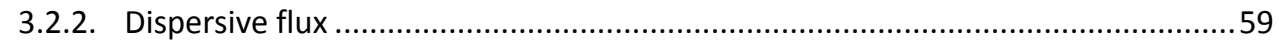

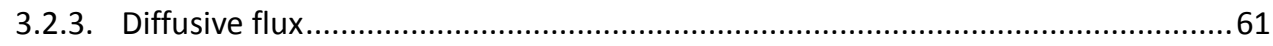

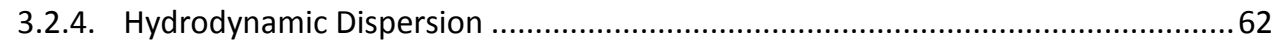

3.2.5. Sources and sinks within the liquid phase ...................................................63

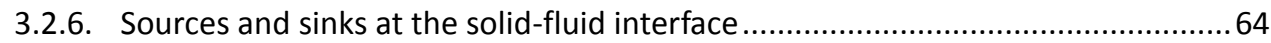

3.3. Model to Evaluate Vertical Transport of Organic Chemicals in the Vadose Zone .............66

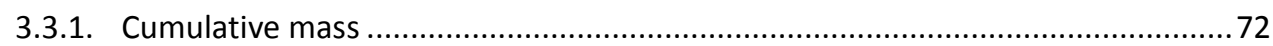

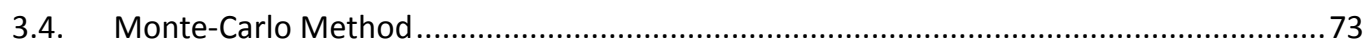

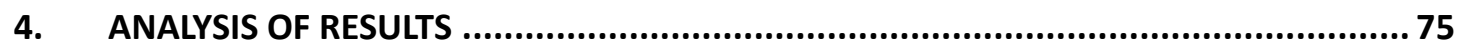

4.1. A Model for Predicting Organic Compounds Concentration Change in Water Associated

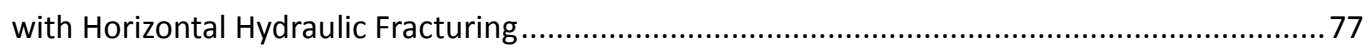

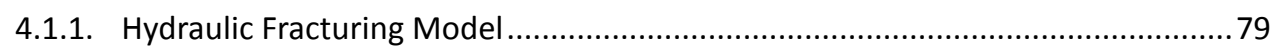

4.1.2. Model application to VOCs and SVOCs. Results and Discussion ..........................102

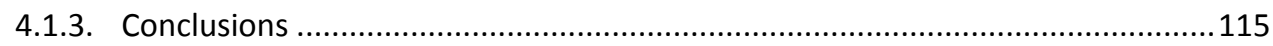

4.2. Determining VOCs Concentrations in Flowback and Produced Waters Storage

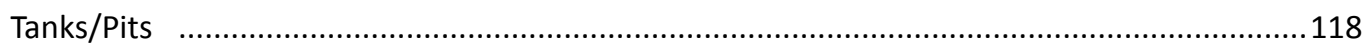

4.2.1. Temporal evolution of Flowback and Produced water volumes ......................120

4.2.2. Temporal evolution of concentrations of VOCs in storage tanks......................125

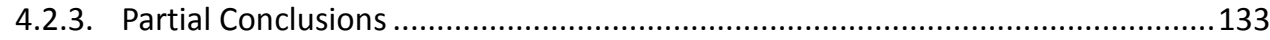

4.3. Analysis of vertical transportation mechanism of VOCs from Horizontal Hydraulic

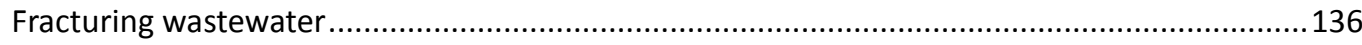

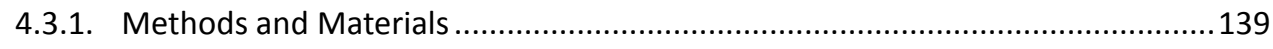

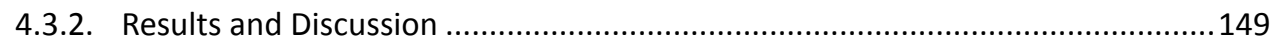

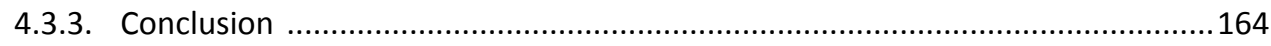

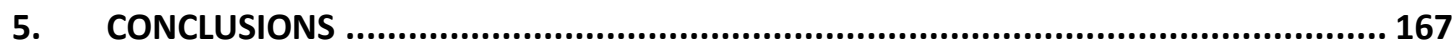


6. FUTURE WORKS ............................................................................... 173

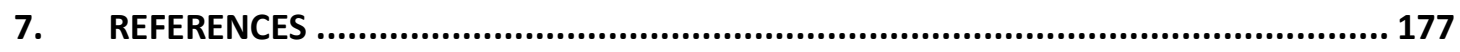

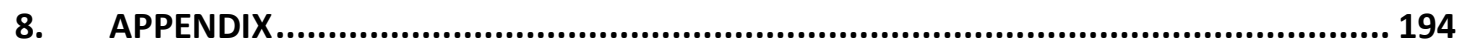




\section{LIST OF FIGURES}

Figure 2-1: Primary energy consumption by fuel in the Reference case, 1980-2040 (quadrillion Btu). 8

Figure 2-2: Global distribution of shale resources (EIA, 2013). 9

Figure 2-3: Hydraulic fracturing and horizontal drilling [Illustration by Al Granberg for ProPublica, (Field et al. 2014)]. 12

Figure 2-4: Schematic representation of the steps used in the geological based approach (McGlade, Speirs, en Sorrell 2013). 26

Figure 2-5: Representation of oil and natural gas resource categorizations (Budzik and Ford, 2014). 27

Figure 2-6: Selected Shale Gas and Oil Basins of Spain (ERI/ARI, 2013). 29

Figure 2-7: Europe Shale Basins (Boyer et al.,2011. Adapted from Kuuskraa et al., 2011).

Figure 2-8: Europe's Shale Resource Assessments (Unproved technically recoverable). Graphic developed from (ERI/ARI, 2013). 31

Figure 2-9: World's Shale Resource Assessments (Unproved Technically Recoverable). Graphic developed from (ERI/ARI, 2013). 32

Figure 2-10: Potential transport pathways of the fluids (Veiguela et al., 2016). 41

Figure 2-11: Contaminant pathways in shale gas development water cycle. 42

Figure 3-1: Pennsylvania Unconventional Well Drilling Permits Issued. 2005 Oil and Gas Annual Report (Pennsylvania, 2016). 52

Figure 3-2: The Map of Samples Locations (Hayes, 2009). 54 
Figure 4-1: Horizontal Hydraulic Fracturing Model Diagram (Jackson et al., 2013b). (a) Cross-section Model of Unconventional Shale Gas Horizontal Fracturing. (b) Modeling the Detail of Hydraulic Fracturing Process

Figure 4-2: Concentration of each compound from all horizontal fracturing wells through whole monitoring period. 86

Figure 4-3: Fittings for Well $\mathrm{F}$ with the model given by equation 9 99

Figure 4-4: Fittings for Well $\mathrm{F}$ with the model given by equation 9 without data corresponding to day 90 . 99

Figure 4-5: Fitting for Well $\mathrm{F}$ with the desorption model of Two Compartments First-order Rate Constants (model given by equation 4.11). 104

Figure 4-6: Results of model fitting. The black points are original mean concentration data and the red lines, the fitting results based on model. Dashed lines indicate that the adjustments may not be appropriate given the available data. 108

Figure 4-7: Estimated concentration ratios of each compound. The grey shaded area represents estimating concentration ratio curve in $1 \sigma$ confidential interval. Estimated mean value concentrations $(\mu)$ are represented by solid line in the figure (in PAH-NAPH this line is coincident with $\mathrm{x}$-axis).

Figure 4-8: Wastewaters storage. 119

Figure 4-9: Evolution of flowback and produced water volumes for D, E, F y G wells. 121

Figure 4-10: Evolution of the mean values (blue curve) and confidence intervals of the accumulated volume for 0.68 (red curves) and 0.95 (green curves) confidence levels. 123

Figure 4-11: Evolution of the mean values (blue solid curve) and confidence intervals of the volume for 0.68 (red dash curves) and 0.95 (green dash curves) confident 
levels

Figure 4-12: Experimental data of the volume values and their confidence intervals for the different wells and days. 126

Figure 4-13: Temporal evolution of Acetophenone concentration in storage tanks associated with fast and slow desorption. 128

Figure 4-14: Temporal evolution of benzene concentration in storage tanks associated with fast and slow desorption. 129

Figure 4-14: Temporal evolution of TEX concentration in storage tanks associated with fast and slow desorption. 130

Figure 4-15: Temporal evolution of TMB concentration in storage tanks associated with fast and slow desorption. 131

Figure 4-16: Temporal evolution of NAPH concentration in storage tanks associated with fast and slow desorption. 132

Figure 4-17: Temporal evolution of PAHs-NAPH concentration in storage tanks associated with fast desorption. 133

Figure 4-19: Wastewater releases process schematic view from disposal storage. _ 140 


\section{LIST OF TABLES}

Table 2-1: Summary of Prospective Resources of Non-conventional Hydrocarbons (ACIEP, 2013). 28

Table 2-2: Shale Gas Reservoir Properties and Resources in Spain (ERI/ARI, 2013). 30

Table 3-1: Number of wells, constituents and data entries in each data source (Abualfaraj et al., 2014).

Table 4-1: Local Geophysical Parameters in the Marcellus Shale 82

Table 4-2: Experimental concentration (ppm) of the pollutant groups. 87

Table 4-3: Experimental concentrations of the groups of contaminants for the upper range of the confidence interval of $1 \sigma$. 90

Table 4-4: Experimental concentrations of the groups of contaminants for the upper range of the confidence interval of $2 \sigma$.

Table 4-5: Fitting criteria corresponding to the data from all the sampled days $(0,1,5$, 14 and 90) and with the data corresponding to the flowback water (days $0,1,5$ and 14). In the case of the fitting with all the data, the obtained values for the first 14 days are also shown, since in some of the cases the $90^{\text {th }}$ day values are of a significantly greater magnitude. 100

Table 4-6: Horizontal Wells Organic Average Concentration Results. 106

Table 4-7: The results of model fitting into the analysis field 111

Table 4-8: Concentration Ratio (calculated using Average $k_{\text {slow }}$ Value) (Maximum Ratios are in Bold and Italics) 114 
Table 4-9: Accumulated volume of Flowback and produced water for the horizontal wells.

Table 4-10: Fitting function values for D, E, F and $G$ wells for which the complete series of data are available. 122

Table 4-11: Confidence intervals for volume evolution at 1, 5, 14 and 90 days for $1 \sigma$ and $2 \sigma$ confidence levels.

Table 4-12: Parameter values of the fitting function for 0.68 and 0.95 levels of confidence. 124

Table 4-13: $C_{0 \_ \text {slow }}$ estimated values for Acetophenone and Benzene. 127

Table 4-14: Basic parameters used for calculations. 147

Table 4-15: Cumulative Mass Percentage of Each Phase in Semi-logarithmic Plots 154

Table 4-16: Predicted Concentration Profile over Time (estimated mean and 1 sigma concentration are represented by solid and dash lines, respectively) 159 


\section{SYMBOLS, ACRONYMS AND ABBREVIATIONS}

BCM - Billion Cubic Meters

COIMCE - Mining Engineers Central Spain College

EIA - US Energy Information Administration

EPA - Environmental Protection Administration

Fm - Formation

FRAC Act - Fracturing Responsibility and Awareness Chemicals Act

GIP - Gas in place

HSE - health, safety and environmental

ICR - Information Collection Request

LNGV - Liquefied Natural Gas

NAPH - Naphthalene

ND - Normal Distribution

NEA - China's National Energy Administration

NGOs - Non-Governmental Organizations

NORMs - Naturally Occurring Radioactive Material

OSFs - Oral Slope Factors

PAHs-NAPH - Polycyclic aromatic hydrocarbon without Naphthalene

PDF - Probability Distribution Functions

REV - Representative Elementary Volume

RFF - Resources for the Future

RfVs - Reference values

R-Benzene - Isopropylbenzene, n-Butylbenzene, n-Propylbenzene, sec-Butylbenzene, p-Isopropyltoluene

SVOCs - Semi-Volatile Organic Compounds 
TCF - Trillion Cubic Feet

TDS - Total Dissolved Solids

TEX - Toluene, Ethylbenzene, Xylene

TFRC - Two-Compartment First-order Rate Constant

TMB - 1,2,4-Trimethylbenzene, 1,3,5-Trimethylbenzene

TOC - Total Organic Carbon

VOCs - Volatile Organic Chemicals

\section{Latin Symbols}

$C$ - Concentration in mass per unit volume of solution [Mass $\cdot$ Length $^{-3}$ ]

$C_{0}$ - Initial concentration $\left[\right.$ Mass $\cdot$ Length ${ }^{-3}$ ]

$\mathrm{C}_{\mathrm{f}}^{\alpha}(\mathrm{t})$ - Concentration of contaminant $\alpha$ at time $\mathrm{t}$ in the flowback or produced water $\left[\right.$ Mass $\cdot$ Length $\left.^{-3}\right]$

$C_{G}$ - Concentration in the gas

$C_{L}$ - Concentration in the liquid

$C_{R}$ - Concentration of an individual component

$C_{0 \_ \text {fast }}$ - Total fast desorbing chemical concentration accessible

$C_{t f a s t}-$ Temporal evolution of pollutant concentration in the water (fast desorption)

$C_{O_{-} \text {slow }}$ - Total slow desorbing chemical concentration accessible

$C_{t_{-} \text {slow }}$ - Temporal evolution of pollutant concentration in the water (slow desorption)

$\mathrm{C}_{\mathrm{w}}^{\alpha}(\mathrm{t})$ - Concentration of contaminant $\alpha$ at time $\mathrm{t}$ in the wastewater tank/pit $\left[\right.$ Mass $\cdot$ Length $^{-3}$ ]

$D$ - Coefficient of hydrodynamic dispersion

$D_{a}$ - Chemical diffusion coefficient in air

$D^{f}$ - Diffusion coefficient

$D_{h}$ - Coefficient of hydrodynamic dispersion $\left(D^{m}+D^{*}\right)$

$D_{G}$ - Dispersion coefficient in the gas phase 
$D_{L}$ - Dispersion coefficients in the liquid phase

$D_{L o}$ - Longitudinal dispersion

$D_{T r}$ - Transverse dispersion

$D^{m}$ - Coefficient of mechanical (or advective) dispersion [Length ${ }^{2} \cdot$ Time $^{-1}$ ] (components $D_{i j}^{m}$ )

$D^{*}$ - Apparent scalar coefficient of molecular diffusion of the element in the fluid phase

$D_{w}$ - Chemical diffusion coefficient in water

$D_{G M}$ - Effective gas diffusion coefficient

$D_{L M}$ - Effective liquid diffusion coefficient

$d_{1}$ - Represent the depth to the top of the contamination source

$d_{2}$ - Represent the depth to the bottom of the contamination source

$d_{3}$ - Represent the depth to the groundwater table

$f_{o c}$ - Fraction of soil that is organic carbon

$J_{a d v}$ - Advective flux [Mass $\cdot \operatorname{area}^{-1} \cdot \operatorname{time}^{-1}$ ]

$J_{\text {diff }}$ - Diffusive flux [Mass $\cdot$ Length $^{-2} \cdot$ Time $^{-1}$ ]

$J_{\text {disp }}$ - Dispersive flux [Mass $\cdot$ Length $^{-2} \cdot$ Time $^{-1}$ ]

$k$ - Desorption first order rate constant $\left[\right.$ Time $\left.^{-1}\right]$

$k_{\text {fast }}$ - The first-order rate constant describing the release rates for the fast desorbing chemical $\left[\right.$ time $\left.^{-1}\right]$

$k_{\text {slow }}$ - The first-order rate constant describing the release rates for the slow desorbing chemical $\left[\right.$ time $^{-1}$ ]

$K_{d}$ - Distribution coefficient

$K_{H}$ - Henry's constant

$K_{S L}$ - The solid-liquid distribution coefficient

$K_{S G}$ - The solid-gas distribution coefficient

$k_{o c}$ - Carbon partition coefficient

$\mathrm{M}_{\mathrm{A}}$ - Cumulative mass to the atmosphere 
$\mathrm{M}_{\mathrm{W}}$ - Cumulative mass to the groundwater

$\mathrm{M}_{\mathrm{w}}^{\alpha}(\mathrm{t})$ - Mass of contaminant $\alpha$ accumulated until the time $\mathrm{t}$ in the wastewater tank/pit [Mass]

Pe - Peclet number

$q_{0}$ - Initial solid-phase concentration prior to desorption

$\mathrm{R}^{2}$ - Coefficient of determination

$R_{d}$ - Retardation factor

$R_{\text {ext }}$ - Volume of liquid added per unit volume of porous medium, per unit time

$R^{j}$ - Rate of production of the element by the $j$ reaction $(\mathrm{j}=1,2, \ldots, \mathrm{n})\left[\mathrm{Time}^{-1}\right]$

$\mathrm{R}_{\mathrm{G}}$ - Partition coefficient in gas

$\mathrm{R}_{\mathrm{L}}$ - Partition coefficient in water

$\mathrm{S}_{\mathrm{ch}}$ - Chemical reactions source (sink) term

$\mathrm{S}_{\mathrm{ext}}$ - Distributed external liquid source (sink) term

$\mathrm{S}_{\mathrm{rd}}$ - Radioactive decay/degradation source (sink) term

$t$ - Time

$v$ - Advective groundwater velocity

$V_{f}(t)$ - The volume of flowback or produced water at time $t$ [Length ${ }^{3}$ ]

$v_{G}$ - Darcy velocity of the gas phase

$v_{L}$ - Darcy velocity of the liquid phase

$v_{x}$ - Average groundwater velocity in the direction of flow [Length $\cdot$ time $^{-1}$ ]

$w^{\prime}$ - Empirical coefficient less than 1 (range between 0.5 to 0.01 )

$z$ - Vertical coordinate taken positive download

\section{Greek Symbols}

$\alpha$ - Porous medium's dispersivity 
$\alpha_{\mathrm{G}}-$ Dispersivity coefficient in the gas phase

$\alpha_{L}-$ Dispersivity coefficient in the liquid phase

$\alpha_{\text {Lo }}$ - Longitudinal dispersivity

$\alpha_{\operatorname{Tr}}-$ Transversal dispersivity

$\theta$ - Effective porosity

$\lambda$ - Radioactive decay/degradation rate constant $\left[\right.$ Time $\left.^{-1}\right]$

$\mu$ - Mean value

$\rho$ - Bulk density

$\sigma$ - Confidence interval in normal distributions

$\phi_{\text {fast }}$ - Fraction of the total fast desorbing chemical present 


\section{RESUMEN}

La fracturación hidráulica, junto con el desarrollo de sondeos horizontales, constituye una tecnología diseñada para incrementar el flujo de gas natural y mejorar la productividad en las formaciones geológicas de baja permeabilidad. Durante estas operaciones, importantes volúmenes de agua, aguas de retorno o flowback más aguas de producción, que contienen una serie de compuestos orgánicos regresan a la superficie con un riesgo potencial de generar impactos negativos en el medioambiente y la salud humana. Para evaluar de manera predictiva el impacto potencial de dichos compuestos a lo largo de todo el proceso de transporte, así como sus cambios de concentración, resulta necesario disponer de modelos matemáticos que puedan ser aplicados en todo el ciclo de vida operacional de fracturación hidráulica. Con el fin de cubrir esta necesidad, a partir de datos de concentración procedentes de operaciones de explotación de Gas No Convencional, se ha desarrollado un modelo predictivo global que permite cuantificar y establecer la evolución de la concentración de los compuestos orgánicos mediante un modelo dinámico de transporte de materia orgánica de doble velocidad, lenta y rápida.

Para la parte rápida del proceso se ha hecho uso de ajustes matemáticos inversos de datos de flowback procedentes de la zona de explotación de gas no convencional de Marcellus, en la cuenca de los Apalaches (EEUU), para poder estimar los coeficientes de transporte, habiéndose obtenido unos elevados coeficientes de determinación $\left(R^{2}\right)$ para los ajustes.

La falta de datos experimentales ha imposibilitado su aplicación a la determinación de los parámetros asociados a la parte lenta del modelo. En este caso las concentraciones han sido estimadas mediante la simulación de Monte-Carlo haciendo uso de modelos teóricos. 
Los resultados muestran que a mayor valor del coeficiente de reparto de carbono orgánico $\left(k_{o c}\right)$ de los compuestos, más tarde se alcanza la máxima concentración en agua. Además, el porcentaje máximo de concentración alcanzaría hasta el $90 \%$ de la concentración inicial disponible en la formación pizarrosa de darse el tiempo necesario para ello.

Además se ha determinado la evolución temporal de los volúmenes de agua de flowback y de producción que, junto con la evolución de las concentraciones, ha permitido determinar la evolución de las concentraciones de contaminantes en los depósitos de almacenamiento de las aguas residuales. Todo ello tanto para valores medios como para extremos superiores de intervalos de confianza para niveles del 68 y/o $95 \%$

Finalmente se ha llevado a cabo una estimación de la contaminación a la que daría lugar un vertido desde los tanques de almacenamiento. Para ello se ha usado una aproximación analítica, adecuada para cálculos posteriores probabilistas de riesgo, que permite obtener tanto la concentración en la zona vadosa como la cantidad de contaminante que se transferiría a los compartimentos ambientales de aguas subterráneas y atmosfera.

En resumen, se trata de un modelo que puede contribuir significativamente a mejorar las técnicas de los procesos de exploración y explotación no convencional de pizarras para la extracción de gas al aumentar los beneficios derivados de la optimización de la evaluación del riesgo tanto para los residentes locales como no locales, así como para brindar experiencia a futuras operaciones. 


\section{Abstract}

The sum of hydraulic fracturing and horizontal wells means a technology designed to increase natural gas flow and to improve productivity in a low permeability geological formation. During this drilling operation, tons of flowback and produced water that contains several organic compounds return to the surface with a potential risk of influencing the surrounding environment and human health. A mathematical model is urgently needed to evaluate predictively the concentration evolution of organic compounds along the water transportation process throughout the whole hydraulic fracturing operational life cycle. A comprehensive predictive model, which fits the experimental data, combining an Organic Matter Transport Dynamic Model with a Two-Compartment First-order Rate Constant (TFRC) Model, has been established to quantify the organic compounds concentration. This model is composed of two transportation rates, fast and slow. For the fast part, the curve fitting technique is used to assess transport coefficients using flowback water data derived from the Marcellus Shale gas fracturing site (Appalachian Basin). The coefficients of determination $\left(R^{2}\right)$ of all analyzed compounds demonstrate a high experimental feasibility of this inverse adjustment method. This technique has not been yet used to obtain the parameters associated with slow rate transport due to the lack of experimental data. In this case the concentrations have been estimated by Monte-Carlo simulation using theoretical models.

The results show that the higher the value of the organic carbon partition coefficient $\left(k_{o c}\right)$ in chemicals, the later the maximum concentration in water will be reached, and the maximum concentration percentage would reach up to $90 \%$ of the initial slow available concentration within a long sufficient period. 
In addition, it has been determined the temporal evolution of volumes of flowback and produced water, which, together with the evolution of concentrations, has allowed to determine the evolution of concentrations of pollutants in the storage tanks of the waste waters. All this for both average values and upper confidence bound of the confidence interval at the $68 \%$ and/or $95 \%$ confidence level.

Finally an estimation of the contamination which would give rise to a discharge from the storage tanks was carried out. For this purpose an analytical approach has been used, suitable for subsequent probabilistic assessments of risk, which allows obtaining both the concentration in the vadose zone and the amount of pollutant that would be transferred to the groundwater and atmosphere environmental compartments.

To sum up, this is a model which would make a significant contribution to enhance Unconventional Shale Gas prospecting-mining processes through increasing benefits out of optimizing health risk assessment and of providing experience to further operations. 


\section{REVIEW OF CHAPTERS}

In this thesis, the first chapter clarifies the basic knowledge about the geological conditions of unconventional natural gas and describes how to use the latest technology - horizontal hydraulic fracturing to exploit natural gas. The main goal in this part is to indicate the possible impacts of this technique to the environment, how it could impact on human health and what shortcomings are in current researches that prevent a more accurate prediction of risks and in taking precautionary measures.

Chapter 2 sets out the main objectives of this study.

Chapter 3 is background information. This part not only describes the local geological setting of the site under study, but also the computational algorithm used Monte-Carlo method - and the mathematical equations that explain the transport phenomena of reactive solutes in soil.

The purpose of chapter 4 is to determine a model that identifies a realistic relationship about organic chemical concentration trends in the produced and flowback waters over time during horizontal hydraulic fracturing operation. Then the concentration in the pits/tanks is estimated and the transport mechanism of volatile organic chemicals (VOCs) through the vadose zone is established and the pollutant releases in the atmosphere and groundwater table is quantified.

Chapter 5 summarizes the principal conclusions of this thesis and Chapter 6 identifies the new possibilities for future research as well as questions raised during this work that would need further investigation. 


\section{Aims and ObJectives}


Hydraulic fracturing is a technology designed to increase natural gas flow and to improve productivity in a low permeability formation. But it also implies tons of flowback and produced water that contains several organic (and inorganic) compounds returned to the surface with a potential risk of influencing the surrounding environment and human health.

Since one of the main risks of environmental contamination related to this technology is related to leaks and spills from areas close to the surface, either in the most superficial parts of the well or in surface storage, it is fundamental to be able to carry out a correct management of the risks associated to return waters. This includes both the contaminants that may be present and the temporal evolution of the concentration of the same. This will allow comparisons with the safety limits of each component and provide for adequate monitoring and mitigation measures.

From a point of simplification of the initial hypotheses, it will be assumed that potential leaks will occur in surface storage.

The evolution of the concentration in surface storage is related both to the volume of return water and to the concentrations of the elements in those waters. And both terms evolve temporarily. This means that it is necessary to have models of temporal evolution for both.

Just as, in this context, there is a model that allows to know the evolution of the concentration with the time of the inorganic components (Balashov et al., 2015), nevertheless, the same thing does not happen with the organic elements, reason why for achieving the goal of an environmentally friendly technology, inter alia, a mathematical model is needed to predictive assessment of organic compounds behavior along the water transportation process as well as concentration change within time throughout the whole hydraulic fracturing operation life cycle. A comprehensive model, which fits the experimental data, combining an Organic Matter Transport Dynamic Model with a Two-Compartment First-order Rate Constant (TFRC) Model has been developed to quantify the organic compounds concentration. This model is composed of two transportation rates, fast and slow respectively. For the fast transportation rate, the curve 
fitting technique is used to assess transport coefficients using flowback water data derived from the Marcellus Shale gas fracturing site. The coefficients of determination $\left(R^{2}\right)$ of all analyzed compounds demonstrate a high experimental feasibility of this inverse adjustment method. This technique has not been yet used to obtain the parameters associated with slow rate transport due to the lack of experimental data. In order to achieve a valid initial approximation to these values, we have used studies based on experimental data that have allowed the obtaining of parametric relationships between physicochemical parameters of the medium and the rate of desorption. Concentration ratio curves have been estimated in the slow part of this model. The results show the relationship between the value of the organic carbon partition coefficient $\left(k_{o c}\right)$ in chemicals and the reach of the maximum concentration in water as well as the maximum concentration percentage of the initial concentration of the various compounds in the shale formation which is expected to reach in a sufficient time-frame.

The predictive evolution of the pollutant concentration in flowback and produced water allows assessing the distribution of a potential spill in the atmosphere, surface water and groundwater. In order to evaluate it an analytical 1D vertical transport model of VOCs through vadose zone to groundwater is settled by assuming linear, equilibrium partitioning between vapor, liquid and adsorbed chemical solid phases (Shan and Stephens, 1995). Firstly, this allows determining the dynamic distribution of the various compounds in the different environmental compartments, but also to determine the most influential parameters of both compounds and environment affecting such distribution

The main objective of the above is to incorporate this predictive knowledge into the various criteria to be taken into account in the shale gas project decision-making process to prevent negative environmental impact as far as possible. 


\section{INTRODUCTION}




\subsection{Shale Gas Overview}

Taking into account that many limitations suffered by humans are the result of the lack of energy access as countries increase economies and improve people's living standards, cheap and plentiful energy for different uses such as production, manufacturing, transportation, etc., is an important requirement to be considered. Fossil fuels, including coal, oil and natural gas, currently remain the primary energy sources. And global energy will be still depending on fossil fuels for at least the next few decades (Shafiee and Topal 2009).

Compared with other fossil fuels, natural gas, where methane $\left(\mathrm{CH}_{4}\right)$ is the major component, may be considered as a cleaner and environmentally friendly fuel. Natural gas is a cleaner burning fuel and emits less sulfur dioxide, nitrogen oxide, particulate and releases almost $30 \%$ and $43 \%$ less carbon dioxide than oil and coal respectively (Energy Information Administration, 1999). Given these advantages, natural gas is being used more and more. Figure 2-1 (EIA, 2015; U.S.Doe, 2013) clearly shows that the proportion of natural gas is increasing rapidly in recent years (Tan, 2014). Specifically in 2013 natural gas as fossil-fired power generation comprised till 27 percent, and was the first time that exceeds the amount of consumed coal.

It appears evident from the significant investments in preliminary leasing activity in many parts of the world that there is significant international potential for shale gas that could play an increasingly important role in global natural gas markets (ESC, 2014; MIT, 2011). Oil companies are shifting their focus and pursuing new alternatives, one of them being the development of shale gas plays because of increasing field maturity and production decline from conventional gas reservoirs (Zhang and Yang, 2015).

Unconventional natural gas in shale deposits, regarded as an important source rock of petroleum reservoirs, has become one of the most rapidly expanding trends in global onshore petroleum exploration and development (Tan, 2014). The latest estimation of technically recoverable unconventional gas resource in 42 evaluated countries is 7795 trillion cubic feet (TCF) and the global distribution of shale resources is showed in Figure 2-2 (EIA, 2011; EIA, 2013). 


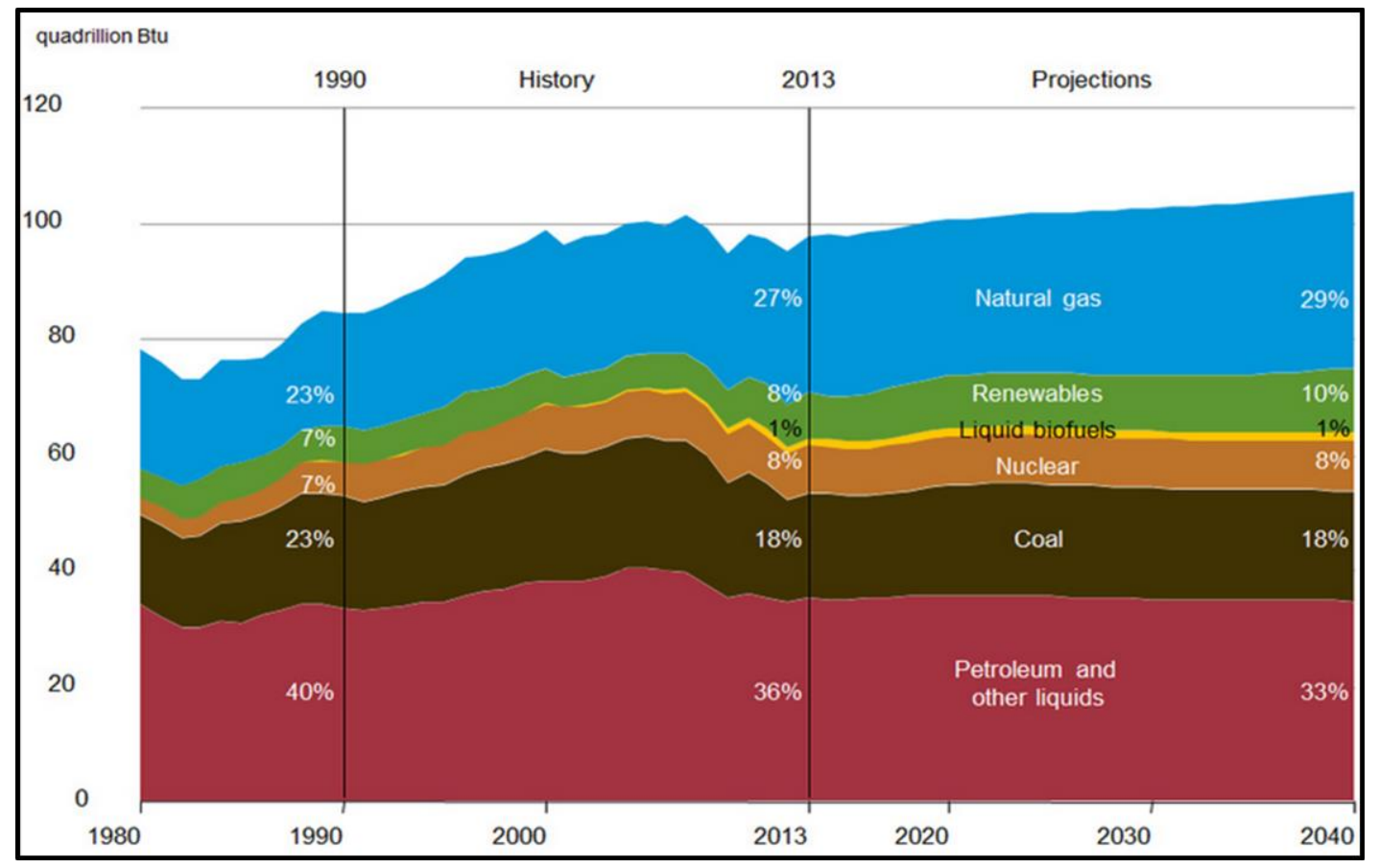

Figure 2-1: Primary energy consumption by fuel in the Reference case, 1980-2040 (quadrillion Btu).

Due to low permeability and porosity in unconventional gas formations and because of typically easily breakable rock in shale formation, hydraulic fracturing and horizontal drilling are key technologies to get possible and marketable production of natural gas from deep underground shale rock formations (Gottardo et al. 2013; Kinnaman 2011; Wright et al. 2012; Jackson R.B. et al., 2013; Alonso Suárez, 2011). Nevertheless, extracting it is controversial and strongly opposed, due to environmental concerns about land use and ground water resources, mainly (U.S. EIA, 2013). As the use of hydraulic fracturing has increased, so have the concerns and debates on its potential impacts on environment, including fresh water resources and water supply stress, contaminating surface water and groundwater, inducing earthquakes, and polluting air. Opponents against shale gas development argued that, the environmental costs to extract natural gas from shale using hydraulic fracturing are too high, considering the potential risks of methane leakage and water contamination (Zhang and Yang, 2015). 


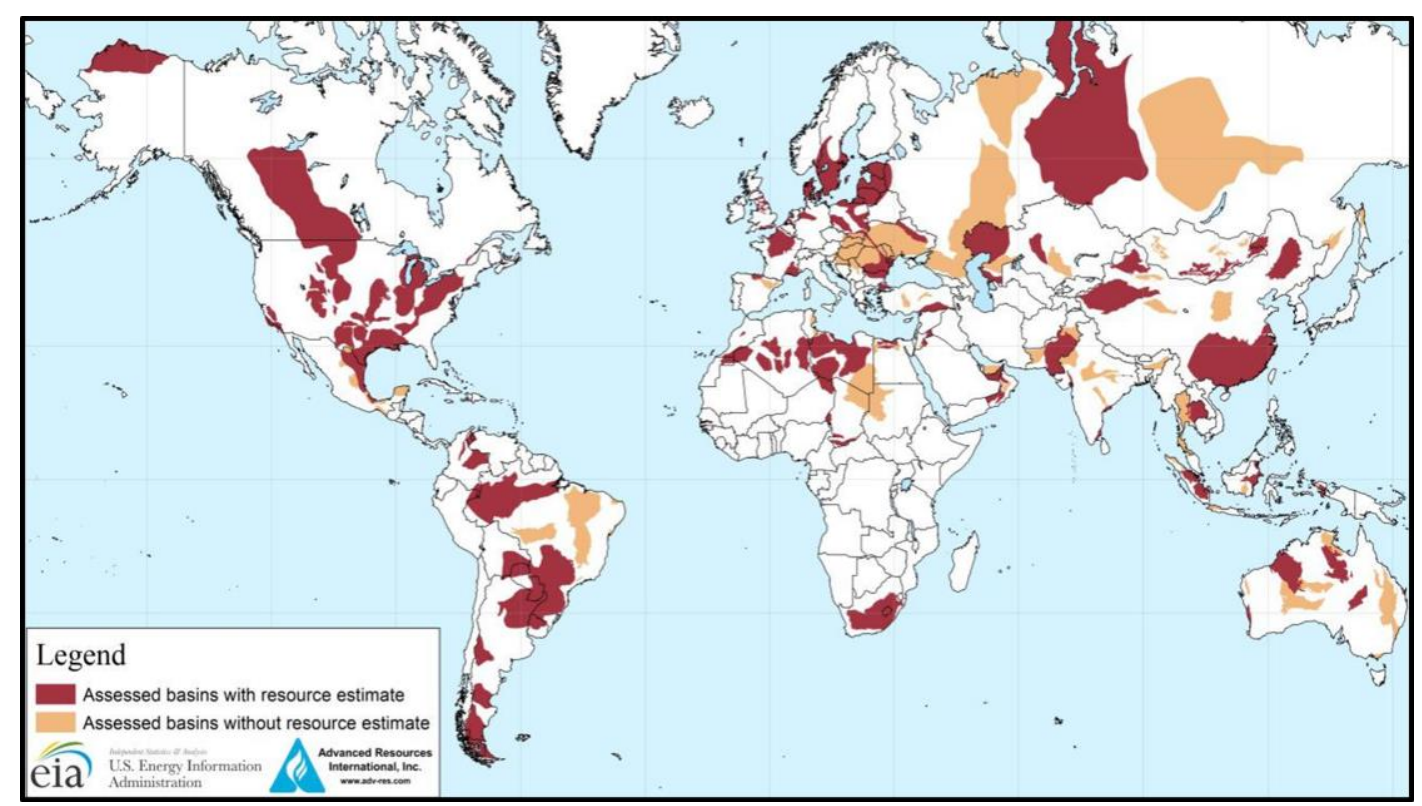

Figure 2-2: Global distribution of shale resources (EIA, 2013).

\subsubsection{Hydraulic Fracturing}

Proved reserves Shale Gas formations can reach depths of over 8,000 feet $(2,438 \mathrm{~m})$ below land surface and requires hydraulic fracturing and horizontal drilling techniques in order to make gas extraction feasible (Rozell and Reaven, 2012; U.S. EIA, 2013). Hydraulic fracturing is a technique used to increase oil and gas extraction of natural gas from shale rock layers through vertical and horizontal drilling together with the injection of highly pressurized fracturing-fluid (Jackson et al., 2013). The technical feasibility of performing horizontal wells is a fundamental development in hydraulic fracturing as it is known nowadays.

From an historical point of view, horizontal drilling emerged around the 30's in the twentieth century. Hydraulic fracturing was first used in the United States in 1947 and entered commercial use after 1949, although experimentation dates back to XIX century (U.S. EIA, 2013). Application of fracturing techniques to stimulate oil and gas production began to grow rapidly in the 1950's. By mid-1970s, a partnership of private 
operators, the U.S. Department of Energy and the Gas Research Institute attempted to develop technologies for the commercial production of natural gas from the relatively shallow Devonian (Huron) shale in the Eastern United States (U.S. EIA, 2013). The advent of large-scale shale gas production did not occur until Mitchell Energy and Development Corporation experimented during the 1980s and 1990s to make deep shale gas production a commercial reality in the Barnett Shale in North-Central Texas (U.S. EIA, 2013). By the early 1980s there were 710,000 wells producing some 3-4 billion cubic meters/year (bcm/y) from the Antrim Shale Play in the Midwest (Stevens, 2010). Practical application of horizontal drilling to oil production began in the early 1980s. The first commercial flows began in 1981 and by the late 1990s the Barnett Play was producing $13 \mathrm{bcm}$ (ESC, 2014; Gülen et al., 2013). In 2002, the first horizontal well was drilled on Barnett Play and by 2009 it was producing $76 \mathrm{bcm}$, over $11 \%$ of total US gas production. The technology has been developing quickly. If it took the Barnett Play 20 years to achieve $5 \mathrm{bcm}$, the Fayetteville Play reached this level in four years (EIA, 2009). The Society of Petroleum Engineers estimate 2.5 million fracturing operations world-wide and over 1 million in the US, and tens of thousands of horizontal wells have been drilled over the past 60 years (King, 2012).

Hydraulic fracturing of unconventional reservoir for extraction of gas has only expanded to Canada and USA but will soon be launched on a global scale//, with significant reservoirs in South America, Northern and Southern Africa, Europe, China and Australia (Vengosh et al. 2014).

The integral process of horizontal hydraulic fracturing is shown in Figure 2-3. Hydraulic fracturing is used after the drilled hole is completed and involves the use of fluid (mainly water with sand and chemical additives) to create or restore small fractures in a formation in order to increase the rate at which fluids can be extracted from the reservoir formations, in some cases of several hundred percent (FracFocus, 2011). Through the production well, the hydraulic fracturing fluid is injected at high pressure. These pumping operations force the flow of the fluid and fracture the reservoir rock. High pressure operation may last from 20 minutes to about 4 hours, depending on the design and the available local geological information (King, 2012). It is possible, therefore, to summarize the whole process by saying that millions of gallons 
of water, thousands of gallons of chemicals, and suspended solids are injected into the target formation under high pressure to create cracks to increase the amount of releasable hydrocarbon that is contained in the target formation. After injection, gas, oil, salt water and hydraulic fracturing fluids flow reverse through the well based on the fact that the generated propped fractures are kept opened and that these are permeable enough to allow the mobility of fluids. Although the range is very variable, it is possible to say that it is expected that between ten and fifty percent of the injected fluid will return to the surface. And here is a fundamental idea in the development of this research work: environmental hazards associated with hydraulic fracturing released wastewater have raised concerns about potential impacts on health (Balaba and Smart, 2012; Elliot et al., 2016; Vengosh et al., 2014).

From a terminological point of view wastewater is divided into produced and flowback water depending on a factor of temporary nature. So, this way, produced water is naturally occurring water found in shale formation that flows to the surface throughout the entire lifespan of the gas well (Vengosh et al., 2014), and flowback water is a fracturing fluid which contains solved chemicals from shale formation and, generally, most occurs within 7-10 days of drilling, but may continue for 3-4 weeks. As well as the target natural gas (mostly methane plus propane, butane, and ethane), wastewater from horizontal fracturing wells contains not only additive compounds such as surfactants, gel, corrosion inhibitors, etc., but also other gases such as carbon dioxide, hydrogen sulphide, nitrogen and helium; formation brine including total dissolved solids (TDS) and trace elements as mercury, arsenic or lead; naturally occurring radioactive material namely radium, thorium, uranium (NORMs); organic constituents and volatile organic compounds, for instance benzene among others (Bloomdahl et al., 2014; King, 2012). Proper disposal of flowback fluids is critically important to the protection of both surface and ground water as well as the design, construction, operation and abandonment of wells, so that when any of them is no longer producing, it should be permanently plugged and abandoned (Krupnick et al., 2014).

The risks posed by high volume hydraulic fracturing for unconventional hydrocarbon extraction seem to be greater than those of conventional extraction. A number of recent reports have looked at opportunities and challenges of unconventional 
fossil fuels and shale gas developments, and found that developing unconventional fossil fuel resources generally poses greater environmental challenges than conventional developments (Broomfield, 2012).

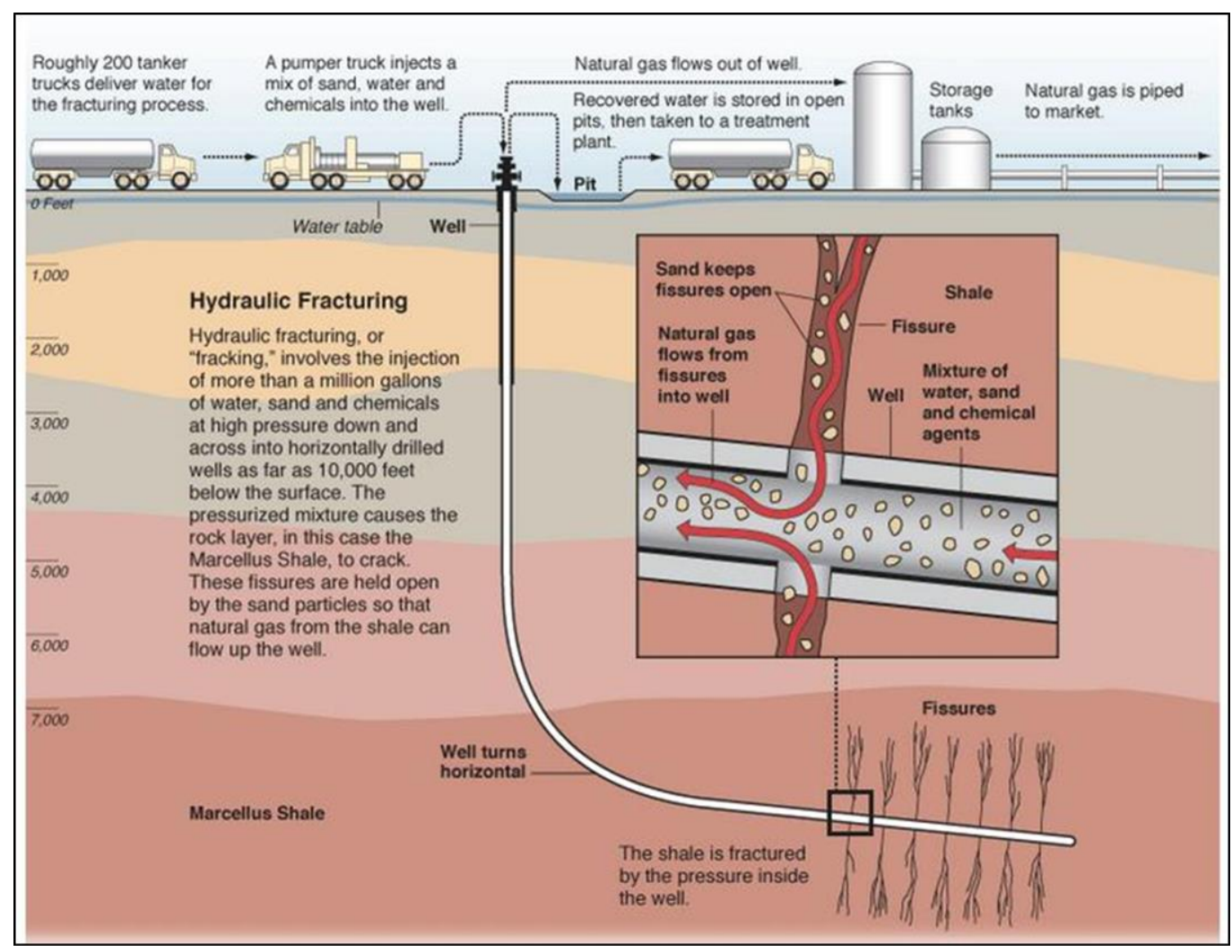

Figure 2-3: Hydraulic fracturing and horizontal drilling [Illustration by Al Granberg for ProPublica, (Field et al. 2014)].

It is in this sense, a number of studies have begun to appear which suggest that problems have been overstated and that many of the environmental problems come from poor well completion rather than fracking itself (Stevens, 2012) and from wastewater with large amounts of inorganic and organic chemicals. Those are stored in holding tanks or often in lined or unlined above-ground pit containers (Hoffman et al., 2014) to be later reused or treated for release (Yost et al., 2016a). A large amount of research indicate that chemicals in wastewater have a potential relationship with surrounding water system contamination when disposal water leaks or when improper disposal operations take place (U.S. EPA, 2015; Osborn et al., 2011; Warner et al., 2013; Barbot et al., 2013). Organic chemicals, such as BTEX, PAHs or pesticides, are 
common components present in waste fluids that are associated with chronic and acute nonlymphocytic leukemia, anemia, blood disorders, impacted lung function and nervous system impairment (McKenzie et al., 2012).

The truth however is that there is no complete and precise state of knowledge on the effects of human exposure to suspected toxic compounds in wastewater, especially to organic matters from shale formation, studies to eliminate these gaps of knowledge are urgently required (Elliott et al., 2016).

To date, a lack of exposure assessment data and systematic studies makes it difficult to assess the extent to which people may be exposed to these chemicals in hydraulic fracturing fluids, flowback, and produced water via contamination of drinking water resources. However, there are specific instances in which hydraulic fracturing activities have been implicated in the contamination of groundwater and surface water. Events that may lead to contamination include surface spills, leaks from flowback/produced water storage pits, and well blowouts (Yost et al., 2016b).

The current state of knowledge can be summarized by the following conditioning factors: (1) Canada and USA share one important trait in common: a relative small number of samples given the total number of wells in operation; (2) lack of specific, long-term and systematic monitoring on nearby environment (Struchtemeyer et al., 2012) of critical elements to determinate the real influence of fracturing operations; (3) large amount of published literature on organic compounds present in produced water informing about risk to human health (McKenzie et al., 2012; Bloomdahl et al., 2014), but also lack of data needed to develop more accurate epidemiological studies is a main issue referred in these research works, and, last but not least, (4) a major source of controversy on the possibility of water contamination is due to the fact that local geophysical experiments not provide sufficient information for the assessment of other cases or potential future situations.

To sum up, research has shown that there is a link between shale gas exploitation and risks of contamination of ground and surface waters as well as air (for instance in Wood et al., 2011; U.S. EPA., 2016; or Srebotnjak and Rotkin-Ellman, 2014). In addition, relevant toxicity data is often lacking for chemicals used in hydraulic 
fracturing fluids suggesting a significant data gap for risk assessment (Colborn et al. 2011; Stringfellow et al., 2014; Yost et al., 2016a; Wattenberg et al., 2015; Elliott et al., 2016). All the above adds up to the fact that there are concerns about potential public health implications, including the potential for hydraulic fracturing related chemicals to impact drinking water resources.

In essence, Shale gas development means therefore new environmental and health concerns that are less well-understood than the risks associated with conventional fossil fuel extraction. In addition, concerns traditionally associated with drilling are being raised in areas that have not had to manage these issues until recently (Krupnick, 2012). More and more people pay attention to nearby area environmental impact and human health of fracturing and drilling activities, some groups already embarked on monitoring and analyzing data from the surrounding. These pioneer countries are good examples for improving techniques and providing experiences, especially failure cases, that is very helpful for others countries to learning, enhancing drilling process and surrounding protective measures. However, nowadays studies are not enough to reflect macro and micro influence of whole environment.

In short, it can be claimed that the health, safety and environmental risks associated with shale gas exploitation can be managed effectively as long as operational best practices are implemented and enforced through regulation (Royal Society, 2012) based and updated on the best available knowledge. But environmental consequences, especially over managing water, is a complicated issue because the implications of hydraulic fracturing for water table and water management are not yet well understood.

Since only exits about ten years of experience accumulated in horizontal hydraulic fracturing, many of design defects have not appear yet or the phenomenon has occurred but did not cause people's attention. Such as in paper "Impact of Shale Gas Development on Regional Water Quality" (Swarthout et al. 2015), a key pathway for shale gas migration through well construction failure is established. In this paper they also set up using groundwater transport model to estimate the risk of groundwater contamination with hydraulic fracturing fluid that it could be lead through advective transport to groundwater aquifers in less than 10 years (Swarthout et al. 2015). However, this model could not been proved because of short period of time that has 
elapsed since horizontal drilling was introduced. And another problem of this model is the distribution of wells. In paper "A critical review of the risks to water resources from unconventional shale gas development and hydraulic fracturing in the United States" (Vengosh et al., 2014) it is said "Much of debate on the possibility of water contamination is related to the availability of baseline water chemistry data in aquifers before shale gas development, yet full baseline data is often unavailable, given the lack of systematic and component specific monitoring of private wells and surface water systems" (Struchtemeyer et al., 2012). That indicates that in different area existing different comprehensive investigations of the hydrology, hydrogeology, water chemistry, and isotopic tracers for delineating the sources and mechanisms of water contaminations, some of geographic area data have been historically used. The background concentration research of the chemicals in this specific zone should be done before well drilling

The second constraints in published papers is lacking of scientific data monitoring. Monitoring sites should submit the regulation, articles, and rules especially increasing site monitoring in the weak already existing failure areas, and the design of data acquisition should be not only focused on fracturing type, drilling area geographic information, chemical concentration in fracturing fluids, well construction which are near of drilling site, but also should pay enough attention on the contaminant concentration changing in the affected area during time periods greater than decades with leaking monitoring when fracturing wells are abandoned.

Consequently, the current researches on environmental and human health impact derived from fracturing and drilling activities have already embarked on monitoring surrounding indicators (Molofsky et al., 2013; Kravchenko et al., 2014), either analyzing whether samples exceed the allowable limits (Bunch et al., 2014) or focusing on processes for wastewater treatments (Rahm et al., 2013).

Understanding the chemical composition of flowback water and the types of constituents that may be present, as well as its time dynamics, is an important issue in order to develop appropriate treatment processes for this waste and to understand the health and environmental impacts of accidental exposures to the fluid (Abualfaraj et al., 2014; Balashov et al. 2015). 
All of the above underlines the need to have predictive estimation models (1) to evaluate the quantity of the various pollutants that could travel to the surface or proximal areas and generate pollution as well as (2) to establish the relationships between the initial and flowback concentrations at every given day of each compound or families of compounds.

Together with characterization studies carried out for typifying the constituents that are found in flowback water (Abualfaraj et al., 2014; Yost et al., 2016b), a model was proposed in which the temporal increase of the salt concentration in flowback is explained by salt diffusion from capillary-bound or free brine in the shale matrix to the injected water that fills fractures after hydrofracturing (Balashov et al. 2015). For these studies the Marcellus Shale Coalition GTI report was used as data source.

However, to date no similar model for the organic chemicals has been proposed for predictive assessment of evolution of the concentrations in the produced water and flowback, despite the importance that these models have from the point of view of the studies of the environmental and health impacts.

\subsubsection{Two perspectives: USA and Europe}

The development of Shale Gas in USA is linked to issues of international geopolitical strategy of achieving energy independence. Achieving that fundamental target has resulted in both a rapid growth in the application of such technology and the fact that Unconventional gas operations in the United States have been remarkably free of restrictive regulations at federal or state levels. In large part this is because the techniques are so different from conventional operations that they are simply not part of the existing regulations, or, in some cases, exclusions could be slipped in by the legislators without attracting much attention. For example, the Energy Policy Act of 2005 exempted hydraulic fracturing from the Safe Drinking Water Act.30 (Stevens, 2010).

During the Obama administration, there were signs that this could begin to change. An example is given by the Fracturing Responsibility and Awareness 
Chemicals (FRAC) Act. It is a legislative proposal in the United States Congress to define hydraulic fracturing as a federally regulated activity under the Safe Drinking Water Act. The proposed Act would require the energy industry to disclose the chemical additives used in the hydraulic fracturing fluid and then the Environmental Protection Administration (EPA) would be permitted to regulate all hydraulic fracturing in the United States. Nevertheless, the gas industry opposes the legislation and Congress had not yet passed either of The FRAC Act bills. The FRAC Act was reintroduced on June 11, 2013, but with very little chance of being enacted (https://www.govtrack.us/congress/bills/113/s1135, accessed June 23, 2017).

In March 2010, the US EPA announced a study to investigate the potential adverse impact of hydraulic fracturing on water quality and public health, and in May 2010, the Pennsylvania state legislature passed the Marcellus Shale Bill that enforced a three-year moratorium on further leasing of exploration acreage until a comprehensive environmental impact assessment has been carried out (Stevens, 2010).

The New York State has imposed a moratorium on oil and gas drilling. In Pennsylvania an executive order barred further natural gas developments of state forest lands and the Delaware River Basin Commission imposed a moratorium in the Marcellus area within the basin. Maryland passed the Shale Safe Drilling Acts of 2011, restricting operations in the Marcellus until 2013 and the completion of a two-year drinking-water EIA. Moratoria have also been introduced at much more local levels. For example, Bartonville, a small town on the Barnet Play, introduced a 90-day moratorium on new permits for drilling and fracking.

The US EPA, as a direct result of the studies carried out, found scientific evidence that hydraulic fracturing activities can impact drinking water resources under some circumstances (U.S. EPA., 2016). US EPA provides a review and synthesis of available scientific information concerning the relationship between hydraulic fracturing activities and drinking water resources in the United States. US EPA states that data gaps and uncertainties limited the ability to fully assess the potential impacts on drinking water resources locally and nationally. Because of these data gaps and uncertainties, it was not possible to fully characterize the severity of impacts, nor was it possible to calculate or estimate the national frequency of impacts on drinking water 
resources from activities in the hydraulic fracturing water cycle.

US EPA has identified a list of 1173 chemicals associated with hydraulic fracturing operations in USA, which includes 1076 chemicals used as additives in hydraulic fracturing fluids, and 134 chemicals reported in flowback or produced water. Using selected high-quality data sources, US EPA compiled toxicity values for these chemicals when available, including chronic oral reference values (RfVs) for non-cancer toxicity and oral slope factors (OSFs) for cancer. These values are commonly used by risk assessors to evaluate hazards of long-term chemical exposure (U.S. EPA., 2015; Brantley et al., 2015).

In 2012 US EPA issued new standards to limit harmful air pollution from the oil and gas industry. In December 2016 announced comprehensive steps to address methane emissions from both new and existing sources in the oil and gas sector. For new, modified and reconstructed sources, the purpose is to introduce a set of standards that will reduce methane, volatile organic compounds (VOCs) and toxic air emissions in the oil and natural gas industry. EPA also started a process to control emissions from existing sources by issuing for public comment an Information Collection Request (ICR) that requires companies to provide the information that will be necessary for EPA to reduce methane emissions from existing oil and gas sources. The final standards are intended to significantly curb methane emissions from new, reconstructed and modified processes and equipment, along with reducing VOCs emissions from sources not covered in the agency's 2012 rules (U.S. EPA., 2017).

However, it seems that the situation now appears to be changing with the Trump Administration. For instance, US EPA has withdrawn the 2016 information request for the oil and gas industry, effective from March 2, 2017 (https://www.epa.gov/controlling-air-pollution-oil-and-natural-gas-industry/oil-and-ga $\underline{\text { s-industry-information-requests, }}$, accessed March 5, 2017).

All of the above is directly reflected in the European context. In response to concerns raised by the general public and stakeholders, several European Member States have prohibited, or are considering the possibility to prohibit the use of hydraulic fracturing. Concurrently, several EU Member States are about to initiate discussions on 
the appropriateness of their national legislation, and contemplate the possibility to introduce specific national requirements for hydraulic fracturing.

Environmentally based opposition to shale gas operations is growing space, especially in Europe. It is growing realization in Europe that there are serious obstacles to replicating the USA experience, among other reasons and especially for aspects of environmental regulation. The laws and regulations covering oil and gas exploration and development in Western Europe do not even make reference to unconventional gas, which means that the existing legal framework is not geared up to its management and there is no comparable onshore service industry in Europe. Putting it simply, the infrastructure in Europe does not currently exist to mount enough unconventional gas projects to make a difference. This can change if the projects appear profitable, but it will take time (Stevens, 2010).

Another serious problem is that Western Europe is densely populated and highly urbanized. Large-scale unconventional gas operations will impinge on local communities and disruptions caused by drilling and hydraulic fracturing are likely to generate huge local opposition, especially given concerns over environmental damage and local communities are certain to pursue a path of local opposition, or 'nimbyism' (Stevens, 2010).

It is likely to be some time before it will become clear whether or not the "shale gas revolution" might sweep Europe because the list of constraints is formidable (Stevens, 2010). For instance, there are growing pressures in Europe from NGOs to restrict shale gas operations on the grounds that increasing gas use by more than $50 \%$ would risk temperature rises that would be catastrophic. France and Bulgaria have already banned shale gas operations. In Germany, where there is very strong local opposition to shale gas operations, ExxonMobil voluntarily agreed to a moratorium on its operations pending an EIA. Within the EU generally, there is considerable concern that there are many serious loopholes in the regulatory environment, and a major report produced in 2011 for the European Parliament concluded that because of risks to the environment and human health it was needed a new directive at European level to provide comprehensive regulation covering all issues in the context of shale operations (European Parliament, 2011). 
On the other hand, The UK House of Commons Select Committee on Energy and Climate Change (House of Commons, 2011) has given fracking a clean bill of health and the Department of Energy and Climate Change rejected calls (from the Tyndall Centre for Climatic Changed Research) for a two-year moratorium on shale gas development until there is a much more thorough understanding of the extraction process.

Recommendations made by the US Department of Energy (US Secretary of Energy Advisory Board SEAB 2011a NPR) (SEAB, 2011), that if implemented will reduce the environmental impacts from shale gas production, are relevant for regulatory authorities in Europe. These recommendations are based on the idea that Incidents causing problems have been unrelated to fracking itself but have arisen from surface spills, poor cementing jobs in wellbores and other operational failures.

A list of, inter alia, Subcommittee's findings and recommendations are given:

- Improve air quality: Measures should be taken to reduce emissions of air pollutants, ozone precursors, and methane as quickly as practicable.

- Protection of water quality: The Subcommittee urges adoption of a systems approach to water management based on consistent measurement and public disclosure of the flow and composition of water at every stage of the shale gas production process.

- Organizing for best practice is needed to improve operational and environmental outcomes. The Subcommittee has identified several activities that deserve priority attention for developing best practices:

- Air: (a) Reduction of pollutants and methane emissions from all shale gas production/delivery activity. (b) Establishment of an emission measurement and reporting system at various points in the production chain.

○ Water: (a) Well completion -casing and cementing including use of cement bond and other completion logging tools. (b) Minimizing water use and limiting vertical fracture growth

- Research and Development needs

In particular, it is recommended that the European Commission should take a 
strategic overview of potential risks. This will require consideration of aspects such as (Broomfield, 2012):

- Undertaking science-based characterization of important landscapes, habitats and corridors to inform planning, prevention, mitigation and reclamation of surface effects.

- Establishing effective field monitoring and enforcement to inform on-going assessment of cumulative community and land use effects

- Restricting or preventing development in areas of high value or sensitivity with regard to biodiversity, water resources, community effects etc. 


\subsection{Shale Gas in Spain}

Although the ramping up of production is relatively recent - only since 2006 have the numbers begun to be significant - the so-called 'shale gas revolution' (Stevens, 2010) was over 20 years in the making (Stevens, 2012). At the beginning the development of unconventional gas was inhibited by the lack of suitable technology. Technological developments, in particular the horizontal drilling and hydraulic fracturing, were a major factor: in 2004, 490 of the 920 wells in the Barnett Play were vertical, by 2008 , as many as 2,600 of the 2,710 wells were horizontal (EIA, 2009; Stevens, 2010). The proliferation of activity into new shale plays has increased shale gas production in the United States from 0.39 Tcf in 2000 to 4.87 in 2010, or 23\% of U.S. dry gas production. Shale gas reserves have increased to about 60.6 Tcf by year-end 2009, when they comprised about $21 \%$ of overall U.S. natural gas reserves, now at the highest level since 1971. Although unconventional gas resources are estimated to be five times those of conventional gas, there is concern that their depletion rates are much faster. In general, currently future prospects for gas prices are extremely uncertain (Stevens, 2012; Foss, 2011). That increased supply has led to a significant drop in US domestic gas prices.

However, there are doubts as to whether this 'revolution' can spread beyond the United States, or even be maintained within it (Stevens, 2010). The US experience was triggered by many favorable factors connected with geology, tax breaks and the existence of a vibrant service industry. There are serious doubts about whether such favorable conditions can be replicated outside the United States, especially in Western Europe (Stevens, 2010). A major potential problem in Europe is that the geology for shale gas is much less promising than in the United States, with much greater skepticism regarding the levels of technically recoverable shale gas resources. In general the deposits are deeper, the materiality in terms of gas deposits lower and the basins smaller. The plays are more fragmented and the shale is richer in clay, making these deposits less amenable to fracturing. In short, they do not hold out the same promise as deposits in North America, which are large and often shallow. Furthermore, they lack the history of drill core evidence that exists in the United States, since onshore drilling in Western Europe has been much more limited (Stevens, 2010). Besides this, 
there are no tax breaks and the service industry for onshore drilling is far behind that in the United States. Finally, there is concern that disruptions caused by shale gas developments will not find public acceptance, especially in a context where the gas is the property of the state and thus the benefits accrue to governments and not local landowners (Stevens, 2010).

The case of Spain is an example in line with situation in the rest of Western Europe, where the conditions that created the shale gas revolution in the United States cannot be replicated and situation analyses suggest that there are serious barriers to develop its potential, which can be summarized in the following points (Stevens, 2012; Kuuskraa et al., 2013):

- Considerable debate over the level of technically recoverable shale gas resources together with significant revisions to some estimates of those resources.

- Growing opposition to shale gas driven by concerns over the environmental impact of hydraulic fracturing and the impact on greenhouse gas emissions.

- Growing fear that shale gas may substitute not for coal as many originally hoped, but for renewables.

- High levels of investor uncertainty.

And so, despite the interest of the companies (in December 2014, there were 70 hydrocarbon exploration permissions in Spain, with a further 75 applications still pending - Álvarez, 2016), all the exploratory activity is practically stopped due to the difficulties to obtain the respective permissions and authorizations (Álvarez-Fernández et al., 2013).

According to data from 2016, Spain imports 99\% of natural gas from ten different countries including Algeria, France, Qatar, Nigeria, Trinidad and Tobago, Peru and Norway. About $58 \%$ of the gas enters the gas pipeline while the remaining $42 \%$ does so in the form of liquefied natural gas (LNG) which is transported by ships. With $37 \%$ of the European total stored capacity, Spain is destined to become the main organized market for liquefied natural gas in Europe (Gobierno de España, 2017).

Compared to some countries in Europe, the structure of gas consumption in 
Spain is atypical. The industrial sector is the largest consumer, accounting for $64.7 \%$ of total consumption in 2014. It is followed by the power sector $(17.2 \%)$ and the domestic and commercial sectors (16.3\% of total consumption), with the remaining $1.8 \%$ going to non-energy uses. Prospects for gas demand in industry may be positive, provided competitiveness can be improved and gas demand for power generation may increase given the future development of renewable technologies, which need gas to cover intermittency and the currently low operating hours of combined cycles (Álvarez et al., 2016).

From the point of view of Spain's balance of trade, energy imports, mainly oil and gas, have contributed to a growing trade deficit over the last decade (rising from $30 \%$ in 2007 to $60 \%$ in 2010). The cost of gas imports came to $€ 3$ billion in 2003 , climbing to $€ 10$ billion in 2012 (plus $€ 60$ billion cost of oil imports in 2012). Within this framework, any domestic gas production would therefore contribute positively to the Spanish economy (Álvarez et al., 2016).

Systematic reviews of Spanish geological basins are being carried out to identify potential non-conventional resources (Boyer et al., 2011), focusing on the identification of rocks rich in organic matter of very different geological ages that have previously generated hydrocarbons (García-Portero, 2012). However, Spain is currently at a very early stage in the exploration of unconventional reserves, but does not seem to present a potential comparable to that of other Western European countries like France, Poland or Germany.

The main areas explored are located in the Basque-Cantabrian, Pyrenean, Ebro and Guadalquivir Basins plus the Bética region. The geological formations of the exploration are focused on formations of Cretaceous and Jurassic-Lias age and in the Westphalian-Estefanian of the Carboniferous particularly in the case of the Cantabrian Basin (Jódar Abellán, 2014). In general, sedimentological analogies cannot be established between the Mesozoic and Cenozoic formations of the Pyrenean, Basque-Cantabrian, Ebro or Duero basins with the Marcellus Formation (Fm) shales because the former are of marine sedimentary environment with potent series of carbonates instead of shales. So the lithologies are far from being comparable to the black slates of Fm Marcellus and do not admit analogies with the shales of Fm 
Marcellus, which have been the objective of this study.

With regard to this, an important issue is the broad ranges in the estimates of resources. Volumes of oil and natural gas that ultimately will be produced cannot be known ahead of time therefore their categories reflect varying degrees of certainty (Budzik and Ford, 2014). Resource estimates change as extraction technologies improve, as markets evolve, and as oil and natural gas are produced. Consequently, the oil and gas industry, researchers, and government agencies spend considerable time and effort defining and quantifying oil and natural gas resources. Estimates of technically recoverable shale gas resources remain highly uncertain, even in regions with a relatively long history of shale gas production; because a large number of parameters must be estimated or calculated when using such methods to determine recoverable volumes of gas (see Figure 2-4). These include the area or volume of shale rock, the total organic content (measured as a percentage of the total weight), the minerals (clay/quartz etc.) contained within the shale and the gas pressure. Therefore, current resource estimates should be treated with considerable caution (McGlade et al., 2013).

For many purposes, oil and natural gas resources are usefully classified into four categories (Budzik and Ford, 2014), avoiding the comparison between different categories (see Figure 2-5):

- Remaining oil and gas in-place (original oil and gas in-place minus cumulative production at a specific date)

- Technically recoverable resources

- Economically recoverable resources

- Proved reserves

With this in mind, in 2013, three main estimations of shale gas Spanish resources have been done by: Gessal-ACIEP, the Mining Engineers Central Spain College (COIMCE) and the US Energy Information Administration (EIA). Estimation ranges from $69.8 \mathrm{Tcf}(1,978 \mathrm{Bcm})$ of Gessal-ACIEP to $8.0 \mathrm{Tcf}(226 \mathrm{Bcm})$ of EIA. An intermediate estimation of $47.3 \mathrm{Tcf}(1,339 \mathrm{Bcm})$ comes from COIMCE (Álvarez-Fernández et al., 2013). 


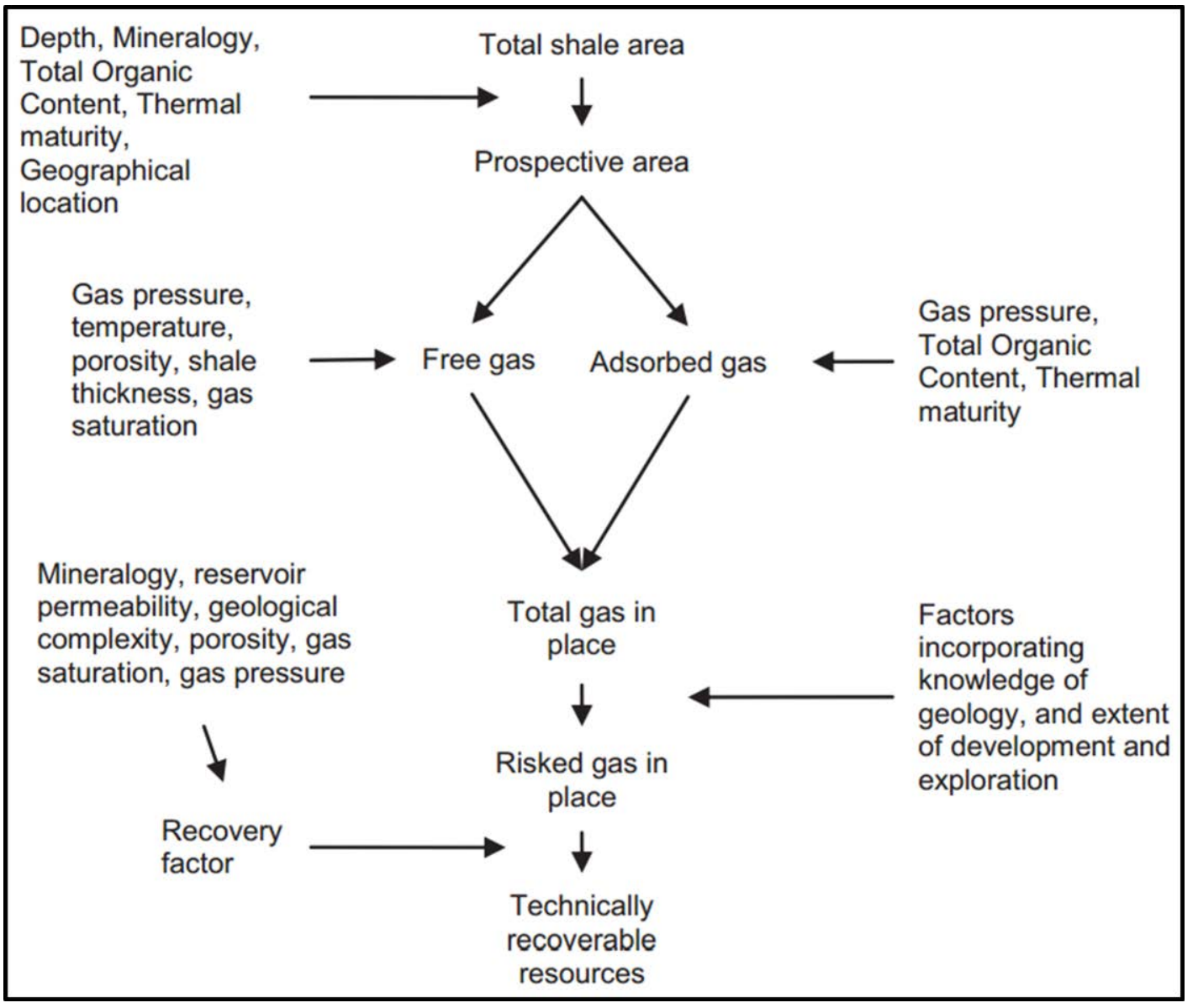

Figure 2-4: Schematic representation of the steps used in the geological based approach (McGlade, Speirs, en Sorrell 2013).

In March 2013, a Prospective resources estimate based on the estimate made by Gessal as part of a report prepared for ACIEP, a Spanish Association of Researchers, Explorers, Producers of Hydrocarbons and Underground Storage, claimed that Spain has 69.8 Tcf of unconventional gas, 38.26 Tcf in the Basque-Cantabrian Basin and pointed to seven other basins with gas potential (see Table 2-1). Calculations of the report are referred to Prospective Resources, to which the report calculations are referenced: accumulations of undiscovered hydrocarbons (oil and gas), but estimated presence based on indirect evidence. They are established according to probabilistic analysis, assuming risk factors and a range of uncertainties P 10, P 50, and P 90 (relative 
to $\%$ probability of existence) (ACIEP, 2013). It means that the report of ACIEP quantified basins that only present a probability of between 10 and $50 \%$ of being exploited (Matesanz-Caparroz, 2013).

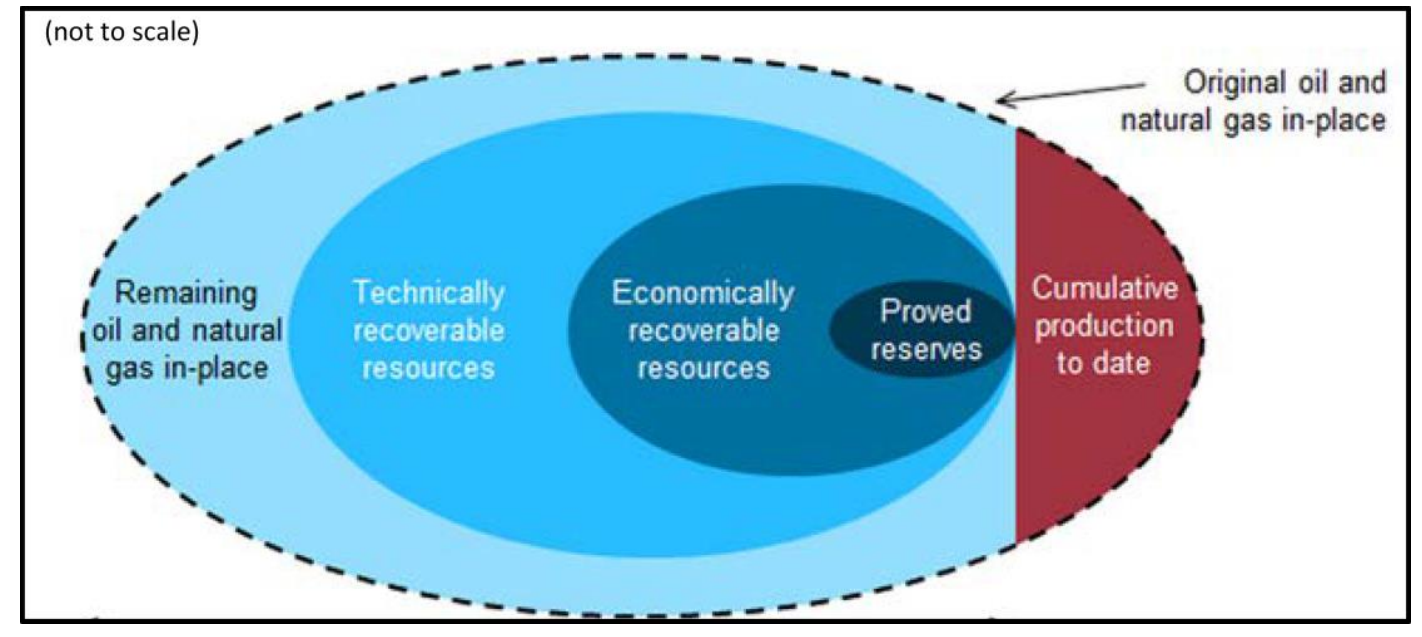

Figure 2-5: Representation of oil and natural gas resource categorizations (Budzik and Ford, 2014).

These prospective resources do not correspond to proven reserves and the development of exploration projects would be necessary to make them potentially retrievable. Based in this estimate, in its baseline scenario the country could become independent of gas imports by 2030 and export gas by 2050 (Deloitte-Aciep, 2014).

On the other hand, at the other end of the range, are the estimates made by U.S. Energy Information Administration (US EIA) \& U.S. Department of Energy (US DOE) in the series of reports about initial assessments of world shale oil and shale gas resources (ERI/ARI, 2013). In this case, the assessed shale formations were selected for a combination of factors that included the availability of data, country-level natural gas import dependence, observed large shale formations, and observations of activities by companies and governments directed at shale resource development. Shale formations were excluded from the analysis if one of the following conditions is true: (1) the geophysical characteristics of the shale formation are unknown; (2) the average total carbon content is less than 2 percent; (3) the vertical depth is less than 1,000 meters 
$(3,300$ feet) or greater than 5,000 meters $(16,500$ feet), or (4) relatively large undeveloped oil or natural gas resources. It is worth pointing out that revisions of resource estimates tend to be lower than before, suggesting greater conservatism in the estimation process (World Energy Council, 2011).

Table 2-1: Summary of Prospective Resources of Non-conventional Hydrocarbons (ACIEP, 2013).

\begin{tabular}{|c|c|c|c|c|}
\hline Geologic Domain & $\begin{array}{l}\text { Shale Gas } \\
(\mathrm{BCM})^{*}\end{array}$ & $\begin{array}{l}\text { Tight Gas } \\
\text { (BCM)* }\end{array}$ & $\begin{array}{l}\text { Coal Bed } \\
\text { (BCM)* }\end{array}$ & $\begin{array}{c}\text { Total } \\
(\mathrm{BCM})^{*}\end{array}$ \\
\hline $\begin{array}{c}\text { Basque-Cantabrian } \\
\text { basin }\end{array}$ & 1,084 & 2 & $\mathrm{x}$ & 1,086 \\
\hline Pyrenees & 260 & 3 & $\mathrm{x}$ & 263 \\
\hline Duero basin & 72 & $\mathrm{x}$ & $\mathrm{x}$ & 72 \\
\hline Ebro basin & 32 & 1 & $\mathrm{x}$ & 33 \\
\hline Iberian Mountains & 95 & $\mathrm{x}$ & $\mathrm{x}$ & 95 \\
\hline $\begin{array}{c}\text { Catalan } \\
\text { Mediterranean } \\
\text { System }\end{array}$ & 15 & $\mathrm{x}$ & $\mathrm{x}$ & 15 \\
\hline Guadalquivir basin & 79 & $\mathrm{x}$ & $\mathrm{x}$ & 79 \\
\hline Baetic basin & $\mathrm{x}$ & 2 & $\mathrm{x}$ & 2 \\
\hline Iberian Massif & 340 & $\mathrm{x}$ & 41.3 & 381 \\
\hline Totals: & 1,977 & 7 & 41 & 2,026 \\
\hline
\end{tabular}

* Recoverable gas

This report highlights only extractable resources in the Basque Basin (see Figure 2-6), and not in the others seven indicated by the Spanish association. Specifically, the Ebro Basin, for instance, would present a profitability inferior to $2 \%$, due to the fact that the Total Organic Carbon (TOC) of these shales averages only about $1 \%$ reason for being excluded from further assessment and subsequently for not being exploited, according with the US DOE. The Duero Basin has important depocenters located in 
front of the Cantabrian Mountains and the Iberian System (Almazán Basin), whose thickness exceeds $2500 \mathrm{~m}$. However, their sedimentary rocks, mainly detrital materials of alluvial origin, fluvial and lacustrine fans, with low organic carbon content, detract from its interest for the exploration of shale gas.

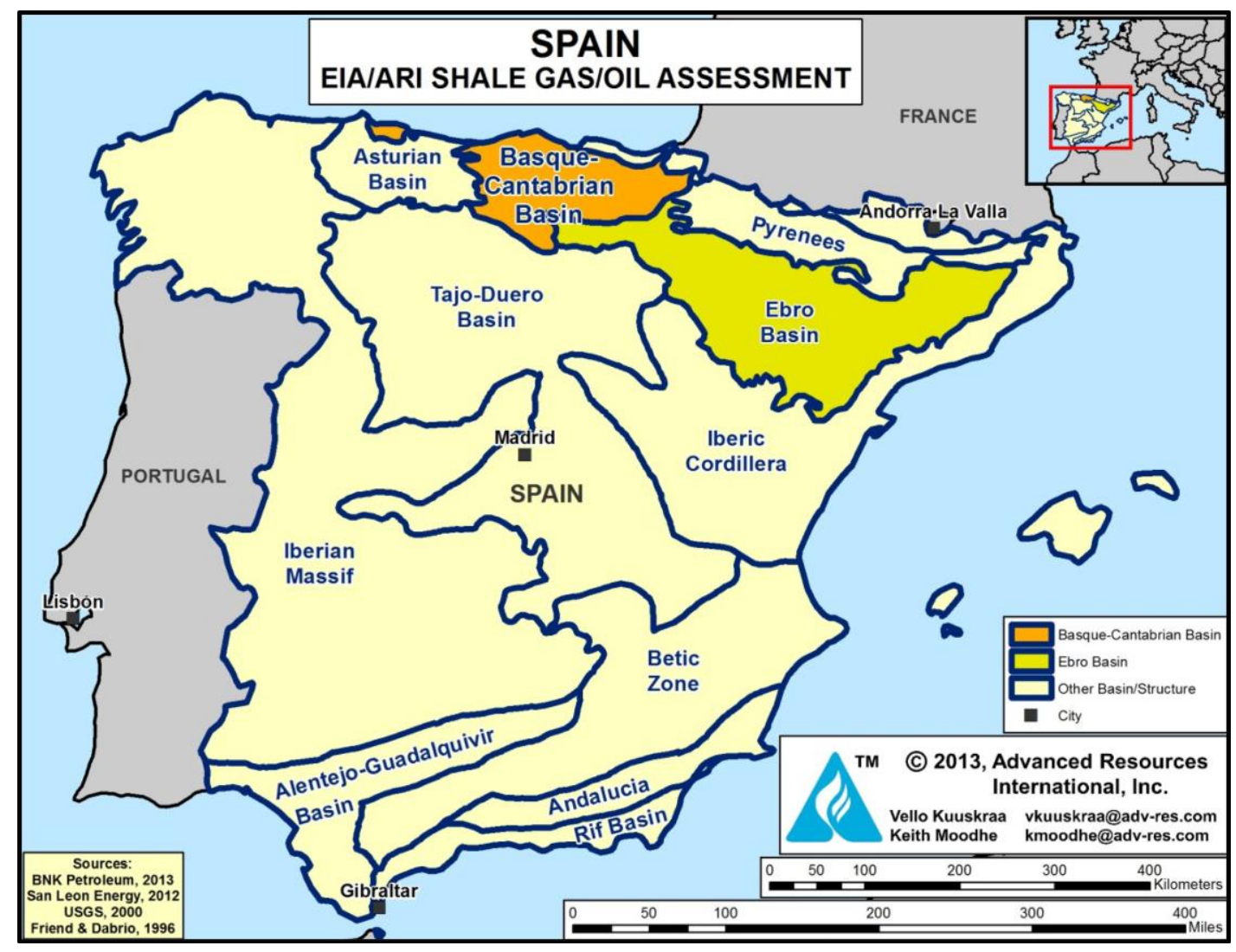

Figure 2-6: Selected Shale Gas and Oil Basins of Spain (ERI/ARI, 2013).

In this way, and according to these estimates, the Jurassic-age (Liassic) marine shale in the Basque-Cantabrian Basin contains an estimated 42 Tcf of risk shale gas resource in-place, with about 8 Tcf as the risked, technically recoverable shale gas resource, equivalent to $226 \mathrm{bcm}$ (see Table 2-2).

According to this report, Spain is one of the ten European countries with shale gas technically recoverable, although its 8 Tcf are far from the 146 of Poland, 137 of France or 51 of Romania. According to these estimates, Western Europe makes a total 
of 470 Tcf of wet shale gas, plus $11 \mathrm{bbl}$ of tight oil (see Figure 2-7 and Figure 2-8) (ERI/ARI, 2013).

These are figures that are far from the potential of other regions such as North America, including the United States, Canada and Mexico (1,741 Tcf of wet shale gas), China (1,115 Tcf), Algeria (707 Tcf), Australia (429 Tcf) or Russia (285 Tcf) (see Figure 2-9) (ERI/ARI, 2013).

Table 2-2: Shale Gas Reservoir Properties and Resources in Spain (ERI/ARI, 2013).

\begin{tabular}{|c|c|c|c|c|c|c|c|}
\hline \multirow{4}{*}{ 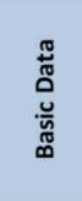 } & \multicolumn{2}{|c|}{ Basin/Gross Area } & $\begin{array}{c}\text { Basque-Cantabrian } \\
\left(6.620 \mathrm{mi}^{2}\right)\end{array}$ & \multirow{4}{*}{ 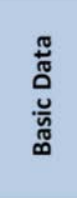 } & \multicolumn{2}{|c|}{ Basin/Gross Area } & $\begin{array}{c}\text { Basque-Cantabrian } \\
\left(6.620 \mathrm{mi}^{2}\right)\end{array}$ \\
\hline & \multicolumn{2}{|c|}{ Shale Formation } & Jurassic & & \multicolumn{2}{|c|}{ Shale Formation } & Jurassic \\
\hline & \multicolumn{2}{|c|}{ Geologic Age } & L. - M. Jurassic & & \multicolumn{2}{|c|}{ Geologic Age } & L. - M. Jurassic \\
\hline & \multicolumn{2}{|c|}{\begin{tabular}{|c|} 
Depositional Environment \\
\end{tabular}} & Marine & & \multicolumn{2}{|c|}{ Depositional Environment } & Marine \\
\hline \multirow{5}{*}{ 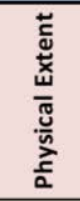 } & \multicolumn{2}{|c|}{ Prospective Area $\left(\mathrm{mi}^{2}\right)$} & 2,100 & \multirow{5}{*}{ 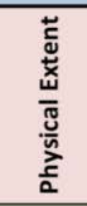 } & \multicolumn{2}{|c|}{ Prospective Area $\left(\mathrm{mi}^{2}\right)$} & 2,100 \\
\hline & \multirow{2}{*}{ Thickness (ft) } & Organically Rich & 600 & & \multirow{2}{*}{ Thickness (ft) } & Organically Rich & 600 \\
\hline & & Net & 150 & & & Net & 150 \\
\hline & \multirow{2}{*}{ Depth (ft) } & Interval & $8,000-14,500$ & & \multirow{2}{*}{ Depth (ft) } & Interval & $8,000-14,500$ \\
\hline & & Average & 11,000 & & & Average & 11,000 \\
\hline \multirow{4}{*}{ 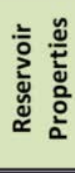 } & \multicolumn{2}{|c|}{ Reservoir Pressure } & Slightly Overpress. & \multirow{4}{*}{ 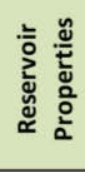 } & \multicolumn{2}{|c|}{ Reservoir Pressure } & Slightly Overpress. \\
\hline & \multicolumn{2}{|c|}{ Average TOC (wt. \%) } & $3.0 \%$ & & \multicolumn{2}{|c|}{ Average TOC (wt. \%) } & $3.0 \%$ \\
\hline & \multicolumn{2}{|c|}{ Thermal Maturity (\% Ro) } & $1.15 \%$ & & \multicolumn{2}{|c|}{ Thermal Maturity (\% Ro) } & $1.15 \%$ \\
\hline & \multicolumn{2}{|c|}{ Clay Content } & Medium & & \multicolumn{2}{|c|}{ Clay Content } & Medium \\
\hline \multirow{4}{*}{ 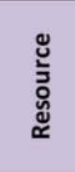 } & \multicolumn{2}{|l|}{ Gas Phase } & Wet Gas & & \multicolumn{2}{|l|}{ Oil Phase } & Condensate \\
\hline & \multicolumn{2}{|c|}{ GIP Concentration (Bcf/mi $\left.{ }^{2}\right)$} & 49.8 & 选 & \multicolumn{2}{|c|}{ OIP Concentration $\left(\mathrm{MMbb} / \mathrm{mi}^{2}\right.$ ) } & 3.4 \\
\hline & \multicolumn{2}{|c|}{ Risked GIP (Tcf) } & 41.8 & ֻू̆ & \multicolumn{2}{|c|}{ Risked OIP (B bbl) } & 2.9 \\
\hline & \multicolumn{2}{|c|}{ Risked Recoverable (Tcf) } & 8.4 & & \multicolumn{2}{|c|}{ Risked Recoverable (B bbl) } & 0.14 \\
\hline
\end{tabular}

With respect to China, which has very large resources of shale gas, is pushing ahead strongly to develop its potential in a context where the US has agreed to allow them to use their technology. In April 2010, the Chinese Ministry of Land and Resources announced that the pioneer shale gas field in Chongqing - on which the Strategic Research Center for Oil \& Gas Resources and the University of Geosciences have been working since 2004 - will start commercial production in 2011 (Stevens, 2010). 


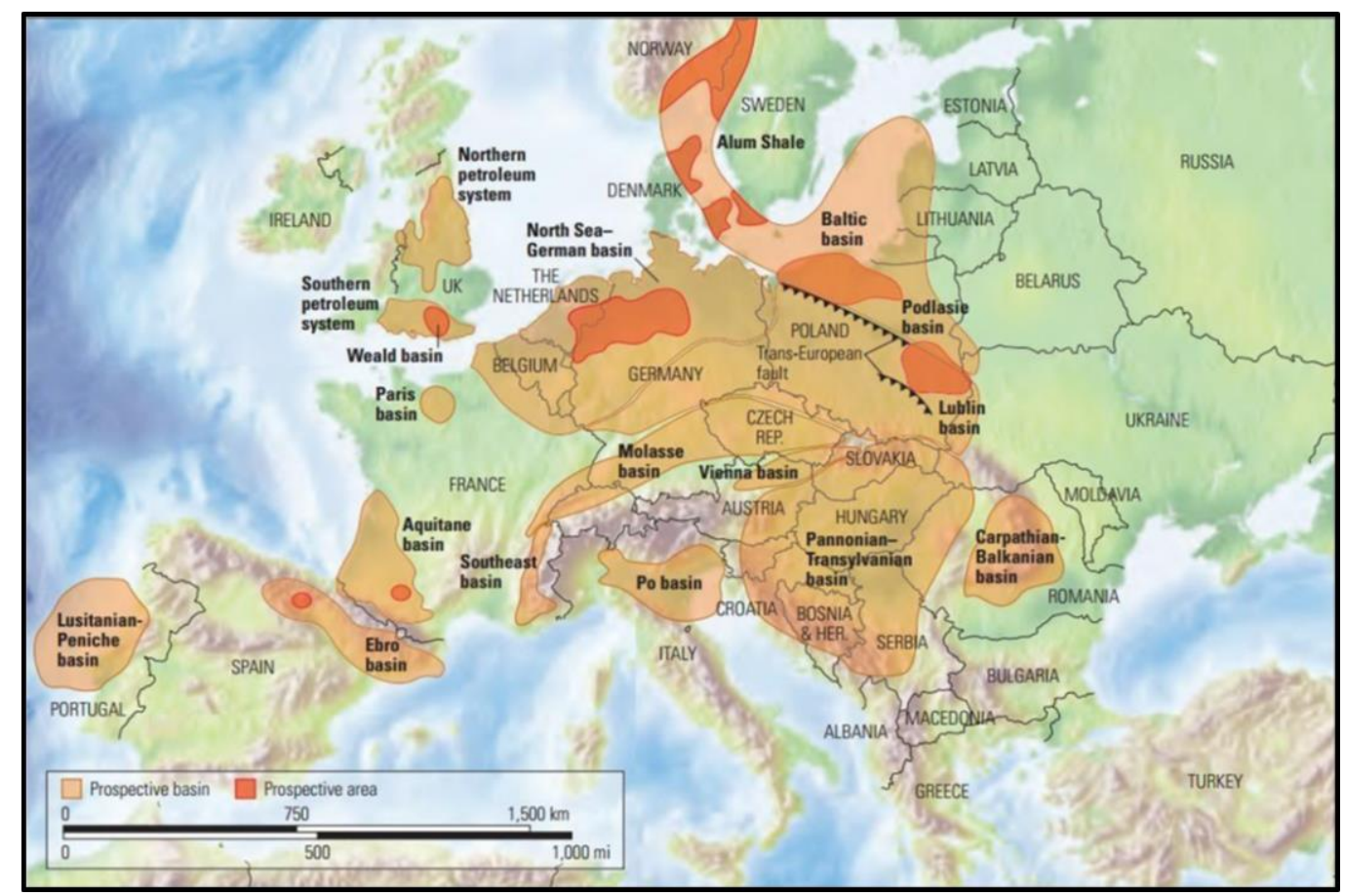

Figure 2-7: Europe Shale Basins (Boyer et al.,2011. Adapted from Kuuskraa et al., 2011).

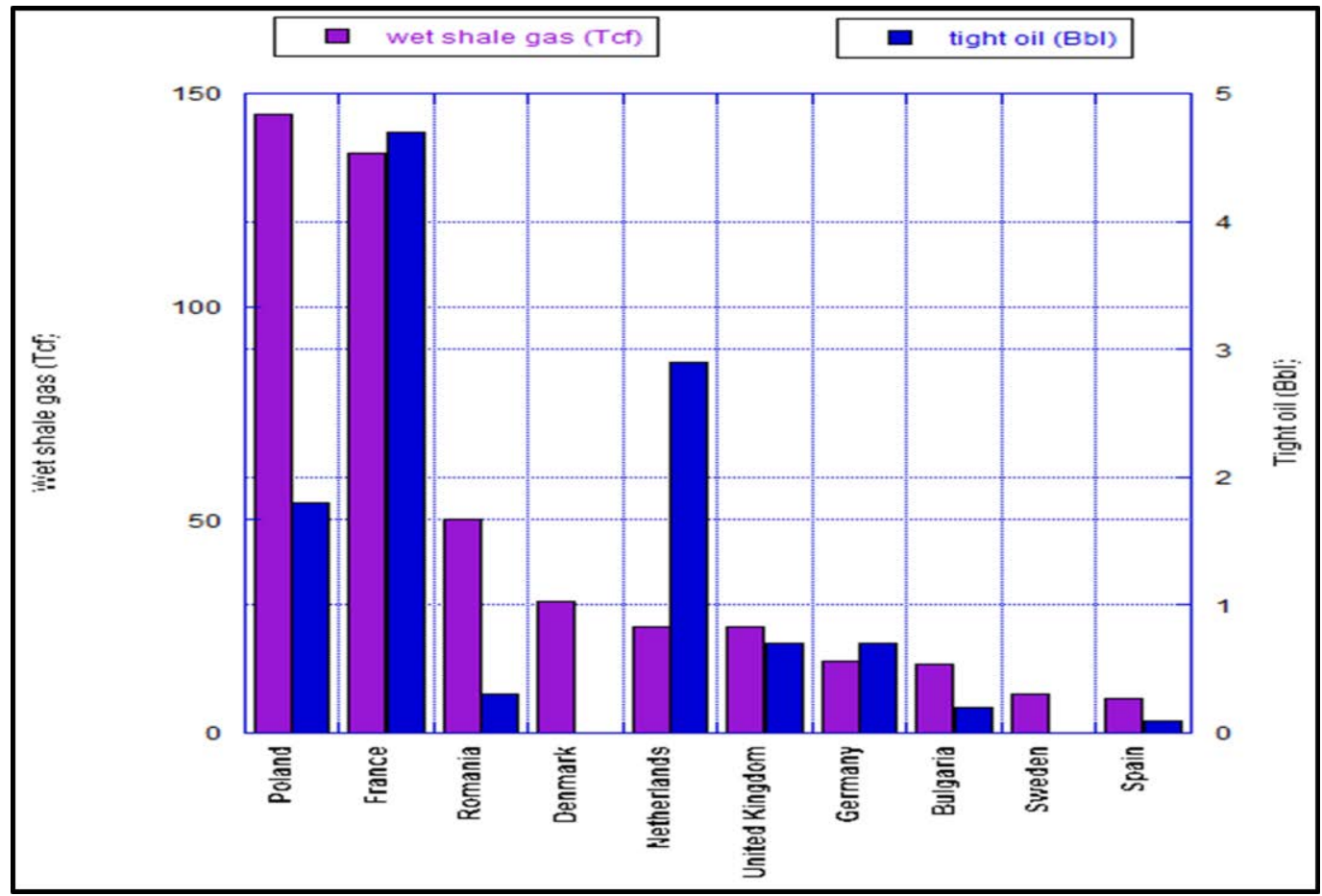

Figure 2-8: Europe's Shale Resource Assessments (Unproved technically recoverable). Graphic developed from (ERI/ARI, 2013). 
In March 2012, China's National Energy Administration (NEA) announced the first five-year plan for the shale gas sector, with output targets of $6.5 \mathrm{bcm}$ in 2015 and 60-100 bcm in 2020 (Stevens, 2012).

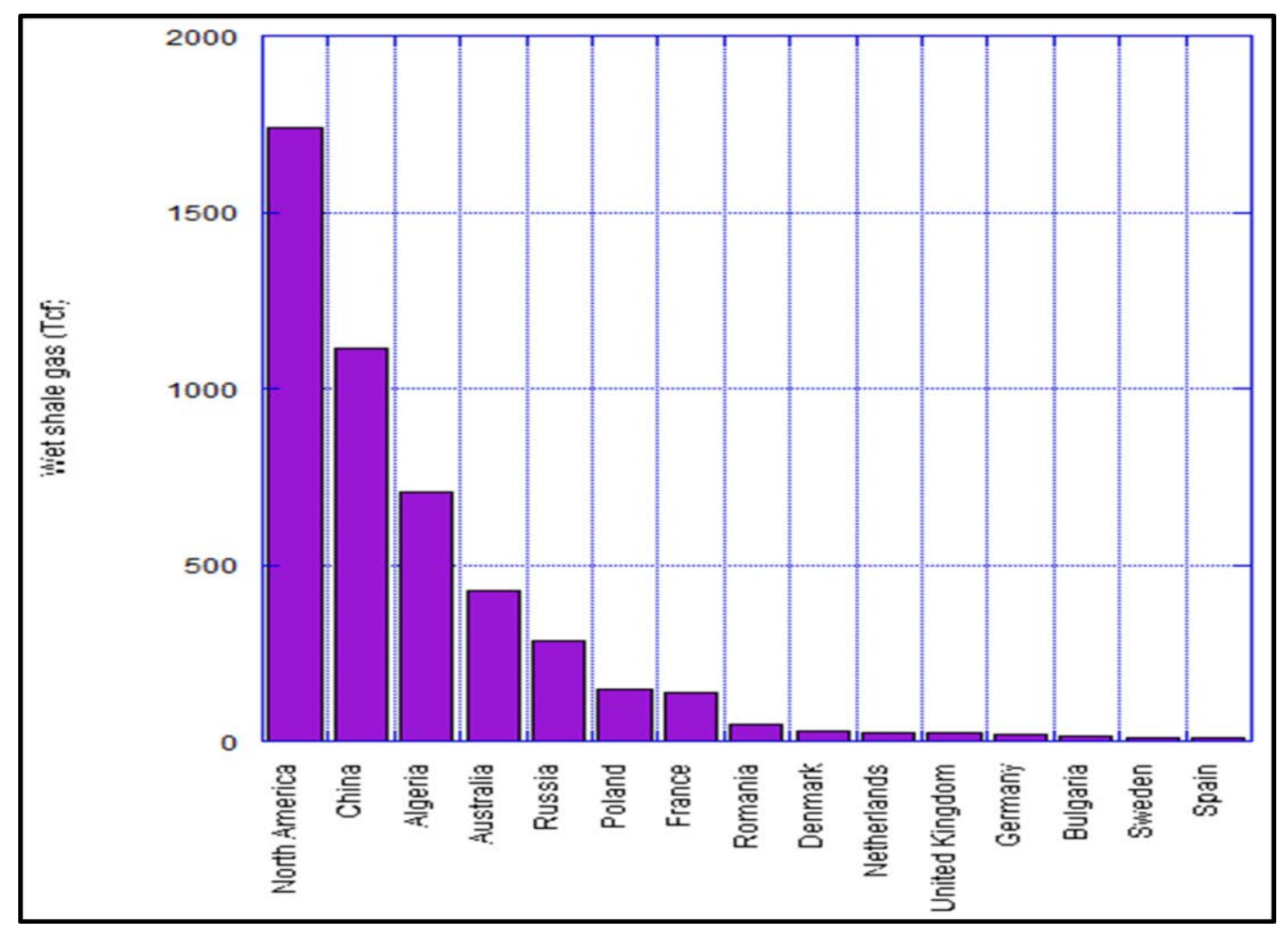

Figure 2-9: World's Shale Resource Assessments (Unproved Technically Recoverable). Graphic developed from (ERI/ARI, 2013).

By the end of July 2014, more than 400 shale gas wells have been drilled in China. First breakthrough has been made in Sichuan Basin where the shale gas development has entered an early stage of commercial development, while the overall development in China is still in start-up stage (Zhang and Yang, 2015).

There has clearly been a great deal of interest in non-conventional gas in China. There are also barriers to development in China along the lines discussed above and many of the constraints outlined for Europe are constraints in China simply because they involve opposition from people and local communities. Perhaps the greatest constraint in China is the ability to access and use the necessary technology. 


\subsection{Unintended consequences of unconventional gas operations: Environmental risk}

There is no human activity without risk. Accordingly, so neither is the extraction of shale gas. In fact this technology has a risk level similar to any other type of industrial activity and particularly those related to oil and gas industry (DNV, 2013; Ewen et al., 2012; Zoback et al., 2010). It is important to highlight the need to properly address these risks, among other reasons, because Public Acceptance also relies on predictive risk assessments.

In the case of shale gas extraction projects we have, on one hand, risks arising from the operation of surface facilities associated with the impacts on safety, health and environment. They are similar to those associated with any other type of project and its assessment is a common practice in various industries. There are methods available for quantitative assessment of the risks that are directly applicable; and there are also tools that have been used in other industrial processes. An important point to bear in mind is the need to not confuse bias and confidence. When the estimations of the probabilities and consequences, i.e., risks, are based directly on experience, the subsequent confidence in the assessment of those risks is to be high, but however usually not bias-free (Pérez, 1988; Slovic and Fischhoff 1977). Therefore, that means that even decisions with the best information available could be not bias-free.

Examples of risk involved in some Shale Gas operations and their comparable industries are (Oraee-Mirzamani et al., 2013):

- Injection operation: EOR, EGR and CBM

- Closing well: Oil industry

- Stewardship: Oil industry

- Local/regional hazards: Oil and Gas, Nuclear, Landfill, EOR, EGR and CBM etc.

- Geotechnical safety: EOR, EGR and CBM 
But, in addition, Shale Gas development raises new environmental and health concerns that are less well-understood than the risks associated with conventional fossil fuel extraction and that emanate from distinguishing characteristics such as (DNV, 2013; Broomfield, 2012): a large number of wells and well pads with high density distribution, associated high density of infrastructure, the use of significant volumes of water and chemicals compared to conventional gas extraction, potential of low level seismic activity related to the activity of the hydraulic fracturing process, the challenge of ensuring the integrity of wells and other equipment throughout the development, operational and post-abandonment lifetime of the plant (well pad) so as to avoid the risk of surface and/or groundwater contamination, the challenge of ensuring a correct identification and selection of geological sites, based on a risk assessment of specific geological features and of potential uncertainties associated with the long-term presence of hydraulic fracturing fluid in the underground.

Even though the evaluation of the significance of each specific risk, i.e., assessment of probabilities and consequences, will depend ultimately on each unconventional gas exploitation site, from a general point of view, the main concerns about these are related to the following aspects (Bunger et al., 2013; Litovitz et al., 2013):

- Induced Seismicity; hydraulic fracturing inherently involves geomechanical risks. The injection of large volumes of pressurized water at depth will most likely alter the in situ stress state and change the fracture propagation propensity or faults to slip, and result in seismic activity (Healy, 2012). It is possible to make a distinction between microseismicity events and larger seismic events that can be triggered by hydraulic fracturing in the presence of pre-stressed faults. Induced seismicity can cause direct damage to persons or property or indirect damage, for instance, through the creation of preferential paths to contamination of aquifers.

- Release of gases into the atmosphere: The unconventional gas extraction processes can result in gas and/or vapor emission into the atmosphere from original additive chemicals, contaminants from shale formation or methane released by the fracking process (Healy, 2012). These emissions are potentially 
important both for the direct risks involved as well as for the high net greenhouse gas footprint.

- Water use: Multiple processes associated with the production of unconventional gas are going to make use of water resources. Estimates of water volume required vary widely, with between 90.000 and 13.500 .000 liters per well (MIT, 2011). This large range is due to the geological nature of the process that causes very significant differences in the concept of well 'lifetime', with operations lasting from days to several years (MIT, 2011). The sources for these volumes of water could be local or imported from other areas. Local sources can impact on the quality and availability of water in uses already allocated, and can generate in addition a significant imbalance between supply and demand of water resources in the area. Remote sources will have additional impacts from transporting water in to the drilling site from further afield: construction of new roads to remote drilling sites and increased heavy road traffic and pollution.

- Water contamination: Of the shale gas potential environmental risks, water contamination is the most controversial issue and causes the main public concern (Zhang and Yang, 2015). This may be due to:

○ Underground migration of fluids: Two migration ways are possible for fracturing fluid and saline formation brine: leak through both faulty casing and cementing in wells and fluid migration upward from deep formation to the shallow aquifer. Evidences of mixing of brines and shallow groundwater through advective flow via faults and fractures have been reported in the literature (Warner et al., 2012). As well as in other aspects of this type of projects, the risks of hydraulic connectivity is unique in each project and depend on the detailed geometry of the shale formation in relation to local aquifers. The potential risk to ground water comes from two sources: the injected fluid (water + chemical additives) and the released natural gas. There are alleged incidents of both contamination types (Healy, 2012; Groat and Grimshaw, 2012; Osborn et al., 2011) although it is true that there has 
only been one confirmed case of gas released from a fracking operation entering a shallow aquifer through poor quality casing (Frogtech, 2013) and it continues to be debated due to a large extent to the uncertainties that arise from the geological nature of the process. Results from a study of several incidents of possible contamination in the US show no confirmed evidence for ground water contamination from the subsurface hydraulic fracturing operation itself, but suggest leakage from waste water above ground (Groat and Grimshaw, 2012).

○ Management of flowback and produced waters: another important concern is what to do with the flowback and produced water. Results from the study of several incidents of possible contamination in the US suggest that the origin and the cause of many of them come from leakage of waste water above ground (Groat and Grimshaw, 2012; Vengosh et al., 2014). The manners how flowback and produced water will be disposed of play significant roles on the environmental risks and overall impacts that might occur. The key concerns in this respect are (Frogtech, 2013):

- Unregulated release to surface and groundwater resources.

- Leakage from on-site storage ponds.

- Improper pit construction, maintenance and decommissioning.

- Incomplete treatment.

- Spills on-site; and

- Waste water treatment accidents.

\section{- Drill site logistics (anthropogenic road traffic and dust, noise and light} pollution): The activities for commercial development of unconventional gas exploitation include facilities, infrastructure and materials, water and equipment to be transported which have the potential to generate unintended environmental impacts, due to issues such as dust emissions, combustion 
emissions (mobile and stationary), land use and associated surface changes, etc.

So, unintended consequences of unconventional gas operations not only might affect financial concerns, stress levels, traffic noise and others societal problems, but also could impact on human health and local wildlife surrounding environment because of water, soil and/or gas pollution; potential induced seismicity by fracturing itself of caused by activities linked to it; and even on a larger scale also potentially affecting the environment via greenhouse gases emanation associated with shale gas exploitation operations not following the best-practice recommendations. Globally, it can be concluded that these unwanted consequences can be due to engineering practices and technologies, human operational factors or factors associated with geologic medium on which it is acting, i.e. this is because a wide range of different causes.

With the above in mind, it should not however be forgotten that risks should not be confused with hazards nor should it be thought that all risks are equal. Even it can happen, as it is sometimes the case, that there is plausible evidence of possible harm but scientific uncertainty and ignorance makes it impossible to reliably quantify and characterize the risks. Furthermore, we must not overlook that not all risks share the same level of probability or severity of consequences. However, derived from case and risk studies it is possible to conclude that there are potentially significant risks from the nature and fate of the fluids used in the drilling and fracturing processes as well as from the effects of the potential natural gas released (Healy, 2012) which should be taken into account and evaluated in a predictive and preventive manner in order to avoid the materialization of potential risks.

From the point of view of air pollution several types of volatile pollutants, such as VOCs, are released to ambient air from the various stages of well drilling, flowback, gas compression, condensation, and transport (McKenzie et al. 2012). Many researches showed the connections that exist between air quality and shale gas based on emissions inventories and air sampling (Moore et al. 2014; Swarthout et al. 2015; Field et al. 2015), with some associated health risk characterization. However, the aforementioned 
studies suffer from insufficient number of systematic research studies and from a quite limited geographic range (Werner et al. 2015). This should be remedied with the development of more geological studies and the acquisition of more information from monitoring. However, what is clear is that it is necessary to develop more and better studies regarding, for instance, the potential effects on soil quality or induced seismicity among other undesirable effects caused by unsuitable practices in shale gas exploration and production activities.

Until such studies were carried out, what is known is that possible further environmental impacts depend on the logistics of the extraction plan and the management of drilling operations at the surface which could involve relocating drilling rigs several times across a large area and over a protracted period (Healy, 2012).

Along with the above from the analysis of accidents and documented incidents, its characteristics (type of impact, frequency, severity) and what led to them, one realizes that all cases of scientifically documented superficial or deep aquifer contamination associated with fracking have occurred either due to (1) faults in cementation / casing of the well, where the incidence rate of leaking casing problems in unconventional gas wells is in the range of $1 \%$ to $3 \%$ (IRGC, 2013), or (2) surface leaks associated with failure in containment ponds or poor treatment of return water (Groat and Grimshaw, 2012; House of Commons, 2011; Royal Society, 2012) rather than from the fracking process itself.

Of these the risks to groundwater from wellbore failure scenario must continue to be considered appropriate by all regulators and construction closely monitored to ensure that best practices are followed. Since unconventional gas production wells bring into contact the target formation with upper aquifers and the surface without intermediaries, those could be preferential leakage pathways. It is for this reason that special care must be taken in the design and installation of wells to isolate the producing zone from other geologic units. Rigorous well testing can help to verify well integrity throughout the exploration, production and decommissioning phases and to identify any potential problem. They are not new problems and risks of these failures occurring may be controlled and reduced by following industry best practices. Because of the high potential for groundwater contamination from the wells, a fundamental rule arises 
and it is that decommissioned wells have to be effectively sealed for hundreds if not for thousands of years (Frogtech, 2013).

The other more significant risks are related to the management of flowback and produced water (CIWEM, 2016). There is no doubt that in hydraulic fracturing millions of liters of water, tens of thousands of liters of chemicals, and a huge amount of suspended solids are injected into the ground under high pressure. Water contamination is a potentially important risk to human health from hydraulic fracturing because the flowback water not only contains lots of known and unknown toxic chemicals from additives, even though they are increasingly environmentally friendly, and mainly from the deep formations. In the long run probably it represents the culmination of the potential impacts of hydraulic fracturing by its possibility of affecting various environmental compartments.

Accepting the above, it follows that any negligence associated with storage, transportation and operations resulting in spills scenarios represent the greatest threats to atmosphere, surface water, as well as to groundwater. Best pollution prevention practices will be essential during exploratory phase as well as construction, production and decommissioning ones. These can be effectively managed and there is no reason why this should not be achievable as it has been on many occasions in the past of oil exploitation. The rules to follow are clear and written. Close monitoring and scrutiny by regulators allied to strict enforcement will continue to be essential to ensure that the industry acts in an appropriately responsible manner. It is also expected by corresponding government agencies operators to demonstrate the best available techniques to protect groundwater in their permit applications (CIWEM, 2016). In the same way, opposite path that implies a relaxation of regulations or control by the competent agencies goes against the risk control, i.e. measured risks in terms of impact, likelihood and control effectiveness. And, in short, this is against the application of this technology in conditions of environmental sustainability and public acceptance.

Several studies that carry out reviews of the empirical literature on the impacts of unconventional shale gas and probability bounds analysis establish that wastewater disposal carried the highest risk and epistemic uncertainty, i.e. lack of knowledge, reflecting the high volumes of wastewater generated and the lack of efficacy of 
industrial or municipal wastewater treatment facilities used to treat these wastewaters (CIWEM, 2016; Rozell and Reaven 2012; Yap, 2016).

To assess the risk associated with this scenario it should be considered two different aspects. The first one is about the knowledge of the elements and the expected concentration of them in those waters and the second one the water contamination pathways. The above are key elements in three fundamental aspects of risk management. First, in the assignment of risk probabilities; second, in the identification of factors that affect the severity of the impacts associated with possible contaminations for activities related to the hydraulic fracturing water cycle (U.S. EPA, 2016); and third, in defining a liable framework of environmental management for flowback and produced waters.

\subsubsection{Water Contamination Pathways}

The hydraulic fracturing water cycle describes the use of water in hydraulic fracturing from water withdrawals to make hydraulic fracturing fluids through the mixing and injection of hydraulic fracturing fluids in production wells, to the final fate of collected produced water either for recycling/reuse or disposal in deep geological formations (action allowed in the United States, but not in Europe) (U.S. EPA, 2016).

In the literature they are described many influencing factors that could adversely affect water local resources system by hydraulic fracturing operations. EPA (U.S. EPA, 2016) has identified and listed a number of activities that have shown greater probabilities and/or impacts on surrounding aqueous system. They are briefly: (1) Water withdrawals for hydraulic fracturing in times or areas of low water availability, particularly in areas with limited or declining groundwater resources; (2) Spills during the management of hydraulic fracturing fluids and chemicals or produced water that result in large volumes or high concentrations of chemicals reaching groundwater resources; (3) Injection of hydraulic fracturing fluids into wells with inadequate mechanical integrity, allowing the transport of gases and liquids from them to groundwater resources; (4) Injection of hydraulic fracturing fluids directly into 
groundwater resources; (5) Discharge of inadequately treated hydraulic fracturing wastewater to surface water resources; and (6) Disposal or storage of hydraulic fracturing wastewater in unlined pits, resulting in contamination of groundwater resources. A synoptic scheme of the potential ways of escape of the fluids in the geological environment is reflected in the Figure 2-10.

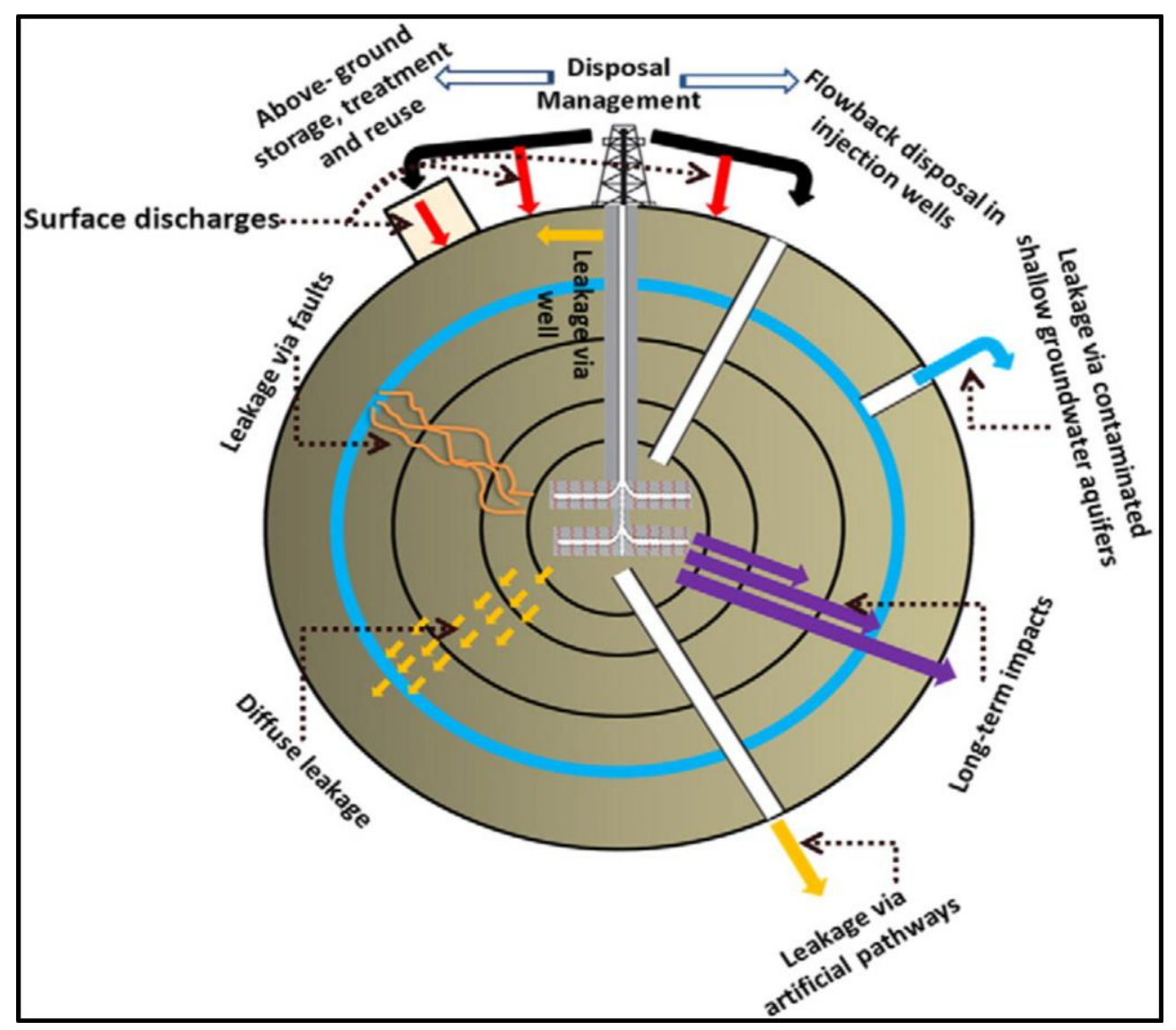

Figure 2-10: Potential transport pathways of the fluids (Veiguela et al., 2016).

In (Rozell and Reaven 2012) it is displayed how processes related to bad practices in shale gas extraction such as negligent transport, well casing failure, contamination migration through fractures, drilling site surface contamination and contamination from disposal of used hydraulic fracturing fluids constitute the five main contamination pathways that could impact the environmental water resources. Based on 
the result of this research, it is possible to figure out the probability that well fractures would leak and the portion of fluid that would leak through the fractures. However, despite the intrinsically interesting nature of these studies especially for long-term environmental risks, from a practical point of view of risk analysis it must be taken into account that the wastewater disposal potential risk and its associated epistemic uncertainty is of greater importance in the short and medium term environmental impacts than the previous ones. This idea, which has already been introduced previously, is based on the case studies that show that during the unconventional gas exploration period, wastewater disposal represents the greatest risk for impacting on the surrounding media environment; it is worth restating, in the short and middle term.

From the above, it is deductible the implicit importance of predictive studies on the environmental impact due to tanker spills to and from the well site within the context defined by the hydraulic fracturing water cycle (in Figure 2-11).

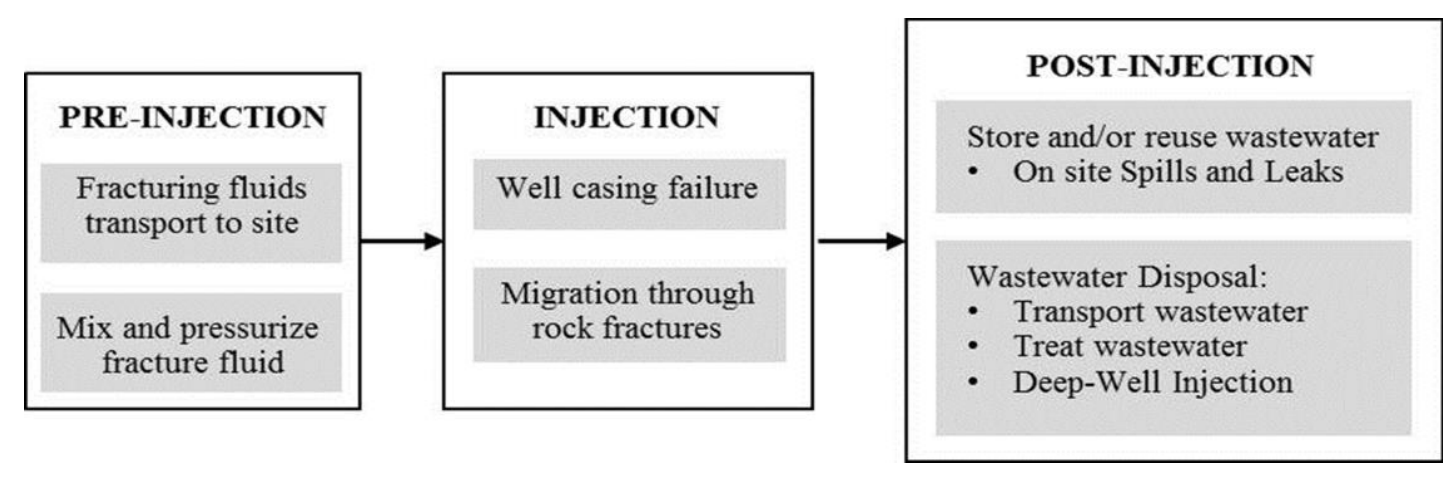

Figure 2-11: Contaminant pathways in shale gas development water cycle.

\subsubsection{Wastewater Chemical Composition}

After hydraulic fracturing, those created and kept open fractures together with the well drilled form the pathway that allow reversing the flow back of a complex fluid to the ground surface. The composition of this fluid is mainly given by more or less large parts of the pre-injected initial water with injection fluids mixed with brine from the porous space and micro fractures of the rock, gas (whose recovery is the main target of the process), and others new products that were initially in the geological formations. 
As already previously indicated millions of liters of water are necessary to be able to perform hydraulic fracturing operation. The amount of the fracturing fluid that is recovered as flowback depends greatly on the geological nature of the site and is highly variable. It ranges from as little as $5 \%$ as for example in the Haynesville shale to as much as 50\% in areas such as the Barnett and the Marcellus shales (King 2012).

About $25 \%$ of the injected water is returned to the surface within 30 days. Specifically this fluid conventionally receives the name of Flowback Fluid. For practical reasons, it should be distinguished from the fluid returning to the surface after those 30 days and that is usually called Produce Water. Flowback water consists mostly of the fluid used to hydraulic fracturing. It is dominated by injection water chemistry which contains dissolved chemicals from shale formation (Stewart et al., 2015) and, generally, occurs over 3 to 4 weeks after water injection. On the other hand, produced water has higher natural formation water content, tend to become increasingly saline, and reflects the chemistry of the formation fluids (Vengosh et al., 2014). Generally, the chemicals concentration of salts of inorganic nature, metals, radioactive materials (called NORMS or naturally occurring radioactive materials), a wide range of organic compounds and other potential substances which belong to local formation water will increase over time as the flow becomes smaller. However, for the fracturing additives, the expected evolution of its chemical concentration is the opposite. So, it will rise over the first few days, when the highest flows occur, and will decrease later. This is decisive in the characterization of the environmental impact of the return water. In this regard, it is worth to be noted that the amount of material dissolved varies widely from one site to other. Therefore, a crucial requirement to mitigate the risks is a systematic chemical monitoring of fracking fluids, including the flowback fluid and produced water (Healy, 2012) before, during and after the development of extraction operations arising from the importance of the concentrations of these substances in the impact on both water contamination and air pollution.

From a conceptual point of view, the chemical components have two main sources, namely, Additives and Components from Shale Formation:

\section{Additives}

The fluid that will be injected at high pressure into a wellbore contains additives, 
namely fracturing fluid and sand and as well as water, the most important fluid in volumetric terms. Its purpose is (1) to create cracks in the shale formation and sustain them by fracturing proppants when the hydraulic pressure is removed from well, (2) to recover the gas that is in the geological layers in operation and, in general terms, (3) to maintain the conditions for proper exploitation. The use of these chemical compounds is a source of concern with regard to environmental impacts and human health (Waxman et al., 2011), especially when, for instance in the United States, there is no legal obligation to declare the composition of the additives used in shale gas operations. This is a situation substantially different from that in Europe, although in the United States it is something that is recommended to do voluntarily and publish (see www.fracfocus.org). Taking into account the above-mentioned points, it should be added that these additives appear to tend to be environmentally friendlier as their technological development progresses. Research is underway to determine if human health has been affected (Meng, 2015; Lonati \& Zanoni, 2012) resulting from environmental practices that need to be improved. Full information about chemical components used, strict safety standards and law enforcement agencies constitute the basic foundations for ensuring the environmentally sustainable development of these activities and that do not lead to a deterioration of human health. According the website www.fracfocus.org, the basic hydraulic fracturing fluids composition is briefly detailed below.

Fresh Water represents about $98 \%$ to $99 \%$ of total volume. As proppant, at about $1 \%$ to $1.9 \%$ of total volume, is usually used sand or ceramic particles that are carried by the fracturing fluid into the fracture to keep the fracture open. It also requires a Friction Reducer (using non-acid polyacrylamide) that could reduce friction pressure of water flowing through the pipe during high rate pumping; Disinfectant (biocide) used to control the growth of certain kinds of microbes; Surfactants mainly to modify surface or interfacial tension, break or prevent emulsions; Gelation chemicals (thickeners) such as guar gum and cellulose polymers. While non-gelled water initiates the fracturing, later gelled water helps in the transport of the proppant (Hoeman et al., 2011); the role of the Scale inhibitors is to prevent mineral scale precipitates, and to eliminate the possibility of concentrating problematic ions for scaling and blockage of tubing and equipment (Houston et al., 2009); Hydrochloric acid may be used in some cases to 
reduce fracture initiation pressure; and, in the end, Corrosion inhibitors. These are several organic compounds with toxic characteristics. In particular, these products are adsorbed on steel and then in the geological formation returning only about 5 to $10 \%$ of the total injected volume to surface in the backflow (King, 2012).

\section{Components from Shale Formation}

A very simple way of succinctly defining Hydraulic Fracturing is as a process in which water and chemicals are pumped into the ground at high pressure in order to extract natural gases from the earth. The problem becomes more complicated when relationships between disturbing and disturbed elements in a complex system of high uncertainty such as the geological environment are taken into consideration. In this context, given that the shale gas contains $1 \%-2 \%$ free or capillary-bound brine (Balashov et al. 2015), and that there are allogenic elements that are constituent elements of the fluids as well as of the geological formations that are located in depth, when the high pressure injection fluid reaches the target depths, a new fluid is produced, mixing all of the above. As already mentioned above, it is a fluid of composition and volume that varies with time, hence the conventional division between flowback and production fluids. Oil and grease, and dissolved organics (including benzene, toluene, ethylbenzene and xylene); salts, including those composed from chloride, bromide, sulfate, sodium, magnesium and calcium; metals including barium, manganese, iron, and strontium; and radioactive materials including radium (radium-226 and radium-228), amongst others, are common components of hydraulic fracturing fluids with the potential to adversely impact human or environmental health.

The substances concentration data from Pennsylvania Marcellus Shale flowback water, to take one of the most important example, were published in 2009 (Hayes, 2009), what represents a key element in stimulating, developing and deepening the health, safety and environmental (HSE) risk assessment studies in order to ensure the health and safety of workers, local inhabitants and, in the future, of the public at large.

The results from horizontal wells indicate that the total dissolved solids (TDS) and organic material concentration vary according to time and geology with a harmful potential. To consider just one example, organic chemicals, such as BTEX, PAHs or pesticides, are common components present in these fluids associated with chronic and 
acute nonlymphocytic leukemia, anemia, blood disorders, impaired lung function and nervous system impairment (McKenzie et al., 2012). In view of the importance of the subject, epidemiological studies on the effects of human exposure to suspected toxic compounds in wastewater, especially to organic matters from shale formation, are urgently required (Elliott et al. 2016).

Consequently, the integral flowback water management, including the final fate of this fluid, is a big issue to be considered in order to avoid the materialization of potential risks to public health and the environment as a result of bad practices.

In the context of an adequate management of these fluids, the predictive estimation of their composition as well as their temporal evolution are very useful tools in the decision making process. In this line of reasoning, modelling the flowback behavior provide indispensable scientific knowledge and has undeniable benefits in optimizing well production operations (Gdanski et al., 2010).

The risk assessment associated with the different chemicals identified in the return and flowback waters requires knowing both the concentration and the volume of wastewater as well as their temporal evolution.

The knowledge of the temporal evolution allows making predictions of concentration that can be analyzed and compared with environmental limits for the different environmental compartments, in the event of undesired leaks in the exploitation process. This is essential for proper risk management.

In order to obtain predictive approximations of the concentrations of inorganic chemicals expected in the return waters the studies carried out by Balashov (Balashov et al., 2015) are applicable and adequate.

However, for the organic chemicals there is no suitable approximation for predictive assessment of evolution of the concentrations in the produced and flowback waters. 


\subsection{Underground Transport Processes}

The hydraulic fracturing process will result in a displacement of formation fluids occasioning transport processes that will mobilize both brine (capillary-bound brine $1 \%$ - 2\% shale) (Balashov et al., 2015) and the adsorbed elements in the rock matrix. Initially, the formation where the hydraulic fracturing is going to take place has a situation of chemical equilibrium between the solid and the liquid phases. In the case of VOCs, because of their hydrophobic nature and the resulting affinity to the sediment's organic matter, they will initially be accumulated in the solid phase. When hydraulic fracturing begins the contaminant concentrations in the aqueous phase decrease resulting in desorption of contaminants. This desorption produces a contaminants source term that will be transported to the surface in the flowback and produced waters together with the formation brine.

Therefore, for the study of the chemical composition of flowback and produced waters it will be necessary to construct and solve a mathematical model for the transport of pollutants in an aqueous phase from the rock matrix to the fractures generated. The different processes physical, chemical and biological should be considered when it addresses the concentration evolution of chemical contaminant compounds in the flowback and produced waters. As the formation fluid moves, it carries the component with it. So, the total flux of a component is made up of the sum of three fluxes (Bear and Bachmat, 1990): an advective flux, a diffusive flux and a dispersive flux. In addition, the continuous variation of the component's concentration is affected by various sources and sinks of the considered component within the domain of interest that can be grouped into two different categories: sources and sinks at the solid-fluid interface and sources and sinks within the liquid phase (e.g. radioactive decay). So, the potential for organic chemicals to reach the flowback water include evaluation of all the processes and factors having an impact on the transport through the matrix.

Accordingly, the mass balance equation for a single component that can be desorbed from the solid surfaces and also it is supposed to undergo chemical reactions within the fluid phase, but at rates that are different for each process, includes the following terms (where applicable): 
- advective flux,

- dispersive flux,

- diffusive flux,

- source/sink due to adsorption,

- $\operatorname{sink}$ due to radioactive decay within the fluid phase,

- source/sink due to degradation within the fluid phase,

- $\quad$ source/sink due to degradation of the adsorbate. 


\section{Methods AND MATERIAls}




\subsection{Initial Database}

Several studies have been conducted in an attempt to characterize the constituents that are found in flowback water (Abualfaraj et al., 2014; Yost et al., 2016b). The main data sources are four, which can be consulted on the Table 3-1 for more information. Undoubtedly, most outstanding source of information is the Marcellus shale region, the Middle Devonian-age, black, low-density, carbonaceous (organic-rich) shale, which has thousands of unconventional well drillings (Figure 3-1); and that occurs in the subsurface beneath much of Ohio, West Virginia, Pennsylvania and New York; and small areas of Maryland, Kentucky, Tennessee, and Virginia.

Table 3-1: Number of wells, constituents and data entries in each data source (Abualfaraj et al., 2014).

\begin{tabular}{cccc}
\hline Source & Number of Wells & Number of constituents & Number of data entries \\
\hline EPA industry data & 20 & 197 & 853 \\
Pennsylvania DEP BOGM & 40 & 240 & 7,689 \\
NYSDEC SGEIS report & 13 & 94 & 244 \\
Marcellus Shale Coalition & 19 & 275 & 26,144 \\
GTI Report (used in this & & & \\
\hline
\end{tabular}

The development of this study has been made based on data from the database on flowback water and production brine samples collected from Marcellus Shale Coalition GTI (Hayes, 2009). The main reason for this, apart from the number of data available (this database accounts for the great majority of records, i.e., 75\% of the total observations), is that the data were taken at fixed days during the production of the 
return water. This fact is fundamental because allow us to carry out studies on the concentrations evolution, essential for the achievement of the objectives set out in this research thesis.

For obvious reasons of maintaining confidentiality of information sources, samples were obtained from locations labeled A through S (see Figure 3-1) from injected water (designated as day 0 ) as well as to the days 1, 5, 14, and 90 days after the hydraulic fracturing event. Sixteen wells were scattered throughout the state of Pennsylvania, while the other three wells were located in the northern section of the state of West Virginia, all belonging to the Marcellus Shale Region, but with an indicated location that is an approximation roughly similar to the real one. This represents an obstacle perhaps insurmountable to the possibility of establishing correlations between values and geology. For this reason, it was not possible to distinguish well-level effects from regional effects.

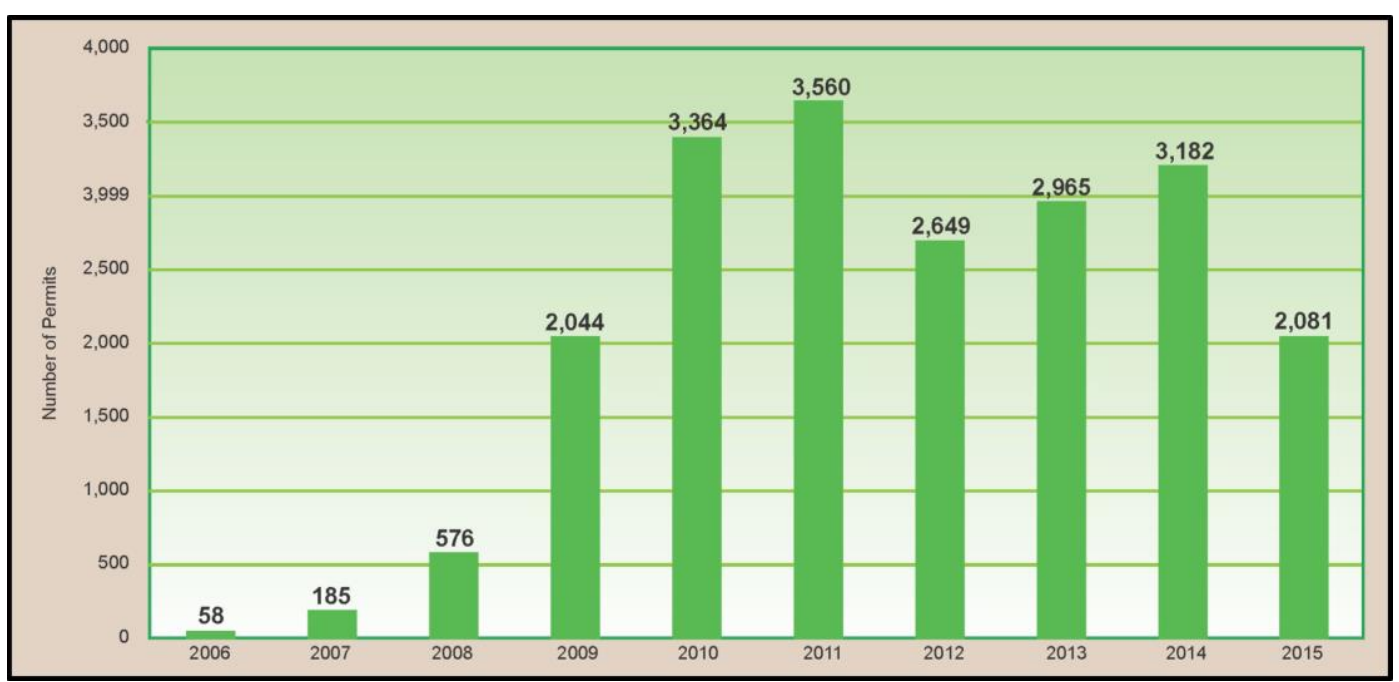

Figure 3-1: Pennsylvania Unconventional Well Drilling Permits Issued. 2005 Oil and Gas Annual Report (Pennsylvania, 2016). 


\subsubsection{Marcellus Shale Region}

The Middle Devonian Marcellus Shale formation extends through the central Appalachian Basin. It is present in Ontario, New York, Pennsylvania, Ohio, West Virginia, Maryland, and Virginia, with an extent of some $1.94 \cdot 10^{11} \mathrm{~m}^{2}(75,000 \mathrm{sq} \mathrm{mi})$ and an average thickness about $183 \mathrm{~m}$ (600 feet) (Bruner and Smosna, 2011)

The Marcellus Shale is considered to be the largest unconventional shale-gas resource in the United States as a single, continuous gas-bearing formation that underlies thousands of square miles (Wang and Carr, 2013). This work uses data released by the Marcellus Shale Coalition in a report of the Gas Technology Institute, coming from 17 shale gas companies that enabled the sampling of 19 locations within the Marcellus Shale Region, including 3 locations in West Virginia and 16 locations in Pennsylvania, as shown in the maps of Figure 3-2 (Hayes, 2009). The approximate positions of all of the sampling locations (Locations A through S) are indicated on the maps. Locations in West Virginia included 2 well completion sites in Lewis County and 1 completion site in Taylor County (Hayes 2009).

The Appalachian Basin is an asymmetrical foreland basin that was formed over a period of approximately 200 million years and through three separate orogenies. From a lithological view point, the Marcellus Shale is a gray to brownish black to black, carbonaceous, highly radioactive shale with some intercalated beds of limestone and carbonate concretions. Chronologically, it stands from the Middle Devonian through Early Mississippian time. It is a stratigraphic trap within the structurally-bound Appalachian Basin, occupying a structural low and straddling the basin axis. 

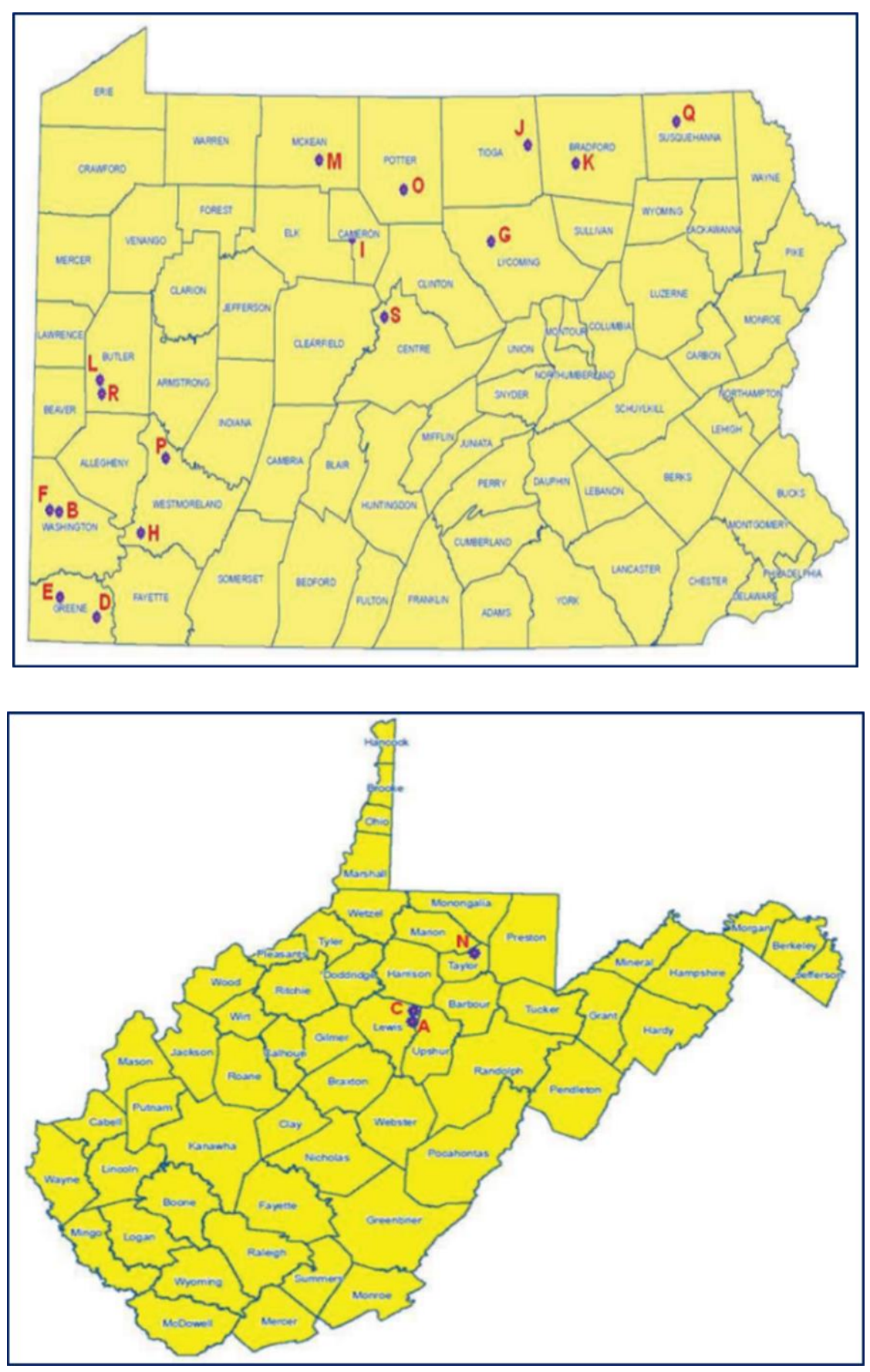

Figure 3-2: The Map of Samples Locations (Hayes, 2009).

The formation thickness exceeds $660 \mathrm{ft}(183 \mathrm{~m})$ in northeastern Pennsylvania, thinning to the west and southwest $(200 \mathrm{ft}(60.96 \mathrm{~m})$ in central Pennsylvania, $140 \mathrm{ft}$ $(42.67 \mathrm{~m})$ in northern West Virginia and pinching out in eastern Ohio (Zielinski and 
McIver, 1982; Wrightstone, 2008; Boyce, 2009). Drilling depth to the base of the shale (top of Onondaga Limestone) increases to the southeast, varying from 2,000 $\mathrm{ft}$ (609.6 m) along Lake Erie to $8,000 \mathrm{ft}(2438.4 \mathrm{~m})$ in northern West Virginia and Maryland to 8,000-10,000 ft (2438.4-3048 m) in central Pennsylvania.

Average porosity ranges from 6\% (Wrightstone, 2008) to 10\% (Bruner and Smosna, 2011). Permeability values are of 0.13-0.77 millidarcies with an average of 0.363 millidarcies (Bruner and Smosna, 2011). Gas saturation ranges from 55\%-80\% and water saturation, from $20 \%-45 \%$ (Kuuskraa and Wicks). The production of formation water is effectively zero (Bruner and Smosna, 2011), suggesting that the shale has no free water or that the relative permeability for water is zero. The fracture porosity in the Devonian shales varies across studies: as high as $3.5 \%-4.5 \%$ in ones, but others found that fracture porosity is less than $1 \%$ even in shale with the highest joint density (Bruner and Smosna, 2011). Fracture width ranges up to $1 \mathrm{~cm}$, and minerals that partly fill the fractures keep them open and maintain the pore network (Bruner and Smosna, 2011).

For unconventional shale reservoirs two critical factors build the response of the hydraulic fracture of a geological formation, stimulation and gas content. The natural gas content of a shale reservoir rock is strongly linked to organic matter content, measured by total organic carbon (TOC).

TOC in the lower Marcellus member is highest (6\%) in northern West Virginia and southwestern Pennsylvania, decreasing somewhat $(2 \%-4 \%)$ elsewhere in the central Appalachian Basin. So, the Marcellus Fm. is a very good to excellent source rock in terms of its organic richness which is highest in the central region (up to $9 \%$ ) and decreases to the east $(1 \%-2 \%)$ and west $(2 \%-3 \%)$ across the basin in New York. Nevertheless, the total organic carbon content of the Devonian shales changes rapidly from place to place and from layer to layer (Bruner and Smosna, 2011). 
The various lithofacies reflect variations of mineral composition and organic matter richness. The original definition of lithofacies is the "sum of all the lithologic features in sedimentary rocks, including texture, color, stratification, structure, components, and grain-size distribution" (Teichert, 1958).The interplay of dilution by terrigenous detritus, organic matter productivity, and organic matter preservation and decomposition affected the distribution of Marcellus Shale lithofacies distribution, which may be attributed to water depth and the distance to shoreline. (Wang and Carr, 2013)

Hydrocarbons in the Marcellus Shale are thermogenic in origin. The natural gas is adsorbed onto solid organic matter and kerogen $(20 \%-40 \%$ of the total (Jarvie et al., 2004); and 18\%-85\% (Kuuskraa et al., 1983)) and stored in interstitial pores and micro fractures. Pores within organic matter are widely recognized as a significant component of pore systems in gas shales (Wang and Carr, 2013)

Kerogen is mostly sapropelic (marine, algal) type II (Bruner and Smosna, 2011) with an hydrogen index $\mathrm{HI}$ as high as $250-400$ and an oxygen index OI less than 50 (Bruner and Smosna, 2011). The Marcellus contains also an admixture of terrestrial humic Type III kerogen in the eastern portion of the basin (Bruner and Smosna, 2011). From a chemical standpoint, kerogen is defined as $\mathrm{OM}$ "that is soluble neither in aqueous alkaline solvents nor in the common organic solvents" (Bruner and Smosna, 2011). The chemical definition of OM type partially overlaps the petrography-based definition, whereby kerogen is generally understood to be associated with particulate $\mathrm{OM}$, either terrigenous or marine, whereas bitumen is a liquid, or a former liquid, hydrocarbon released into pores during kerogen maturation.

The nature and origin of the contained organic material is important in that algal matter generates a greater quantity of hydrocarbons than woody matter and at a lower temperature. In Marcellus Shale Fm., three palynological biofacies were 
identified, the Tasmanites biofacies, a marine biofacies, and a terrestrial biofacies . The Tasmanites biofacies contains a palynomorph assemblage dominated by this single genus of marine green algae. The marine biofacies is a heterogeneous mix of algae and zooplankton and reflects normal sea-water chemistry. Finally, the terrestrial biofacies comprises mostly woody material derived from the adjacent landmass, reflecting that sea water there may have been influenced by a large riverine influx (Catskill Delta clastic wedge) (Bruner and Smosna, 2011).

Thermal maturity of the Marcellus increases progressively eastward across the basin as directly related to maximum burial depth beneath the Acadian and Alleghenian clastic wedges (Bruner and Smosna, 2011). Maximum burial depth was perhaps 5,000 ft $(1542 \mathrm{~m})$ in the west and 8,000 ft $(2438.4 \mathrm{~m})$ in the east (Bruner and Smosna, 2011).

But thermal maturity is also directly related to burial history. The Marcellus was subjected to a first stage of rapid burial in the Devonian-Mississippian, uplift in the Pennsylvanian (Alleghenian Orogeny), a second stage of rapid burial in the Permian-Triassic, followed by steady uplift to the present time with a continuous erosion of 7,000-10,000 ft (2133.6-3048 m) of overburden.

The generation of hydrocarbons converts organic matter from the solid phase to a gas, creating reservoir space for the hydrocarbons to reside. Thus, the quality of the source rock and its thermal history are the main controls in the petroleum system (Bracht, 2010, Wendt et al., 2015). Gas distribution and movement in the black shale is thought to be: molecular diffusion through the shale matrix, adsorption onto fracture faces, and free gas in the open fractures (Bruner and Smosna, 2011). Gas in place (GIP) is currently estimated to range from $20-150 \mathrm{bcfg}$ per sq mi to $60-100 \mathrm{scfg} /$ ton rock (Bruner and Smosna, 2011). 
The Marcellus Shale is highly radioactive. The radioactive nature of shales is a manifestation of varying contributions of potassium (K), thorium (Th), and uranium (U). These three major contributing elements behave quite differently from one another in both seawater and sediments. Thus, under anoxic conditions $U$ exists dominantly in organic complexes and typically is strongly correlated with TOC. Under euxinic conditions uranium is dominantly associated with the sulfidic fraction, although it is not taken up in any substantial amount by authigenic sulfides (Bruner and Smosna, 2011).

\subsection{Description of Transport Phenomena of Reactive Solutes in Soil}

The transport study of brine and solutes through the shale matrix is an important point to explain how flowback or/and production water chemistry changes with time. The starting point is the macroscopic mass balance equation for a component. The total flux is made up of the sum of advective, dispersive and diffusive flux. In addition, the continuous variation of the component's concentration is affected by various sources and sinks of the considered component within the domain of interest, e.g., by chemical reactions. In what follows, we shall discuss each of these terms in detail.

\subsubsection{Convection Advective flux}

The term advection refers to the transport of a solute by the bulk movement of groundwater, the movement of particles within flowing water through the soil matrix. The velocity of the bulk movement of groundwater is the average linear groundwater velocity, also called the advective velocity when referring to the transport of solutes in a 
groundwater medium. Therefore, the one-dimensional advective flux of a solute in underground aqueous media can be expressed by (Darcy’s law):

$$
J_{a d v}=v_{x} \cdot \theta \cdot C
$$

where $J_{a d v}$ is the advective flux $\left[\mathrm{Mass} \cdot \mathrm{area}^{-1} \cdot \mathrm{time}^{-1}\right], v_{x}$ is the average groundwater velocity in the direction of flow [Length $\cdot$ time $\left.^{-1}\right], C$ is the concentration in mass per unit volume of solution [Mass $\cdot$ Length $^{-3}$ ] and $\theta$ is the effective porosity of the geological medium, that is the interconnected porosity.

The Equation (3.1) assumes that the contaminant transport does not affect the fluid flow velocity.

\subsubsection{Dispersive flux}

This flux results from the variation of the microscopic velocity in both magnitude and direction across any pore cross-section within the Representative Elementary Volume $(R E V)^{1}$. Observations on a microscopic scale show velocity variations in both magnitude and direction across any pore cross-section. The shape of the interconnected pore space makes the streamlines fluctuate in space with respect to the mean direction of flow. This phenomenon, referred to as mechanical dispersion, causes a mechanical mixing and dilution of the solute within the bulk movement of groundwater. Although this spreading occurs in both the longitudinal direction (flow direction) and in the direction transversal, it is primarily in the longitudinal direction and it is generally assumed that longitudinal dispersivity is about 10 times larger than transverse

\footnotetext{
${ }^{1} R E V$ is the smallest volume over which a measurement can be made that will yield a value
} representative of the whole. 
dispersivity.

Phenomenologically, dispersion has two effects: it increases the passage time of a pulse and it lowers the maximum concentration. For the case of a toxic contaminant for instance, this leads to a longer exposure time but also to a lower maximum concentration.

The dispersive flux per unit volume of fluid is given by:

$$
J_{d i s p}=-\theta \cdot D^{m} \cdot \nabla C
$$

where $J_{\text {disp }}$ is the dispersive flux [Mass $\cdot$ Length $^{-2} \cdot$ Time $^{-1}$ ], $C$ is the concentration in mass per unit volume of solution [Mass $\cdot$ Length $^{-3}$ ], $\theta$ is the effective porosity of the geological medium, that is the interconnected porosity and $D^{m}$ is the coefficient of mechanical (or advective) dispersion $\left[\right.$ Length $^{2} \cdot$ Time $\left.^{-1}\right]$.

The coefficient of mechanical dispersion, $D^{m}$ (components $D_{i j}^{m}$ ), is the product of advective groundwater velocity $v$, by the porous medium's dispersivity, $\alpha$ (components longitudinal dispersivity, $\alpha_{L o}$, and transversal dispersivity, $\alpha_{T r}$, in a principal coordinate system):

$$
D^{m}=\left[\begin{array}{ccc}
\alpha_{L o} \cdot v & 0 & 0 \\
0 & \alpha_{T r} \cdot v & 0 \\
0 & 0 & \alpha_{T r} \cdot v
\end{array}\right]
$$

The dispersivity is a characteristic property of the geological medium, and differs in value for each of the spatial components. For examples, if all the pores are nearly the same size, dispersivity of the rock or sediment would be low. Dispersivity in the direction of flow is referred to as longitudinal dispersivity, dispersivity perpendicular to flow is referred to as transverse dispersivity both in a horizontal plane to flow (in 
$\mathrm{y}$-direction) and in a vertical plane to flow (in z-direction, flow up or down in a groundwater medium).

According this, the mechanical dispersion also could be represented by:

$$
J_{\text {disp }}=-\theta \cdot \alpha \cdot v \cdot \nabla C
$$

\subsubsection{Diffusive flux}

This flux is due to pollutant concentration gradients, where ionic or molecular constituents move in the direction of their concentration gradients. This phenomenon is often referred to as molecular diffusion and it is caused by the random motion of molecules in a fluid. This produces an additional flux of tracer particles (at the microscopic level) from regions of higher tracer concentrations to those of lower ones.

At the microscopic level, the flux of molecular diffusion, $J_{\text {diff, }}$ is expressed by Fick's law:

$$
J_{\text {diff }}=-\theta \cdot D^{*} \cdot \nabla C
$$

where $J_{\text {diff }}$ is the diffusive flux [Mass $\cdot$ Length $^{-2} \cdot$ Time $^{-1}$ ], $C$ is the concentration in mass per unit volume of solution [Mass $\cdot$ Length $^{-3}$ ], $\theta$ is the effective porosity of the geological medium and $D^{*}$ is the apparent scalar coefficient of molecular diffusion of the element in the fluid phase.

In this expression $D^{*}$ it has been defined since the Fick's law was derived for chemicals in unobstructed water solutions. When this law is applied to porous media, the diffusion coefficient should be smaller since the ions follow longer paths caused by the presence of solid particles in the solid matrix. This yields an apparent diffusion 
coefficient $D^{*}$ represented by $D^{*}=w \cdot D^{f}$, where $D^{f}$ is the diffusion coefficient and ' $w$ ' is an empirical coefficient less than 1 (range between 0.5 to 0.01 (Freeze and Cherry, 1979)) which takes into account the effect of the solid phase of the porous media on the diffusion (Patil and Chore 2014).

\subsubsection{Hydrodynamic Dispersion}

Because both the diffusive and the dispersive fluxes of a component are proportional to $\nabla C$ and that the separation between the two fluxes is rather artificial, as they are inseparable, it is common to add the two fluxes and define the flux of hydrodynamic dispersion, $J_{h}$, as:

$$
J_{h}=\theta \cdot D_{h} \cdot \nabla C
$$

where $D_{h}$ is the coefficient of hydrodynamic dispersion $\left(D^{m}+D^{*}\right)$. This includes spreading out the solute in direction of flow (longitudinal dispersion, $D_{L o}$ ) and perpendicular to it (transverse dispersion, $D_{T r}$ ).

$$
\begin{aligned}
& D_{L o}=\alpha_{L} \cdot v+D^{*} \\
& D_{T r}=\alpha_{T} \cdot v+D^{*}
\end{aligned}
$$

In regions of high velocity the effect of molecular diffusion on the spreading of a component may be negligible, relative to the effect of mechanical dispersion, while at a very low velocity, molecular diffusion predominates. In the limit, for a stagnant fluid, we have only molecular diffusion. 


\subsubsection{Sources and sinks within the liquid phase}

Sources and sinks may be due to a withdrawal (or injection) of liquid, containing the component, from the porous medium and also may result from various processes within the fluid phase, e.g., chemical reactions among components within the phase, radioactive decay and growth/decrease due to bacterial activities, that cause the quantity of the considered component within the phase to decrease, or increase.

The mathematical expression will depend on the process:

- Withdrawal (or injection) of liquid

Let a distributed external liquid source (sink) at a rate $R_{\text {ext }}$ (volume of liquid added per unit volume of porous medium, per unit time) containing a considered component at a known concentration $C_{R}$. Then the source term in the balance equation is (+ source and - sink):

$$
S_{\text {ext }}=( \pm) R_{\text {ext }} \cdot C_{R}
$$

- Radioactive decay/degradation phenomena:

These reactions are modeled as first-order processes for which the rate of loss or gain is proportional to the existing concentration to the first power. Then, the sink term, expressing the rate of disappearance of the component, is given by:

$$
S_{r d}=-\theta \cdot \lambda \cdot C
$$

where $\lambda$ is the radioactive decay/degradation rate constant $\left[\right.$ Time $\left.^{-1}\right]$

- Chemical reactions: 
When an element participates in chemical reactions which cause its concentration to increase (or decrease), it can be expressed by:

$$
S_{c h}=( \pm) \theta \cdot \sum_{j} R^{j}
$$

where $R^{j}$ is the rate of production of the element by the $j$ reaction $(j=1,2, \ldots, n)\left[\right.$ Time $\left.^{-1}\right]$

\subsubsection{Sources and sinks at the solid-fluid interface}

These are processes that remove or add chemicals across the domain boundaries. For example, we have:

- Adsorption/Desorption of a species of an aqueous liquid on the solid matrix. This is the phenomenon of accumulation/reduction of a component of a fluid on the solid at the fluid - solid interface. The main factors affecting the adsorption and desorption are the physical and chemical characteristics of the component and of the solid's surface.

- Ion exchange. The reaction involved is essentially an exchange between ions in the solution and ions that are fixed on the solid;

- Precipitation of a considered species;

- Dissolution of the solid phase;

- Evaporation of a volatile species dissolved in a liquid phase into a gaseous phase that occupies part of the void space; 
- Condensation of a species present in the gaseous phase; and

- Diffusive transfer of a species that can dissolve in two adjacent liquid phases. In all these examples, a chemical species is transferred from one phase to an adjacent one, across their common boundary.

These processes are influenced by the physical and chemical characteristics of the component and of the solid's surface. Other factors to consider are temperature and the presence of other components in the fluid phase (e.g., through the $\mathrm{pH}$ that results from their presence in the fluid phase). To model these is used an adsorption isotherm. This is an expression that relates the mass of adsorbed component per unit mass of solid (adsorbent) to the concentration, $\mathrm{c}$, in the fluid phase, at a constant temperature. Different adsorbate-adsorbent pairs have different isotherms (Travis, 1978; Bear and Bachmat, 1990).

\subsubsection{1. $\quad$ Sorption/Retention}

This is the phenomenon of reduction of a component of a fluid when it is adhere to the grain particles of the geological media. The main factors affecting the adsorption are the physical and chemical characteristics of the component and of the solid's surface. Two types of sorption can be distinguished: reversible, that causes retardation in the concentration front behind the advective front, and irreversible, that effectively removes solute from the fluid phase.

In the case of fast reaction, with Freundlich linear adsorption isotherm, the effect of reversible sorption is described by the retardation factor.

$$
R_{d}=1+\frac{\rho}{\theta} K_{d}
$$

where $R_{d}$ is the retardation factor, $\rho$ is the bulk density, $\theta$ the effective porosity 
and $K_{d}$ the distribution coefficient (solute mass adsorbed by the soil matrix/concentration of solute in the fluid)

In the case of hydrophobic organic chemical pollutants, with limited solubility in water, a first approximation to $K_{d}$ can be estimated using the approach that this is not especially sensitive to the exact source of the organic carbon for many hydrophobic chemicals in soils. So, $k_{o c}$, the organic carbon-water partition, can be used to estimate $R_{d}:$

$$
R_{d}=1+\frac{\rho}{\theta} \cdot k_{o c} \cdot f_{o c}
$$

where $R_{d}$ is the retardation factor, $\rho$ is the bulk density, $\theta$ the effective porosity, $k_{o c}$ the organic carbon-water partition coefficient (chemical concentration sorbed to organic carbon $(\mathrm{mg} / \mathrm{g}) /$ chemical concentration in water $(\mathrm{mg} / \mathrm{ml}))$ and $f_{o c}$ is the fraction of soil that is organic carbon

\subsection{Model to Evaluate Vertical Transport of Organic Chemicals in the Vadose Zone}

As shown in the previous section, the chemical composition of the flowback and produced waters will depend on the transport phenomena that cause the brine and the chemical components present in the geological formation to become part of the waters that return to the surface (return waters). These waters will be stored at first in surface storages, whether pools or tanks. In order to determine the risks associated with the failure of these storage structures, it is necessary to know not only the concentration of the different compounds but also the temporal evolution of a possible leakage in function of different characteristics of the soils. To do this, an analytical approach is 
used which takes into account the transport in the Vadose zone until reaching the water table.

An analytical solution is displayed for one-dimensional vertical transport of volatile chemicals through the vadose zone to groundwater (Shan and Stephens, 1995). The governing equation includes convective, diffusive and dispersive fluxes and decay phenomena in 1D:

$$
D \frac{\partial^{2} C}{\partial z^{2}}-V \frac{\partial C}{\partial z}-\lambda C=\frac{\partial C}{\partial t}
$$

where $z$ is the vertical coordinate taken positive download; $t$ is time; $\lambda$ is the decay constant; $C$ is the total concentration defined as the total amount of chemical in liquid, gas and solid phases per unit of soil, $V$ is the average flux velocity in the direction of flow and $D$ is the coefficient of hydrodynamic dispersion.

The model assumes a linear, equilibrium partitioning between water, gas and the adsorbed chemical phases. So, concentration in the liquid, $C_{L}$, and concentration in the gas, $C_{G}$, is related to the total concentration, $C$, by:

$$
R_{L} C_{L}=R_{G} C_{G}=C
$$

where the two coefficients $R_{L}$ and $R_{G}$ can be calculated by:

$$
\begin{aligned}
& R_{L}=\rho_{b} K_{S L}+\theta+(\phi-\theta) K_{H}+\rho_{b} K_{H} K_{S G} \\
& R_{G}=\frac{R_{L}}{K_{H}}=\rho_{b} \frac{K_{S L}}{K_{H}}+\frac{\theta}{K_{H}}+(\phi-\theta)+\rho_{b} K_{S G}
\end{aligned}
$$

Respectively, where $\theta$ is the volumetric water constant; $\phi$ is the porosity; $\rho_{b}$ is the bulk density; $K_{H}$ is Henry's constant; and $K_{S L}$ and $K_{S G}$ are the solid-liquid and the solid-gas distribution coefficients, respectively. The value $K_{S L}$ can be taken from: 


$$
K_{S L}=k_{o c} \cdot f_{o c}
$$

where $k_{o c}$ is the partition coefficient; and $f_{o c}$ is the fraction of organic carbon. The parameter $K_{S G}$ is a function of water content, and needs to be estimated from laboratory tests.

The parameter $V$ in equation can be called the overall pore velocity defined by:

$$
V=\frac{v_{L}}{R_{L}}+\frac{v_{G}}{R_{G}}
$$

where $v_{L}$ and $v_{G}$ are the Darcy velocities of the liquid and gas phases, respectively, considered here under steady-state conditions.

The parameter $D$ in equation can be called the overall dispersion coefficient defined by:

$$
D=\frac{D_{L}}{R_{L}}+\frac{D_{G}}{R_{G}}
$$

where $D_{L}$ and $D_{G}$ are the dispersion coefficients in the liquid and gas phases, respectively, which can be calculated by:

$$
D_{L}=\alpha_{L} v_{L}+D_{L M}
$$

and

$$
D_{G}=\alpha_{G} v_{G}+D_{G M}
$$

where $\alpha_{L}$ and $\alpha_{G}$ are the dispersivity coefficients in the liquid and gas phases, respectively, which can be estimated by formula presented in (Shoemaker et al., 1990) 


$$
D_{L M}=\frac{\theta^{10 / 3}}{\phi^{2}} D_{w} \quad D_{G M}=\frac{(\phi-\theta)^{10 / 3}}{\phi^{2}} D_{a}
$$

where $D_{w}$ and $D_{a}$ represent the chemical diffusion coefficients in water and air, respectively. It is worthwhile to point out that equation is the model, which was developed for estimating gas diffusion coefficients in porous media. The calculated coefficient $D_{G M}$ is usually called the effective gas diffusion coefficient and $D_{L M}$ effective liquid diffusion coefficient.

With all parameters now defined, we start solving Eq. 3.13 for our particular problem. The initial concentration is assumed as:

$$
C(z, 0)=C_{i}
$$

where $C_{i}$ stands for the initial concentration, which is assumed as;

$$
C_{i}=0 \quad\left(0 \leq z \leq d_{1} \quad d_{2} \leq z \leq d_{3}\right) ; C_{i}=C_{0} \quad\left(d_{1} \leq z \leq d_{2}\right)
$$

where $C_{0}$ is a non-zero constant; and $d_{1}, d_{2}$ and $d_{3}\left(0 \leq d_{1} \leq d_{2} \leq d_{3}<\infty\right)$ represent the depths to the top and the bottom of the contamination source, and to the groundwater table, respectively. The latter can more precisely be the capillary fringe above the groundwater table. For purpose of generality, we assume $0<d_{1}<d_{2}<d_{3}<\infty$, such that the derived solution can also be applied to special cases where $d_{1}=0$ representing a surface source, or $d_{2}=d_{3}$ representing a water table source.

For our problem, we assume for boundary conditions:

$$
\begin{gathered}
C(0, t)=0 \\
\left(\frac{\partial C}{\partial z}\right)_{z=d_{3}}=0
\end{gathered}
$$


The boundary condition thus assumes that advection is the only significant transport mechanism for chemicals from the vadose zone to enter the groundwater.

The analytical solution was obtained by means of series expansion. It is calculated using different formula in three different depth intervals:

$$
\begin{aligned}
& C_{1}(z, t)=\sum_{n=1}^{8}(-1)^{n} f_{1}\left(t, \alpha_{n}, \beta_{n}^{(0)}\right)+\sum_{m=1}^{\infty} C^{(m)} \\
& \quad\left(0 \leq z \leq d_{1}\right) \\
& C_{2}(z, t)=C_{0} \cdot e^{-\lambda t}+\sum_{n=1}^{7}(-1)^{n} f_{1}\left(t, \alpha_{n}, \beta_{n}^{(0)}\right)-f_{2}\left(t, \alpha_{8}, \beta_{8}^{(0)}\right)+\sum_{m=1}^{\infty} C^{(m)} \\
& \left.C_{3}(z, t)=\sum_{n=1}^{6}(-1)^{n} f_{1}\left(t, \alpha_{n}, \beta_{n}^{(0)}\right)+f_{2}\left(t, \alpha_{7}, \beta_{7}^{(0)}\right)-d_{2}\right) \\
& \quad\left(t, \alpha_{8}, \beta_{8}^{(0)}\right)+\sum_{m=1}^{\infty} C^{(m)} \\
& \left(d_{2} \leq z \leq d_{3}\right)
\end{aligned}
$$

where

$$
\left.\begin{array}{c}
f_{1}\left(t, \alpha_{n}, \beta_{n}^{(0)}\right)=\frac{C_{0}}{2} \exp \left(\alpha_{n}+\frac{V \beta_{n}^{(0)}}{2 \sqrt{D}}-\lambda t\right) \cdot \operatorname{erfc}\left(\frac{V \sqrt{t}}{2 \sqrt{D}}+\frac{\beta_{n}^{(0)}}{2 \sqrt{t}}\right) \\
f_{2}\left(t, \alpha_{n}, \beta_{n}^{(0)}\right)=\frac{C_{0}}{2} \exp \left(\alpha_{n}+\frac{V \beta_{n}^{(0)}}{2 \sqrt{D}}-\lambda t\right) \cdot \operatorname{erfc}\left(-\frac{V \sqrt{t}}{2 \sqrt{D}}-\frac{\beta_{n}^{(0)}}{2 \sqrt{t}}\right)
\end{array}\right\}
$$




$$
\begin{gathered}
\alpha_{1}=V\left(z-d_{2}\right) /(2 D) \beta_{1}^{(m)}=\left[2(m+1) d_{3}-d_{2}+z\right] / \sqrt{D} \\
\alpha_{2}=V\left(z-d_{1}\right) /(2 D) \beta_{2}^{(m)}=\left[2(m+1) d_{3}-d_{1}+z\right] / \sqrt{D} \\
\alpha_{3}=\alpha_{2}, \quad \beta_{3}^{(m)}=\left[2(m+1) d_{3}-d_{1}-z\right] / \sqrt{D} \\
\alpha_{4}=\alpha_{1}, \quad \beta_{4}^{(m)}=\left[2(m+1) d_{3}-d_{2}-z\right] / \sqrt{D} \\
\alpha_{5}=\alpha_{2}, \quad \beta_{5}^{(m)}=\left[2 m d_{3}+d_{1}+z\right] / \sqrt{D} \\
\alpha_{6}=\alpha_{1}, \quad \beta_{6}^{(m)}=\left[2 m d_{3}+d_{2}+z\right] / \sqrt{D} \\
\alpha_{7}=\alpha_{1}, \quad \beta_{7}^{(m)}=\left[2 m d_{3}+d_{2}-z\right] / \sqrt{D} \\
C_{8}^{(m)}=\frac{2 C_{0}}{\pi \sqrt{D}} \exp \left[-\left(\lambda+\frac{V^{2}}{4 D}\right) t\right] \cdot l \\
\beta_{8}^{(m)}=\left[2 m d_{3}+d_{1}-z\right] / \sqrt{D}
\end{gathered}
$$

where

$$
\begin{aligned}
I=\int_{0}^{\infty} & \frac{e^{-u t}}{\gamma \sqrt{u}} \sin (z \sqrt{u / D}) \cos \left[(2 m+1)\left(\delta+d_{3} \sqrt{u / D}\right)\right] \\
& \times\left\{e^{\alpha_{1}} \sin \left[\left(d_{3}-d_{2}\right) \sqrt{u / D}\right]-e^{\alpha_{2}} \sin \left[\left(d_{3}-d_{1}\right) \sqrt{u / D}\right]\right\} \cdot d u \\
\gamma & =\frac{\sqrt{V^{2}+4 D u}}{2 D} ; \delta=\tan ^{-1}(2 \sqrt{D u} / V)
\end{aligned}
$$


There is also an optional formula to calculate the term for $m=1$;

$$
C^{(1)}=\sum_{n=1}^{8}(-1)^{n} g\left(t, \alpha_{n}, \beta_{n}^{(1)}\right)
$$

In addition:

$$
g\left(t, \alpha_{n}, \beta_{n}^{(1)}\right)=\frac{C_{0} V \sqrt{t}}{\sqrt{\pi D}} \exp \left[\alpha_{n}-\frac{\left(\beta_{n}^{(1)}\right)^{2}}{4 t}-\left(\lambda+\frac{V^{2}}{4 D}\right) t\right]-\left(1+\frac{V \beta_{n}^{(1)}}{\sqrt{D}}+\frac{V^{2}}{4 D}\right) f_{1}\left(t, \alpha_{n}, \beta_{n}^{(1)}\right)
$$

\subsubsection{Cumulative mass}

\subsubsection{Cumulative Mass to Groundwater}

The time-dependent cumulative mass to the groundwater is an important indicator of the fate of the VOCs released to the soil. The cumulative mass is simply the integration of equations with respect to $t$ :

$$
M_{W}=\frac{v_{L}}{R_{L}} \int_{0}^{t}\left(C_{3}\right)_{z=d_{3}} \cdot d t
$$

$$
\begin{aligned}
\int_{0}^{t} C^{(m)} \cdot d t & =\frac{2 C_{0}}{\pi \sqrt{D}} \int_{0}^{\infty} \frac{1-\exp \left[-\left(u+\lambda+V^{2} / 4 D\right) t\right]}{\gamma \sqrt{u} \cdot\left(u+\lambda+V^{2} / 4 D\right) t} \times \sin \left(d_{3} \sqrt{u / D}\right) \\
& \times \cos \left[(2 m+1)\left(\delta+d_{3} \sqrt{u / D}\right)\right] \times\left\{\exp \left[V\left(d_{3}-d_{2}\right) / 2 D\right]\right. \\
& \times \sin \left[\left(d_{3}-d_{2}\right) \sqrt{u / D}-\exp \left[V\left(d_{3}-d_{1}\right) / 2 D\right]\right. \\
& \left.\times \sin \left[\left(d_{3}-d_{1}\right) \sqrt{u / D}\right]\right\} d u
\end{aligned}
$$

\subsubsection{Cumulative mass to atmosphere}

The time-dependent cumulative mass to the atmosphere is other important 
indicator of the fate of the VOCs released to the soil. The cumulative mass is simply the integration of equations with respect to $t$ :

$$
\begin{gathered}
M_{A}=\frac{D_{G}}{R_{G}} \int_{0}^{t}\left(\frac{\partial C_{1}}{\partial z}\right)_{z=0} \cdot d t \\
\int_{0}^{t}\left(\frac{\partial C_{1}}{\partial z}\right)_{z=0} \cdot d t=\frac{2 C_{0}}{\pi \sqrt{D}} \sum_{m=0}^{\infty} \int_{0}^{\infty} \frac{1-\exp \left[-\left(u+\lambda+V^{2} / 4 D\right) t\right]}{\gamma\left(u+\lambda+V^{2} / 4 D\right) t} \\
\times \cos \left[(2 m+1)\left(\delta+d_{3} \sqrt{u / D)}\right) \times\left\{\exp \left[-V d_{2} / 2 D\right] \cdot \sin \left[\left(d_{3}-d_{2}\right) \cdot \sqrt{u / D}\right]\right.\right. \\
\left.-\exp \left[V d_{1} / 2 D\right] \cdot \sin \left[\left(d_{3}-d_{1}\right) \cdot \sqrt{u / D}\right]\right\} \cdot d u
\end{gathered}
$$

\subsection{Monte-Carlo Method}

Monte-Carlo Analysis is a computer-based method of analysis that uses statistical sampling techniques for evaluating a probabilistic approximation to the solution of a mathematical equation or model.

Monte-Carlo simulation would involve many calculations of the intake rate rather than a single calculation; for each calculation, the computation would use a value for each input parameter randomly selected from the probability density function (PDF) for that variable because of the uncertainty (lack of knowledge about specific factors, parameters, or models) and variability (differences attributable to true heterogeneity or diversity in a population or exposure parameter) factors (U.S. EPA, 1997). Over multiple calculations, the simulation uses a range of values for the input parameters that reflects the probability density function of each input parameter. Thus, estimated results are shown by probability density function or cumulative density function. Based on the distribution of the output, a results representing the high end (e.g., $95^{\text {th }}$ percentile), central tendency (median or mean), or any other desired level of probability can be identified (Poulter, 1998). Moreover, after Monte-Carlos Method sensitivity analysis, 
the output of the mathematical model could provide a ranking of the model's input assumptions with respect to their contribution to model output variability or uncertainty. In a broader sense, sensitivity can refer to how conclusions may change if models, data, or assessment assumptions are changed (U.S. EPA, 1997). 


\section{Analysis of Results}




\subsection{A Model for Predicting Organic Compounds Concentration Change in Water Associated with Horizontal Hydraulic Fracturing}

Potential environmental toxicity and water quality pollution impacts of flowback, and produced water will depend on toxic pollutant concentrations (Jiang et al., 2014) in above-ground pit containers. This aspect is of particular interest since in 2013, Resources for the Future (RFF) released the results of a study of four key stakeholder groups in shale gas development-industry, regulators, nongovernmental organizations (NGOs), and academics (Krupnick et al. 2013). In this survey, the risk pathway (linking routine shale gas development activities to the burdens that impact the environment and local communities) that was most often selected by the stakeholder groups was on-site pit storage of flowback and produced water constituents and the potential for leakage into surface water (Kuwayama et al., 2015). In addition to concerns regarding surface water, the risk to groundwater resources generated by on-site pit storage of flowback and produced water constituents was also a pathway that was common to all groups' top 10 most selected pathways (Krupnick, and Gordon, 2015).

In order to reduce the high associated uncertainties to organic chemical concentrations (Jiang et al. 2014) and to be able to carry out an inventory of the masses and concentrations present in holding tanks a model that allows estimating the time evolution of the concentration of pollutants in flowback and produced waters is necessary. This model together with the expected water volumes throughout the life of a production well (Kondash et al. 2017) will allow adjusting the amount of contaminants present in the above-ground pit containers over time and make a more accurate estimate of their potential environmental toxicity. Almost $77 \%$ wetland and $13 \%$ 
river will exposed in high risk situation (Meng, 2015) related to the surrounding water system contamination when disposal water leaks or improper disposal operations take place (U.S. EPA, 2015; Osborn et al., 2011; Warner et al., 2013; Vidic et al., 2013).

The current research on environmental and human health impact derived from fracturing and drilling activities has already embarked on monitoring surrounding water indicators (Molofsky et al., 2013; Kravchenko et al., 2014) analysing whether contaminants concentration in samples exceed the limits imposed by the authorities (Bunch et al., 2014) and providing forward opinions on treatment (Rahm et al., 2013). However, the current state of knowledge is determined by the following constraining factors: (1) unconventional hydraulic fracturing of shale formation for extraction of shale gas has only expanded to Canada, USA and a few other countries (Vengosh et al., 2014) with a relative small number of flowback and produced water sample analysis available given the total number of wells in operation; (2) lack of specific, long-term and systematic monitoring of the nearby environment (Struchtemeyer et al., 2012), to understand critical macro or micro elements influence of fracturing operations; (3) a large amount of published literature on organic compounds present in produced water informing about risk to residents (McKenzie et al., 2012; Bloomdahl et al., 2014), but a lack of data needed to develop more accurate epidemiological studies and (4) an important source of controversy on the possibility of water contamination due to the possibility that local geophysical experiments cannot provide sufficient information for an assessment. All of the above underlines the need to have predictive estimation models to: 1) evaluate the quantity of the various pollutants that could travel to the surface or proximal areas and generate pollution; and 2) establish the relationships between the initial and flowback concentration for any given day for each compound or families of compounds.

Therefore, the purpose of this study is to provide a model that could forecast 
almost all-realistic organic chemical concentration trends in wastewater over time to prevent the hazards occur. Being able to anticipate the expected chemical composition over time in produced and flowback water is an important step toward an appropriate safety and risk assessment. This work will allow us to identify and/or develop adequate treatments for these wastes and to predict the health and environmental risks derived from accidents and exposures. This assessment study procedure is as follows: (1) reassembling a new comprehensive model resulting from previous studies on organic chemical transport dynamics and a first-order desorption kinetics model, (2) utilizing published Volatile Organic Compounds (VOCs) and Semi-VOCs concentration data to verify and test our model, and (3) estimating prospective concentration ratio range tendency in produced water for a long time period (10 years). Environmental hazards and potential toxicity in residents have a close link with chemicals doses and exposure time to contaminated areas. Thus risk management should be analysed throughout the whole operation period. This is the reason why concentration forecast is considered to be a crucial data. All in all, this model could serve as a contribution to increase the benefits of optimizing health risk assessment for local residents and to provide experience to further operations, as well as to define and adjust the monitoring aspects in flowback and produced water.

\subsubsection{Hydraulic Fracturing Model}

A simplified geometrical model of the hydrofractures in the rock matrix will be used for the a priori determination of the mathematical model to fit the temporal evolution of the concentrations of experimentally observed organic compounds (Hayes, 2009). The physical processes involved in the fluids movement present in the geological formation will be applied on this model. For fitting and validation of the model this work uses data released by the Marcellus Shale Coalition (Hayes database) in a report of the Gas Technology Institute (Hayes, 2009). 


\subsubsection{1. $\quad$ Hydraulic Fracturing Model Setup}

After a horizontal section is drilled through the target shale layer, rock in shale formation was fractured by means of a pressurized liquid and the cracks provide an avenue for natural gas, petroleum and brine to more quickly return to the surface (Gandossi, 2013). This report's approach of the average behaviour of an hydraulic fracturing is a model based on previous works that describe both the network generation (Jackson et al., 2013b) as a mathematical representation and the parameters associated with it (Balashov et al., 2015) which have been considered within the scope of this work as both involve the same formations.

The horizontal hydraulic fracturing shale gas model is shown in Figure 4-1a (Jackson et al., 2013b) with the fracturing process illustrated in Figure 4-1b (Jackson et al., 2013b). The model assumes a horizontal well length of $1500 \mathrm{~m}(\approx 5000 \mathrm{ft}$.) divided into 10 equal parts (Jurus et al., 2013). 


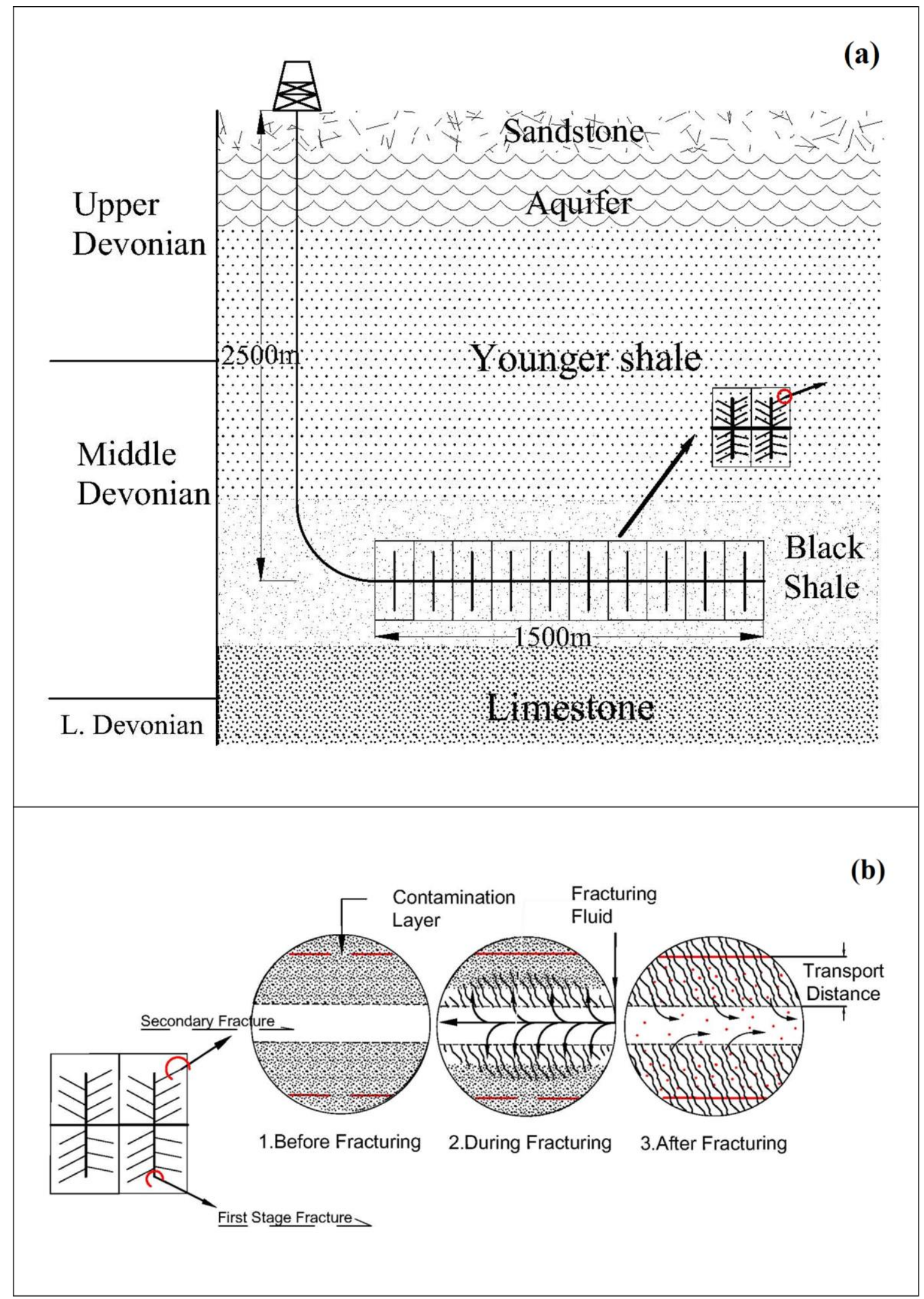

Figure 4-1: Horizontal Hydraulic Fracturing Model Diagram (Jackson et al., 2013b). (a) Cross-section Model of Unconventional Shale Gas Horizontal Fracturing. (b) Modeling the Detail of Hydraulic Fracturing Process 
Studies carried out based in the model displayed in Figure 4-1a (Jackson et al., $2013 b)$, assuming as reasonable value 1 secondary fracture per 6 meter (19.68ft) length (Balashov et al., 2015), the average chemicals (in all phases) transmission distance $x$ equalled 3 meters (9.8ft). Therefore, the simplified model, displayed in Figure 4-1b, presumes there was a constant contaminant concentration layer 3 meters $(9.8 \mathrm{ft})$ away from the secondary fracture. After the fracturing operation, the contamination would flow with hydraulic fluid to the fractures. It's assumed that the hydraulic conductivity did not change with time.

Local Geophysical Parameters in the Marcellus Shale as the bulk particle density, the partition of organic matter in soil matter and the hydraulic gradient are shown in Table 4-1. Also effective upscale transport parameters, such as effective diffusivity and hydraulic conductivity, used to extrapolate pore scale processes up to the continuum

Table 4-1: Local Geophysical Parameters in the Marcellus Shale

\begin{tabular}{|c|c|c|}
\hline Parameter & Coefficient & Reference \\
\hline Effective particle porosity of sample $\left(\phi_{e}\right)$ & $\mathrm{ND}^{*}(0.02,0.01,0.01$ & (Balashov et al., 2015) \\
\hline Diffusion coefficient of porous media $\left(D_{0}\right.$, & $\mathrm{ND}^{*}(6.34 \mathrm{E}-9,1 \mathrm{E}-9$ & (Balashov et al., 2015) \\
\hline Average particle size $(l, \mathrm{~m})$ & $\mathrm{ND}^{*}(0.0003,0.0001,0$ & (He, Wang, Liu, Barbot, and \\
\hline Bulk particle density $\left(\rho, \mathrm{kg} / \mathrm{m}^{3}\right)$ & $\mathrm{ND}^{*}(2.5,0.1,0,4)$ & (Manger, 1963) \\
\hline Partition of organic matter in soil matter & $\mathrm{ND}^{*}(0.05,0.005,0,1)$ & (Birdwell, Cook, and \\
\hline $\begin{array}{l}\text { Soil Organic Carbon-Water Partitioning } \\
\text { Coefficient }\left(k_{o c}\right)\end{array}$ & $\begin{array}{l}\text { Depend on compounds } \\
\text { properties }\end{array}$ & $\underline{\text { https://rais.ornl.gov/ }}$ \\
\hline
\end{tabular}

* ND - Normal Distribution Function (Mean, Standard Deviation, Minimum, and Maximum)

scale, are displayed in the table $4-1$. 


\subsubsection{Selected data from horizontal well}

Multiple, horizontal sections extending from a single vertical well enable production from larger subsurface areas from a single well pad on the land's surface. In generally, the length of horizontal drilling well in the shale formation will reach to 1500 $\mathrm{m}$, and there are divided into 10 parts for relatively independent hydraulic fracturing. Comparing with the vertical well construction, horizontal well has greater contact surface in the target rock formation that could exploit more gas as well as formation water to the surface. In order to ensure the rigor of this research, only the horizontal wells' data are selected for analyzing,

\section{Interested chemicals}

The analyses carried out in produced water indicate that their chemical composition include hydrocarbons, metals, radioactive materials (NORMs) and other naturally occurring elements. Each of these measures was taken in different times, covering flowback and produced water.

\section{A) Metals}

Heavy metals of toxicological concern that are often associated with urban industrial activity (including chromium, copper, nickel, zinc, lead, cadmium, mercury and arsenic) are at very low levels in all of the shale gas water samples compared to levels reported for municipal wastewaters (Hayes 2009).

\section{B) Organic Compounds}

The organic compounds included in the characterization of water samples included the categories of VOCs, SVOCs, chlorinated pesticides, organophosphorus pesticides, and polychlorinated biphenyls. The ability of organic chemicals to cause health effects varies greatly from those that are highly toxic, to those with no known 
health effects. As with other pollutants, the extent and nature of the health effect will depend on many factors including level of exposure and length of time exposed. Eye and respiratory tract irritation, headaches, dizziness, visual disorders, and memory impairment are among the immediate symptoms that some people have experienced soon after exposure to some organics. At present, not much is known about what health effects occur from the levels of organics usually found in homes. Many organic compounds are known to cause cancer in animals; some are suspected of causing, or are known to cause, cancer in humans (https://www.epa.gov/indoor-air-quality-iaq).

Due to the health hazard impact from organic compounds, this work will focus on identifying and physically characterizing the time evolution of Volatile Organic Compounds (VOCs) and Semi-Volatile Organic Compounds (SVOCs).

\section{Grouping chemicals}

As stated above, the core of this research is to find a liable model that fits the available data of VOCs and SVOCs concentrations both in flowback and in produced waters. For that purpose, consideration shall be given to time evolution in expected compounds at sites where hydraulic fracturing has been carried out as well as to available experimental data. Given the large number of compounds first analyzed on the Hayes database, the elements were studied in detail in order to group them together by representative families. According to the organic compounds data in flowback water from Hayes (Hayes, 2009), the chemical compounds were classified in the same group according to their similar physicochemical and ecotoxicological properties. Moreover, chemicals had to be filtered into a new intentional group whose $k_{o c}$ (Soil Organic Carbon-Water Partitioning Coefficient) value was quite different to other compounds in the same group, for example, Benzene and TEX. Nine groups were settled in our research: Acetophenone, Benzene, Phenol, TEX (Toluene, Ethylbenzene, Xylene), TMB (1,2,4-Trimethylbenzene, 1,3,5-Trimethylbenzene), R-Benzene 
(Isopropylbenzene, n-Butylbenzene, n-Propylbenzene, sec-Butylbenzene, p-Isopropyltoluene), NAPH (Naphthalene), PAHs-NAPH (Polycyclic aromatic hydrocarbon without Naphthalene).

As has already been mentioned, the Hayes report (Hayes, 2009) reported that approximately $96 \%$ of VOCs in flowback water was found at non-detectable levels; among SVOCs, more than $98 \%$ of all determinations were at non-detectable levels, and $0.03 \%$ of these constituents were above $1 \mathrm{ppm}$. In order to conveniently perform the analysis the average concentration values were calculated for model fitting. We take into account the concentration of organic constituents in the same group coming from all horizontal wells (Locations C, D, E, F, G, K, M and O in Hayes report). Due to the aforementioned characteristics of the data, we have worked with the average values of concentration of the grouped elements corresponding to all wells.

\section{Average concentration calculation}

Day 0 - samples extracted from the supply water plus hydraulic fracturing additives, without sand. For some compounds considered in groups, the concentration in day 0 is much higher than in day 1 sample because they are some of the additives used. The mean and superior concentrations values for $68 \%$ confidence interval $(1 \cdot \sigma$ in normal distributions) are shown in Figure 4-2 and Table 4-2. 


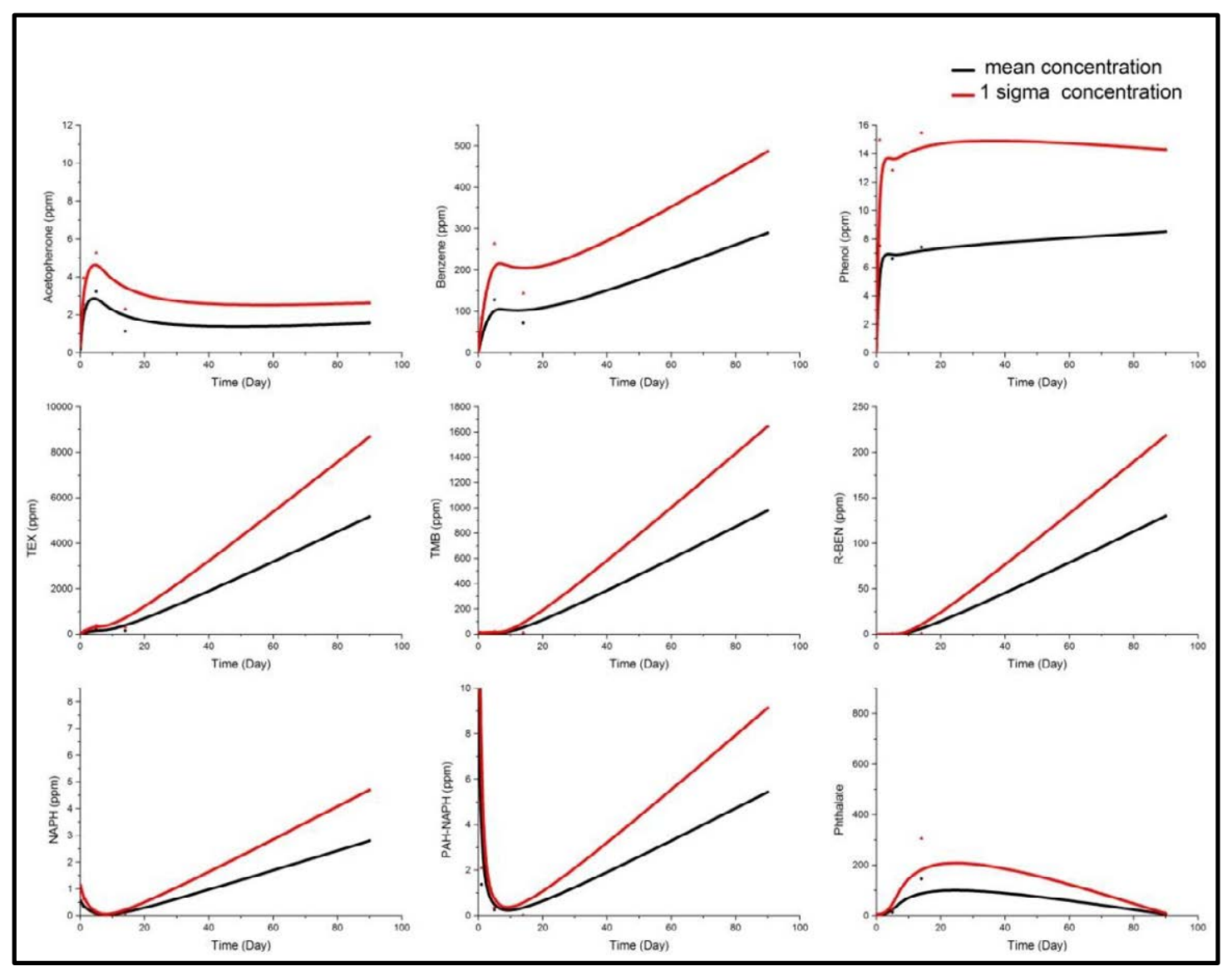

Figure 4-2: Concentration of each compound from all horizontal fracturing wells through whole monitoring period.

With the available data it is possible to establish a range of variability of the same, so that it is possible to establish higher limits of predictive concentration and, therefore, to establish probabilities of exceeding normative limits. For this purpose, the mean concentration data from the eight horizontal wells is required in order to fit the model (see Figure 4-2), as well as the confidence intervals of mean concentration corresponding to $1 \cdot \sigma$ and $2 \cdot \sigma$ (Table $4-2$, Table $4-3$, Table $4-4$ ). 
Table 4-2: Experimental concentration (ppm) of the pollutant groups.

\begin{tabular}{|c|c|c|c|c|c|c|c|c|c|}
\hline Time & Well & Acetophenone & Benzene & Phenol & TEX & TMB & R-BEN & NAPH & PAHs-NAPH \\
\hline \multirow{8}{*}{0 day } & $\mathrm{C}$ & 0 & 0 & 0 & 0 & 0 & 0 & 0 & 1.58 \\
\hline & $\mathrm{D}$ & 0.97 & 0 & 0 & 0 & 0 & 0 & 0 & 8.79 \\
\hline & $\mathrm{E}$ & 0 & 0 & 0 & 5.6 & 0.72 & 0 & 0 & 1.3 \\
\hline & $\mathrm{F}$ & 0 & 0 & 0 & 0 & 0 & 0 & 0 & 0 \\
\hline & $\mathrm{G}$ & 0.21 & 2.2 & 0 & 0 & 0 & 0 & 0 & 0 \\
\hline & $\mathrm{K}$ & 0 & 0 & 0 & 36.7 & 62 & 0 & 3.9 & 56.8 \\
\hline & $\mathrm{M}$ & 0 & 0 & 0 & 0 & 0 & 0 & 0 & 0 \\
\hline & Mean 0 & 0.17 & 0.31 & $\mathbf{0}$ & 6.04 & 8.96 & 0 & 0.56 & 9.78 \\
\hline \multirow{5}{*}{1 day } & $\mathrm{C}$ & 2.9 & 0 & 0.28 & 0 & 0 & 0 & 0 & 2.49 \\
\hline & $\mathrm{D}$ & 5 & 0 & 0.35 & 0 & 0 & 0 & 0 & 4.01 \\
\hline & $\mathrm{E}$ & 9 & 7.8 & 2.92 & 3.8 & 0 & 0 & 0.73 & 0 \\
\hline & $\mathrm{F}$ & 0 & 280 & 48.8 & 427.6 & 11 & 0 & 0 & 0 \\
\hline & $\mathrm{G}$ & 0.98 & 0 & 0 & 0 & 0 & 0 & 1.7 & 3.14 \\
\hline
\end{tabular}




\begin{tabular}{|c|c|c|c|c|c|c|c|c|c|}
\hline & $\mathrm{K}$ & 0 & 0 & 0 & 4.8 & 21.7 & 0 & 0 & 0 \\
\hline & M & 0 & 3.5 & 0.28 & 7 & 2.8 & 0 & 0 & 0 \\
\hline & Mean 1 & 2.55 & 41.61 & 7.52 & 63.31 & 5.07 & $\mathbf{0}$ & 0.35 & 1.38 \\
\hline Time & Well & Acetophenone & Benzene & Phenol & TEX & TMB & R-BEN & NAPH & PAHs-NAPH \\
\hline \multirow{8}{*}{5 day } & $\mathrm{C}$ & 0 & 8 & 0.21 & 0 & 0 & 0 & 0 & 0.34 \\
\hline & $\mathrm{D}$ & 0 & 0 & 0 & 0 & 15 & 0 & 0 & 0.83 \\
\hline & $\mathrm{E}$ & 10 & 5.8 & 4.07 & 12.8 & 1.74 & 0.67 & 0 & 0.27 \\
\hline & $\mathrm{F}$ & 11 & 880 & 41 & 1289 & 52 & 0 & 0 & 0.29 \\
\hline & $\mathrm{G}$ & 0.81 & 0 & 0 & 5.1 & 0.64 & 0 & 0 & 0 \\
\hline & $\mathrm{K}$ & 0 & 0 & 0 & 3 & 13 & 0 & 0 & 0 \\
\hline & M & 0.8 & 3.2 & 0.95 & 11.43 & 7.3 & 0.53 & 0 & 0 \\
\hline & Mean 5 & 3.23 & 128.14 & 6.6 & 188.76 & 12.81 & 0.17 & $\mathbf{0}$ & 0.25 \\
\hline 14 day & $\mathrm{C}$ & 0 & 3 & 0 & 1.6 & 0 & 0 & 0 & 0 \\
\hline
\end{tabular}




\begin{tabular}{|c|c|c|c|c|c|c|c|c|c|}
\hline & $\mathrm{E}$ & 6.4 & 17 & 0.38 & 16.2 & 0 & 0 & 0 & 0 \\
\hline & $\mathrm{F}$ & 0 & 400 & 43.8 & 843 & 33 & 0 & 0 & 0 \\
\hline & $\mathrm{G}$ & 0.38 & 0 & 0 & 3.2 & 0 & 0 & 0 & 0 \\
\hline & $\mathrm{K}$ & 0 & 1.5 & 0.41 & 5.3 & 6.7 & 2.3 & 0 & 0 \\
\hline & M & 0 & 6.2 & 0 & 9.6 & 0.98 & 0 & 0 & 0 \\
\hline & Mean 14 & 1.13 & 71.28 & 7.43 & 146.48 & 6.78 & 0.38 & $\mathbf{0}$ & $\mathbf{0}$ \\
\hline Time & Well & Acetophenone & Benzene & Phenol & TEX & TMB & R-BEN & NAPH & PAHs-NAPH \\
\hline \multirow{5}{*}{90 day } & $\mathrm{D}$ & 2.1 & 0 & 3.5 & 0 & 0 & 0 & 0 & 12.7 \\
\hline & $\mathrm{E}$ & 1.3 & 0 & 1 & 0 & 0 & 0 & 0 & 0 \\
\hline & $\mathrm{F}$ & 0 & 290 & 0 & 5170 & 980 & 130 & 0 & 12 \\
\hline & $\mathrm{G}$ & 0 & 0 & 0 & 0 & 0 & 0 & 0 & 0 \\
\hline & Mean 90 & 0.85 & 72.5 & 1.13 & 1292.5 & 245 & 32.5 & 0 & 6.18 \\
\hline
\end{tabular}


Table 4-3: Experimental concentrations of the groups of contaminants for the upper range of the confidence interval of $1 \sigma$.

\begin{tabular}{|c|c|c|c|c|c|c|c|c|c|c|c|c|c|c|c|c|}
\hline Time & \multicolumn{2}{|c|}{ Acetophenone } & \multicolumn{2}{|c|}{ Benzene } & \multicolumn{2}{|c|}{ Phenol } & \multicolumn{2}{|c|}{ TEX } & \multicolumn{2}{|c|}{ TMB } & \multicolumn{2}{|c|}{ R-Benzene } & \multicolumn{2}{|c|}{ NAPH } & \multicolumn{2}{|c|}{ PAHs-NAPH } \\
\hline (Days) & $C_{\text {mean }}$ & $C_{\max }$ & $C_{m e a n}$ & $C_{\max }$ & $C_{\text {mean }}$ & $C_{\max }$ & $C_{m e a n}$ & $C_{\max }$ & $C_{\text {mean }}$ & $C_{\max }$ & $C_{\text {mean }}$ & $C_{\max }$ & $C_{\text {mean }}$ & $C_{\max }$ & $C_{m e a n}$ & $C_{\max }$ \\
\hline $\mathbf{0}$ & 0.17 & 0.32 & 0.31 & 0.65 & 0.00 & 0.00 & 6.04 & 11.65 & 8.96 & 18.54 & 0.00 & 0.00 & 0.56 & 1.16 & 9.78 & 18.37 \\
\hline 1 & 2.55 & 3.95 & 41.61 & 84.70 & 7.52 & 14.99 & 63.31 & 129.10 & 5.07 & 8.5 & 0.00 & 0.00 & 0.35 & 0.62 & 1.38 & 2.10 \\
\hline 5 & 3.23 & 5.27 & 128.10 & 264.00 & 6.60 & 12.85 & 188.80 & 387.50 & 12.81 & 20.30 & 0.17 & 0.29 & 0.00 & 0.00 & 0.25 & 0.37 \\
\hline 14 & 1.13 & 2.30 & 71.28 & 143.90 & 7.43 & 15.46 & 146.50 & 300.20 & 6.78 & 12.69 & 0.38 & 0.81 & 0.00 & 0.00 & 0.00 & 0.00 \\
\hline 90 & & & & & & & & & & & & & & & & \\
\hline
\end{tabular}


Table 4-4: Experimental concentrations of the groups of contaminants for the upper range of the confidence interval of $2 \sigma$.

\begin{tabular}{|c|c|c|c|c|c|c|c|c|c|c|c|c|c|c|c|c|}
\hline Time & \multicolumn{2}{|c|}{ Acetophenone } & \multicolumn{2}{|c|}{ Benzene } & \multicolumn{2}{|c|}{ Phenol } & \multicolumn{2}{|c|}{ TEX } & \multicolumn{2}{|c|}{ TMB } & \multicolumn{2}{|c|}{ R-Benzene } & \multicolumn{2}{|c|}{ NAPH } & \multicolumn{2}{|c|}{ PAHs-NAPH } \\
\hline (Days) & $C_{\text {mean }}$ & $C_{\max }$ & $C_{\text {mean }}$ & $C_{\max }$ & $C_{\text {mean }}$ & $C_{\max }$ & $C_{m e a n}$ & $C_{\max }$ & $C_{\text {mean }}$ & $C_{\max }$ & $C_{\text {mean }}$ & $C_{\max }$ & $C_{\text {mean }}$ & $C_{\max }$ & $C_{\text {mean }}$ & $C_{\max }$ \\
\hline $\mathbf{0}$ & 0.17 & 0.50 & 0.31 & 1.08 & 0.00 & 0.00 & 6.04 & 18.69 & 8.96 & 30.59 & 0.00 & 0.00 & 0.56 & 1.92 & 9.78 & 29.17 \\
\hline 1 & 2.55 & 5.71 & 41.61 & 138.90 & 7.52 & 24.38 & 63.31 & 211.90 & 5.07 & 12.81 & 0.00 & 0.00 & 0.35 & 0.95 & 1.38 & 3.02 \\
\hline 5 & 3.23 & 7.84 & 128.10 & 434.80 & 6.60 & 20.70 & 188.80 & 637.50 & 12.81 & 29.72 & 0.17 & 0.44 & 0.00 & 0.00 & 0.25 & 0.52 \\
\hline $\begin{array}{l}14 \\
90\end{array}$ & 1.13 & 3.84 & 71.28 & 240.40 & 7.43 & 26.13 & 146.50 & 504.60 & 6.78 & 20.54 & 0.38 & 1.37 & 0.00 & 0.00 & 0.00 & 0.00 \\
\hline
\end{tabular}


Chapter 4: Analysis of Results 


\subsubsection{Mathematical Model}

For the study of the chemical composition of flowback and produced waters it will be necessary to construct and solve a mathematical model for the transport of pollutants in an aqueous phase from the rock matrix to the fractures generated. The different processes physical, chemical and biological should be considered.

As Balashov's previous research has proven (Balashov et al, 2015), the physical mechanism that described the process by which inorganic chemicals present in the pore fluid from Marcellus Shale matrix are diffused into flowback or production waters can be approached as the case of diffusion between a limited stirred volume (the hydraulic fracturing water) and a solid layer of infinite thickness (the shale matrix). This approximation was valid to describe the experimental salinity results and how the brine salt from shale could explain the salinity of the produced water (Balashov et al., 2015). In the present case we are going to maintain the same geometry for the transport model, that is, a set of parallel aperture fractures $w$ and separated by a distance $h$, filled at time $t=0$ by the fracturing fluid. Under these conditions, the hypothesis of the organic compounds transport from location to fractures was primarily one-dimensional. Furthermore, the concentration in the shale matrix zone has been considered constant. A steady uniform flow field was imposed and the effects of dispersion were considered spatially constant.

The starting point for the transport study of solutes is the macroscopic mass balance equation for a component. The total flux is made up of the sum of advective, convective and dispersive flux. In addition, the continuous variation of the components 
concentration is affected by various sources and sinks within the domain of interest (i.e. chemical reactions). There has not been introduced the effects of biodegradation because these are not great enough to bring about a change in the behaviour of the system given the objectives of this research (Shan and Stephens, 1995). Indeed, although the general transport equation may include a biodegradation term, which in the first approximation may be described in terms of first-order reactions wherein the transformation rate is proportional to the solute concentration (Runkel, 1996), this process has been excluded as a result of studies conducted with the production waters that do not indicate an abundance of microbes (Akob et al., 2015) so the biodegradation is expected to be small in shales (Schlegel et al., 2013). Yet the goal of the study is placed within the context of risk management, from this point of view the non-consideration of this term introduces bias in a rational and feasible manner faced to improve safety. That is to say, an upper limit to the concentrations is being obtained within the limitations defined by the conservative risk regulations (Viscusi et al., 1997).

According to these assumptions, the organic contaminate transportation equation was established with constant process parameters for convection, diffusion, dispersion, adsorption retention and desorption (Runkel, 1996):

$$
\left.\begin{array}{c}
R_{d} \frac{\partial C}{\partial t}=\left(D_{1}+D_{2}\right) \cdot \frac{\partial^{2} C}{\partial x^{2}}-v \frac{\partial C}{\partial x}-k \cdot R_{d} \cdot C \\
C(x, 0)=0, x>0 \\
C(0, t)=C_{0}, t=0 \\
C \propto(9)=0, t \geq 0
\end{array}\right\}
$$


where $C$ is the concentration in mass per unit volume of solution [mass $\cdot$ length ${ }^{-3}$ ]; $v$ is the average groundwater velocity in the direction of flow [length $\cdot$ time $\left.^{-1}\right] ; D_{l}$ is the coefficient of molecular diffusion of the element in the fluid phase $\left[\right.$ length $\left.{ }^{2} \cdot \operatorname{time}^{-1}\right] ; D_{2}$ is the coefficient of mechanical (or convective) dispersion $\left[\right.$ length $\left.^{2} \cdot \operatorname{time}^{-1}\right] ; k$ is the desorption first order rate constant $\left[\right.$ time $\left.^{-1}\right] ; R_{d}$ is the retention factor; $t$ is the time coordinate [time] and $x$ is the space coordinate [length].

Dividing both sides of the retention factor $R_{d}$ in Equation 1, we obtained the following expression:

$$
\frac{\partial C}{\partial t}=\frac{D}{R_{d}} \cdot \frac{\partial^{2} C}{\partial x^{2}}-\frac{v}{R_{d}} \cdot \frac{\partial C}{\partial x}-k \cdot C
$$

Where $D=D_{1}+D_{2}$ is the coefficient of hydrodynamic dispersion $\left[\right.$ length ${ }^{2} \cdot$ time $\left.^{-1}\right]$ and $k$ is the desorption first order rate constant $\left[\right.$ time $\left.^{-1}\right]$

Generally, the desorption part is described by an isotherm equation, $C=C_{0} \exp (-k \cdot t)$. This expression is not dependent on spatial coordinate, thus a parameter $C_{l}$ has been introduced.

$$
C=C_{1} \cdot \exp (-k \cdot t)
$$

So, equation 4.3 could be rewritten as:

$$
\frac{\partial C_{1}}{\partial t}=\frac{D}{R_{d}} \cdot \frac{\partial^{2} C_{1}}{\partial x^{2}}-\frac{v}{R_{d}} \cdot \frac{\partial C_{1}}{\partial x}
$$

with $C_{1}$ - Concentration without considering desorption activity 
After Laplace transformation, the analytic solution for $C_{l}$ was given by (Sauty, 1980).

$$
C_{1}(x, t)=\frac{C_{0}}{2} \cdot\left\{\operatorname{erfc}\left[\frac{x-\left(v / R_{d}\right) \cdot t}{2 \sqrt{\left(D / R_{d}\right) \cdot t}}\right]+\exp \left[\frac{\left(v / R_{d}\right) \cdot x}{\left(D / R_{d}\right)}\right] \cdot \operatorname{erfc}\left[\frac{x+\left(v / R_{d}\right) \cdot t}{2 \cdot \sqrt{\left(D / R_{d}\right) \cdot t}}\right]\right\}
$$

where $C_{0}$ is the initial concentration

Therefore, combining equations 4.4 and 4.6 yields the analytical solution for this model:

$$
\begin{aligned}
C= & C_{1}(x, t) \cdot \exp (-k \cdot t)= \\
& =\frac{C_{0}}{2} \cdot\left\{\operatorname{erfc}\left[\frac{x-\left(v / R_{d}\right) \cdot t}{2 \sqrt{\left(D / R_{d}\right) \cdot t}}\right]+\exp \left[\frac{\left(v / R_{d}\right) \cdot x}{\left(D / R_{d}\right)}\right] \cdot \operatorname{erfc}\left[\frac{x+\left(v / R_{d}\right) \cdot t}{2 \cdot \sqrt{\left(D / R_{d}\right) \cdot t}}\right]\right\} \times \exp (-k \cdot t)
\end{aligned}
$$

The desorption phenomenon (term $\exp (-k \cdot t)$ in equation 4.7) constitutes the source term of polluting substances and is produced from shale bituminous rock to fractures by which water flows. It is a process that may have subsequent effects on the toxicity and associated hazard to human and aquatic life when these pollutants are transported to the surface in the flowback and produced waters. Therefore, it is important that desorption of contaminants from the rock matrix is properly explained in order to evaluate the potential risk of shale gas projects.

Expression 4.7 can be simplified by taking into account a series of assumptions which will be detailed below:

Average transportation distance for all chemicals analysed was 3 meters as shown in Figure 4-1b. This spacing of hydrofractures is consistent with the results 
indicated in Balashov, where for usual hydrofracking values the fracture aperture varies between tenths of millimetres and millimetres and the spacing varies between 0.2 and $5 \mathrm{~m}(0.7$ and $16 \mathrm{ft})$ (Balashov et al.,2015);

- $\alpha \cdot v>>D_{a q}$ ( $\alpha$ was characterization of dispersion and it can be calculated as $\alpha=0.83 \cdot(\log x)^{2.414}($ Neuman, 1990)),

- $\quad$ therefore $D_{a q}$ value can be eliminated and the parameter $D$ can be represented by the velocity as:

$$
\frac{D}{R_{d}}=\frac{\alpha \cdot v+D_{a q}}{R_{d}}=\frac{0.83(\log x)^{2.414} \cdot v+D_{a q}}{R_{d}} \approx \frac{0.14 v}{R_{d}}
$$

Due to the Peclet number in our model $P e=v \cdot x / D>200$, the error when the second addend is removal in eq. 7 is less than $4 \%$. Therefore this part of the expression (4.7) can be ignored (Bear and Verruijt, 1987) and the transport equation is simplify to:

$$
\left.C(t)=\frac{C_{0}}{2} \cdot e r f\right\rfloor\left\lfloor\frac{4}{\sqrt{\left(v / R_{d}\right) \cdot t}}-1.34 \sqrt{\left(v / R_{d}\right) \cdot t}\right\rfloor \times \exp (-k \cdot t)
$$

where $C(t)$ is the pollutant concentration in the water in time $t ; C_{0}$ is the initial concentration available in the rock medium, i.e., that can be desorbed; $v$ is the velocity of the fluid; $R_{d}$, the coefficient of delay; and $k$, the desorption constant.

When the expression (4.9) obtained by such simplifications adequately describes the physics in the medium, an inverse fitting with the experimental data can be performed and high coefficients of goodness-of-fit of the data are obtained. The 
required parameters to calculate with the least squares fitting method are: $C_{0}, v / R_{d}$ and $k$. To validate the model, the BTEX concentrations (Benzene, Toluene, Xylene and Ethylbenzene) corresponding to well F of the Hayes database (Hayes, 2009) have been used. The fitting made can be seen in Figure 4-2. Both the figure and the statistics associated with the fitting (see Table 4-2) indicate that the experimental data from Hayes database cannot be well fitted with the simple first-order kinetics model used in equation 4.9 .

Adjustments show that either 90 day data dominate (toluene, xylene), with adjustments that do not work well during the first 14 days, or that day 90 is not properly adjusted (Benzene). However, if the equation 4.9 is used to fit only the first $14^{\text {th }}$ days data, a proper fitting is obtained (see figure 4-3).

In order to be able to estimate the errors present in the determination of the predictive values obtained with the application of the model with respect to the experimental values, three criteria have been used: coefficient of determination (Pearson's $R$ (Mean Squared Error)), Nash-Sutcliffe efficiency E (Nash and Sutcliffe, 1970) and index of agreement $d$ (Willmot, 1981). The differences in the values of the criteria used to measure the goodness-of-fit (see Table 4-5) show that the data associated with the first 14 days can be grouped and described with a constant of desorption. However, it can also be inferred from the used criteria that it is not possible to fit the data for the $90^{\text {th }}$ day at the same time. 


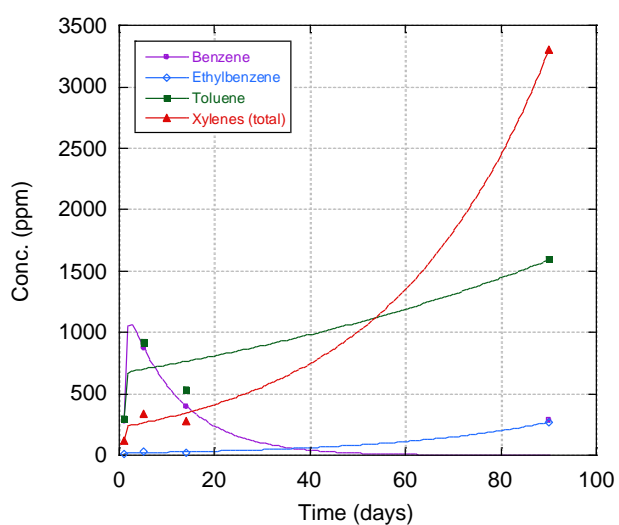

Figure 4-3: Fittings for Well $F$ with the model given by equation 9

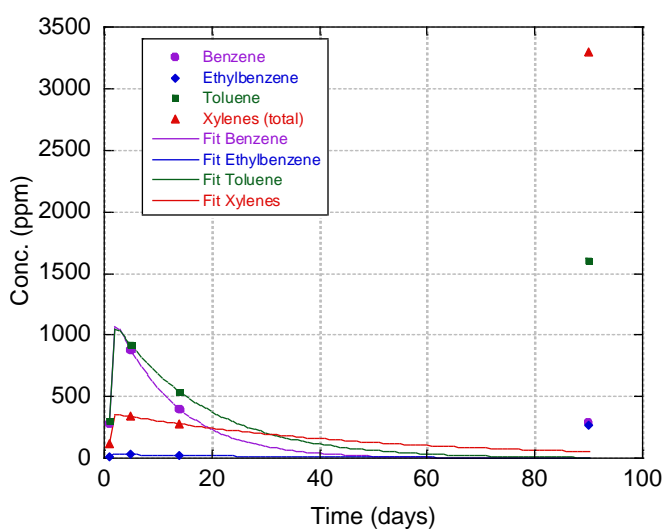

Figure 4-4: Fittings for Well $F$ with the model given by equation 9 without data corresponding to day 90 .

These results indicate that the model is not complete and that show that a new desorption model had to be adopted in order to can adequately explain the concentrations evolution.

Different models have been developed to explain desorption kinetics. Unfortunately, even though a large amount of mechanistic laboratory research has been directed toward understanding and quantifying the fate of hydrophobic chemicals in contact with naturally occurring particles in the water column, the ability to predict their fate is still quite poor (Kan et al., 2000). There are several factors that control desorption processes and the relative extent of desorption such as swelling of the sediment organic matter, the characteristics of mineral surfaces, or the micropore size in the geosorbents (Elhaddad, 2012). 
Table 4-5: Fitting criteria corresponding to the data from all the sampled days $(0,1,5,14$ and 90$)$ and with the data corresponding to the flowback water (days $0,1,5$ and 14). In the case of the fitting with all the data, the obtained values for the first 14 days are also shown, since in some of the cases the $90^{\text {th }}$ day values are of a significantly greater magnitude.

\begin{tabular}{|c|c|c|c|c|c|}
\hline & Fitting & $\begin{array}{l}\text { Adjusting index } \\
\text { obtained for days }\end{array}$ & $\begin{array}{l}\text { Nash-Sutc } \\
\text { liffe } \\
\text { efficiency } \\
(E)\end{array}$ & $\begin{array}{l}\text { Index of } \\
\text { agreement } \\
\qquad(d)\end{array}$ & $\begin{array}{l}\text { Pearson's } \\
R\end{array}$ \\
\hline \multirow[t]{3}{*}{ Benzene } & Figure 4-3 & $\mathrm{All}^{(\mathrm{a})}$ & 0.653 & 0.933 & 0.932 \\
\hline & & Flowback $^{(\mathrm{b})}$ & 0.999 & 0.999 & 0.999 \\
\hline & Figure 4-4 & Flowback $^{(\mathrm{b})}$ & 1.000 & 1.000 & 1.000 \\
\hline \multirow[t]{3}{*}{ Ethylbenzene } & Figure 4-3 & $\mathrm{All}^{(\mathrm{a})}$ & 0.998 & 0.999 & 0.999 \\
\hline & & Flowback $^{(\mathrm{b})}$ & 0.667 & 0.908 & 0.832 \\
\hline & Figure 4-4 & Flowback $^{(b)}$ & 1.000 & 1.000 & 1.000 \\
\hline \multirow[t]{3}{*}{ Toluene } & Figure 4-3 & $\mathrm{All}^{(\mathrm{a})}$ & 0.898 & 0.973 & 0.948 \\
\hline & & Flowback $^{(\mathrm{b})}$ & 0.497 & 0.830 & 0.711 \\
\hline & Figure 4-4 & Flowback $^{(\mathrm{b})}$ & 1.000 & 1.000 & 1.000 \\
\hline \multirow[t]{3}{*}{ Xylenes } & Figure 4-3 & $\mathrm{All}^{(\mathrm{a})}$ & 0.998 & 0.999 & 0.999 \\
\hline & & Flowback $^{(\mathrm{b})}$ & 0.614 & 0.893 & 0.808 \\
\hline & Figure 4-4 & Flowback $^{(\mathrm{b})}$ & 1.000 & 1.000 & 1.000 \\
\hline
\end{tabular}

${ }^{(a)}$ All data: days $0,1,5,14$ and $90 ;{ }^{(b)}$ Flowback data: days $0,1,5$ and 14

One of the empirical algorithms more commonly used to fit data and obtain release rate parameters is the Two-compartment First-order Rate Constant (TFRC) kinetic model by Cornelissen et al. (1997); Birdwell et al. (2007) and Barnier et al. (2014). This empirical method is based on the observation of biphasic desorption and the observed shape of desorption profiles. Its usability is justified by the fact that the 
detailed mechanistic understanding of slow desorption rate is not yet available. So this TFRC model was chosen (equation 10), with each compartment defined by its respective rate constant (Barnier et al., 2014).

$$
C_{t}=C_{0} \cdot\left[\exp \left(-k_{\text {fast }} \cdot t\right)+\phi \cdot \exp \left(-k_{\text {slow }} \cdot t\right)\right]
$$

where $C_{t}$ is the liquid phase chemical concentration at some time after $t=0$ [contaminant-mass $\cdot$ sorbent-mass $\left.{ }^{-1}\right] ; C_{0}$ is the solid-phase concentration prior to desorption; $\phi$ is the fraction of the total slow desorbing chemical present; and $k_{\text {fast }}$ and $k_{\text {slow }}$ are the first-order rate constants describing the release rates for the fast and slow desorbing chemical, respectively $\left[\right.$ time $\left.^{-1}\right]$.

Therefore, in equation 4.9 the decreasing exponential term, which represents the desorption part, was replaced by TFRC. The final model is given by equation 4.11:

$$
\begin{gathered}
C=\frac{C_{0}}{2} \cdot \operatorname{erfc}\left\lfloor\frac{4}{\sqrt{\left(v / R_{d}\right) \cdot t}}-1.34 \cdot \sqrt{\left(v / R_{d}\right) \cdot t}\right\rfloor \times\left[\exp \left(-k_{\text {fast }} \cdot t\right)+\phi \cdot \exp \left(-k_{\text {slow }} \cdot t\right)\right] \\
C_{t_{-} \text {fast }}=\frac{C_{0_{-} \text {fast }}}{2} \cdot \operatorname{erfc}\left[\frac{4}{\sqrt{\left(v / R_{d}\right) \cdot t}}-1.34 \sqrt{\left(v / R_{d}\right) \cdot t}\right] \times \exp \left(-k_{\text {fast }} \cdot t\right) \\
C_{t_{-} \text {slow }}=\frac{C_{0_{-} \text {slow }}}{2} \cdot \operatorname{erfc}\left[\frac{4}{\sqrt{\left(v / R_{d}\right) \cdot t}}-1.34 \sqrt{\left(v / R_{d}\right) \cdot t}\right] \times \exp \left(-k_{\text {slow }} \cdot t\right)
\end{gathered}
$$

where $C_{t \text { fast }}$ and $C_{t_{-} s l o w}$ are the expressions for fast and slow chemical transport and $C_{0 \text { fast }} / C_{0 \_ \text {slow }}$ represents the initial chemical concentration present in the shale formation that is available for fast/slow desorption. So, the transportation process for 
organic chemicals is dependent on two parameters $-k_{\text {fast }}$ and $k_{\text {slow }}$. The initial fast release occurs during the first few days after fracturing and it is followed by a slower stage which can take months or years (Birdwell et al., 2007).

Figure 4-5 shows that this model allows fit all the experimental points for the different measurement days. The Nash-Sutcliffe efficiency $E$ (NSE) exceeds in all cases the value of 0.99 , as it happens with the rest of the criteria applied, the index of agreement $d$ and the Pearson's $R$. But, given the number of parameters to adjust involve in equation 4.11, and the small amount of temporal data available the values of the fitting parameters are not unique. This forces us to separate the posterior analysis into two blocks, one with the flowback data (first $14^{\text {th }}$ days) and another with the data corresponding to day 90 .

\subsubsection{Model application to VOCs and SVOCs. Results and Discussion}

Direct discharge of oil and gas produced water is prohibited by federal law (EPA, 2013) but Jiang developed this case to assess the maximum potential toxicity of Marcellus shale flowback and produced water. It is also used to identify the chemical species in flowback and produced water with the largest environmental toxicity, enabling improved design of wastewater treatment. With this scenario the potential toxicity of the chemicals in the wastewater from the well site in Marcellus exceeds those associated with supply chain production, except for carcinogenic effects. (Jiang et al 2014). This scenario is very unlikely but wastewater leaks are the most probably pollution causes in Marcellus shale gas and in general shale gas industry (Davies el al 
2014). In addition, the organic compounds are brought above ground in the fracking flowback or produced water, which often are put into open impoundments (frack ponds), where the waste water releases its organic compounds into the air. $37 \%$ of the chemicals used during fracturing and natural gas production have been found to be volatile and be airborne. $71 \%$ of the volatile chemicals can harm the cardiovascular system and blood, $66 \%$ can harm the kidneys, and the chances of exposures to volatile chemicals are significantly increased when they are inhaled by humans or are even taken in and absorbed through the skin (Colborn et al., 2011; Meng, 2015). The flowback and produced water analysis show that more than 212 organic compound are presented (Hayes, 2009). The chemical composition of the flowback and production waters is variable over time and the development of a tool that allows predicting this temporary variation would facilitate the necessary (Sovacool, 2014) improvement in risk management and monitoring;

Once the model has been developed, it is going to be applied to other families of organic compounds present in the return waters. To determinate the composition of the source term for the risk assessment, this work uses data released by the Marcellus Shale Coalition (Hayes database) in a report of the Gas Technology Institute, coming from 19 Marcellus hydraulic fractured wells (Hayes, 2009) from three sites in the northern half of West Virginia with the other 16 sites in Pennsylvania. Out of a total of 19 wells, this work focuses on those sites that have horizontal wells (Locations C, D, E, F, G, K and $\mathrm{M}$ in the Hayes report). The analyses carried out in produced water indicate that its chemical composition includes hydrocarbons, metals, NORM and other naturally occurring compounds. Each of these measurements were taken at different times, 


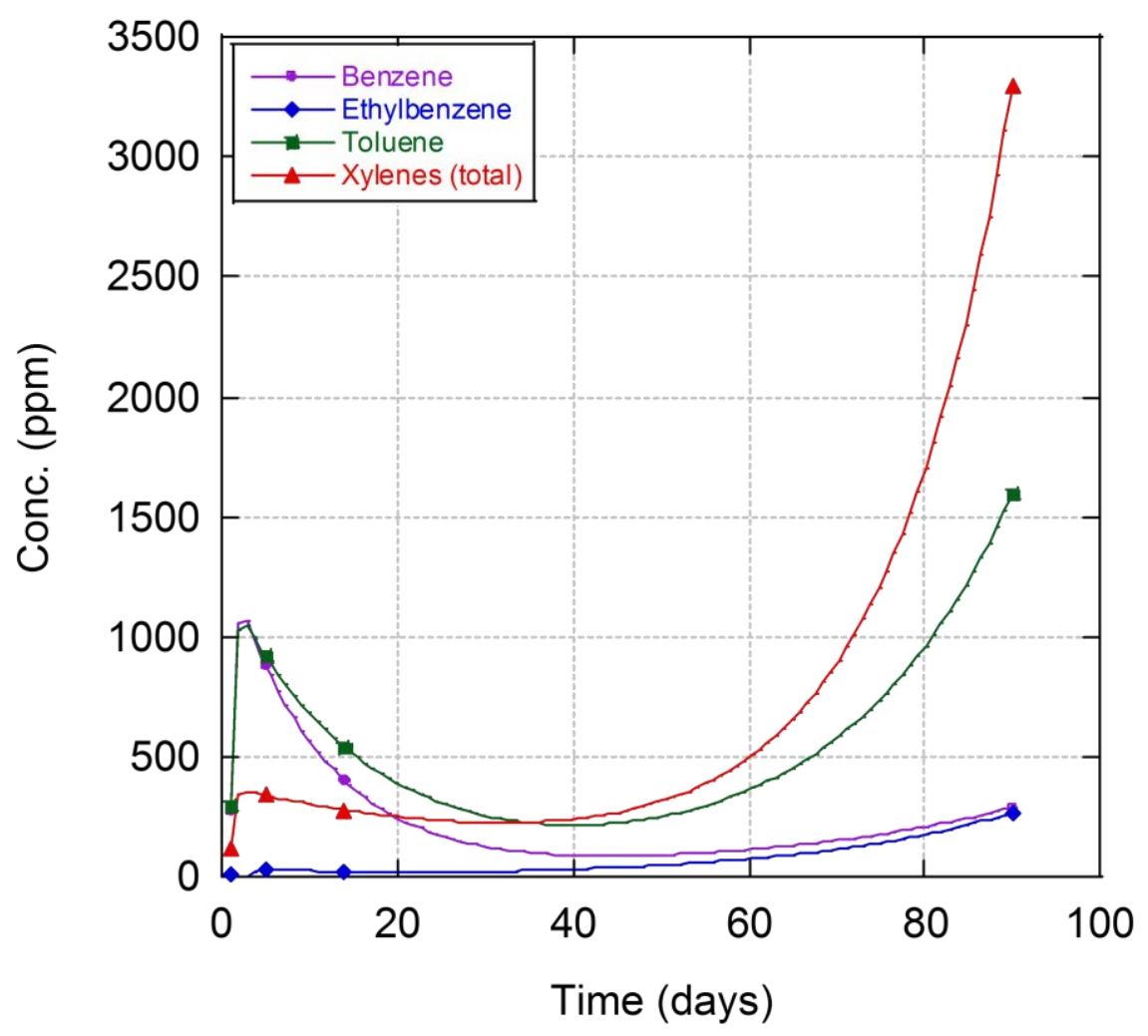

Figure 4-5: Fitting for Well $\mathrm{F}$ with the desorption model of Two Compartments First-order Rate Constants (model given by equation 4.11).

covering flowback and produced water. For this purpose, measures available at every given time point will be used: Day 0 - samples extracted from the supply water plus hydraulic fracturing additives, yet without sand. Days 1, 5, 14 - after having collected hydraulic fracturing chemicals samples, produced water at day 90 after completion was collected (Hayes, 2009).

Given the large number of compounds first analysed on the Hayes database, the elements were studied in detail in order to group them together by representative 
families. The process was as follows: according to the organic compounds data in flowback water from Hayes (Hayes, 2009), chemicals data with similar physicochemical and ecotoxicological properties were classified and grouped. Moreover, chemicals had to be filtered into a new intentional group whose $k_{o c}$ (soil organic carbon-water partitioning coefficient) value was quite different than other compounds in the same group, for example, benzene and TEX (toluene, ethylbenzene, xylene). Eight groups were settled in our research: acetophenone, benzene, phenol, TEX, TMB (1,2,4-trimethylbenzene, 1,3,5-trimethylbenzene), R-Benzene (isopropylbenzene, N-butylbenzene, N-propylbenzene, Sec-butylbenzene, P-isopropyltoluene), NAPH (naphthalene), and PAH-NAPH (Polycyclic aromatic hydrocarbons - naphthalene).

Hayes 2009 reported that approximately $96 \%$ of VOCs in flowback water were found at non-detectable levels; among SVOCs, more than $98 \%$ of all determinations were at non-detectable levels, and $0.03 \%$ of these constituents were above $1 \mathrm{ppm}$. In order to conveniently perform the analysis the average concentration values were calculated for model fitting. We take into account the concentration of organic constituents in the same group coming from all horizontal wells (Locations C, D, E, F, $\mathrm{G}, \mathrm{K}$ and $\mathrm{M}$ in the Hayes report).

The final average data calculated from the concentrations of the different compounds included in each group for all the horizontal wells can be seen in Table 4-6. The value of day 0 corresponds to the injected water concentrations (Hayes, 2009). So, in some cases, the flowback water would be strongly influenced by this injected water. 
Table 4-6: Horizontal Wells Organic Average Concentration Results.

\begin{tabular}{ccccccccc}
\hline $\begin{array}{c}\text { Time } \\
\text { (day) }\end{array}$ & Acetophenone & Benzene & Phenol & TEX & TMB & R-Benzene & NAPH & PAH-NAPH \\
\hline 0 & 0.17 & 0.31 & 0 & 6.04 & 8.96 & 0 & 0.56 & 9.78 \\
1 & 2.55 & 41.61 & 7.52 & 63.31 & 5.07 & 0 & 0.35 & 1.38 \\
5 & 3.23 & 128.14 & 6.6 & 188.76 & 12.81 & 0.17 & 0 & 0.25 \\
14 & 1.13 & 71.28 & 7.43 & 146.48 & 6.78 & 0.38 & 0 & 0 \\
90 & 0.85 & 72.5 & 1.13 & 1292.5 & 245.0 & 32.5 & 0 & 6.18 \\
\hline
\end{tabular}

Given the scarcity of temporal data, the TFRC model should be applied with caution. Although the experimental adjustment for the fast part of the transportation model (eq. 4.11a) was adequate (days 0, 1,5 and 14) the purely empirical adjustment for the slow transportation part (eq. 4.11b) was not feasible due to the insufficient available data. In Hayes 2009 article only limited data (90 ${ }^{\text {th }}$ day) appeared associated with the slow-part behaviour of the TFRC model and it is impossible to fit the model in a univocal way.

Therefore, to estimate the predictive behaviour of VOCs and SVOCs, the $C_{t \text { fast }}$ model (eq. 4.11a) will be applied for fitting in the range of the first 14 days, with fast desorption. In order to obtain a first long-term predictive approximation to the slow part behaviour $\left(C_{t_{-} \text {slow }}\right.$ eq.4.11b) a $k_{\text {slow }}$ value based on representative equations will be calculated (Birdwell et al., 2007):

$$
k_{\text {slow }}=\frac{D_{0}}{\phi_{e}^{-1 / 3} \cdot R_{d} \cdot l^{2}} ; \quad R_{d}=1+\frac{\rho_{b}}{\phi_{e}} \cdot K_{o c} \cdot f_{o c}
$$


For these calculations it will be necessary to use, on the one hand, the flow velocity obtained from the adjustment of the fast part as well as local geographic parameters $D_{0}, l, k_{o c}, f_{o c}, \rho_{b}$ and $\phi_{e}$ based on local geophysical information (see Table 4-1). $C_{0 \_ \text {slow }}$ (see eq.4.11b) represents the initial chemical concentration present in the shale formation that is available for slow desorption and acts as a scaling factor. It can be determined in some cases by making use of the experimental concentration in $90^{\text {th }}$ day. Monte-Carlo methods were used to propagate the uncertainty throughout the slow model calculation process. This allows obtaining a first long-term predictive approximation to the behaviour of the groups of compounds as well as the uncertainties associated with such behaviour.

\subsubsection{1. $\quad$ Fitting the Model with Fast-Part Transportation Data}

Using the time evolution of the chemical concentrations makes it possible to reconstruct the transport coefficients for each element or group of elements by solving an inverse problem for equation (eq. 4.11a). Starting from equation (eq. 4.11a), with the unknown quantities $C_{0 \_ \text {fast }}, v / R_{d}$ and $k_{\text {fast }}$, we adjust these parameters so that the simulated evolution of concentrations fits into the experimental values using a least squares fitting method. 
The data used for the adjustment was the mean value of concentrations for all the wells at every time point and for every considered chemical family. By observing the fitting data resulting curves in Figure 4-6, we found that, when fracturing began, dissolved organic chemicals were mobilized into lower concentration fluids. This was the reason why flowback water concentration value increased during the first days. The value of concentration in flowback water increases until reaching the curve peak, and
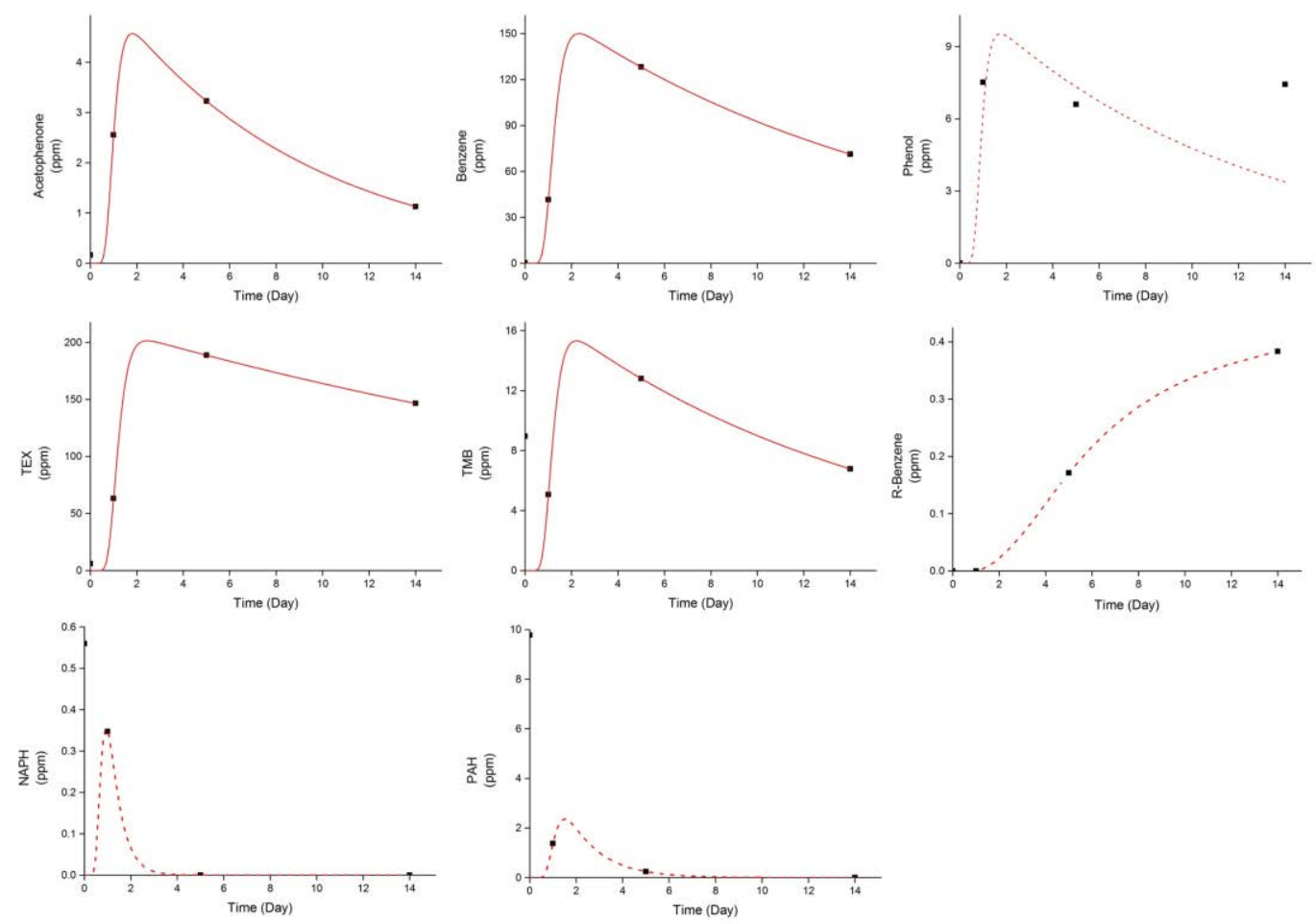

Figure 4-6: Results of model fitting. The black points are original mean concentration data and the red lines, the fitting results based on model. Dashed lines indicate that the adjustments may not be appropriate given the available data.

then the concentration would decline because the dissolved chemicals are consumed on the first days.

The results of Figure 5 allow observing three types of behaviours. A first case, which would include Acetophenone, Benzene, TEX, and TMB, consists of those 
compounds that, or are not present in the water that is injected or, if they are initially in the injected water, their concentrations are very low in comparison with the concentrations in the flowback waters. These compounds present a clear separation between the processes associated with rapid/slow desorption and the developed model is capable of making an adequate predictive estimate of their time evolution.

There is a second behaviour associated with the Phenol group or any other compound with high solubility. The $14^{\text {th }}$-day concentration value of phenol was a little higher than $5^{\text {th }}$-day data, and value of $R^{2}$ indicates that the model does not adequately explain the experimental data. The reason is explained by the fact that Phenol was easily soluble in a higher temperature environment. That means that the result at the $14^{\text {th }}$ day was a combined $k_{\text {slow }}$ and $k_{\text {fast }}$ transportation behaviour. The existing data is not enough to make the fit in an adequate way because the fast and slow behaviours described by their respective equations cannot be applied separately.

Data for R-Benzene in the $1^{\text {st }}$ and $5^{\text {th }}$ days' data are under the analytical detection limits so it was not possible to carry out the fitting. Finally, we have the behaviour given by those groups of compounds, such as those of NAPH and PAH-NAPH, which have high concentrations in the injection water and, therefore, these values will affect the concentrations measured in the first days, especially those of the $1^{\text {st }}$. In addition, the data of these groups as well as those of the R-Benzene, indicate that the associated desorption processes have very slow characteristic times since there are concentrations in the flowback waters starting from the measurement times of $14^{\text {th }}$ and $90^{\text {th }}$ days. The number of available data does not allow a good fit for the fast desorption behaviour. 
Because these compounds are extremely difficult to dissolve in water, there was insufficient temporal data in wastewater from Hayes (2009) for further analysis given that, in these cases, the curve peak would occur after that sampling time.

The theory has been proven by the resulting curves that show that the higher the $k_{o c}$ value was, the later the maximum concentration was reached. With the increase of property value of $k_{o c}$, the concentration curve peak would occur later. TMB and R-Benzene need more time to dissolve into the flowback fluid than Acetophenone or BETX compounds because of the $k_{o c}$ value.

Previously published articles have provided and proven the range number for $k_{\text {fast }}$ and the distribution of the kinetic rate constant values ranging from 0.01 to $50 \mathrm{~d}^{-1}$ for the fast scenario (Birdwell et al., 2007). For our fitting results, the rate $k_{f a s t}$ ranged from 0.02 to $2 \mathrm{~d}^{-1}$ (Table 4-7), and all of the fitting values were within the prediction range.

The purpose of hydraulic fracturing for shale gas is to create cracks by means of high-pressure fluid in sedimentary shale formation that could let hydrocarbons flow more freely. Oil and gas may be produced in this manner. Hydraulic conductivity is a measure of a material's capacity to transmit water. Generally, in a shale formation the value varies between $10^{-13}$ and $10^{-9} \mathrm{~m} / \mathrm{s}\left(3 \times 10^{-13}-3 \times 10^{-9} \mathrm{ft} / \mathrm{s}\right)$. Organic compounds' effective transport velocities depended on the retention factor $R_{d}$. This factor is inversely proportional to the organic carbon partition coefficient $k_{o c}$. The fitting result of $v$ value ranged from $10^{-6}$ to $10^{-4} \mathrm{~m} / \mathrm{s}\left(3 \times 10^{-6}-3 \times 10^{-4} \mathrm{ft} / \mathrm{m}\right)(0.36-3.58 \mathrm{~m} / \mathrm{d}$ $(0.11-1.1 \mathrm{ft} / \mathrm{d}))$ since the porosity was elevated by hydraulic fracturing operation in the shale formation. 
Table 4-7: The results of model fitting into the analysis field

\begin{tabular}{|c|c|c|c|c|c|}
\hline & Acetophenone & Benzene & Phenol & TEX & TMB \\
\hline 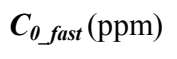 & 5.79 & 177.50 & 11.27 & 217.32 & 18.24 \\
\hline $\boldsymbol{v} / \boldsymbol{R}_{\boldsymbol{d}}(\mathrm{m} / \mathrm{d})$ & 2.97 & 2.43 & 3.24 & 2.54 & 2.54 \\
\hline $\boldsymbol{k}_{\text {fast }}\left(\mathrm{d}^{-1}\right)$ & 0.12 & 0.065 & 0.085 & 0.028 & 0.071 \\
\hline$R^{2}$ & 0.98 & 0.99 & $\underline{-0.41}$ & 0.99 & 0.99 \\
\hline
\end{tabular}

The coefficient of determination $\left(R^{2}\right)$ was meant to define how close the sampling data fitted this modelling line. The determination coefficient value of compounds accounts for more than 0.98 (except for phenol), which means that our model could precisely describe the actual samples concentration change and dynamic transportation. The accurate model fitting obtained also allow concluding that, in this particular case, it is not necessary to introduce additional processes, such as biodegradation, to explain the system's behaviour.

\subsubsection{Estimating Long-Term (Slow-Part) Transportation Concentration}

The predicted concentration ratios in wastewater modified in Figure 6- the grey shaded area represent estimating concentration ratio curve in one confidence interval $(\sigma)$ range- covered a large part of the estimation result, which could be representative if 
forecasting the curve tendency. $k_{\text {slow }}$ was the most important parameter in equation 4.12. The mean $(\mu)$ value of $k_{\text {slow }}$ was used to estimate the concentration ratio in each analysed chemical, and the estimation results obtained are represented by the black solid line in Figure 4-7.
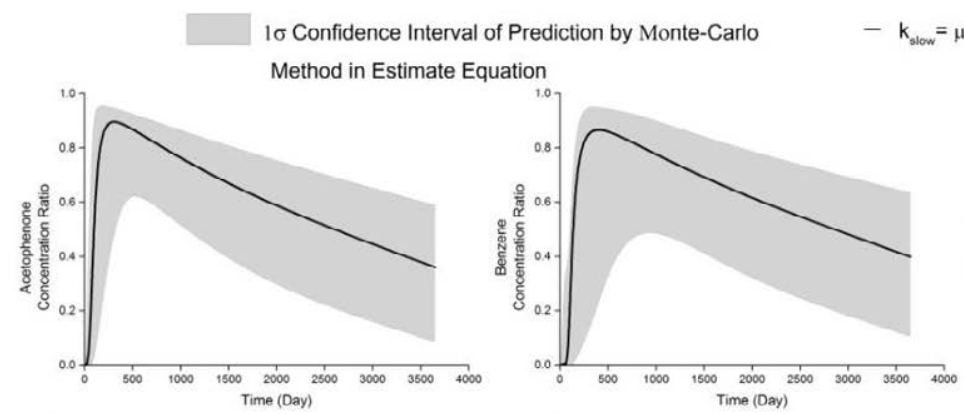

Concentration Ratio Prediciton
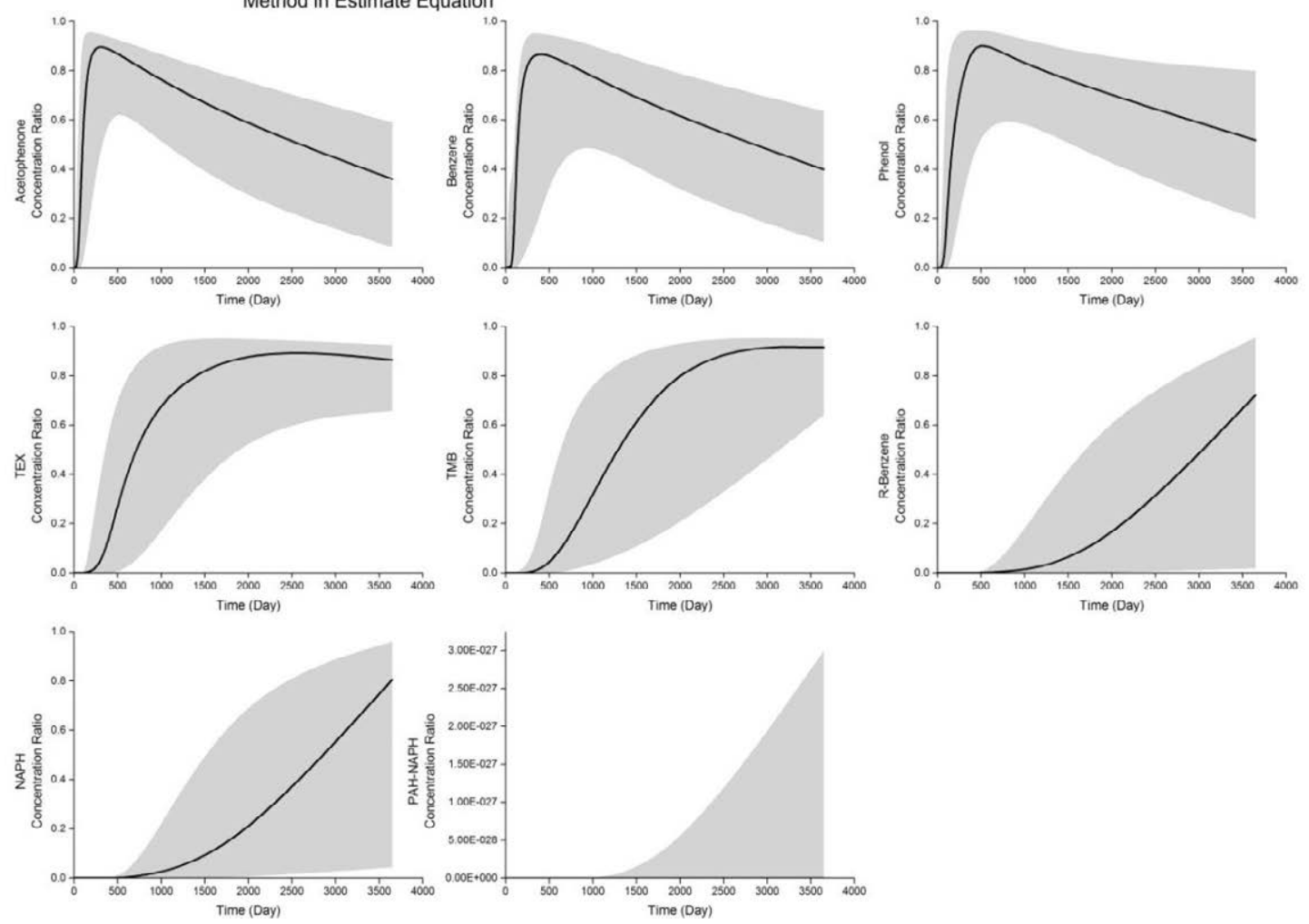

Figure 4-7: Estimated concentration ratios of each compound. The grey shaded area represents estimating concentration ratio curve in $1 \sigma$ confidential interval. Estimated mean value concentrations $(\mu)$ are represented by solid line in the figure (in PAH-NAPH this line is coincident with $\mathrm{x}$-axis).

The bold values in Table 4-6 and black solid lines in Figure 4-7 depict the estimated results of the concentration ratio calculated with average $k_{\text {slow }}$ value. As mentioned above, parameters $k_{\text {slow }}$ plays a decisive role in this predictive model for different compounds. The organic carbon partition coefficient $k_{o c}$ was the most 
important parameter for organic effective transport velocity. The higher the substances $k_{o c}$ value, the later the maximum concentration in estimation curve is reached. For instance, acetophenone is a water-soluble substance and $k_{o c}$ value is 52 . The estimated maximum ratio in $1 \sigma$ confidence interval would reach up to $90 \%$ compared with initial concentration within half a year after a fracturing operation. With the increase of the $k_{o c}$ value, the maximum concentration peak would appear later in time. For the benzene and phenol estimation curves, the peak would probably occur at the first year in this model estimation. On the other hand, for TEX and TMB chemicals, the maximum concentration for them all would appear at the $5^{\text {th }}$ year. The maximum concentrations under the estimated conditions for the right four compounds would appear at the $10^{\text {th }}$ year.

In the model developed, without considering biodegradation and chemical decay of some organic chemicals during the transportation process, the maximum concentration of organic compounds in produced water -shown in Table 4 in bold and italics- would reach up to $90 \%$ of the initial chemical concentration present in the shale formation that is available for slow desorption. For some low solubility substances such as R-Benzene, NAPH, or PAH-NAPH, ten years were not sufficient to reflect the whole transportation in the subsurface, therefore, estimation curves only represent the initial evolution of organic concentration and it was difficult to define when, and how much, the peak of maximum concentration would appear. 
Table 4-8: Concentration Ratio (calculated using Average $k_{\text {slow }}$ Value) (Maximum Ratios are in Bold and Italics)

\begin{tabular}{|c|c|c|c|c|c|c|c|c|}
\hline $\begin{array}{l}\text { Time } \\
\text { (day) }\end{array}$ & Acetopheone & Benzene & Phenol & TEX & TMB & R-Benzene & NAPH & $\begin{array}{l}\text { PAH } \\
\text {-NAPH }\end{array}$ \\
\hline 1 & 0 & 0 & 0 & 0 & 0 & 0 & 0 & 0 \\
\hline 5 & $3.74 \mathrm{E}-41$ & $1.10 \mathrm{E}-93$ & 0 & 0 & 0 & 0 & 0 & 0 \\
\hline 14 & $3.39 \mathrm{E}-13$ & $4.43 \mathrm{E}-16$ & $1.37 \mathrm{E}-15$ & 0 & 0 & 0 & 0 & 0 \\
\hline 50 & $1.87 \mathrm{E}-02$ & 7.41E-03 & $1.34 \mathrm{E}-04$ & $2.94 \mathrm{E}-27$ & $2.25 \mathrm{E}-47$ & 0 & 0 & 0 \\
\hline 90 & $4.42 \mathrm{E}-01$ & $3.82 \mathrm{E}-03$ & $5.63 \mathrm{E}-02$ & 4.14E-14 & $2.93 \mathrm{E}-25$ & $5.18 \mathrm{E}-75$ & $5.60 \mathrm{E}-68$ & 0 \\
\hline 150 & $9.03 E-01$ & 8.14E-01 & $5.15 \mathrm{E}-01$ & $1.32 \mathrm{E}-07$ & $3.17 \mathrm{E}-14$ & $4.68 \mathrm{E}-44$ & $7.80 \mathrm{E}-40$ & 0 \\
\hline 365 & $9.02 \mathrm{E}-01$ & $8.89 E-01$ & $9.57 E-01$ & $3.26 \mathrm{E}-02$ & $1.16 \mathrm{E}-04$ & $1.03 \mathrm{E}-16$ & $5.50 \mathrm{E}-15$ & 0 \\
\hline 730 & $8.15 \mathrm{E}-01$ & 8.24E-01 & 8.64E-01 & $6.56 \mathrm{E}-01$ & $1.04 \mathrm{E}-01$ & 2.82E-07 & $1.96 \mathrm{E}-06$ & 0 \\
\hline 1825 & $6.00 \mathrm{E}-01$ & $6.32 \mathrm{E}-01$ & 7.17E-01 & $9.29 E-01$ & $9.21 E-01$ & $5.10 \mathrm{E}-02$ & $9.38 \mathrm{E}-02$ & 0 \\
\hline 3650 & $3.60 \mathrm{E}-01$ & $3.98 \mathrm{E}-01$ & $5.18 \mathrm{E}-01$ & 8.64E-01 & $9.16 \mathrm{E}-01$ & $7.22 E-01$ & $8.06 E-01$ & $9.49 E-54$ \\
\hline
\end{tabular}

Our comprehensive model provides a new perspective to estimate prospective organic concentration ratio range tendency. The parameters of this model are associated with local geophysical information and physicochemical characteristics from organic substances. This means the model has strong adaptability to suit the different geological 
conditions and different organic compounds by tuning parameters. However, this model need to be improved with a large amount of data from different locations and with more frequent monitoring and covering longer times periods.

It is known that the leaking from storage tank may alter the transport channels in soil. In addition, the chemical interactions between tank wastewater and atmosphere and water system may lead to eco-toxicological risks (Chen et al., 2017; Jiang et al. 2014). Only understanding the local geo-information, organic leaking-processes, volatile and/or adsorption models, the environment risk assessment could be obtained faster and easier. All the above may contribute to optimize health risk assessment for local residents and provide knowledge to reduce the eco-toxicological risks from shale gas exploitations.

\subsubsection{Conclusions}

The core aim of this study is to determine a model meant to account for the whole transport process of organic compounds in a shale formation during the horizontal hydraulic fracturing operational life-cycle. A comprehensive model, combining organic matter transport dynamic model (including convection, diffusion, dispersion, desorption, adsorption and retention reaction in shale formation) and two-compartment first-order rate constant (TFRC) model in desorption profile, has been established.

In order to test and verify whether the model can be helpful in the risk assessment management by allowing the organic characterization of the source term and its time evolution, West Virginia and Pennsylvania Marcellus Shale data was chosen. There are two parameters - $k_{\text {fast }}$ and $k_{\text {slow }}$ - in our model to describe the physical-chemical 
desorption process, another one to characterize the advective-convective process $-v-$ and two last associated to the initial contaminants concentration available in the local environment to participate on desorption processes $-C_{0 \_ \text {fast }}$ and $C_{0 \_}$slow . The transport model for the first 14 days is adequately explained with the processes described with the fast desorption. Two-thirds of the values of the criteria used to measure the goodness-of-fit are higher than 0.90 , and even some of them reach the 0.99 . This demonstrates that the implemented model describes adequately the transport processes of the analysed chemical substances to the flowback waters.

Based on the slow transportation part of numerical analysis and parameters, we are able to forecast concentration tendency of relevant chemicals. Under our analysis situation, Monte-Carlo methods succeeded in solving problems providing a probabilistic interpretation. On the basis of numerical ranges of hydraulic conductivity obtained from fitting results, local geographic parameters and model, the estimation mean value $(\mu)$ is made with one confidential interval $(\sigma)$ concentration ratio curve. The results from curves indicate that different organic compounds, with the higher $k_{o c}$ value, will have the last to reach peak concentration and this phenomenon can be explained by the retention factor theory during transportation. Finally, under our studied conditions, the maximum concentration in wastewater reaches up to $90 \%$ of the initial concentration available to slow desorption transport processes.

Nevertheless, there are some aspects that can be improved and the contamination transportation model can continue being updated to reflect a more realistic situation. During the transportation process, there is degradation and decay processes for organic 
chemicals although biocides are normally added to control bacterial growth in the geological formation and in surface production equipment. But these processes do not seem to be necessary in the fast desorption transportation given the good fit obtained. However, surely they may be necessary during the slow desorption transport phase that takes place over long periods of time, even reaching years. The lack of data during this period does not allow its evaluation. From the point of view of the risk assessment not considering these processes implies a conservative approach in favour of safety, as these would result in an expected decrease in the concentration of the analysed substances. From an operational point of view, the situation is the opposite since not considering them could lead to increased costs to meet regulations.

It would be interesting to apply this model in other sites with a greater number of time intervals monitoring covering especially the periods corresponding to slow desorption processes. It may contribute to have a more precise estimates of the expected concentrations in the return waters, which would be reflected in the preventive measures to be taken and therefore in the risks to the health of the local residents. 


\subsection{Determining VOCs Concentrations in Flowback and Produced Waters Storage Tanks/Pits}

In order to be able to assess the potential risks to human and ecological health associated with on-site pit storage of flowback and produced waters it is essential to know the concentration of pollutants in these wastewaters. This aspect is of particular interest since in 2013, Resources for the Future (RFF) released the results of a study of four key stakeholder groups in shale gas development-industry, regulators, nongovernmental organizations (NGOs), and academics. On this they found that of 264 possible "risk pathways" there are 15 pathways that were common across all four stakeholder groups. In this survey, the risk pathway that was most often selected by the stakeholder groups is on-site pit storage of flowback and produced water constituents and the potential for leakage into surface water (Kuwayama, 2015). In addition to concerns regarding surface water, the risk to groundwater resources generated by on-site pit storage of flowback and produced water constituents was also a pathway that was common to all groups' top 10 most selected pathways (Krupnick and Gordon, 2015).

The determination of pollutant concentration in surface wastewaters storage structures require the temporal evolution of both, volume of flowback returned to surface and pollutant concentration in this waters (see Figure 4-8), being the expression as follows: 


$$
\begin{aligned}
& M_{w}^{\alpha}(t)=\int_{t^{\prime}=0}^{t} C_{f}^{\alpha}\left(t^{\prime}\right) \cdot V_{f}\left(t^{\prime}\right) \cdot d t^{\prime} \\
& C_{w}^{\alpha}(t)=\frac{\int_{t^{\prime}=0}^{t} C_{f}^{\alpha}\left(t^{\prime}\right) \cdot V_{f}\left(t^{\prime}\right) \cdot d t^{\prime}}{\int_{t^{\prime}=0}^{t} V_{f}\left(t^{\prime}\right) \cdot d t^{\prime}}
\end{aligned}
$$

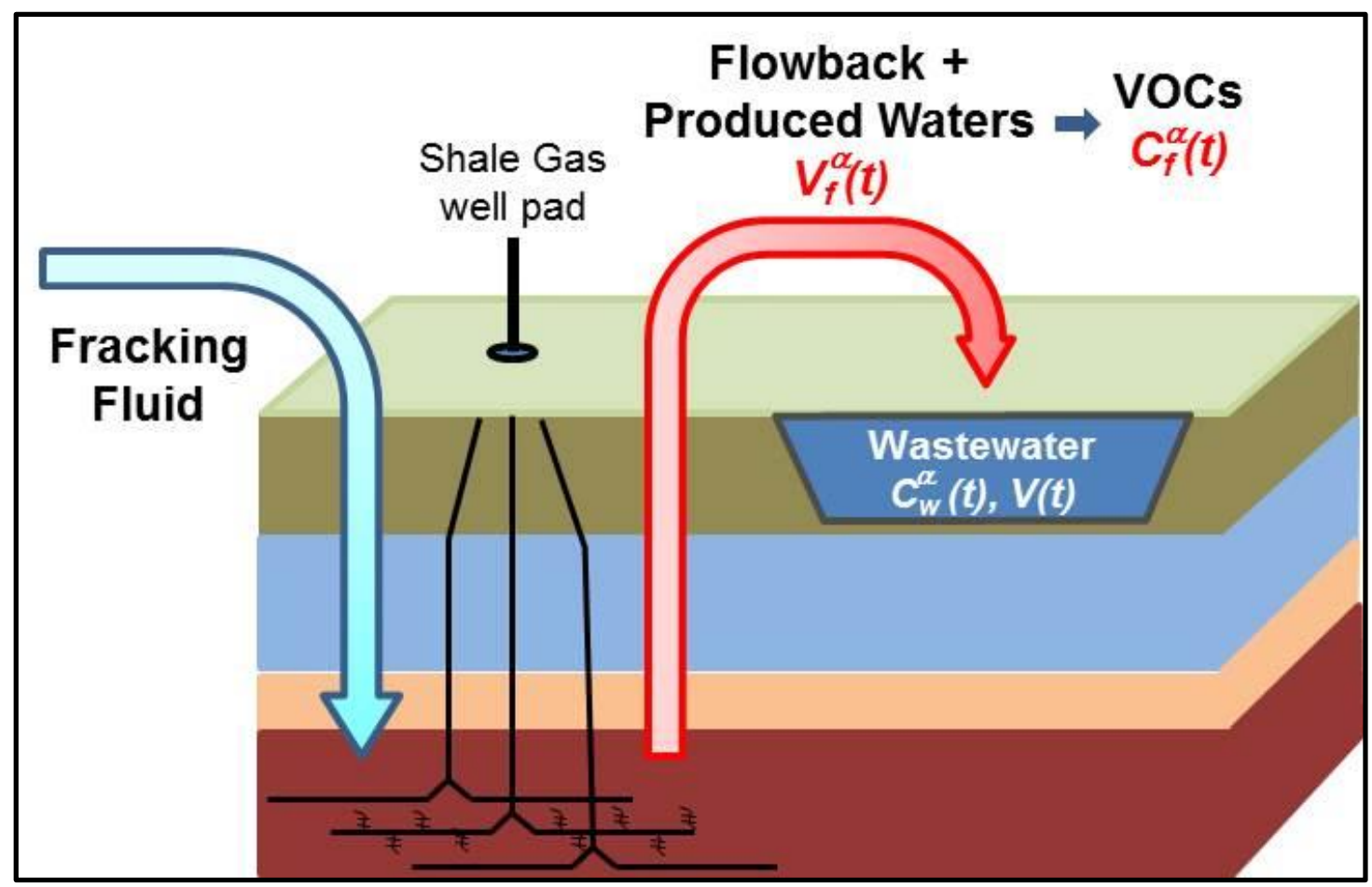

Figure 4-8: Wastewaters storage.

In expression (4.16), $M_{w}^{\alpha}(t)$ is the mass of contaminant " $\alpha$ " accumulated until the time $t$ in the wastewater tank/pit [Mass]; $C_{w}^{\alpha}(t)$ is the concentration of contaminant " $\alpha$ " at time $t$ in the wastewater tank/pit [Mass $\cdot$ Length $\left.^{-3}\right] ; C_{f}^{\alpha}(t)$ is the concentration of contaminant $\alpha$ at time $t$ in the flowback or produced water [Mass $\cdot$ Length ${ }^{-3}$ ] and $V_{f}(t)$ 
is the volume of flowback or produced water at time $t\left[\right.$ Length $\left.^{3}\right]$.

\subsubsection{Temporal evolution of Flowback and Produced water volumes}

The previous sections of this paper allow us to estimate the temporal evolution of the concentrations of VOCs. The experimental data of volumes of flowback and produced water make it possible to assess its time evolution. The flowback volume can be seen in the Table 4-9 at 1, 5, 14 and 90 days for the horizontal wells (Hayes, 2009).

Table 4-9: Accumulated volume of Flowback and produced water for the horizontal wells.

\section{Horizontal Well}

\begin{tabular}{c|cccccccc}
\hline $\begin{array}{c}\text { Time } \\
(\text { day* })\end{array}$ & $\mathrm{C}\left(\mathrm{m}^{3}\right)$ & $\mathrm{D}\left(\mathrm{m}^{3}\right)$ & $\mathrm{E}\left(\mathrm{m}^{3}\right)$ & $\mathrm{F}\left(\mathrm{m}^{3}\right)$ & $\mathrm{G}\left(\mathrm{m}^{3}\right)$ & $\mathrm{K}\left(\mathrm{m}^{3}\right)$ & $\mathrm{M}\left(\mathrm{m}^{3}\right)$ & $\mathrm{O}\left(\mathrm{m}^{3}\right)$ \\
\hline 1 & 525.93 & 453.75 & 1360.93 & 520.21 & 193.81 & 914.34 & 2610.41 & 815.76 \\
5 & 1534.55 & 1284.14 & 3232.21 & 1721.83 & 1191.29 & 1274.44 & 2851.44 & 3052.87 \\
14 & 2542.37 & 1580.02 & 3912.68 & 1960.47 & 1982.73 & 1506.09 & 3135.71 & \\
90 & & & & & & & & \\
\hline
\end{tabular}

(*Days from the hydraulic fracturing event.)

The evolution of flowback and produced water volumes shows a wide range of variability between wells. This conditions the obtaining of a fitting function to an empirical expression as a function of time. For the case of the horizontal wells this expression is given by the following: 


$$
V(t)=a_{1}+\frac{a_{2} \cdot \ln (t)}{t^{a_{3}}}
$$

in which $V(t)$ is the generated volume of water $\left(\mathrm{m}^{3}\right)$ over a period of time of $t$ days and $a_{1}, a_{2}$ y $a_{3}$ are the fitting parameters.

Figure 4-9 shows the experimental values for D, E, F and G wells, for which the complete series of data are available, just as the adjustment obtained with the previous expression, whose parameters are shown in the Table 4-10.

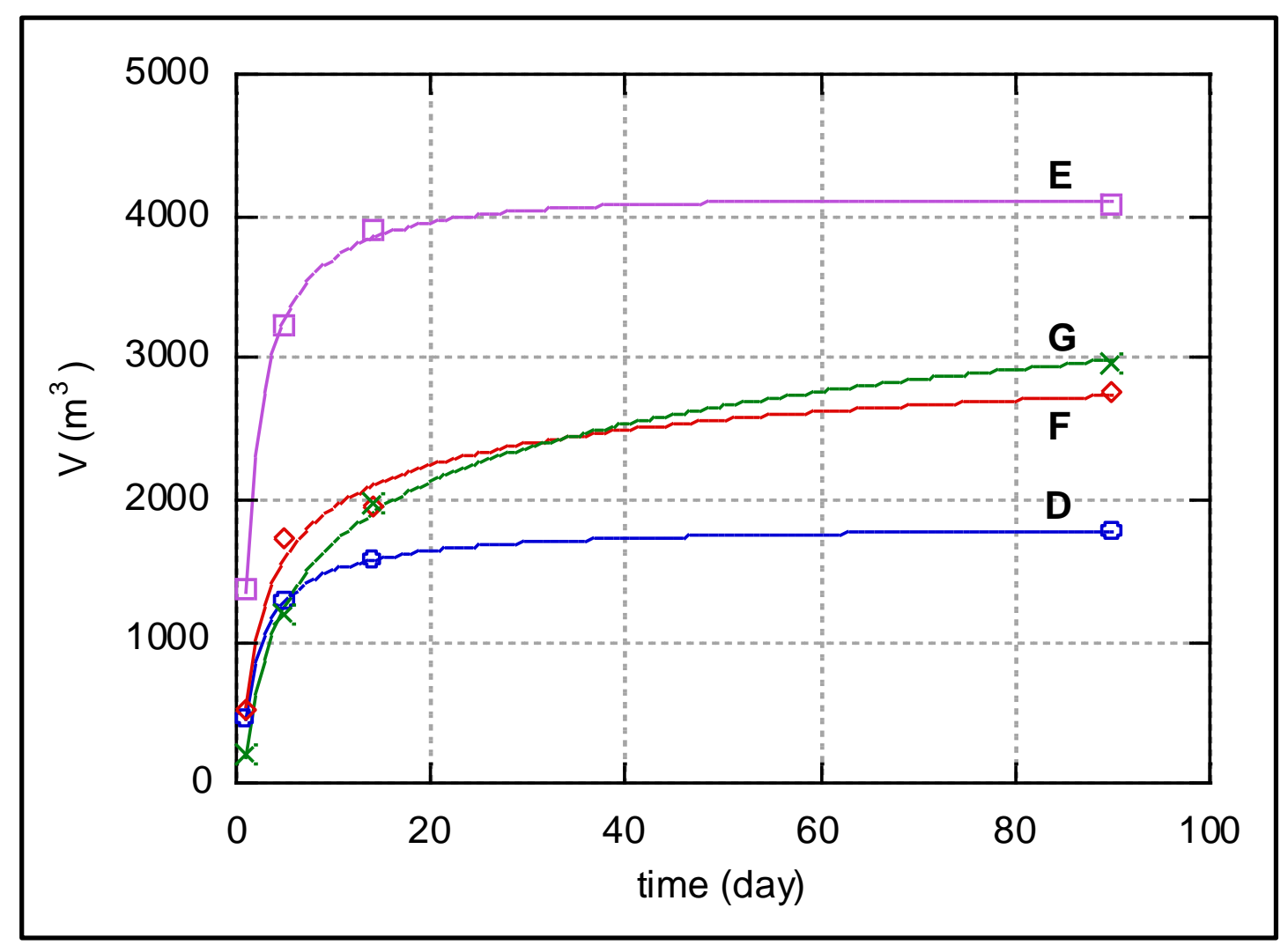

Figure 4-9: Evolution of flowback and produced water volumes for D, E, F y G wells. 
Table 4-10: Fitting function values for D, E, F and G wells for which the complete series of data are available.

\begin{tabular}{|c|c|c|c|c|}
\hline \multirow[b]{2}{*}{ Well } & \multicolumn{4}{|c|}{ Model Parameters } \\
\hline & $a_{1}$ & $a_{2}$ & $a_{3}$ & $\mathrm{R}^{2}$ \\
\hline $\mathrm{D}$ & 452.75 & 712.64 & 0.19602 & 0.99997 \\
\hline $\mathrm{E}$ & 1350.8 & 1753.2 & 0.23393 & 0.99914 \\
\hline $\mathrm{F}$ & 547.53 & 764.75 & 0.10073 & 0.993 \\
\hline $\mathrm{G}$ & 176.18 & 707.37 & 0.027779 & 0.99866 \\
\hline
\end{tabular}

With the disadvantage of a small number of wells with the complete series of data, the confidence intervals have been determined for a sigma value of 1 (confidence value of 0.68 ) and 2 (confidence value of 0.95) through the application Student's $t$ Distributions since the number of data is insufficient to accept the normality hypothesis. The results are shown in Table 4-11 and Figure 4-10.

Table 4-11: Confidence intervals for volume evolution at $1,5,14$ and 90 days for $1 \sigma$ and $2 \sigma$ confidence levels.

\section{Return Water Volume $\left(\mathbf{m}^{3}\right)$}

\begin{tabular}{c|c|cc|cc}
\hline \multicolumn{2}{c}{ 1 } & \multicolumn{2}{c}{$2 \sigma$} \\
\hline \multirow{2}{*}{ Time(days) } & Mean & Min & Max & Min & Max \\
& \multirow{2}{*}{5} & & & & \\
5 & 2017.846 & 1687.459 & 2348.233 & 1287.911 & 2747.782 \\
14 & 2374.296 & 2012.306 & 2736.286 & 1557.158 & 3191.434 \\
90 & 2899.73 & 2337.928 & 3461.532 & 1395.935 & 4403.525 \\
\hline
\end{tabular}


As described in Table 4-11 the lower value of the confidence interval for a confidence level of $95 \%$ is lower than the volume obtained for 14 days. This is due to the small number of wells with values in all the records of the series of days. Specifically for day 90 there are only data for four wells. This implies that wells with high values of flowback and produced water have been eliminated, although have been taken into account in the 14-day registry. Figure 4-10 shows the evolution of the mean values and confidence intervals of the accumulated volume for 0.68 and 0.95 confident levels, due to the mean values do not have the sufficient level of significance.

The parameter values of the fitting function for 0.68 and 0.95 levels of confidence are given in Table 4-12. In addition, Figure 4-12 shows the experimental data of the volume values and their confidence intervals for the different wells and days.
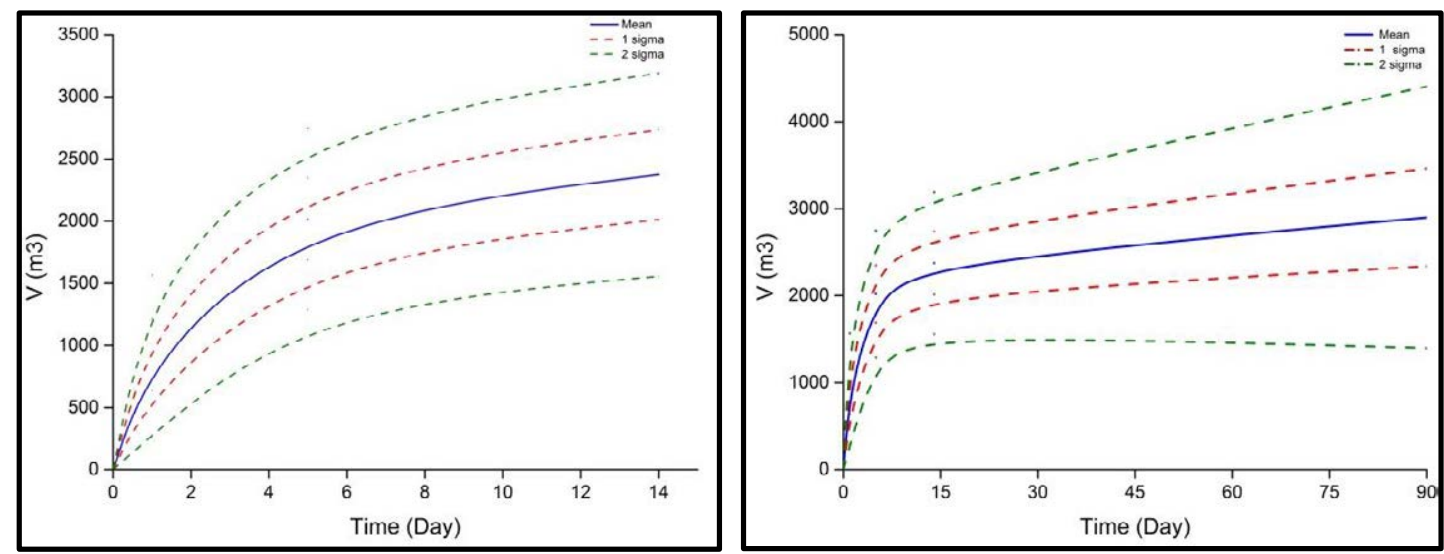

Figure 4-10: Evolution of the mean values (blue curve) and confidence intervals of the accumulated volume for 0.68 (red curves) and 0.95 (green curves) confidence levels. 
Table 4-12: Parameter values of the fitting function for 0.68 and 0.95 levels of confidence.

\begin{tabular}{c|cccc}
\hline & \multicolumn{4}{|c}{ Model Parameters } \\
\hline Curve & $\mathrm{a}_{1}$ & $\mathrm{a}_{2}$ & $\mathrm{a}_{3}$ & $\mathrm{R}^{2}$ \\
\hline Mean & 932.49 & 812.46 & 0.13906 & 0.99911 \\
Min (0.68) & 637.85 & 859.54 & 0.18356 & 0.9997 \\
Max (0.68) & 1227.3 & 776.79 & 0.101 & 0.99857 \\
Min (0.95) & 275.72 & 1106.3 & 0.32758 & 0.99769 \\
$\operatorname{Max}(0.95)$ & 1590.4 & 677.65 & 0.019586 & 0.9975 \\
\hline
\end{tabular}

So, with the foregoing fits and the derivative of the expession 4.52 the instantaneous return water volumes can be obtained. Results are shown in the Figure 4-11 where mean and confidence intervals volumes for each day are shown. In addition, negative volume values had been represented as 0 making use of the physical meaning of this parameter.

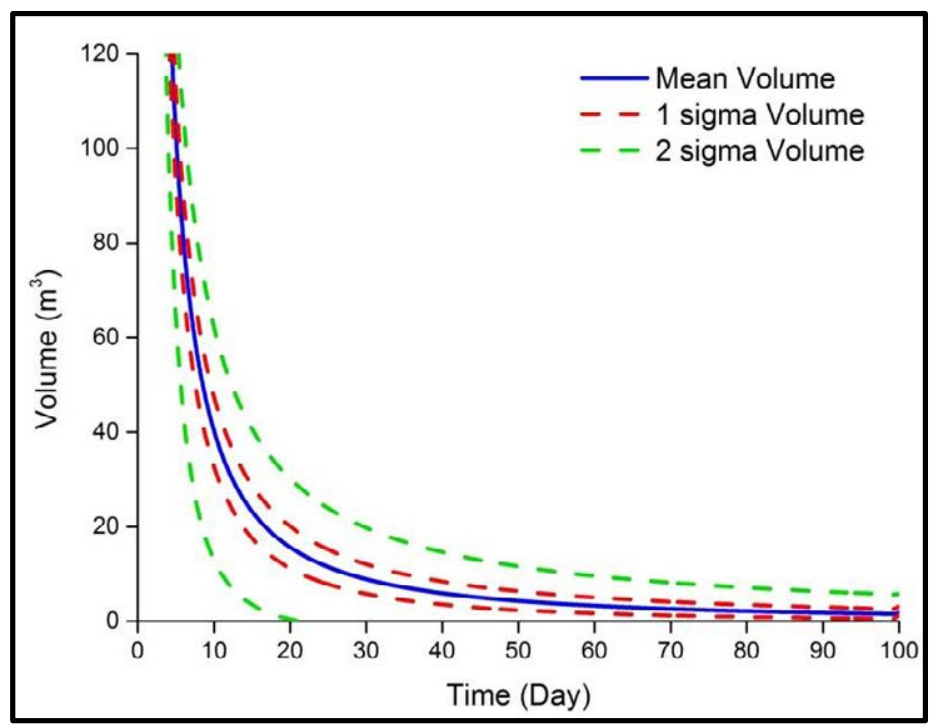

Figure 4-11: Evolution of the mean values (blue solid curve) and confidence intervals of the volume for 0.68 (red dash curves) and 0.95 (green dash curves) confident levels 


\subsubsection{Temporal evolution of concentrations of VOCs in storage}

\section{tanks}

Once determined the volume temporal evolution of the flowback and return waters as well as the temporal evolution of the VOCs present in them, the content concentration of the various VOCs groups are obtained via expression 4.15 to estimate the concentration of VOCs in the storage tanks. Differentiation between evolutions associated to "Fast" and "Slow" desorption must be maintained due to the diversities in the calculation procedures need to be introduced to determine each of these evolutions, which in turn causes the errors associated with both terms to be very different.

The calculation of the accumulated concentrations associated with the "Fast" desorption requires the direct use of the expressions obtained by inverse fit to the experimental data.

The expressions estimated in section 4.5 correspond to normalized concentration $\left(C / C_{O_{-} \text {slow }}\right)$ in the accumulation case due to flowback and production water concentrations associated with "Slow" desorption. As already indicated above, the $C_{0 \_ \text {slow }}$ parameter of the equation 4.13 can be estimated via the experimental concentration for day 90 to obtain absolute concentrations through the following expression:

$$
C_{0 \_ \text {slow }}^{\alpha}=\frac{C_{\text {exp }}^{\alpha}(t=90)}{\operatorname{erfc}\left[\frac{a}{\sqrt{b \cdot 90}}-c \cdot \sqrt{b \cdot 90}\right] \cdot \exp \left[-90 \cdot k_{\text {slow }}\right]}
$$


in which $C_{\text {exp }}^{\alpha}(t=90)$ represents the experimental concentration at day 90 for each of the groups of organic compounds considered $(\alpha)$; and $a, b, c$ and $k_{\text {slow }}$ are the fit function parameters for the calculation of the concentration evolution associated to desorption obtained by Monte-Carlo estimate in section 4.5.

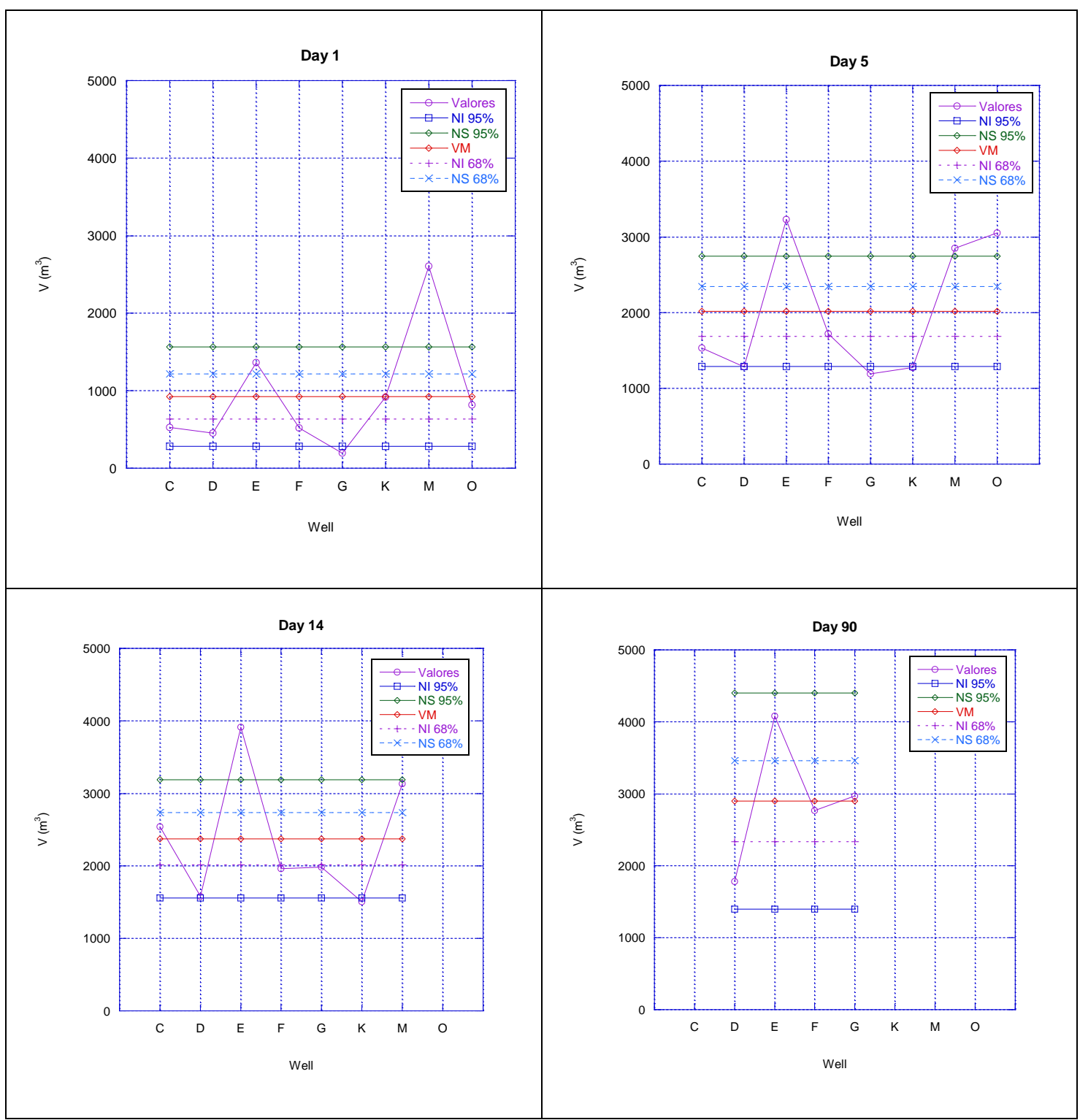

Figure 4-12: Experimental data of the volume values and their confidence intervals for the different wells and days. 
This process is valid for the Acetophenone and Benzene groups and this has been done for the calculation of their respective $C_{0_{-} \text {slow }}($ see Table 4-13). But in the case of the other groups they have $k_{\text {slow }}$ values such that the corresponding simulated assessments for day 90 tend to zero (see Table 4-8). Thus make it impossible for it to be used for reliable determination of $C_{0 \_}$slow since in these cases the experimental value can collect contributions (residual concentrations associated with tail of the fast desorption functions) as well as errors (Acetophenone experimental precisions much smaller than the value to be determined) of orders of magnitude greater than the theoretical value of the concentration on day 90 .

Table 4-13: $C_{0 \_s l o w}$ estimated values for Acetophenone and Benzene.

\begin{tabular}{lcc}
\hline & $\overline{\boldsymbol{C}(\boldsymbol{t}=\mathbf{9 0 d})}$ & $\boldsymbol{C}_{\mathbf{0}_{-} \text {slow }}$ \\
\hline Acetophenone & $0.85 \mathrm{ppm}$ & $1.016 \mathrm{ppm}$ \\
Benzene & $72.5 \mathrm{ppm}$ & $94.09 \mathrm{ppm}$ \\
\hline
\end{tabular}

The absolute or relative ratio concentrations in flowback and return water in the storage tank for the different considered groups, for both fast and slow desorption, are shown in Figure 4-13, Figure 4-14, Figure 4-14, Figure 4-15, Figure 4-16 and Figure 4-17: 


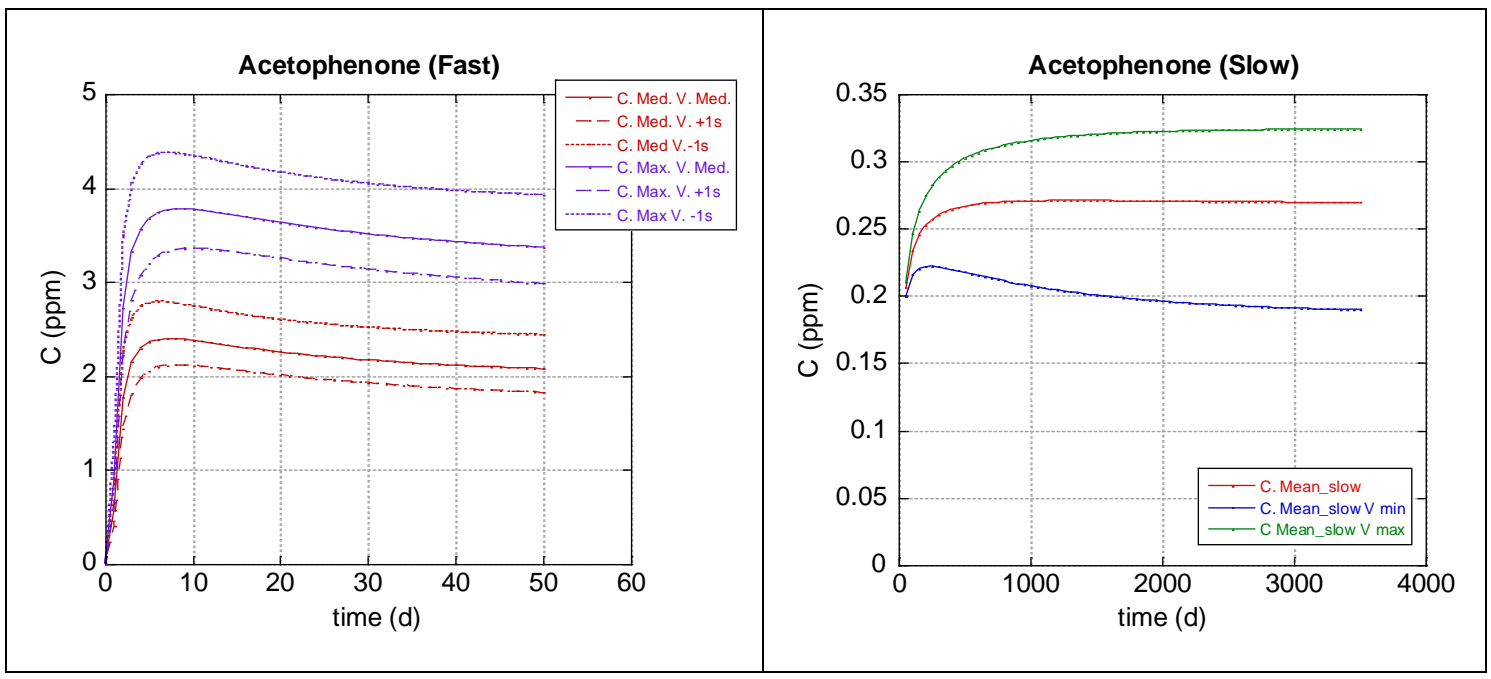

Figure 4-13: Temporal evolution of Acetophenone concentration in storage tanks associated with fast and slow desorption. The figure associated with fast desorption presents the accumulated concentrations associated with the mean value of concentration (red lines) and the upper value (blue lines) in the confidence interval of $68 \%$ ( 1 sigma value of a normal distribution). In both cases the volumes used in the calculations have been: the mean volumes (solid line); the lower value in confidence interval of $68 \%$ (dashed lines) and the upper value in confidence interval of $68 \%$ (dotted lines). The curves associated with slow desorption present the accumulated concentrations associated with the mean value of concentration and: the mean volume value (red line), the upper volume value in confidence interval of $68 \%$ (green line) and the lower volume in confidence interval of $68 \%$ (blue line). The concentration curves including fast and slow parts desorption are shown: the mean value of concentration (red lines) and the upper value in confidence interval of 68\% (1 sigma value of a normal distribution). In both cases the volumes used in the calculations have been: the mean volumes (solid line); the lower value in confidence interval of $68 \%$ (dashed lines) and the upper value in confidence interval of $68 \%$ (dotted lines). 


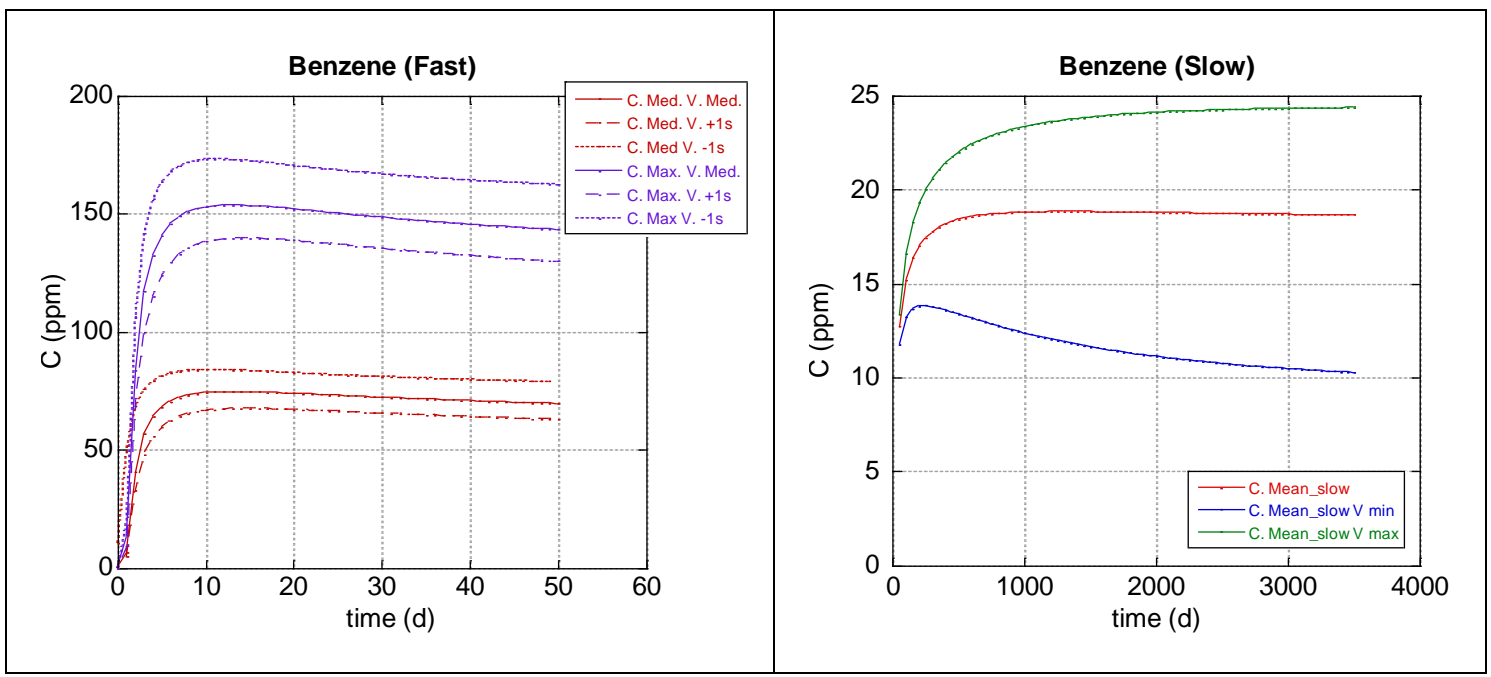

Figure 4-14: Temporal evolution of benzene concentration in storage tanks associated with fast and slow desorption. The figure associated with fast desorption present the accumulated concentrations associated with the mean value of concentration (red lines) and the upper value in the confidence interval of $68 \%$ ( 1 sigma value of a normal distribution). In both cases the volumes used in the calculations have been: the mean volumes (solid line); the lower value in confidence interval of 68\% (dashed lines) and the upper value in confidence interval of $68 \%$ (dotted lines). The curves associated with slow desorption present the accumulated concentrations associated with the mean value of concentration and: the mean volume value (red line), the upper volume value in confidence interval of $68 \%$ (green line) and the lower volume in confidence interval of $68 \%$ (blue line). The concentration curves including fast and slow parts desorption are shown. The mean value of concentration (red lines) and the upper value in confidence interval of $68 \%$ ( 1 sigma value of a normal distribution) are displayed. In both cases the volumes used in the calculations have been: the mean volumes (solid line); the lower value in confidence interval of $68 \%$ (dashed lines) and the upper value in confidence interval of $68 \%$ (dotted lines). 


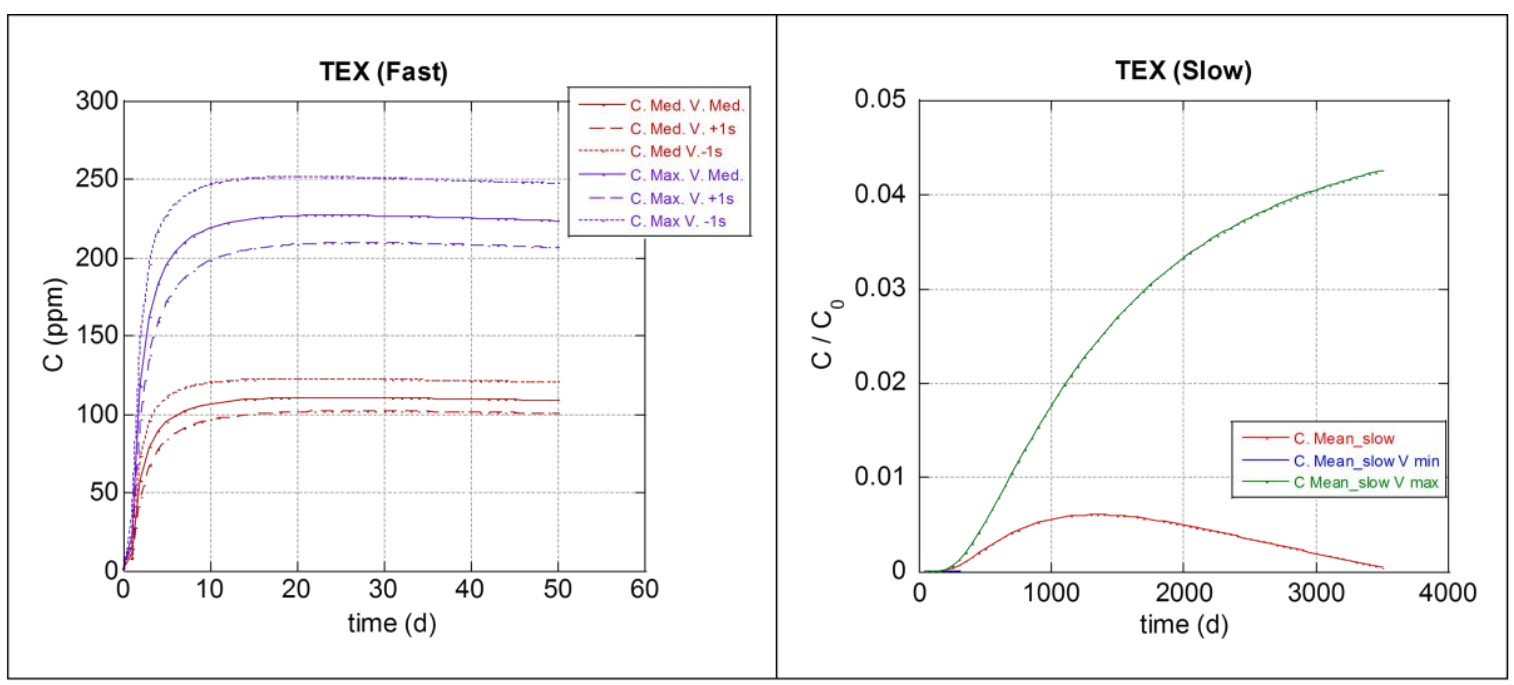

Figure 4-15: Temporal evolution of TEX concentration in storage tanks associated with fast (absolute concentration) and slow (relative concentration) desorption. The figure associated with fast desorption presents the accumulated concentrations associated with the mean value of concentration (red lines) and the upper value in the confidence interval of $68 \%$ ( 1 sigma value of a normal distribution). In both cases the volumes used in the calculations have been: the mean volumes (solid line); the lower value in confidence interval of $68 \%$ (dashed lines) and the upper value in confidence interval of $68 \%$ (dotted lines). The curves associated with slow desorption present the accumulated concentrations associated with the mean value of concentration and: the mean volume value (red line), the upper volume value in confidence interval of $68 \%$ (green line) and the lower volume in confidence interval of $68 \%$ (blue line). 


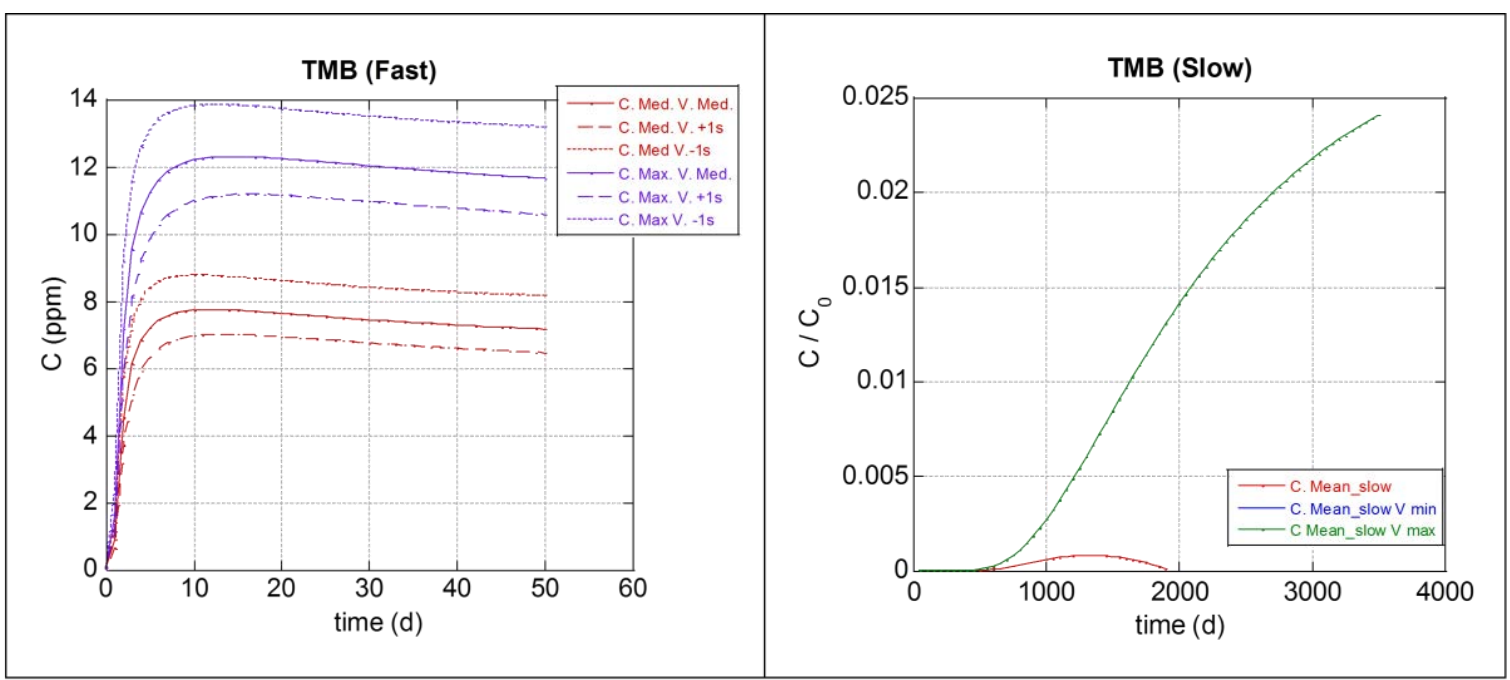

Figure 4-16: Temporal evolution of TMB concentration in storage tanks associated with fast (absolute concentration) and slow (relative concentration) desorption. The figure associated with fast desorption presents the accumulated concentrations associated with the mean value of concentration (red lines) and the upper value in the confidence interval of $68 \%$ ( 1 sigma value of a normal distribution). In both cases the volumes used in the calculations have been: the mean volumes (solid line); the lower value in confidence interval of $68 \%$ (dashed lines) and the upper value in confidence interval of $68 \%$ (dotted lines). The curves associated with slow desorption present the accumulated concentrations associated with the mean value of concentration and: the mean volume value (red line), the upper volume value in confidence interval of $68 \%$ (green line) and the lower volume in confidence interval of $68 \%$ (blue line). 


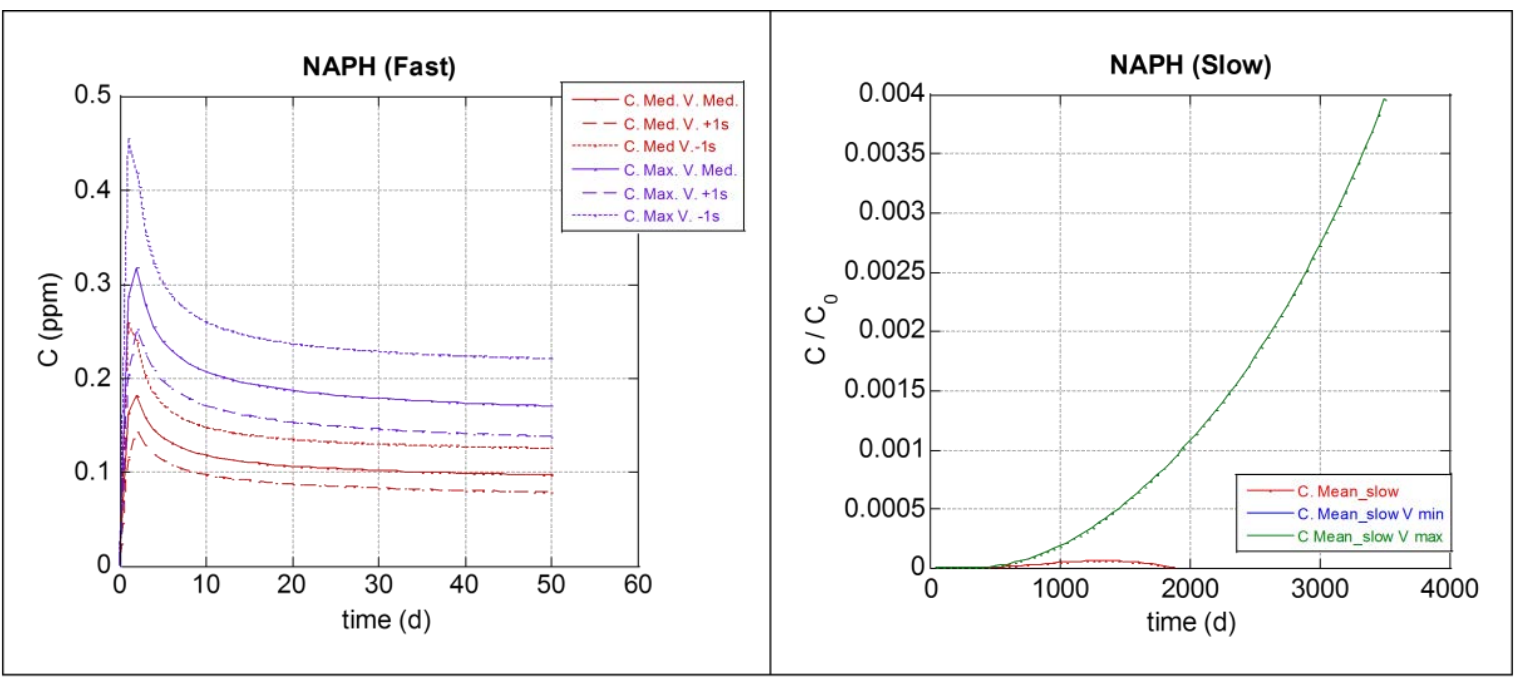

Figure 4-17: Temporal evolution of NAPH concentration in storage tanks associated with fast (absolute concentration) and slow (relative concentration) desorption. The figure associated with fast desorption presents the accumulated concentrations associated with the mean value of concentration (red lines) and the upper value in the confidence interval of $68 \%$ ( 1 sigma value of a normal distribution). In both cases the volumes used in the calculations have been: the mean volumes (solid line); the lower value in confidence interval of $68 \%$ (dashed lines) and the upper value in confidence interval of $68 \%$ (dotted lines). The curves associated with slow desorption present the accumulated concentrations associated with the mean value of concentration and: the mean volume value (red line), the upper volume value in confidence interval of $68 \%$ (green line) and the lower volume in confidence interval of $68 \%$ (blue line). 


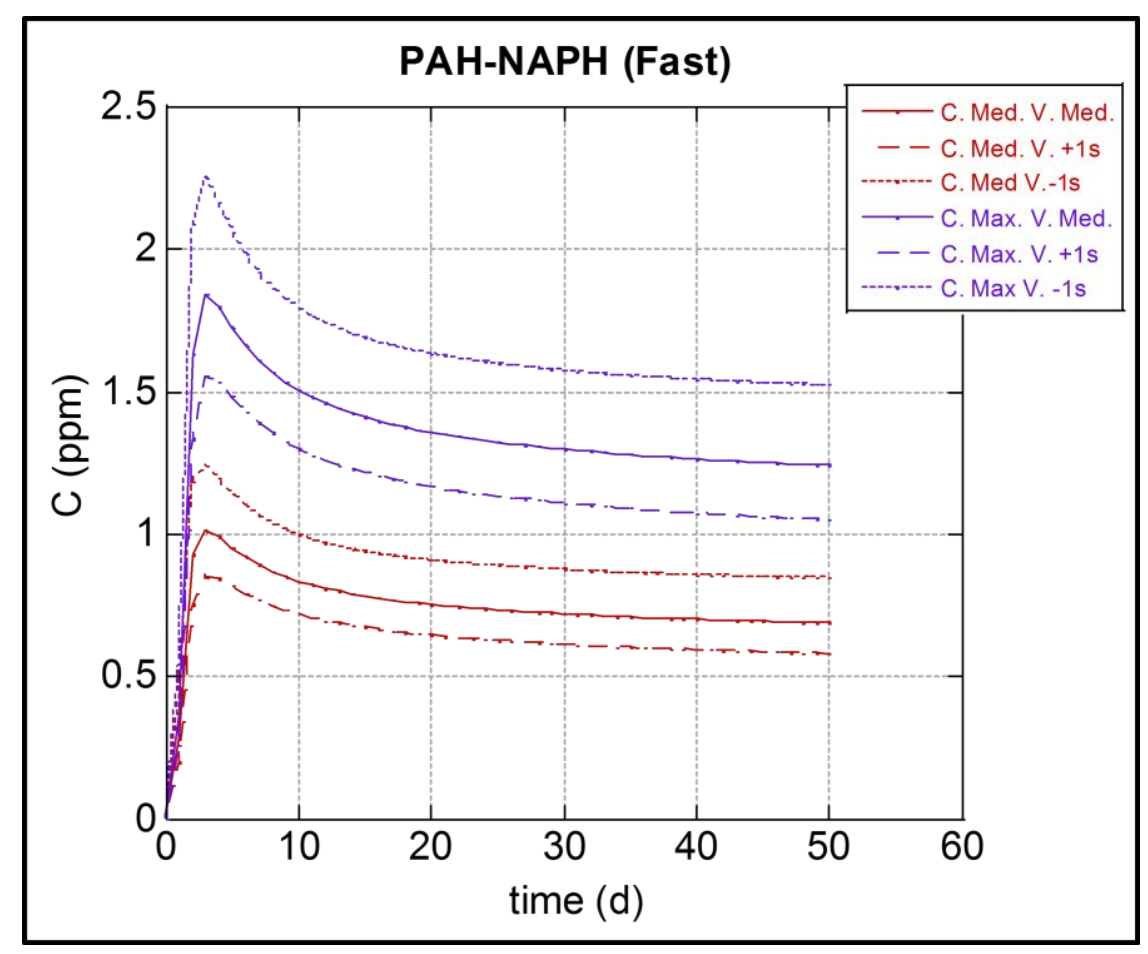

Figure 4-18: Temporal evolution of PAHs-NAPH concentration in storage tanks associated with fast (absolute concentration) desorption. It presents the accumulated concentrations associated with the mean value of concentration (red lines) and the upper value in the confidence interval of $68 \%$ ( 1 sigma value of a normal distribution). In both cases the volumes used in the calculations have been: the mean volumes (solid line); the lower value in confidence interval of $68 \%$ (dashed lines) and the upper value in confidence interval of $68 \%$ (dotted lines).

\subsubsection{Partial Conclusions}

The above graphs show that, generally, the evolution of concentrations is a function of each group. Even so, both groups for which it was possible to determine their absolute concentrations both for concentrations due to fast and slow desorption result in higher concentrations in the short term in the storage tanks. 
The graphs show that each set of compounds has its own transport evolution behavior. Together with the above, in those groups where it has been possible to determine the absolute concentrations, that is, concentrations due to rapid and slow desorption, , it can also be observed that the major concentrations are reached in the part corresponding to the term of rapid desorption.

It reaches its highest concentrations in the initial times, associated with flowback water, registering the maximum values before 10 days, and subsequent slow decreasing trend. For long times, these values are stabilized without decrease to zero in any of the cases within the considered time range.

As for the rest, for the TEX, TMB and NAPH groups the concentration associated to the fast desorption has been calculated, as well as the evolution for the one associated with the slow desorption. The estimation of an absolute value is possible in those cases where a concentration value is available in a time that allows fit $C_{0 \_}$slow.

Lastly, the evolution associated with the slow desorption of the PAHs-NAPH group could not be calculated since the associated values of $k_{\text {slow }}$ are so small that there were still no appreciable concentrations even for the 3,500 days to which the analysis has been extended.

In all groups, it is verified that the concentrations in the storage tanks of contaminants associated with fast desorption reaches a maximum or in the order of the first 10 days. 
The behavior associated with slow desorption shows greater variation, observing that for the TEX, TMB and NAPH groups an equilibrium concentration in surface storage tanks is not reached within the 3,500 days considered.

The possibility of being able to determine in advance the behavior of certain organic compounds are an important element in the establishment of treatments of return and flowback waters as well as in the determination of the most appropriate times to perform monitoring.

Finally, no determinations have been made for the Phenol group. This is because the too low $R^{2}$ value corresponding to the fast desorption fit. This indicates that the Fast/Slow separation occurs in a time prior to 14 days, so it is not possible to do so due to the lack of necessary experimental data to make liable reverse fits. 


\subsection{Analysis of vertical transportation mechanism of VOCs from Horizontal Hydraulic Fracturing wastewater}

From the point of view of potential contamination risk associated with hydraulic fracturing wastewater disposal, in this section we study the expected behavior of the VOCs present in the return waters from a potential leakage that can come from tanks/pits as elements representing surface storage. The study takes into account both the Vadose Zone and the potential associated atmospheric and groundwater contamination.

This is justified by the fact that the potential contamination risk associated with hydraulic fracturing wastewater disposal is several orders of magnitude larger than the other pathways. Even in a best-case scenario, it was very likely that an individual well would release at least $200 \mathrm{~m}^{3}$ of contaminated fluids (Rozell and Reaven, 2012).

One of the most fundamental aspects in order to reduce the uncertainties associated with such releases is to determine the concentrations of contaminants that may be present in the surface storage. These calculations were performed for VOCs in sections 4.1 and 4.2 of the present study and will serve as a basis for further risk analysis.

Transport of a volatile organic chemical (VOCs) in the gas phase through the vadose zone is recognized as an important mechanism that can lead to groundwater contamination as a result of chemical spills or releases from flowback and produced waters (i.e., return waters) in the surface storage tanks and/or in the shallowest parts of the injection and production wells (Kuwayama et al., 2017). 
When there is no a non-aqueous phase present, VOCs occur either dissolved in the liquid phase or partitioned into the gas phase. In arid or semi-arid areas where the infiltration rate is small but the air-filled porosity is large, transport of VOCs through the gas phase can become the dominant process. The Jury model (Jury, 1983) assumes "linear, equilibrium partitioning between vapor, liquid and adsorbed chemical phases, first-order degradation, and chemical movement to the atmosphere by volatilization loss through a stagnant air boundary layer at the soil surface”. The transport mechanisms considered in that model are aqueous-phase advection and diffusion, gas-phase diffusion, and adsorption of VOCs to the solids. From this, transport in different phases is described by a single equation using the total resident concentration as dependent variable and its solution can be used to estimate the mass flux to the groundwater. The developed model considers a uniform contamination source located within a prescribed depth interval in the vadose zone. Using the principle of superposition, the solution can be applied to more general problems where the initial source is non-uniform.

The final purpose of this section is to quantify the pollutant releases in a groundwater table to some finite depth and its importance from a risk management perspective for predictive or preventative purposes.

Flowback water including those mentioned above high concentration salts and toxic organic compounds from hydraulic fracturing operation will be stored on the surface in storage tanks and/or ponds. These are activities with accomplishments and points needing improvement. It is true that future hydraulic fractures represent 
substantial opportunities for the reuse of these waters, especially during the growth phase of each shale gas development area (Hayes and Severin, 2012). It requires a predictive analysis.

But, on the other hand, it is also true however that it is an activity with an associated risk that must be managed to reduce or control the materialization of pollution. For instance, it is not the same the use of storage tanks or ponds. These are two concrete choices which demonstrate two different level of associated risk. This also requires a predictive analysis.

Wastewater with toxic organic compounds spills via faulty storage could lead to groundwater contamination; and/or portion of substances would volatile to atmosphere and/or be adsorbed in the solid phase creating a risk of negative impacts on the water, soil, air, biodiversity, and/or human health that should be evaluated.

Because unconventional hydraulic fracturing of shale formation for extraction of shale gas has operated in only a few countries (Vengosh et al. 2014) (1) there is a lack of enough data to define the type of toxic organic compounds in flowback water; (2) hydraulic fracturing wastewater leaching researches are rare and could not exhibit a whole vertical contaminants transportation process through the unsaturated zone. It points to the need for a one-dimensional vertical analytical model of VOCs transportation through vadose zone to determine how the different precipitation, time and physicochemical factors could affect the atmosphere, groundwater and soil matters in the event of a hydraulic fracturing flowback water leakage. 
An intermediate target is to find out a dynamic transport model of organic chemicals in subsurface media. This study is based on (1) a grouping of substances by family according to their similar behavior and toxicity and subsequent selection according to their concentrations and negative impact and (2) on a VOCs one-dimensional vertical transportation model (Jury et al. 1990; Shan and Stephens 1995). This enables to obtain modeling results of cumulative mass percentage curves in the various phases and total concentration curves under the different recharge rate conditions. The modeling results are significant for environmental risk assessment. That combined with the estimate of the temporal evolution of the concentrations in surface storage provide necessary and effective information to risk assessment and to remediation operations of the shale gas exploitation.

\subsubsection{Methods and Materials}

\subsubsection{1. $\quad$ Vertical Transport Model}

In this part, we are focused on contamination vertical transport mechanism behavior from surface disposal storage, for instance, tank storage into aquifer table. In Figure 4-20 is shown a schematic diagram of the model, on the assumption that all of the organic chemicals dissolved in the wastewater and water spills advection is the only significant $1 \mathrm{D}$ transport mechanism through vadose zone. 


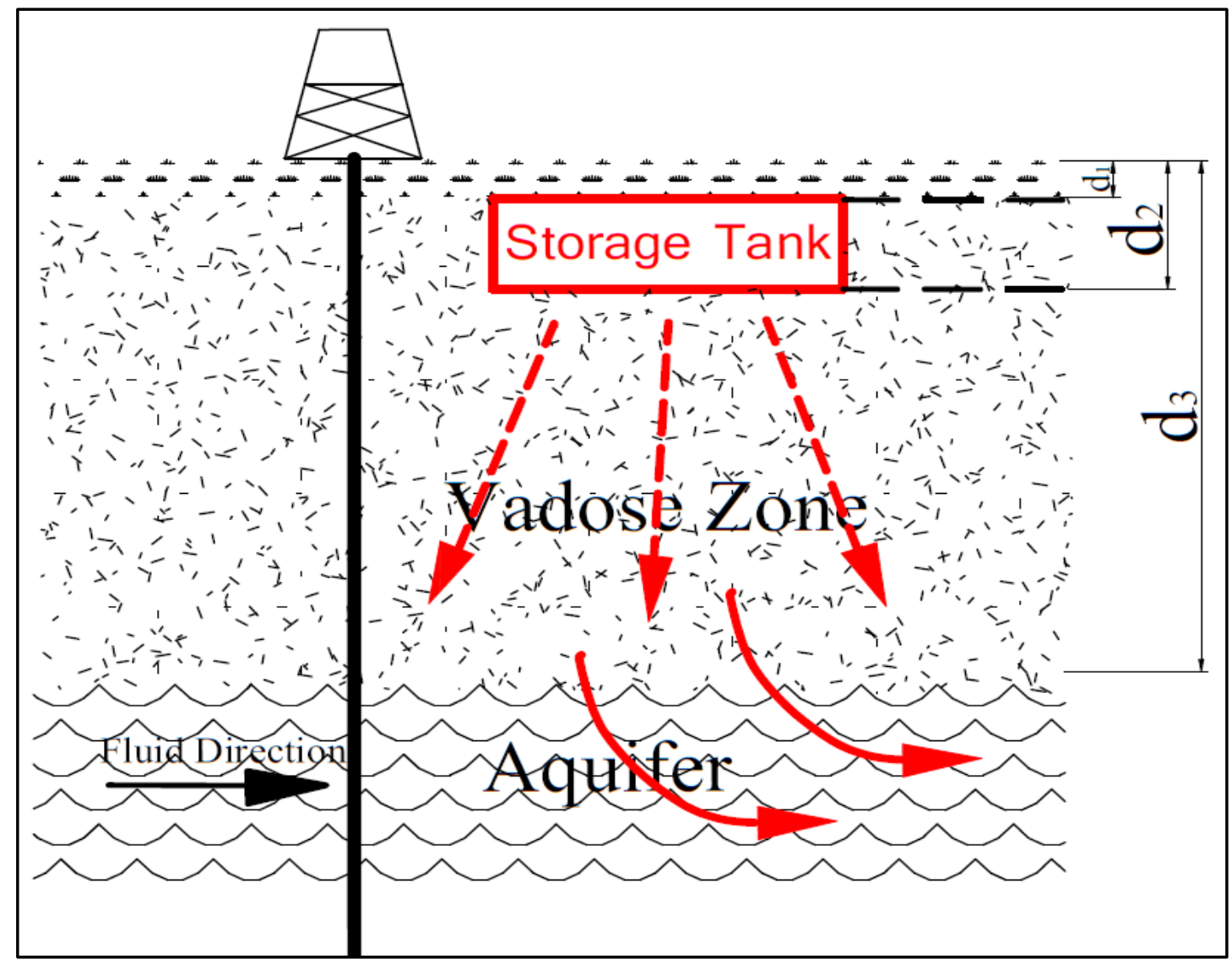

Figure 4-19: Wastewater releases process schematic view from disposal storage.

The transportation model considers aqueous-phase advection and diffusion, gas-phase diffusion and adsorption of VOCs to the solids. However it has not been introduced the effects of biodegradation activities because of two interacting fundamental reasons which can be summarized by telling that their effects are not great enough to bring about a change in the behavior of the systems given the objectives of this research work (Shan and Stephens 1995). Indeed, although the general transport equation may include a biodegradation term, which in the first approximation may appear as a decreasing exponential, this process has been excluded due to that studies conducted with the production waters do not indicate an 
abundance of microbes (Akob et al. 2015) and the amount of expected biodegradation is to be small in shales (Schlegel, 2013). Furthermore the goal of the study is placed within the context of risk management. From the point of view of risks the non-consideration of this term introduces bias in a rational and feasible manner faced to improve safety. That is to say, an upper limit to the concentrations is being obtained within the limitations defined by the conservative risks regulations (Viscusi et al., 1997).

The one-dimensional vertical transport analytical general solution is like:

$$
D \frac{\partial^{2} C}{\partial z^{2}}-V \frac{\partial C}{\partial z}-\lambda C=\frac{\partial C}{\partial t}
$$

$z$ is the vertical coordinate taken positive download; $t$ is time; $\lambda$ is the decay constant; $C$ is the total concentration defined as the total amount of chemical in liquid, gas and solid phases per unit of soil.

This is a general solution model that it is necessary to match our objectives using the analytical solution (Shan and Stephens 1995) for understanding the chemicals' migration behaviors and determining the most influential parameters of both compounds and external environment affecting. The essential difference between this particular analytic solution approach and others consists in the fact that the one contemplated assumes that there is a limit on the depth of the unsaturated medium.

The concentration in the liquid $C_{L}$ and the concentration in the gas $C_{G}$, are related to the total concentration $C$, by: 


$$
R_{L} C_{L}=R_{G} C_{G}=C
$$

where $R_{L}$ is the partition coefficient for the liquid phase and $R_{G}$ is the partition coefficient for the gaseous phase.

The parameter $V$ and $D$ in equation 5.1 can be defined overall pore velocity and dispersion coefficient by:

$$
\begin{gathered}
V=\frac{v_{L}}{R_{L}}+\frac{v_{G}}{R_{G}} \\
D=\frac{D_{L}}{R_{L}}+\frac{D_{G}}{R_{G}} \\
D_{L}=\alpha_{L} v_{L}+D_{L M} \quad \text { and } \quad D_{L M}=\frac{\theta^{10 / 3}}{\phi^{2}} D_{w} \\
D_{G}=\alpha_{G} v_{G}+D_{G M} \quad \text { and } \quad D_{G M}=\frac{(\phi-\theta)^{10 / 3}}{\phi^{2}} D_{a} \\
R_{L}=\rho_{b} \cdot K_{S L}+\theta+(\phi-\theta) K_{H}+\rho_{b} K_{H} K_{S G} \\
R_{G}=\frac{R_{L}}{K_{H}}=\rho_{b} \frac{K_{S L}}{K_{H}}+\frac{\theta}{K_{H}}+(\phi-\theta)+\rho_{b} K_{S G} \\
K_{S L}=K_{o c} f_{o c}
\end{gathered}
$$

where $v_{L}$ and $v_{G}$ are the Darcy velocities of the liquid and gas phases, respectively, considered here under steady-state conditions. $D_{L}$ and $D_{G}$ are the dispersion coefficients in the liquid and gas phases; $\alpha_{L}$ and $\alpha_{G}$ are the dispersion coefficients in the liquid and gas phases; $D_{w}$ and $D_{a}$ represent the chemical diffusion coefficients in water and air, respectively. $\theta$ is the volumetric water constant; $\phi$ is the porosity; $\rho_{b}$ is the bulk 
density; $K_{H}$ is Henry's constant; and $K_{S L}$ and $K_{S G}$ are the solid-liquid and the solid-gas distribution coefficients; $K_{o c}$ is the partition coefficient; and $f_{o c}$ is the fraction of organic carbon. The parameter $K_{S G}$ is a function of water content, and needs to be estimated.

\subsubsection{Concentration Predictive Model}

We are assuming the initial concentration as:

$$
\left.\begin{array}{c}
C(z, 0)=C_{i} \\
C_{i}=0 \quad\left(0 \leq z \leq d_{1} ; d_{2} \leq z \leq d_{3}\right) \\
C_{i}=C_{0} \quad\left(d_{1} \leq z \leq d_{2}\right)
\end{array}\right\}
$$

where $C_{0}$ is initial concentration in liquid; $d_{1}, d_{2}$ and $d_{3}\left(0 \leq d_{1} \leq d_{2} \leq d_{3}<\infty\right)$ represent the depths to the top, to bottom of the tank, and to the aquifer, respectively.

The concentration model at different depths was shown as:

$$
\begin{aligned}
& C_{1}(z, t)=\sum_{n=1}^{8}(-1)^{n} f_{1}\left(t, \alpha_{n}, \beta_{n}^{(0)}\right)+\sum_{m=1}^{\infty} C^{(m)} \\
& C_{2}(z, t)=C_{0} \cdot e^{-\lambda t}+\sum_{n=1}^{7}(-1)^{n} f_{1}\left(t, \alpha_{n}, \beta_{n}^{(0)}\right)-f_{2}\left(t, \alpha_{8}, \beta_{8}^{(0)}\right)+\sum_{m=1}^{\infty} C^{(m)} \\
& \left(d_{1} \leq z \leq d_{2}\right) \\
& C_{3}(z, t)=\sum_{n=1}^{6}(-1)^{n} f_{1}\left(t, \alpha_{n}, \beta_{n}^{(0)}\right)+f_{2}\left(t, \alpha_{7}, \beta_{7}^{(0)}\right)-f_{2}\left(t, \alpha_{8}, \beta_{8}^{(0)}\right)+\sum_{m=1}^{\infty} C^{(m)} \\
& \left(d_{2} \leq z \leq d_{3}\right)
\end{aligned}
$$




\subsubsection{3. $\quad$ Cumulative Mass Predictive Model}

In a certain period of time, organic cumulative mass percentage in each phase associated with physicochemical properties and external environmental factors. The cumulative mass models in groundwater and atmosphere are simply the integration of equations with respect to time:

$$
\begin{aligned}
& M_{W}=\frac{v_{L}}{R_{L}} \int_{0}^{t}\left(C_{3}\right)_{z=d_{3}} \cdot d t \\
& M_{A}=\frac{D_{G}}{R_{G}} \int_{0}^{t}\left(\frac{\partial C_{1}}{\partial z}\right)_{z=0} \cdot d t
\end{aligned}
$$

\subsubsection{4. $\quad$ Modeling Parameters}

A number of realistic and not associated with any particular site assumptions have been made to be able to carry out simulations of the evolution of the contaminants once released in the soil.

The purpose of this is to test the model and establish the behavior of the different groups of VOCs considered in this work in the event of a leakage from return water accumulated in surface storage as a consequence, for example, of operations not in accordance with the best practices in the exploitation of shale gas.

The assumptions imposed are as follows: a half-buried tank-type surface disposal storage, with a leak in the buried part located between 50 and 150 centimeters deep and water table at a depth of $10 \mathrm{~m}$ to the surface and assuming the following values of soil 
bulk density, porosity, water content and organic content: $1.35 \mathrm{~g} / \mathrm{cm}^{3}, 0.5 \mathrm{~cm}^{3} / \mathrm{cm}^{3}$, $0.2 \mathrm{~cm}^{3} / \mathrm{cm}^{3}$ and $0.0125 \mathrm{~cm}^{3} / \mathrm{cm}^{3}$, respectively. It is also an initial hypothesis that the value of solid-gas distribution coefficients is twice the value of solid-liquid phase distribution coefficients $\left(K_{S G}=2 K_{S L}\right)$ (Shan and Stephens, 1995), which was calculated by fraction organic content and compounds liquid-solid partitioning coefficient for soil carbon $\left(K_{S L}=K_{o c} \cdot f_{o c}\right)$. It is considered that there is no need of introducing ventilation system in this target area. Finally, it is considered that the value of gas advection velocity is zero. In summary, the parameters required in the calculations are listed in Table 4-14.

The main aim in this part of the research study is to determine how the recharge rate factor ( $v_{L}$ considered here under steady-state conditions) influences the organic compound transportation processes in the unsaturated zone. Accordingly, three orders of magnitude number of recharge rate are set to contain in a reasonable manner all geological considerable conditions in fracturing operation zone. An appropriate recharge rate value $\left(V_{L}\right)$ of $0.01 \mathrm{~cm} /$ day represents the situation in arid area; 0.10 $\mathrm{cm} /$ day, the semi-arid area; and $1.00 \mathrm{~cm} /$ day is an appropriate value for humid zone. However, in respect to substances with higher solubility in water, such as Acetophenone and Phenol, it's a prerequisite to pre-test the value range with the purpose of ensuring the accuracy of the model.

The solution has been obtained by imposing a uniform initial source of contamination, equal to all the compounds considered, $C_{0}$, of value $100 \mathrm{ppm}$. It has been considered that it extends between 50 and $150 \mathrm{~cm}$ below the surface. This has 
been done in order to facilitate the comparison of soil behavior between the different compounds. In order to obtain the results corresponding to a specific case, it is sufficient to multiply the solution by $C_{\text {tank }} / C_{0}$, with $C_{\text {tank }}$ being the concentration of the compound in the surface storage at the time of the leakage obtained in section 4.2.

In addition, although the solution was developed for an initial source of uniform type, it can be applied to non-uniform ones through the application of the superposition principle. 
Table 4-14: Basic parameters used for calculations.

\begin{tabular}{|c|c|c|c|c|c|c|c|c|c|}
\hline & & Acetophenone & Benzene & Phenol & TEX & TMB & R-Benzene & NAPH & PAHs-NAPH \\
\hline$k_{o c}\left(\mathrm{~cm}^{3} / \mathrm{g}\right)$ & $\begin{array}{l}\text { Liquid-solid } \\
\text { partitioning } \\
\text { coefficient for } \\
\text { soil carbon }\end{array}$ & 52 & 146 & 187 & 366 & 624 & 1738 & 1540 & 63384 \\
\hline$K_{H}$ & Henry's constant & $4.25 \mathrm{E}-04$ & $2.3 \mathrm{E}-01$ & $1.36 \mathrm{E}-05$ & $2.7 \mathrm{E}-01$ & $2.6 \mathrm{E}-01$ & $5 \mathrm{E}-01$ & $1.8 \mathrm{E}-02$ & $3.95 \mathrm{E}-04$ \\
\hline$D_{w}\left(\mathrm{~cm}^{2} /\right.$ day $)$ & $\begin{array}{l}\text { Water diffusion } \\
\text { coefficient }\end{array}$ & 0.75 & 0.89 & 1.17 & 0.84 & 0.68 & 0.65 & 0.73 & 0.60 \\
\hline$D_{a}\left(\mathrm{~cm}^{2} / \mathrm{day}\right)$ & $\begin{array}{l}\text { Air diffusion } \\
\text { coefficient }\end{array}$ & 5633.28 & 7732.79 & 7205.76 & 5961.61 & 5261.76 & 4950.72 & 5227.18 & 3862.08 \\
\hline$\rho_{b}\left(\mathrm{~g} / \mathrm{cm}^{3}\right)$ & Bulk density & & & & & 1.35 & & & \\
\hline$C_{0}(\mathrm{ppm})$ & $\begin{array}{c}\text { Initial } \\
\text { concentration }\end{array}$ & & & & & 100 & & & \\
\hline$d_{l}(\mathrm{~cm})$ & $\begin{array}{c}\text { Depths to the top } \\
\text { source }\end{array}$ & & & & & 50 & & & \\
\hline$d_{2}(\mathrm{~cm})$ & $\begin{array}{l}\text { Depths to the } \\
\text { bottom source }\end{array}$ & & & & & 150 & & & \\
\hline
\end{tabular}




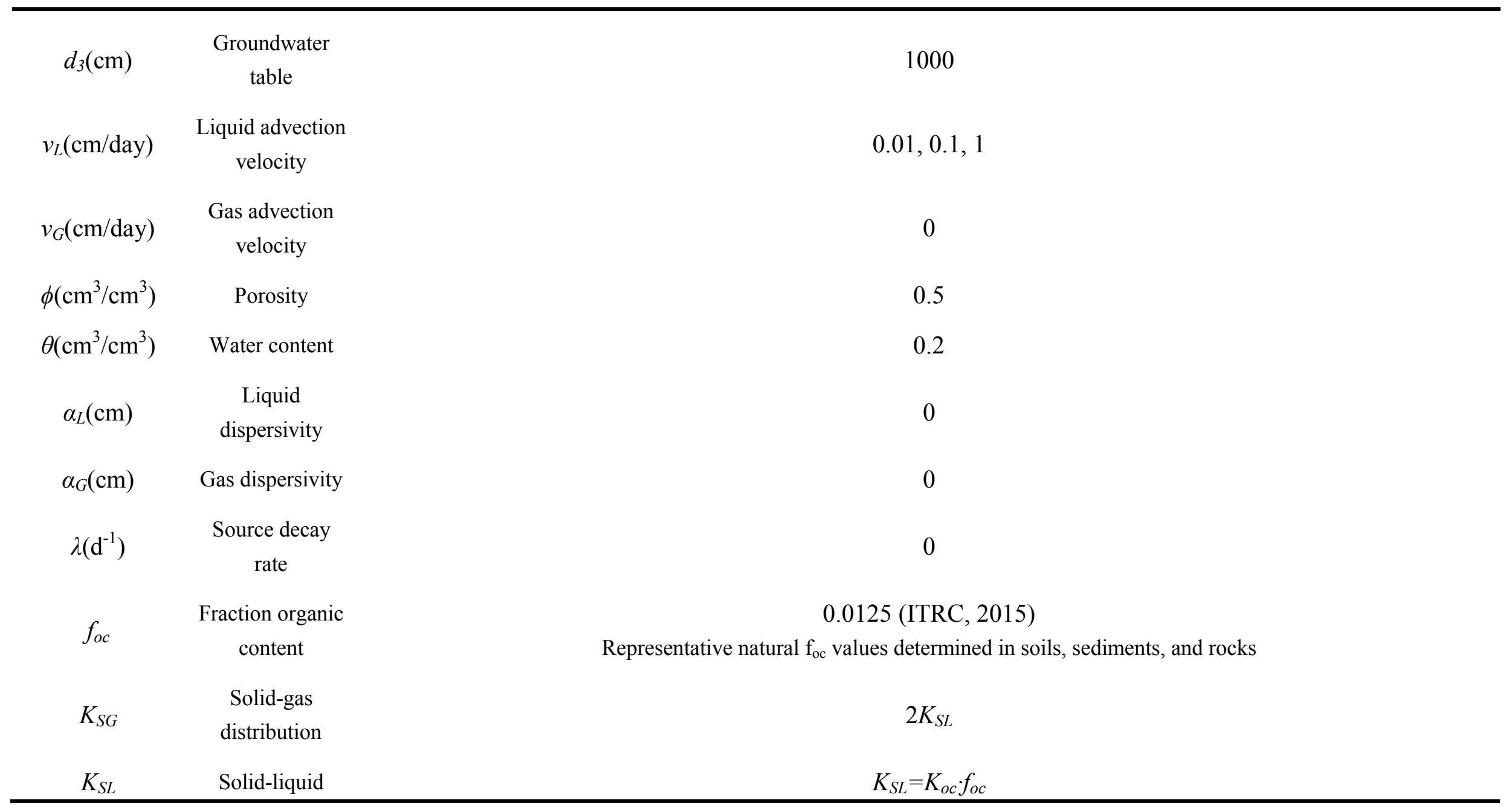




\subsubsection{Results and Discussion}

In this study, the main goal is focused in how external parameters (especially liquid advection velocity, $V_{L}$ ) and physicochemical properties work together and (or not) reinforcing one another in the organic compound transportation for the unsaturated area. For cumulative mass percentage estimated semi-logarithmic plot estimations (logarithmic time factor item in $\mathrm{X}$-axis and mass percentage in Y-axis) has been selected for an appropriate graphical representation of the results given that their estimation has been calculated for a timing range defined by the values $(t=10,100$, 1,000, 10,000 days). Under the different liquid advection velocity's conditions, (different column represents different recharge rate value), Table 4-15 shows (top row) dynamic three-phase mass percentage evolution over time and (bottom row) predicted total concentration profiles. In cumulative mass percentage figures, blue and purple dots presented the chemicals mass percentage in gas phase and in liquid phase, respectively.

Predicted concentration profile results are shown in Table 4-16, black, red and blue lines symbolize estimations in arid, semi-arid and moist area respectively. On the other hand, square, triangle, cross and null dots in predicted concentration profiles represent the organic concentration curves at 10, 100, 1,000 and 10,000 days, respectively. Solid and dash lines represent the concentration tendency under the mean and 1 sigma confidence interval concentration, respectively.

\subsubsection{Dissolved, non-volatile organic substances}

Since a critical value of liquid advection velocity is require by the model, a maximum recharge rate equal to $0.7 \mathrm{~cm} /$ day has been established for Acetophenone material. 
Chemicals adsorbed in solid phase have priority over dissolution into water because of the lower solubility of the organic substances under study (priority substances for risk analysis) and higher $f_{o c}$ (fraction organic content) value in soil. Estimated results of Acetophenone (Figure $A 1, A 2$ and $A 3$ in Table 4-15) shown that almost all compounds are absorbed in soil organic matter since the dissolution of a substance in water is not an obvious phenomenon within the first 100 days. Estimated concentration curves at 10 and 100 days (figure $a 1$ and $a 2$ ) in Table 4-16 also shown that three predicted concentration curves almost overlapping although different recharge rate conditions were considered. This implies, at least for the imposed conditions, the recharge rate does not seem to be an important factor influencing the contaminate transportation within a short time period migration.

As time goes by, substance mass in liquid phase increases rapidly until virtually all of substance is dissolved in groundwater. The comparison of results (figure $A 1, A 2$ and $A 3$ in Table 4-15) (figures $a 3, a 4$ in Table 4-16) show that the bigger value of recharge rate and the longer substances migration, the more chemicals dissolved into liquid phase what would speed up migration to the aquifer layer. Just as the recharge rate equal $0.01 \mathrm{~cm} /$ day groundwater mass percentage did not have a significant change within the assuming period, the rate takes values between 0.1 and $0.7 \mathrm{~cm} /$ day, the groundwater mass curve shows a marked rise at 4000 and 1600 days, respectively. For long-term analysis, the recharge rate plays an important role in the vertical transportation model.

Compared concentration profiles of Acetophenone under the different period migration ( $A 1, A 2$ and $A 3$ in Table 4-15), with a lower volatility, cumulative gas percentage curves (under different recharge conditions) indicate that some molecules volatilize into atmosphere with the leaking time, yet the increments in gas phase can be ignored. 
Retention factor will become progressively more important for organic chemicals transportation as time goes on, it could explain why the maximum concentration values are smaller, but the curves at 10,000 days (a4 in Table 4-16) are boarder than others which have been calculated under the shorter transportation period profiles (a1, a2 and $a 3$ in Table 4-16).

Phenol is soluble in most organic solvents. Its solubility in water is limited at room temperature but above $68^{\circ} \mathrm{C}$ it is entirely water-soluble (NCBI, n.d.). For higher solubility substances is assigned a value of $0.10 \mathrm{~cm} /$ day in the model for the maximum liquid advection velocity. In Figures $C 2$ and $C 3$ (Table 4-15) is shown how the recharge rate value has been reached, but it is also observable that in the case of $C 3$ it takes up larger timeframe ( $t=400,4,000,40,000,400,000$ days). Once possible explanation for why the concentration in groundwater is altered only in figure $C 3$ may be the fact that only considering migration in arid and semi-arid zone $\left(V_{L}=0.01 \mathrm{~cm} /\right.$ day and $V_{L}=0.10 \mathrm{~cm} /$ day) could result in a delay in the desorption phenomenon.

\subsubsection{Dissolved, volatile organic substance}

Similarly as Acetophenone material, results of Benzene (Figures B1, B2 and B3 in Table 4-15) dissolved into water also not an obvious phenomenon at the first 1,000 days for all recharge rate values. In addition, Benzene is a volatile chemical, substances in gas phase is occupied in greater proportion. The longer leakage occurred, a greater number of molecules are dissolved in groundwater or evaporated into the atmosphere.

On the assumption of arid $\left(V_{L}=0.01 \mathrm{~cm} /\right.$ day $)$ and semi-arid areas $\left(V_{L}=0.1\right.$ $\mathrm{cm} /$ day), the contaminated mass in gas phase exceeds the adsorbed contents after only one year. Three years later the volatilization growth trend slowly decreases in this dynamic equilibrium state until most of the chemical, at close to $90 \%$, volatile into atmosphere, meaning that a transfer of pollution to the atmosphere, i.e., air pollution, 
takes place. The physicochemical behavior of Benzene implies that almost all absorbed chemical is allocated into gas or liquid phase after a long period leaking. Estimations (see Figure $B 3$, Table $4-15)$ in moist areas $\left(V_{L}=1 \mathrm{~cm} /\right.$ day) prove that after 1,000 days Benzene dissolved in groundwater shows a positive trend until a dynamic equilibrium between water and vapor phase occurs. Compared the estimated results (Figure $B 1, B 2$ and B3, Table 4-15) under the different recharge rate conditions, along with the increase of precipitation (from $0.01 \mathrm{~cm} /$ day to $1 \mathrm{~cm} /$ day), the mass percentage in liquid phase would raise (from $0.1 \%$ to $55 \%$ ), but the percentage in gas would decrease correspondingly (from $90 \%$ to $45 \%$ ).

For TEX, TMB and R-Benzene, classified as volatile organic compounds, cumulative mass percentage results have similar behaviors with the corresponding Benzene ones, i.e., the longer the leaks, the less recharge, the more materials volatilize in atmosphere. For the 10,000 days results, estimated gas mass percentage in arid area $\left(V_{L}=0.01 \mathrm{~cm} /\right.$ day) of $T E X, T M B$ and $R$-Benzene reach to $82 \%, 78 \%$ and $70 \%$ above all phases, respectively; while the recharge rate value changed to $1 \mathrm{~cm} /$ day, content of TEX, $T M B$ and $R$-Benzene in gas phase decrease to $45 \%, 40 \%$ and $50 \%$, respectively.

As dissolved organic chemicals are preferentially adsorbed on the soil interface while wastewater spills along with recharge water, then materials would desorb or volatilize to others phases, and re-adsorbing, re-desorbing, re-volatilizing processes occur over and over again until eventually reach the water table or atmosphere. For volatile organic compounds, greater proportion of substances in gaseous volatilized from liquid instead of solid phase. TEX and TMB have the similar value of Henry's constants' number, but the $T M B$ has larger $k_{o c}$ value than TEX. Therefore in moist area and after 10,000 days transportation (figure D3 and E3 in Table 4-15), TMB (42\%) more firmly adsorbed on solid phase than TEX (18\%), less TMB (18\%) dissolved in liquid than $T E X(40 \%)$, and less $T M B(40 \%)$ volatilized in atmosphere $T E X(42 \%)$. 
Regarding with volatile organic compounds, usually in the case of dry soils the gas diffusion is a dominant transport mechanism (Shan and Stephens 1995), recharge rate is proportional to the migration rate and it is inversely proportional to the volatility. Despite the above, the model results show that thanks to the fact that VOCs vaporization process into gas phase is more effective than the dissolution in water process, increased ventilation in the affected area is the best method to remove VOCs in short term.

\subsubsection{Insoluble, non-volatile organic substances}

For $N A P H$, the Henry's constant value is $1.8 \mathrm{E}-02$. This explains why in interpreting the results shown in figures $(G 1, G 2)$ a part of the total of the substances enter the atmosphere for conditions of arid and semi-arid areas. However, the most of the substances are absorbed in the solid phase like $P A H s-N A P H$. As time goes on, more and more substances dissolve into liquid and eventually migrate to the aquifer.

Briefly, in this chapter, a study has been carried out of the contaminations that can occur in the different environmental compartments (vadose zone, groundwater and atmosphere) associated with leakage from the storage units of the flowback and production waters of the considered families of chemical compounds. This enables to make a comparison of the normalized behaviors of each family, but nevertheless it is not sufficient to deduce the expected toxicity by not considering the ranges of effective concentrations associated with each family. The combination of the results of this chapter with the ranges of concentrations expected in the different times obtained in section 4.2 will allow systematic studies of the expected exposures of each of the groups. That, combined with the toxicity values of each of the elements, allows hierarchizing and prioritization for evaluating environment risk and health hazard. 
Table 4-15: Cumulative Mass Percentage of Each Phase in Semi-logarithmic Plots

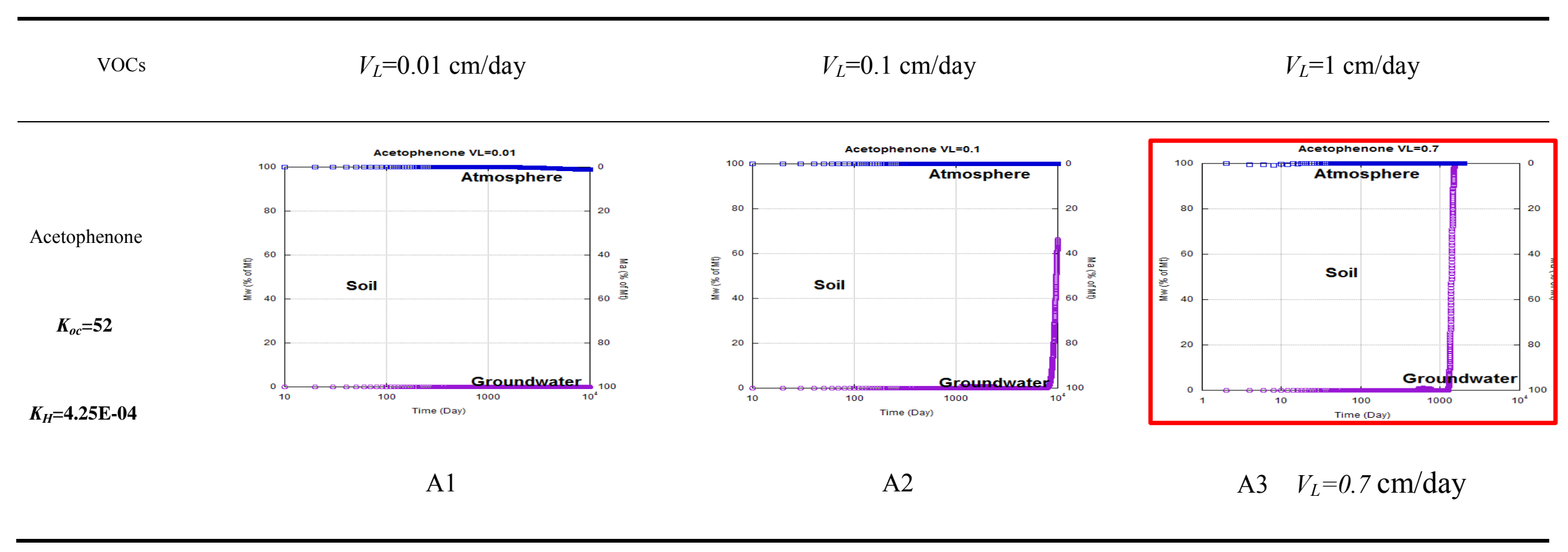




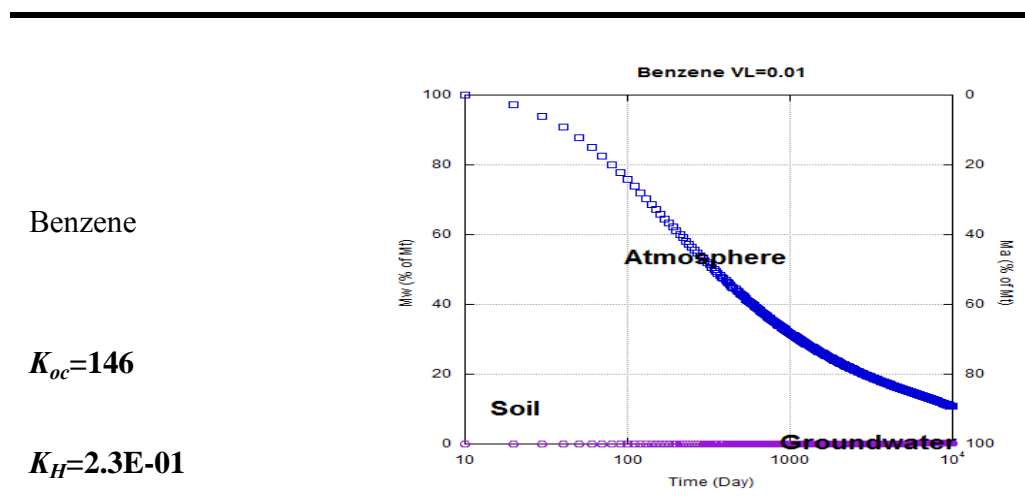

B1

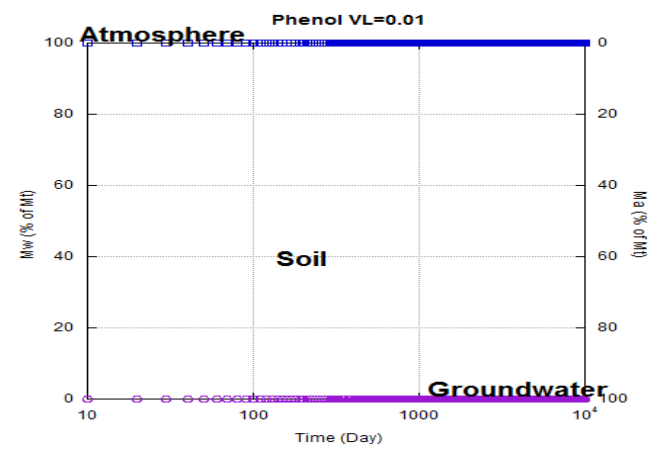

$\mathrm{C} 1$

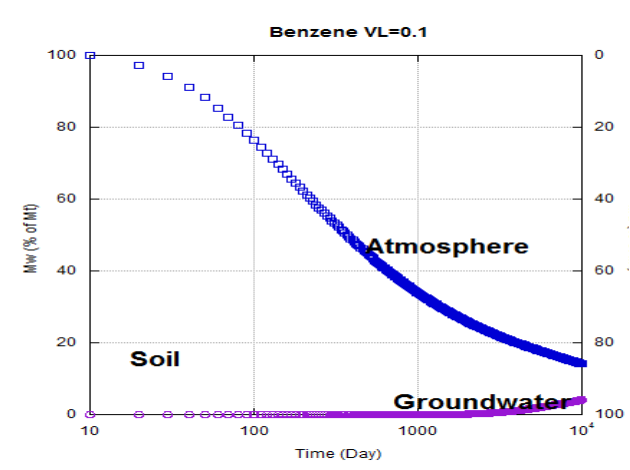

B2

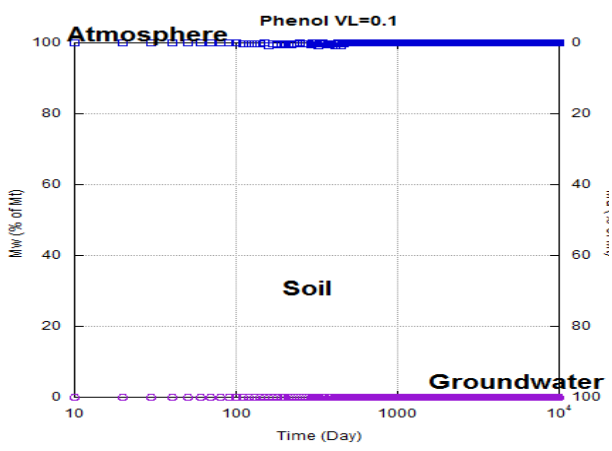

C2

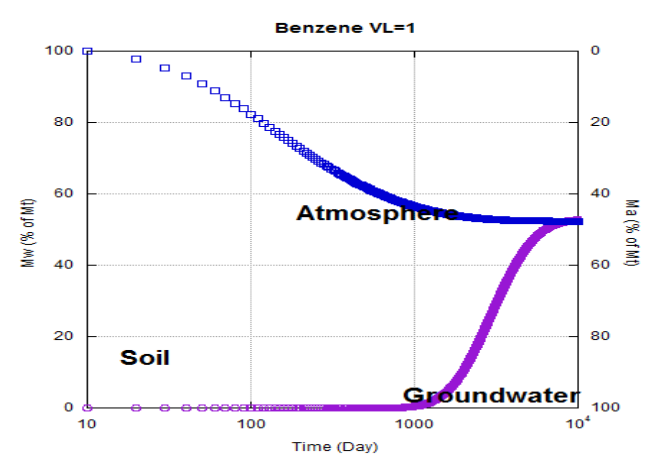

B3

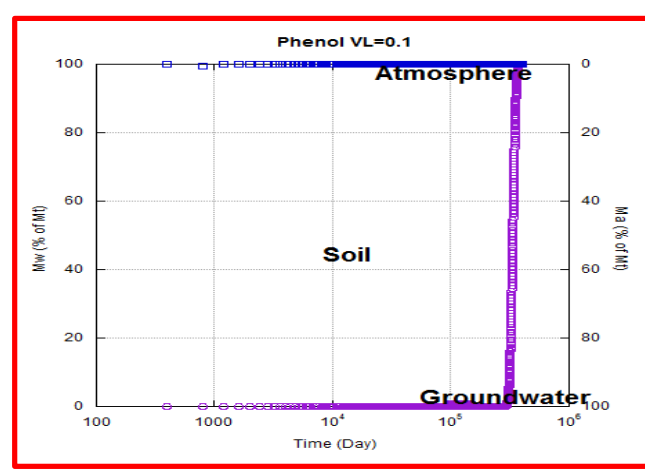

$\mathbf{C 3}\left(V_{L}=0.1 \mathrm{~cm} /\right.$ day, $t=400,4,000,40,000$, 
400,000 days)

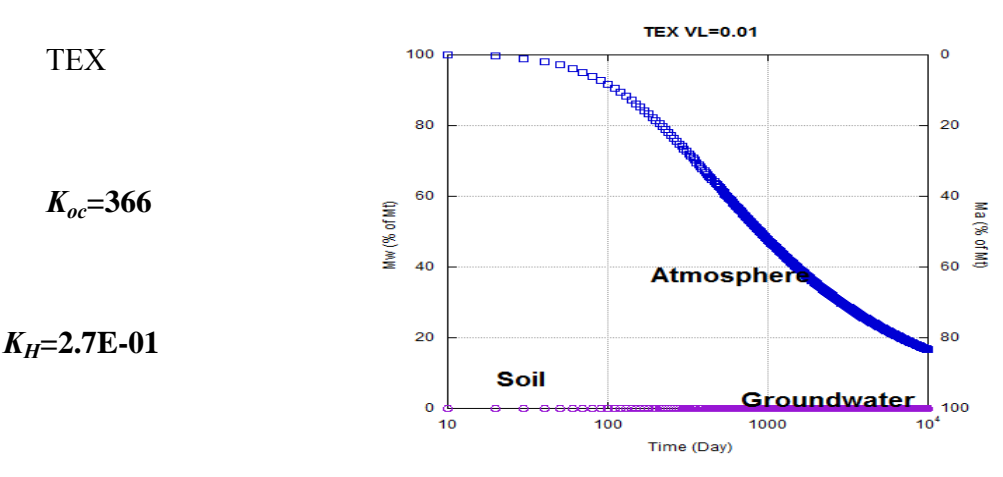

D1

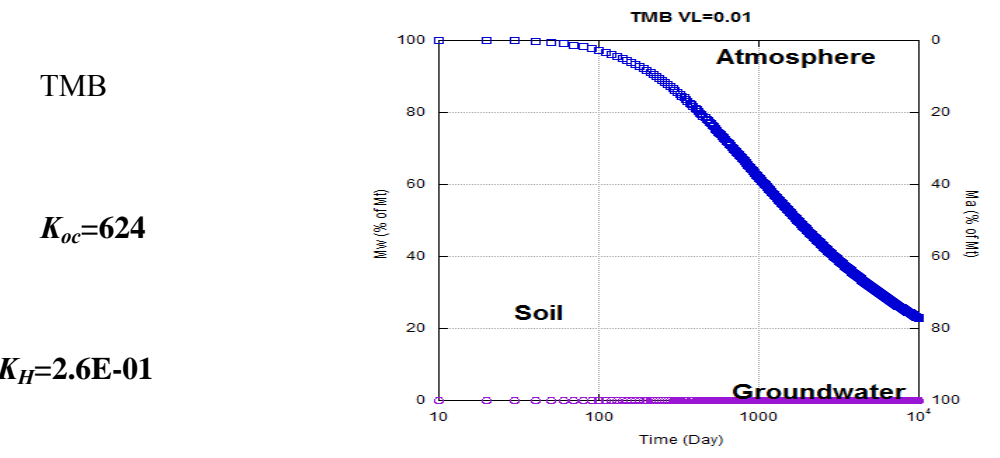

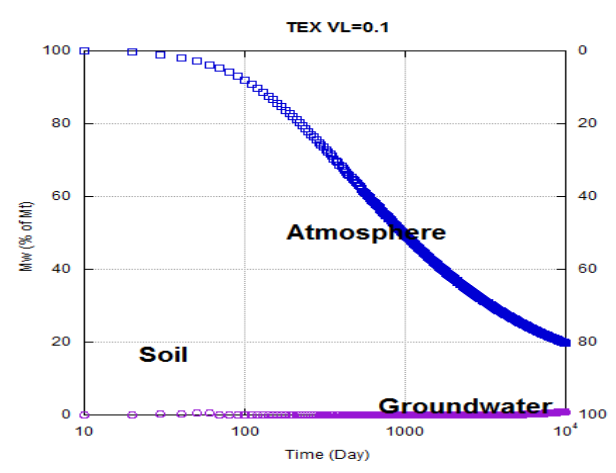

D2

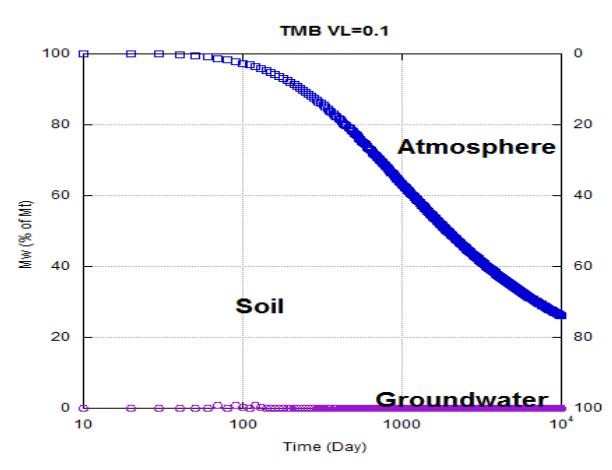

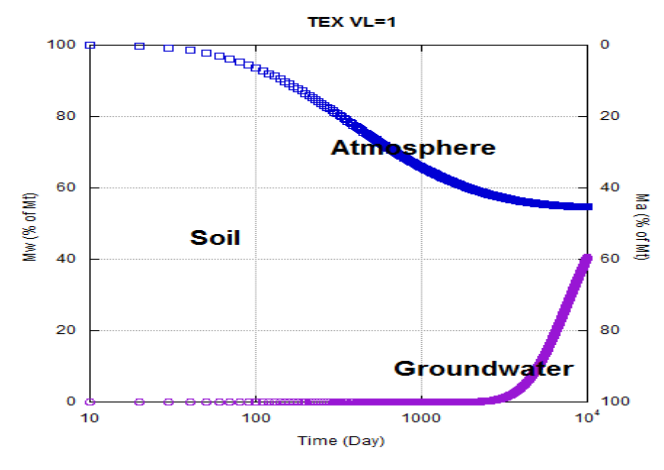

D3

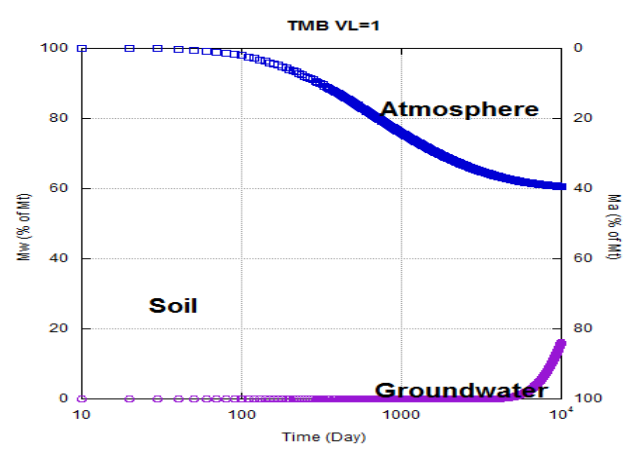




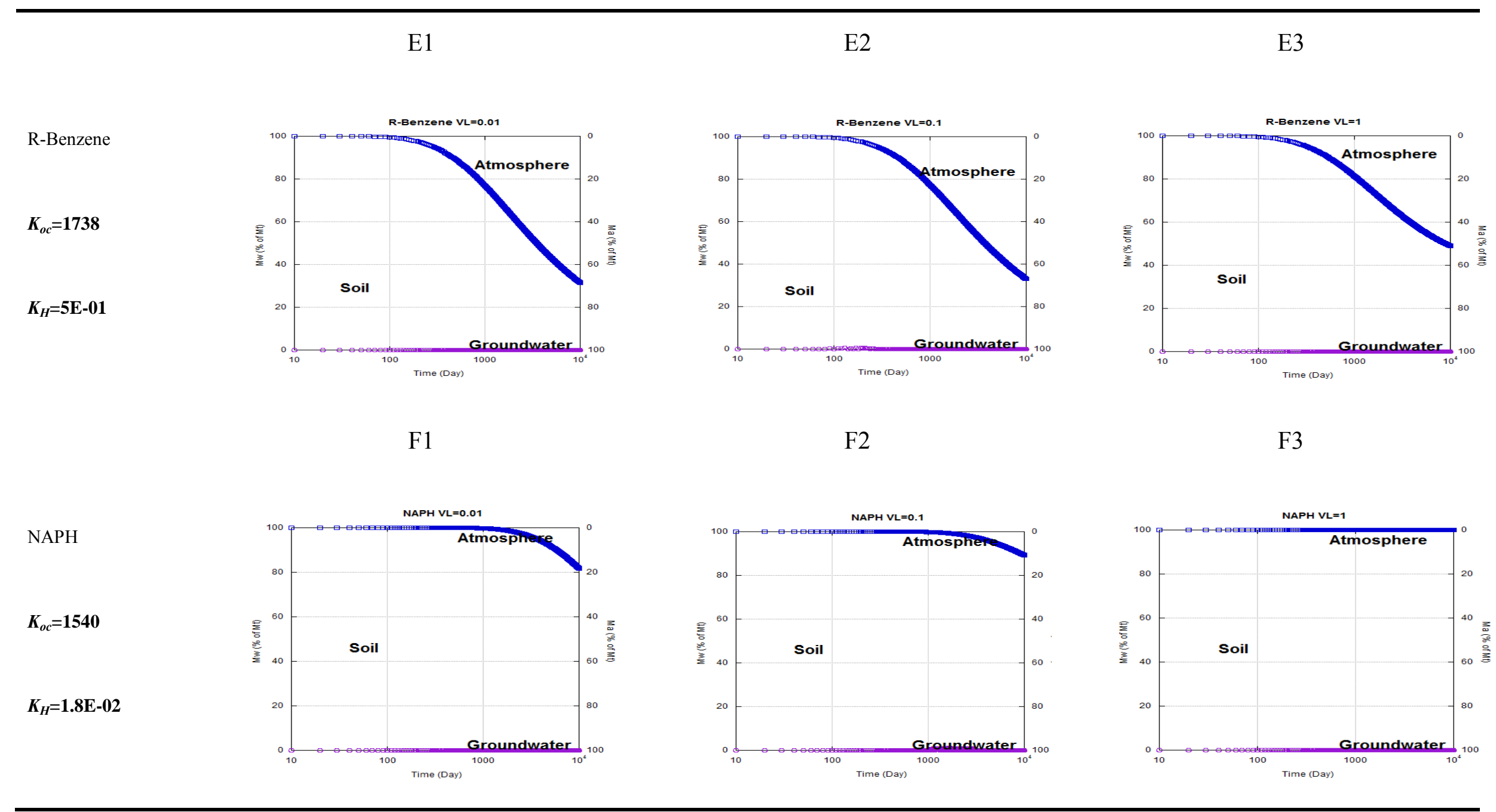


G1

PAHs-NAPH

$K_{o c}=63384$

$K_{H}=3.9 \mathrm{E}-04$

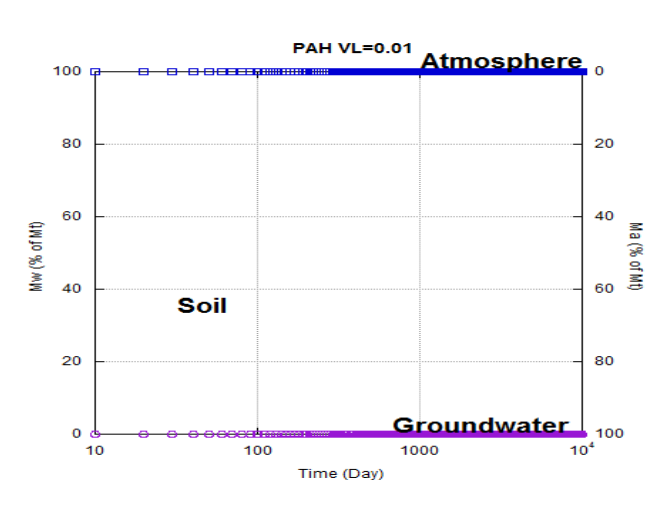

H1
G2

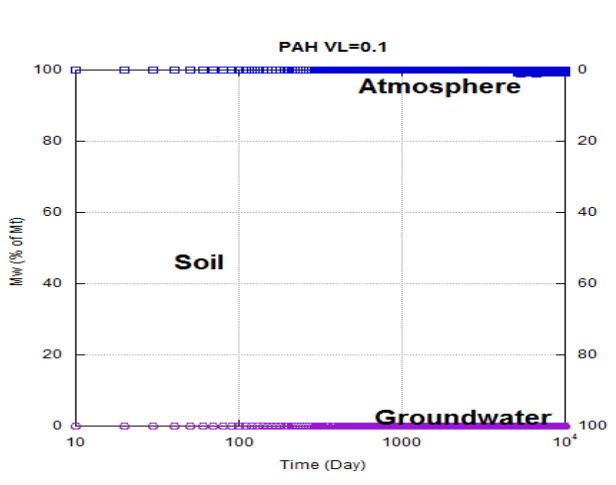

$\mathrm{H} 2$

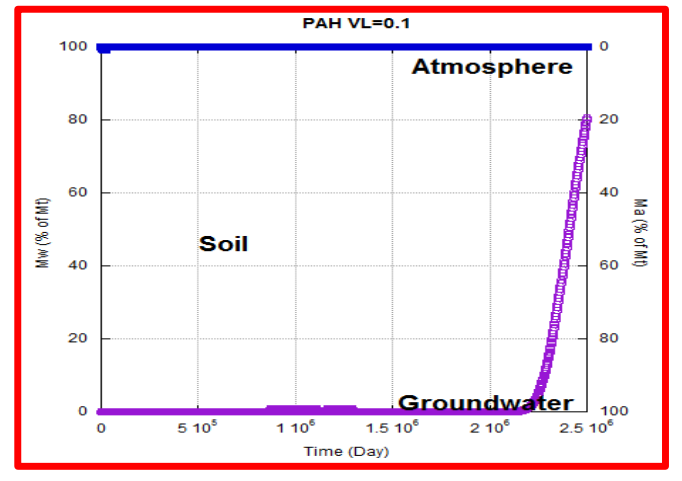

H3 $\left(V_{L}=0.1, t=2,500,25,000,250,000,2,500,000\right.$

days) 
Table 4-16: Predicted Concentration Profile over Time (estimated mean and 1 sigma concentration are represented by solid and dash lines, respectively)

Cululated concentration in solid phase over time

\section{Organic}

compounds

Acetophenone

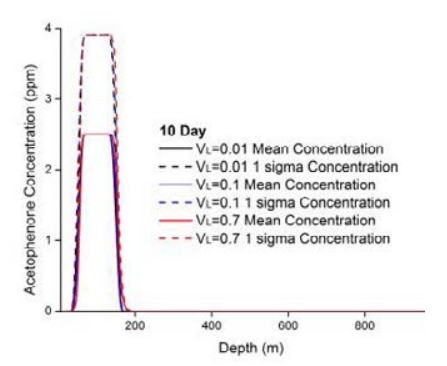

a1

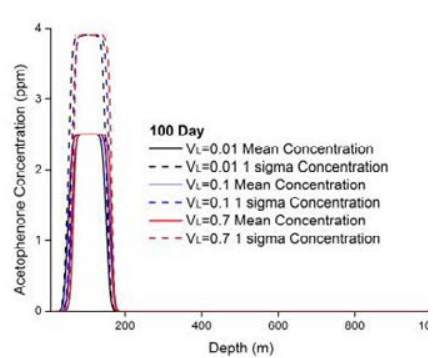

a2

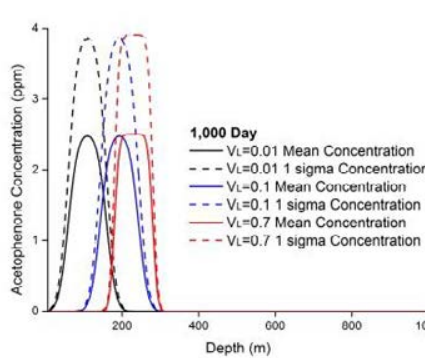

a3

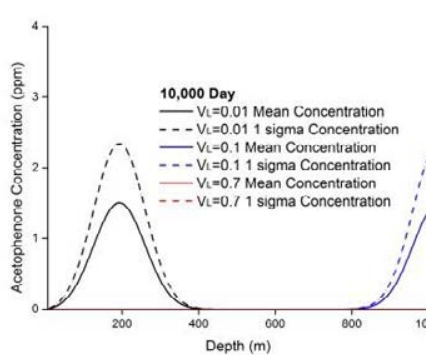

a4 


\section{Benzene}

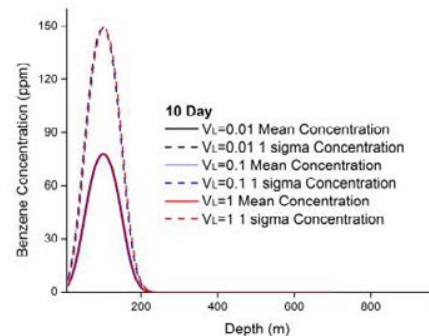

b1

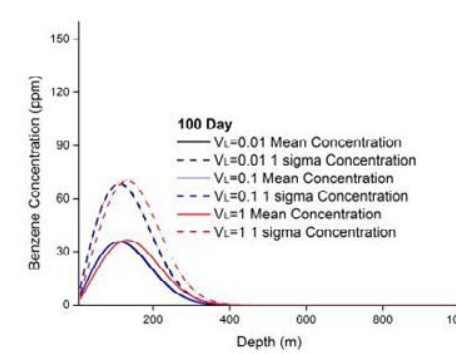

b2

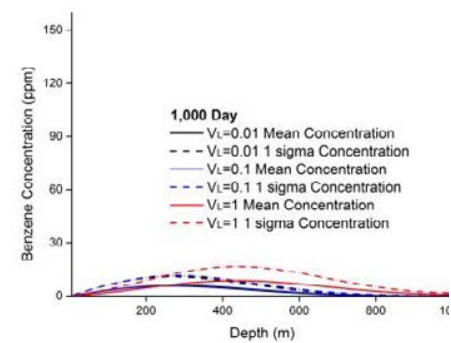

b3

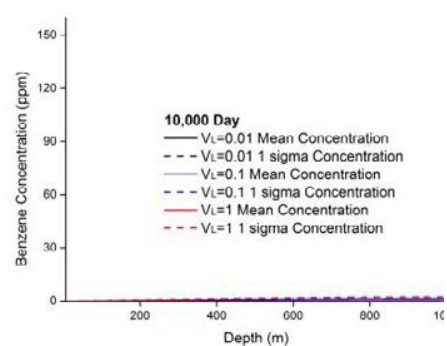

b4
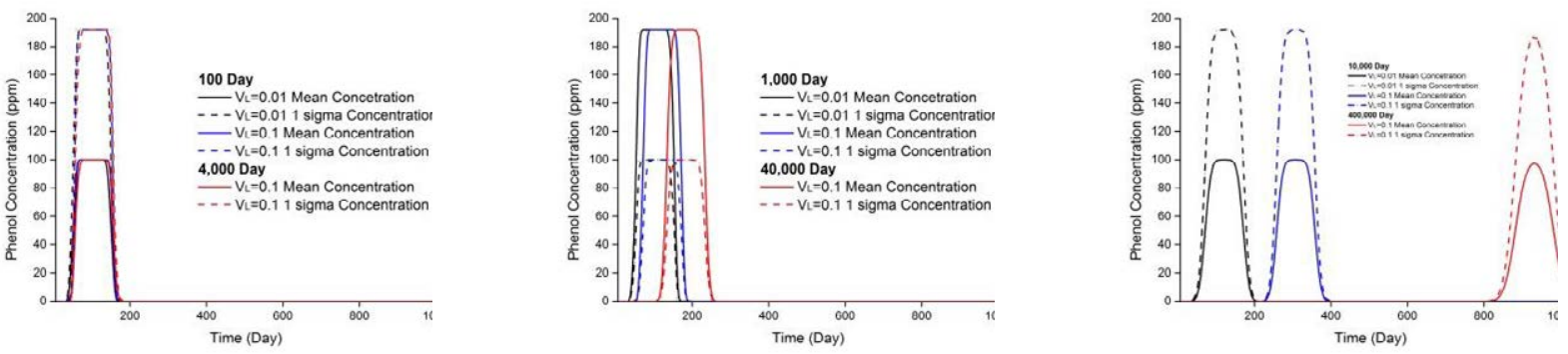

c4 
TEX

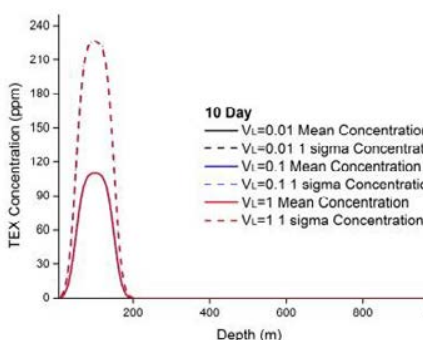

d1

TMB

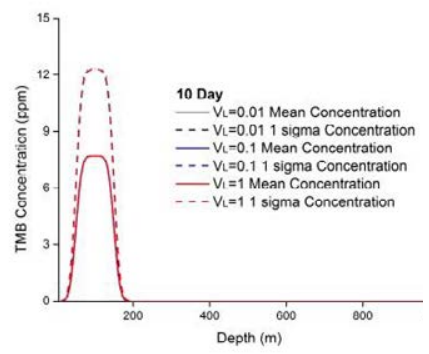

el

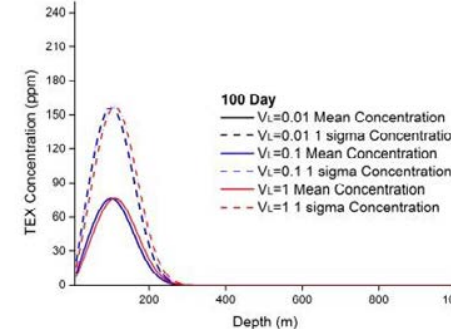

$\mathrm{d} 2$

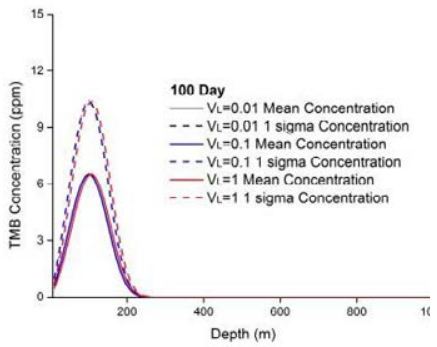

e2

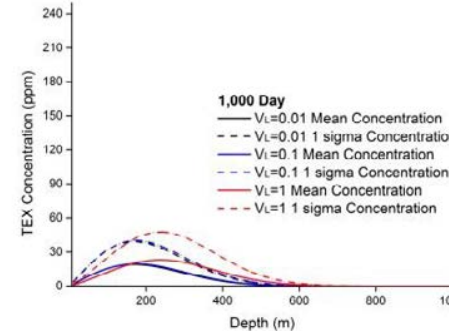

d3

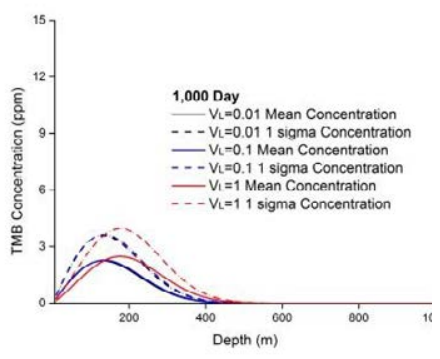

e3

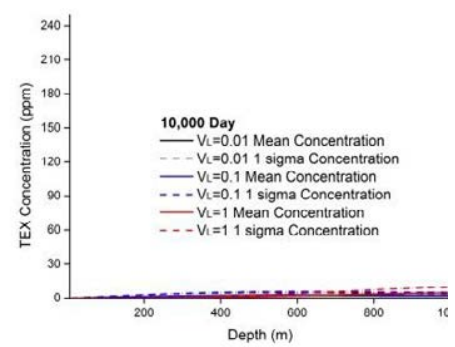

d4

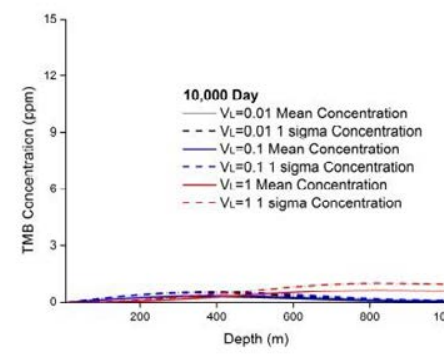

e4 
R-Benzene

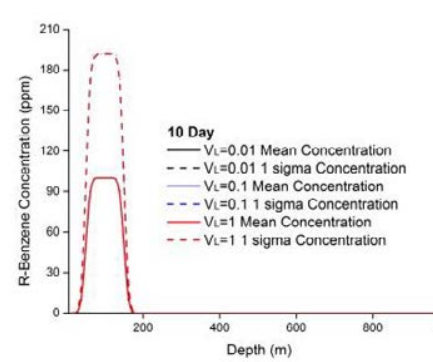

f1

NAPH

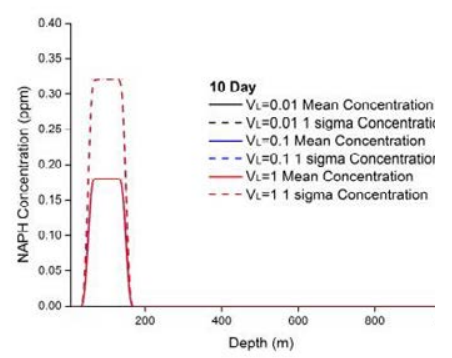

g1

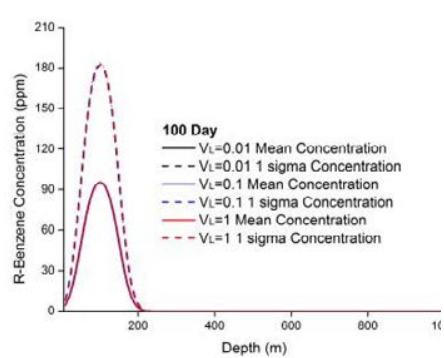

f2

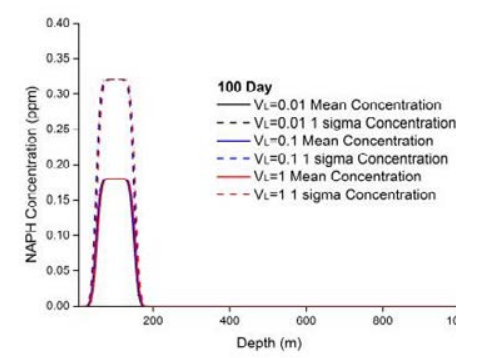

g2

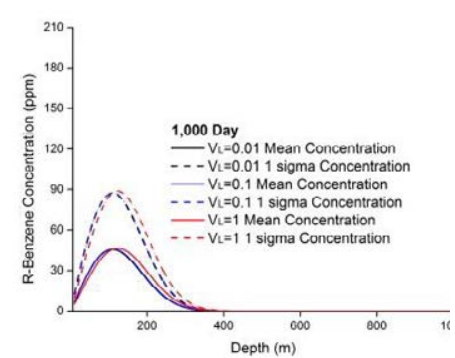

f3

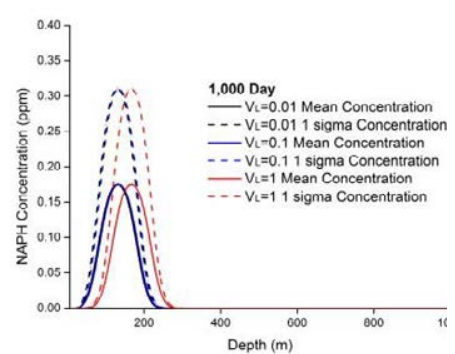

g3

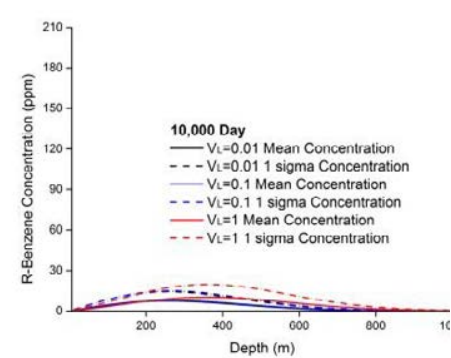

$\mathrm{f} 4$

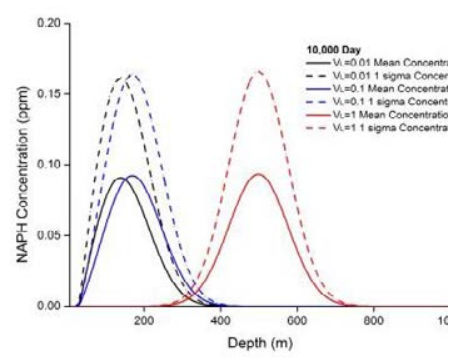

g4 


\section{PAH-NAPH}

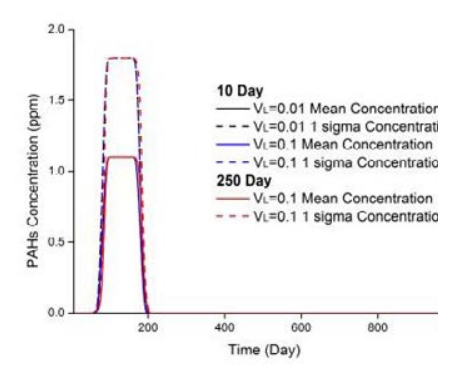

h1

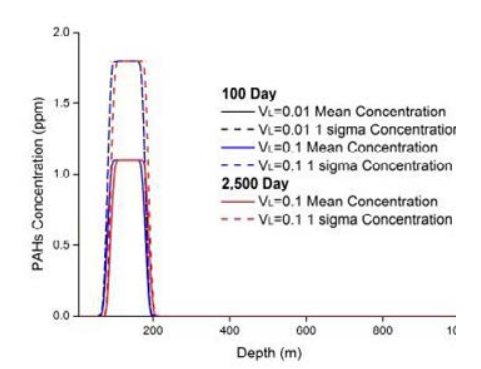

h2

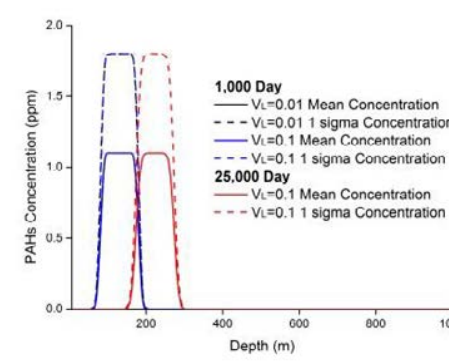

h3

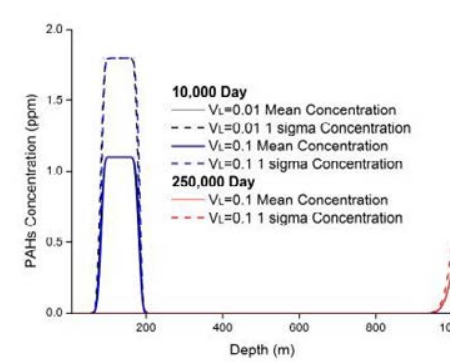

h4 


\subsubsection{Conclusion}

Hydraulic fracturing represents a fundamental technology for exploitation of unconventional gas resources. Together with unquestionable advantages of this technology tons of flowback water from the original shale formation plus additives, which contain many toxic organic compounds are disposed on a surface storage before its final fate. Given the possibility of leaks arising from malpractice or any other event it surges the responsibility to manage the impacts for surrounding environment from a double perspective: in a predictive way (risk assessment) and in a reactive way against an already materialized risk. The main purport of this analysis was to determine an analytical model that could explain one-dimensional vertical leakage behavior of organic compounds in wastewater through vadose zone to the aquifer. Analytical solution was used for predicting how the recharge rate impact on various organic compounds of cumulative mass percentage curves in each phase and migrated concentration curves in the vadose zone.

The determination of pollutant concentration in surface wastewaters storage structures require the temporal evolution of both, volume of flowback returned to surface and pollutant concentration in this water. Based on horizontal wells' volumes empirical expression model and predicting organic compounds concentration model, within 1,000 days organic chemicals' maximum concentration in tank had been calculated.

Predicted results are graphically represented through semi-logarithmic cumulative mass percentage curves for each phase and total concentrations curves in arid, semi-arid and humid areas. Given that the interest of the study is focused in organic compounds and in vadose zone, assuming there is a higher value of fraction of organic carbon, the mass percentage results show that virtually all organic compounds whose behavior has been modeled and analyzed, and for the conditions imposed in the 
study are adsorbed in solid phase at the initial stage (i.e. within the interval of the first 100 days). Even more, the recharge rate factor has a limited effect as desorption phenomenon in the short-term period. There is no doubt that more and more substances would dissolve into the liquid phase as time increases. The higher value of external recharge rate and water solubility of organic compounds, the faster the organic compounds are dissolved and migrate to the aquifer. In this model, Henry's constant and recharge rate are both key parameters in the assessment of the cumulative mass percentage in atmosphere. Under the same conditions, comparison of the curves of gas percentage from different compounds allows to understand and conclude that to a greater number of substances with a high number of Henry's constant greater volatility into the gas phase. For a certain volatile organic compounds, a minor amount of constitutes in atmosphere is produced in moist area compared with the gas mass percentage value in the arid zone.

This model is not only a tool to simulate and understand the one-dimensional vertical transportation behavior of volatile organic chemicals through the vadose zone to the groundwater, but also allow to (1) promote greater understanding of the mechanism by which external environmental variables (especially recharge rate) affect organic compounds migration in the vadose zone; (2) predict chemical concentration tendencies under the different conditions; (3) draw the alarm residences' risk line directly in the estimated concentration profiles via the organic toxic value; (4) acquaint which phases of contamination would have a greater impact on human health, and (5), but not less, establish an estimate of the time that chemicals could remain in the contaminated areas. Contamination concentration in solid and water table tendencies, mass percentage in different phases had been calculated,

Furthermore, risk assessment model would allow for estimating of which and to what extent organic compounds could have a negative impact on the health of humans. Therefore, and in summary, these are studies with an important potential contribution in 
the improvement of techniques for the safe exploitation of shale gas resources, in the optimization of Health, Safe and Environmental (HSE) risk assessment at local and larger scales and in providing experience for other cases or similar situations.

Semi-logarithmic plot for cumulative mass percentage estimations (logarithmic time factor item in $\mathrm{X}$-axis and mass percentage in $\mathrm{Y}$-axis) has been selected for an appropriate graphical representation of the results given that their estimation has been calculated for a long-term perspective defined by the values $(t=10,100,1,000,10,000$ days) so that the behaviors of the different compounds considered can be described. Under the different liquid advection velocity's conditions (different column represents different recharge rate value), Table 4-15 shows dynamic three-phase cumulative mass percentage evolution over time and Table 4-16 shows predicted total concentration profiles. 


\section{Conclusions}


The core aim of this study was to determine a model to adjust the whole transport process of organic compounds in shale formation during horizontal hydraulic fracturing operation life-cycle in order to predict their potential impacts on Health, Safe and Environmental (HSE) risks. A comprehensive model, combining an Organic Matter Transport Dynamic Model (including convection, diffusion, dispersion, desorption, adsorption and retention reaction in shale formations) and a Two-Compartment First-order Rate Constant (TFRC) Model in desorption profile, has been established. The conclusions drawn are the following:

- In order to test and verify whether the model could reflect the concentration change in a fracturing situation or not, data on organic concentration in flowback water from the West Virginia and Pennsylvania Marcellus Shale were chosen. A double speed desorption process has been identified, which implies the existence of two parameters associated with it $-k_{\text {fast }}$ and $k_{\text {slow }}{ }^{-}$, over the whole transportation process. The first 14-days concentration data can be explained using the fast-desorption part in transportation model. Two-thirds of the fitting values of determination coefficient $\left(R^{2}\right)$ were more than 0.9 , and in some chemicals the determination coefficient even reached to 0.99. This means a high experimental feasibility of this model in order to predict the concentration evolution of analyzed compounds.

- Based on the slow transportation part, we are able to estimate forecast concentration tendencies of relevant chemicals in the long term. Under our analysis situation, characterized by a paucity of data for this process, Monte-Carlo methods succeeded in solving problems dealing with a probabilistic interpretation. The results, as reflected by concentration curves, indicated that different organic compounds, which had the higher $k_{o c}$ value, would be the last to reach peak concentration and the phenomenon could be explained by the retention factor theory during transportation 
process. Finally, under our analysis conditions, the maximum concentration in wastewater would reach up to $90 \%$ of the total slow desorbing chemical concentration $\left(C_{0 \_ \text {slow }}\right)$.

- It should also be concluded that there are some limitations in our research. This model can be more precisely improved if a larger amount of data from different locations and longer monitoring is available allowing the model to be updated to reflect a more realistic situation. In the narrow sense, there are some reducing concentration processes that have not been considered in the model, such as degradation and decay reaction for organic chemicals, as, in fact, biocides are added to control bacterial growth in the formation and in surface production equipment. Nevertheless, these processes do not seem to be necessary in the fast transportation part, given the good adjustment obtained. However, they may be necessary during the slow part. The scarcity of data for this period does not allow its evaluation. From the point of view of the risks, failure to consider these processes implies a conservative approach in favor of safety, as these would result in an expected decrease in the concentration of the substances analyzed. However, it has to be noted that from the point of view of operation, the situation is the opposite. Failure to consider them could lead to unnecessarily increased costs to meet regulations.

- From the point of view of potential leaks from surface storages due to malpractices or any other event, the main objective was to determine an analytical model that could explain one-dimensional vertical leakage behavior of organic compounds in wastewater through vadose zone in arid, semi-arid and humid areas to the aquifer. An analytical solution was used for predicting how the recharge rate impacts on various organic compounds of cumulative mass percentage curves in each phase and migrated concentration curves in the vadose zone. The conclusions drawn are the following:

$\circ$ The previous model allows estimating the volume of each compound accumulated in surface storage, namely tanks or ponds, over time. In this way 
the evolution of the effect of a possible leakage of the surface storage as a function of time can be studied.

- Given that the study is focused in organic compounds in the vadose zone, assuming there is a higher value of fraction of organic carbon there, the mass percentage results show that virtually all organic compounds whose behavior has been modeled and analyzed for the conditions imposed in the study are adsorbed in solid phase at the initial stage (i.e. within the interval of the first 100 days and under the assumptions of this study, the compounds would not have reached the groundwater level, which would lead to an easier mitigation or minimization treatment). Even more, the recharge rate factor has a limited effect in the short-term period. There is no doubt that more and more substances would dissolve into the liquid phase as time increases. The higher the values of external recharge rate and water solubility of organic compounds, the faster the organic compounds are dissolved and migrate to the aquifer. In this model, Henry's constant and recharge rate are both key parameters in the assessment of the cumulative mass percentage in atmosphere. Under the same conditions, comparison of the curves of gas percentage from different compounds allows to understand and conclude that to a greater number of substances with a high number of Henry's constant greater is the volatility into the gas phase. For a certain volatile organic compounds, a minor amount of constitutes in atmosphere is produced in the moist area compared with the gas mass percentage value in the arid zone.

○ This model represents not only a tool to simulate and understand the one-dimensional vertical transportation behavior of volatile organic chemicals through the vadose zone to the groundwater, but also allow to (1) promote greater understanding of the mechanism by which external environmental variables (especially recharge rate) affect organic compounds migration in the vadose zone; (2) predict chemical concentration tendencies under the different 
conditions; (3) provide the necessary data for Dose Estimation in the risk analysis for the affected area-dwelling population; (4) acquaint which phases of contamination would have a greater impact on human health; and (5) establish an estimate of the time that chemicals could remain in the contaminated areas.

Therefore, and as a global conclusion, it can be established that:

- The combination of a series of data and tools, such as drilling samples, local geological information, and a set of comprehensive models (including organic concentration changing in hydraulic fracturing wastewater model, flowback volume model, VOCs vertical transportation model, and risk assessment model) would allow the predictive estimation of which and to what extent organic compounds could, finally, represent a negative impact on human health. In summary, these are research studies with an important potential contribution in the improvement of techniques for the safe exploitation of shale gas resources, in the optimization of HSE risk assessment at different spatial and temporal scales and in providing experience for other cases or similar situations. 


\section{FUtURe Works}


Further research will be focus in the following lines:

- Although the concentration model has been successfully established, it could be improved which requires more data, especially from the slow process, as long as more information will be available from different locations and longer-term monitoring with shorter intervals than those available for the present work. This would allow the introduction of the degradation and decay action for organic chemicals, which means an improvement of the model since it would reflect a more realistic situation.

- Expand research on the contamination affectation in the different environmental compartments according to the characteristics of different types of soils.

- Study of the effect of the parameters associated to the physical model of hydraulic fracturing on the behavior of the chemical compounds under study and their impact in the return waters as well as the establishment of the minimum geological characterization required.

- Combine the risk assessment methodology (which include the concepts of application of the Threshold Limit Value for each compound or family of compounds) with a complete model that captures the connections between evolution in organic compound concentrations from shale formations to the different spatial and temporal scales of affectation could be established. This integral model could assess predictively health, safety and environmental risks and provide experience to other future operations. 


\section{REFERENCES}

Abualfaraj, N.; Gurian, P. L. and Olson, M. S. (2014). Characterization of Marcellus Shale Flowback Water. Environmental Engineering Science. September 2014, 31(9): 514-524. doi:10.1089/ees.2014.0001.

ACIEP (2013). Evaluación preliminar de los Recursos Prospectivos de Hidrocarburos Convencionales y No Convencionales en España.

Akob, D.M.; Cozzarelli, I.M.; Dunlap, D.S.; Rowan, E.L.; Lorah, M.M. (2015) Organic and inorganic composition and microbiology of produced waters from Pennsylvania shale gas Wells. Applied Geochemistry. Volume 60, September 2015, Pages 116-125.

Alonso Suárez, Alejandro (2012). The Expansion of Unconventional Production of Natural Gas (Tight Gas, Gas Shale and Coal Bed Methane), Advances in Natural Gas Technology, Dr. Hamid Al-Megren (Ed.), InTech, DOI: 10.5772/37404. Available

from: https://www.intechopen.com/books/advances-in-natural-gas-technology/the-exp ansion-of-unconventional-production-of-natural-gas-tight-gas-gas-shale-and-co al-bed-methane-

Álvarez, E.; Álvarez, N.; Suárez, C. (2016). Shale Gas, Strategic, technical, environmental and regulatory issues. Cuadernos Orkestra 2016/16 ISSN 2340-7638.

Álvarez-Fernández I, Arenillas-González A, Cayola-Cortés FJ, Cienfuegos-Suárez P, García de la Noceda-Márquez $\mathrm{C}$, Loredo-Pérez J, Martínez-Orio R, Mazadiego-Martínez LF, Vázquez-Teijeira D, Vicuña-Irusta JC and Tarín-Egoscozabal I. (2013). Gas no convencional en España, una oportunidad de futuro. Informe del Consejo Superior de Colegios de Ingenieros de Minas. Cámara Rascón, Á.; Pendás Fernández, F. (Eds.) 2013.

Balaba, R. and Smart, R.B. (2012). Total arsenic and selenium analysis in Marcellus shale, high-salinity water, and hydrofracture flowback wastewater. Chemosphere 89(11):1437-42. July 2012.

Balashov, V. N.; Engelder, T.; Gu, X.; Fantle, M. S.; Brantley, S. L. (2015). A model describing flowback chemistry changes with time after Marcellus Shale hydraulic fracturing. AAPG Bulletin, 99(1), 143-154. http://doi.org/10.1306/06041413119

Barbot, E.; Vidic, N.; Gregory, K.; Vidic, R. (2013). Spatial and temporal correlation of water quality parameters of produced waters from devonian-age shale following 
hydraulic fracturing. Environmental Science and Technology, 47, 2562-2569. Retrieved from http://dx.doi.org/10.1021/es304638h

Barnier, C.; Ouvrard, S.; Robin, C.; Morel, J. L. (2014). Desorption kinetics of PAHs from aged industrial soils for availability assessment. The Science of the Total Environment, 470-471, 639-45. http://doi.org/10.1016/j.scitotenv.2013.10.032

Bear, J. and Bachmat Y. (1990). Introduction to modeling of transport phenomena in porous media. Kluwer Academic Publishers. ISBN 978-0-7923-1106-5.

Bear, J. and Bachmat, Y. (1990) Introduction to Modeling of Transport Phenomena in Porous Media. Springer Netherlands. eBook ISBN 978-94-009-1926-6. DOI 10.1007/978-94-009-1926-6.

Bear, J., and Verruijt, A. (1987). Modeling Groundwater Flow and Contaminant Transport. http://doi.org/10.1007/978-94-009-3379-8

Birdwell, J.; Cook, R. L. and Thibodeaux, L. J. (2007). Desorption kinetics of hydrophobic organic chemicals from sediment to water: a review of data and models. Environmental Toxicology and Chemistry / SETAC, 26(3), 424-434.

Bloomdahl, R.; Abualfaraj, N.; Olson, M.,; Gurian, P. L. (2014). Assessing worker exposure to inhaled volatile organic compounds from Marcellus Shale flowback pits. Journal of Natural Gas Science and Engineering, 21, 348-356. http://doi.org/10.1016/j.jngse.2014.08.018

Boyce, M. and Carr, T., (2009). Lithostratigraphy and Petrophysics of the Devonian Marcellus Interval in West Virginia and Southwestern Pennsylvania: http://www.unconventionalenergyresources.com/marcellusLithoAndPetroPaper. $\underline{\mathrm{pdf}}$

Boyer, C.; Clark, B.; Jochen, V.; Miller, C.K. (2011). Shale Gas: A Global Resource. Oilfield Review 23(3):28-39. September 2011.

Bracht, R.O. (2010). Geochemistry and depositional environment of The Union Springs Member of the Marcellus Shale In Pennsylvania. The Pennsylvania State University. Master Thesis.

Brantley, H.S.; Thoma, E.D. and Eisele, A.P. (2015). Assessment of volatile organic compound and hazardous air pollutant emissions from oil and natural gas well pads using mobile remote and on-site direct measurements. J Air Waste Manag Assoc. 2015 Sep; 65(9):1072-82.

Broomfield M. (2012) Support to the identification of potential risks for the environment and human health arising from hydrocarbons operations involving 
hydraulic fracturing in Europe. Report for European Commission. AEA reference: Ref: AEA/R/ED57281- Issue Number 17. 2012.

Bruner Kathy R. and Smosna Richard. (2011) A Comparative Study of the Mississippian Barnett Shale, Fort Worth Basin, and Devonian Marcellus Shale, Appalachian Basin. U.S. Department of Energy DOE/NETL-2011/1478. April 2011.

Budzik, P. and Ford, M. (2014). Oil and natural gas resource categories reflect varying degrees of certainty. U.S. Energy Information Administration, July 17, 2014. https://www.eia.gov/todayinenergy/detail.php?id=17151

Bunch, A. G.; Perry, C. S.; Abraham, L.; Wikoff, D. S.; Tachovsky, J. A.; Hixon, J. G.; Urban, J.D.; Harris, M.A.; Haws, L. C. (2014). Evaluation of impact of shale gas operations in the Barnett Shale region on volatile organic compounds in air and potential human health risks. Science of the Total Environment, 468-469, 832842. http://doi.org/10.1016/j.scitotenv.2013.08.080

Bunger, A.P.; McLennan J. and Jeffrey R. (Eds.) (2013) "Effective and Sustainable Hydraulic Fracturing” ISBN 978-953-51-1137-5, 1072 pages. Publisher: InTech. DOI: $10.5772 / 45724$ May 2013.

CIWEM. (2016) Shale Gas and Water 2016. An independent review of shale gas extraction in the UK and the implications for the water environment. February 2016.

Chen, S. S., Sun, Y., Tsang, D. C. W., Graham, N. J. D., Ok, Y. S., Feng, Y., \& Li, X. D. (2017). Potential impact of flowback water from hydraulic fracturing on agricultural soil quality: Metal/metalloid bioaccessibility, Microtox bioassay, and enzyme activities. Science of the Total Environment, 579, 1419-1426. http://doi.org/10.1016/j.scitotenv.2016.11.141

Colborn, T.; Kwiatkowski, C.; Schultz, K.; Bachran, M. (2011) Natural Gas Operations from a Public Health Perspective. Hum. Ecol. Risk Assess. 2011, 17 (5), 1039-1056.

Cornelissen, G., Noort, P.C.M.V., Parsons, J.R., Govers, H.A.J., (1997) Temperature dependence of slow adsorption and desorption kinetics of organic compounds in sediments. Environ. Sci. Technol.(1997) 31 (2), 454-460.

Davis, J. P., Struchtemeyer, C. G., \& Elshahed, M. S. (2012). Bacterial Communities Associated with Production Facilities of Two Newly Drilled Thermogenic Natural Gas Wells in the Barnett Shale (Texas, USA). Microbial Ecology, 64(4), 942-954. http://doi.org/10.1007/s00248-012-0073-3 
Deloitte-Aciep (2014) Análisis del impacto del desarrollo de la exploración y producción de hidrocarburos en la economía española. Febrero 2014.

DNV (2013) "Risk Management of Shale Gas Developments and Operations" Recommended Practice DNV-RP-U301. January 2013.

EIA. (2011). Review of Emerging Resources: U.S. Shale Gas and Shale Oil Plays. Energy, (July), 105. Retrieved from ftp://ftp.eia.doe.gov/natgas/usshaleplays.pdf

EIA. (2013). EIA/ARI World Shale Gas and Shale Oil Resource Assessment, (June), 707. Retrieved from http://www.adv-res.com/pdf/A_EIA_ARI_2013 World Shale Gas and Shale Oil Resource Assessment.pdf

EIA (2015) Annual Energy Outlook 2015 with projections to 2040. DOE/EIA-0383(2015) April 2015. https://www.eia.gov/outlooks/aeo/

Elhaddad, E. (2012) Sorption and Desorption Processes of Organic Contaminants on Carbonaceous Materials. Dissertation zur Erlangung des akademischen Grades Doktor der Naturwissenschaften. Technischen Universität Darmstadt.

Elliott, E. G., Ettinger, A. S., Leaderer, B. P., Bracken, M. B.,; Deziel, N. C. (2016). A systematic evaluation of chemicals in hydraulic-fracturing fluids and wastewater for reproductive and developmental toxicity. Journal of Exposure Science and Environmental Epidemiology, (May 2015), 1-10. http://doi.org/10.1038/jes.2015.81

Energy Information Administration. (1999). Natural Gas 1998 Issues and Trends. U.S. Department of Energy, DOE/EIA-0560(98). April 1999. www.eia.doe.gov/oil_gas/natural_gas/analysis_publications/natural_gas_1998_i ssues_and trends/it98.html

EPA Title 40: Protection of Environment. Part 435 - Oil and gas extraction point source category (2013).

http://www.ecfr.gov/cgi-bin/text-idx?c=ecfr\&sid=b8fed7acf50261521a80ea807 ee5 $\mathrm{cf} 2 \mathrm{a} \& \mathrm{rgn}=\operatorname{div} 5 \&$ view $=$ text $\&$ node $=40: 31.0 .1 .1 .11 \& \mathrm{idno}=40 \#$ top.

ERI/ARI (2013) World Shale Gas and Shale Oil Resource Assessment. Technically Recoverable Shale Gas and Shale Oil Resources: An Assessment of 137 Shale Formations in 41 Countries Outside the United States. Prepared for: U.S. Energy Information Administration \& U.S. Department of Energy. Prepared by: Advanced Resources International, Inc. 4501 Fairfax Drive, Suite 910, Arlington, VA 22203 USA. P: 703.528.8420 | http://www.adv-res.com. June 2013. Last updated: September 24, 2015.

ESC (Energy Science Center of ETH Zürich) (2014). Shale Gas and Fracking: State of 
the Art. Workshop and panel discussion organized by the Energy Science Center of ETH Zürich, under the auspices of the Swiss Gas \& Water Industry Association and the Swiss Competence Center for Energy Research SoE Wednesday, April 2014.

European Parliament (2011), 'The Impact of Shale Gas and Shale Oil Extraction on the Environment and Public Health', Report from Policy Department A: Economic and Scientific Policy, Directorate General for Internal Policies.

Ewen, C.; Borchardt, D.; Richter, S.; Hammerbacher R. (2012) "Hydrofracking Risk Assessment Executive Summary" Panel of experts. Study Status Conference that was held in Berlin, Germany on 6 and 7 March 2012. ISBN 978-3-00-038263-5. April 2012.

Field, R. A.; Soltis, J.; McCarthy, M. C.; Murphy, S.; Montague, D. C. (2015). Influence of oil and gas field operations on spatial and temporal distributions of atmospheric non-methane hydrocarbons and their effect on ozone formation in winter. Atmospheric Chemistry and Physics, 15(6), 3527-3542. http://doi.org/10.5194/acp-15-3527-2015

Field, R. A.; Soltis, J. and Murphy, S. (2014). Air quality concerns of unconventional oil and natural gas production. Environmental Science. Processes \& Impacts, 16(5), 954-69. http://doi.org/10.1039/c4em00081a

Foss, M.M. (2011) The Outlook for U.S. Gas Prices in 2020: Henry hub at $\$ 3$ or $\$ 10$ ?. Oxford Institute for Energy Studies. NG 58. December 2011. ISBN 978-1-907555-39-8.

FracFocus. (2011) National Hydraulic Fracturing Chemical Disclosure Registry. $\begin{array}{llll}\text { Launched } & \text { on } & \text { April } & 11,\end{array}$ https://fracfocus.org/hydraulic-fracturing-how-it-works/hydraulic-fracturing-pro cess. Accessed June 23, 2017.

Freeze, R.A. and Cherry, J.A. (1979). Groundwater. Prentice Hall, Inc., New Jersey. ISBN: 978-0133653120.

FROGTECH (2013) Potential Geological Risks Associated with Shale Gas Production in Australia. Project Code: AAS801. January 2013.

García-Portero, J. (2012) El gas natural no convencional. El gas natural como energía puente entre el presente energético y el deseable futuro sostenible. $11^{\circ}$ Congreso Nacional del Medio Ambiente (CONAMA 2012). Comunicación técnica escrita. Libro de Actas del $12^{\circ}$ Congreso Nacional del Medio Ambiente (CONAMA). Madrid, España., Volume ISBN 978-84-695-6377-9. 
Gandossi, L. (2013). An overview of hydraulic fracturing and other formation stimulation technologies for shale gas production. European Commisison Joint Reserach Center Technical Reports. http://doi.org/10.2790/99937

Gdanski, R. D.; Fulton, D. D. and Johnson, B. J. (2010). Returns Matching Reveals New Tools for Fracture/Reservoir Evaluation. Society of Petroleum Engineers. http://doi.org/10.2118/133806-MS

Gobierno de España. (2017) El Gas Natural. Secretaría de Estado de Energía. Ministerio de Energía, Turismo y Agenda Digital. Gobierno de España. http://www.minetad.gob.es/energia/Gas/Paginas/Index.aspx

Gottardo, S.; Amenta, V.; Mech, A.; Sokull-Klüttgen, B. (2013). Assessment of the use of substances in hydraulic fracturing of shale gas reservoirs under REACH. http://doi.org/10.2788/86037

Groat, C. G. and Grimshaw T. W. (2012) "Fact-Based Regulation for Environmental Protection in Shale Gas Development" A Report by: Energy Institute. University of Texas. February 2012.

Gülen, G.; Browning, J.; Ikonnikova, S.; Tinker, S. W. (2013). Barnett Shale Production Outlook. SPE Economics and Management 5(3):89-104. July 2013.

Hayes, T. (2009). Sampling and Analysis of Water Streams Associated with the Development of Marcellus Shale Gas. Marcellus Shale Coalition Report.

Hayes, T. and Severin, B. F. (2012). Barnett and Appalachian Shale Water Management and Reuse Technologies. Project Report by Gas Technology Institute for Research Partnership to Secure Energy for America (RPSEA), (1700), 1-10.

He, C.; Wang, X.; Liu, W.; Barbot, E.; Vidic, R. D. (2014). Microfiltration in recycling of Marcellus Shale flowback water: Solids removal and potential fouling of polymeric microfiltration membranes. Journal of Membrane Science, 462, 88-95. http://doi.org/10.1016/j.memsci.2014.03.035

Healy, D. (2012) "Hydraulic Fracturing or 'Fracking': A Short Summary of Current Knowledge and Potential Environmental Impacts”. July 2012.

Hoeman, K.; Klasner, S. and Karcher, A. L. (2011). Method for Identification and Analysis of Polysaccharide-Based, Hydraulic-Fracture Flowback Fluid. Society of Petroleum Engineers. SPE International Symposium on Oilfield Chemistry, 11-13 April, The Woodlands, Texas, USA. SPE-141146-MS http://doi.org/10.2118/141146-MS

Hoffman, A.; Gustaf, O. and Andreas, L. (2014). Shale Gas and Hydraulic Fracturing 
Framing the Water Issue. Report Nr. 34. SIWI, Stockholm.

House of Commons. (2011). Shale Gas. Energy and Climate Change Committee. Fifth Report of Session 2010-12. HC 795. Published on 23 May 2011.

Houston, N. A.; Blauch, M. E.; Weaver, D. R.; Miller, D.; Hara, D.O. (2009). Fracture-Stimulation in the Marcellus Shale-Lessons Learned in Fluid Selection and Execution. Society of Petroleum Engineers. SPE Eastern Regional Meeting, 23-25 September 2009, Charleston, West Virginia, USA. SPE-125987-MS http://doi.org/10.2118/125987-MS

IRGC (International Risk Governance Council). 2013 "Risk Governance Guidelines for Unconventional Gas Development". International Risk Governance Council, Lausanne, 2013. ISBN 978-2-9700-772-8-2.

ITRC (Interstate Technology \& Regulatory Council). 2015. Integrated DNAPL Site Characterization and Tools Selection (ISC-1). Washington, D.C.: Interstate Technology \& Regulatory Council, DNAPL Site Characterization Team. www.itrcweb.org/DNAPL-ISC tools-selection.

http://www.itrcweb.org/DNAPL-ISC tools-selection/Content/Appendix \%20I.\% 20Foc\%20Tables.htm

Jackson, R. B.; Vengosh, A.; Darrah, T. H.; Warner, N. R.; Down, A.; Poreda, R. J.; Osborn, S. G.; Zhao, K.; Karr, J. D. (2013). Increased stray gas abundance in a subset of drinking water wells near Marcellus shale gas extraction. Proceedings of the National Academy of Sciences of the United States of America, 110(28), 11250-11255. http://doi.org/10.1073/pnas.1221635110

Jackson, R. E., Gorody, a. W., Mayer, B., Roy, J. W., Ryan, M. C.,; Van Stempvoort, D. R. (2013). Groundwater protection and unconventional gas extraction: The critical need for field-based hydrogeological research. Groundwater, 51(4), 488510. http://doi.org/10.1111/gwat.12074

Jaime, A. and Caparroz, M. (n.d.). Repercusiones territoriales de la fractura hidráulica o " fracking” en Cantabria , Burgos y Palencia . Los Permisos de Investigación Bezana y Bigüenzo, 141. Retrieved from http://eprints.ucm.es/23795/1/Fracking_pdf.pdf

Jarvie, D.M.; Hill, R.J.; Pollastro, R.M.; Claxton, B.L.; Bowker, K.A., (2004) Evaluation of hydrocarbon generation and storage in the Barnett Shale, Fort Worth basin, in Barnett Shale and other Fort Worth basin plays, Ellison Miles Memorial Symposium, Ellison Miles Geotechnical Institute, Brookhaven College, TX, p. 2-5.

Jiang, M.; Hendrickson, C.T. and VanBriesen, J. M. (2014). Life Cycle Water 
Consumption and Wastewater Generation Impacts of a Marcellus Shale Gas Well. Environ. Sci. Technol. 2014, 48, 1911-1920. dx.doi.org/10.1021/es4047654

Jódar Abellán, A. (2014). Recursos no convencionales susceptibles de ser explotados mediante Fracking. $12^{\circ}$ Congreso Nacional del Medio Ambiente (CONAMA). Libro de Actas del $12^{\circ}$ Congreso Nacional del Medio Ambiente (CONAMA). Madrid, España., Volume: ISBN: 978-84-697-2060-8.

Jurus, W. J.; Whitson, C. H. and Golan, M. (2013). Modeling Water Flow in Hydraulically-Fractured Shale Wells. Paper presented at the SPE Annual Technical Conference and Exhibition held in New Orleans, Louisiana, USA, 30 Spetpermeber-2 October 2013. SPE-166439-MS. doi: 10.2118/166439-MS.

Jury, W. A.; Russo, D.; Streile, G.; El Abd, H. (1990). Evaluation of Volatilization by Organic Chemicals Residing Below the Soil Surface. Water Resources Research 26(1), 13-20.

Jury, W. A.; Spencer, W. F.; and W. J. Farmer. (1983). Behavior assessment model for trace organics in soil: I. Model description. J. Environ. Qual. Vol. 12 (4): 558-564.

Kan, A.T.; Chen, W.; Tomson, M.B. (2000) Desorption kinetics of neutral hydrophobic organic compounds from field-contaminated sediment. Environmental Pollution 108 (1) pp.81-89.

King, G. E. (2012). Hydraulic Fracturing 101: What Every Representative, Environmentalist, Regulator, Reporter, Investor, University Researcher, Neighbor and Engineer Should Know About Estimating Frac Risk and Improving Frac Performance in Unconventional Gas and Oil Wells. S. Proceedings of the SPE Hydraulic Fracturing Technology Conference, 80 pp. http://doi.org/10.2118/152596-MS

Kinnaman, T. C. (2011). The economic impact of shale gas extraction: A review of existing studies. Ecological Economics, 70(7), 1243-1249. http://doi.org/10.1016/j.ecolecon.2011.02.005

Kondash A.J.; Albright E. and Vengosh A. (2017). Quantity of flowback and produced waters from unconventional oil and gas exploration. Science of the Total Environment 574 (2017) 314-321

Kravchenko, J., Darrah, T. H., Miller, R. K., Lyerly, H. K.; Vengosh, A. (2014). A review of the health impacts of barium from natural and anthropogenic exposure. Environmental Geochemistry and Health, 36(4), 797-814. http://doi.org/10.1007/s10653-014-9622-7 
Krupnick A. J.; Gordon H. and Olmstead S. (2013). Pathways to Dialogue: What the Experts Say about the Environmental Risks of Shale Gas Development. RFF Report. February 2013. Available on: http://www.rff.org/files/sharepoint/Documents/RFF-Rpt-PathwaystoDialogue_F ullReport.pdf . (Last access 2017/10/24)

Krupnick, A. and Gordon, H. (2015). What Experts Say about the Environmental Risks of Shale Gas Development. Agricultural and Resource Economics Review 44 (2): 106-19.

Krupnick, A.; Wang, Z. and Wang, Y. (2014). Environmental risks of shale gas development in China. Energy Policy, 2014, vol. 75, issue C, pages 117-125.

Krupnick, A.J. (2012). Risk Matrix for Shale Gas Development. Resources for the Future. Available at http://www.rff.org/blog/2012/risk-matrix-shale-gas-development

Kuuskraa, V.; Stevens, S.H. and Moodhe, K.D. (2013) Tecchnically recoverable shale oil and shale gas resources: An assessment of 137 shale formations in 41 countries outside the United States 2013.

Kuuskraa, V.; Stevens, S.; Van Leeuwen, T.; Moodhe, K. (2011) World Shale Gas Resources: An Initial Assessment of 14 regions Outside the United States. Washington, DC, US DOE EIA, April 2011.

Kuuskraa, V.A.; Wicks, D.E.; Sawyer, W.K.; Esposito, P.R., (1983) Technically recoverable Devonian shale gas in Ohio: DOE/MC/19239-1525 (DE84003057), July 1983, 101 p.

Kuwayama, Y.; Roeshot, S.; Krupnick, A.; Richardson, N.; Mares, J. (2017) Risks and mitigation options for on-site storage of wastewater from shale gas and tight oil development. Energy Policy 101 (2017) 582-593.

Kuwayama, Y.; Roeshot, S.; Krupnick, A.; Richardson, N.; Mares, J. (2015) Pits versus Tanks: Risks and Mitigation Options for On-site Storage of Wastewater from Shale Gas and Tight Oil Development. Resources for the Future. Discussion Paper RFF DP 15-53. December 2015.

Litovitz, A., Curtright, A., Abramzon, S., Burger, N.; Samaras, C. (2013). Estimation of regional air-quality damages from Marcellus Shale natural gas extraction in Pennsylvania. Environmental Research Letters, 8(1), 14017. http://doi.org/10.1088/1748-9326/8/1/014017

Logan J.D. (2001) Transport modeling in hydrogeochemical systems. Publisher: Springer-Verlag New York 2001. eBook ISBN 978-1-4757-3518-5. 
Lonati, G. and Zanoni, F. (2012). Probabilistic health risk assessment of carcinogenic emissions from a MSW gasification plant. Environment International, 44(1), 8091. http://doi.org/10.1016/j.envint.2012.01.013

Manger, E. G. (1963). Porosity and Bulk Density of Sedimentary Rocks. Geological Survery Bulletin 1144-E, 62.

Matesanz-Caparroz, J. (2013). Repercusiones territoriales de la fractura hidráulica o fracking en Cantabria, Burgos y Palencia. Los Permisos de Investigación Bezana y Bigüenzo. Universidad Complutense de Madrid.

McGlade, C.; Speirs, J. and Sorrell, S. (2013). Methods of estimating shale gas resources - Comparison, evaluation and implications. Energy. Volume 59, 15 September 2013, Pages 116-125. http://dx.doi.org/10.1016/j.energy.2013.05.031

McKenzie, L. M.; Witter, R. Z.; Newman, L. S.; Adgate, J. L. (2012). Human health risk assessment of air emissions from development of unconventional natural gas resources. Science of the Total Environment, 424, 79-87. http://doi.org/10.1016/j.scitotenv.2012.02.018

Meng, Q. (2015). Spatial analysis of environment and population at risk of natural gas fracking in the state of Pennsylvania, USA. The Science of the Total Environment, 515-516, 198-206. http://doi.org/10.1016/j.scitotenv.2015.02.030

MIT - Massachusetts Institute of Technology. (2011). The future of Natural Gas. An Interdisciplinary MIT Study. 2011. http://energy.mit.edu/wp-content/uploads/2011/06/MITEI-The-Future-of-Natura 1-Gas.pdf

Molofsky, L. J.; Connor, J. A.; Wylie, A. S.; Wagner, T.; Farhat, S. K. (2013). Evaluation of Methane Sources in Groundwater in Northeastern Pennsylvania. Groundwater, 51(3), 333-349. http://doi.org/10.1111/gwat.12056

Moore, C. W.; Zielinska, B.; Pétron, G.; Jackson, R. B. (2014). Air impacts of increased natural gas acquisition, processing, and use: A critical review. Environmental Science and Technology, 48(15), 8349-8359. http://doi.org/10.1021/es4053472

Nash, J. E. and Sutcliffe, J. V. (1970). River flow forecasting through conceptual models, Part I - A discussion of principles.J. Hydrol., 10, 282-290, 1970.

Natural Resources Canada. (2016). Shale Gas Strategic, technical, environmental and regulatory issues. Government of Canada, (February). Retrieved from http://www.nrcan.gc.ca/node/5687

NCBI - National Center for Biotechnology Information (NCBI)[Internet]. Bethesda 
(MD): National Library of Medicine (US), National Center for Biotechnology Information; (1988). PubChem Compound Database; CID=996, https://pubchem.ncbi.nlm.nih.gov/compound/996 [accessed Apr. 24, 2017].

Neuman, P. (1990). Universal Scaling of Hydraulic Conductivities and Dispersivities in Geologic Media. Water Resour. Res., 26(8), 1749-1758. http://doi.org/10.1029/WR026i008p01749

Oraee-Mirzamani, B.; Cockerill, T. and Makuch Z. (2013) "Risk assessment and management associated with CCS”. Energy Procedia 37 ( 2013 ) 4757 - 4764.

Osborn, S. G.; Vengosh, A.; Warner, N. R.; Jackson, R. B. (2011). Methane contamination of drinking water accompanying gas-well drilling and hydraulic fracturing. Proceedings of the National Academy of Sciences of the United States of America, 108(20), 8172-8176. http://doi.org/10.1073/pnas.1109270108

Patil, S.B. and Chore, H.S. (2014) Contaminant transport through porous media: An overview of experimental and numerical studies. Advances in Environmental Research, Vol. 3(1) 45-69.

Pennsylvania Department of Environmental Protection. (2016). 2015 Oil and Gas Annual Report. 8000-RE-DEP-4621 6/2016 Available at: http://www.elibrary.dep.state.pa.us/dsweb/Get/Document-113887/8000-RE-DE P4621.pdf

Pérez, Ma.P. (1988) Razonamiento probabilístico y correlacional: influencia de teorías previas y de datos. Tesis doctoral. Dpto. de Psicología Básica, Social y Metodología. Facultad de Psicología. Universidad Autónoma de Madrid, 1988.

Poulter, S. R. (1998). Monte-Carlo Simulation in Environmental Risk Assessment Science, Policy and Legal Issues. Risk: Health, Safety \& Environment Vol 9 (1) Article 4. (1998).

Rahm, B. G.; Bates, J. T.; Bertoia, L. R.; Galford, A. E.; Yoxtheimer, D. A.; Riha, S. J. (2013). Wastewater management and Marcellus Shale gas development: Trends, drivers, and planning implications. Journal of Environmental Management, 120, 105-113. http://doi.org/10.1016/i.jenvman.2013.02.029

Royal Society/Royal Academy of Engineering (RS/RAEng). (2012) Shale Gas Extraction in the UK: A Review of Hydraulic Fracturing. DES2597. London, UK: RS/RAEng; 2012.

Rozell, D. J. and Reaven, S. J. (2012). Water Pollution Risk Associated with Natural Gas Extraction from the Marcellus Shale. Risk Analysis, 32(8), 1382-1393. http://doi.org/10.1111/j.1539-6924.2011.01757.x 
Runkel, R. L. (1996). Solution of the advection-dispersion equation: continuous load of finite duration. Journal of Environmental Engineering Vol. 122, Issue 9: 830-832 (September http://ascelibrary.org/doi/10.1061/\%28ASCE\%290733-9372\%281996\%29122\% 3A9\%28830\%29\#sthash.EN19Fe7L.dpuf

Sauty, J.P. (1980) An analysis of hydrodispersive transfer in aquifers. Water Resources Research, Vol. 16 (1), pp. 145-158, February 1980.

Schlegel, M. E.; McIntosh, J. C.; Petsch, S. T.; Orem, W. H.; Jones, E. J.P.; Martini, A. M. (2013). Extent and limits of biodegradation by in situ methanogenic consortia in shale and formation fluids. Applied Geochemistry. Volume 28, January 2013, Pages 172-184.

SEAB (2011). The SEAB Shale Gas Production Subcommittee Ninety-Day ReportAugust 2011. 11, Available at http://thehill.com/images/stories/blogs/energy/subcommrpt.pdf

Shan, C. and Stephens D. B. (1995) An analytical solution for vertical transport of volatile chemicals in the vadose zone: Journal of Contaminant Hydrology, v. 18, no. 4, p. 259-277, doi:10.1016/0169-7722(95)00011-J.

Shafiee, S. and Topal, E. (2009). When will fossil fuel reserves be diminished? Energy Policy, 37(1), 181-189. http://doi.org/10.1016/j.enpol.2008.08.016

Shoemaker. CA.; Culver, T.B.; Lion, L.W.; Peterson, M.G., (1990). Analytical models of the impact of two-phase sorption on subsurface transport of volatile chemicals. Water Resour. Res., 26(4): 745-758.

Slovic, P. and Fischhoff, B. (1977) On the psychology of experimental surprises. Journal of Experimental Psychology: Human Perception and Performance, 3, 1977.

Sovacool, B.K. (2014). Cornucopia or curse? Reviewing the costs and benefits of shale gas hydraulic fracturing (fracking). Renewable and Sustainable Energy Reviews 37. pp 249-264

Srebotnjak, T. and Rotkin-Ellman, M. (2014). Fracking Fumes: Air Pollution from Hydraulic Fracturing Threatens Public Health and Communities. NRDC Issue BRIEF, IP:14-10-A. December 2014.

Stevens, P. (2012). The 'Shale Gas Revolution': Developments and Changes. Energy, Environment and Resources, August 2012. EERG BP 2012/04.

Stevens, P. (2010). The 'Shale Gas Revolution': Hype and Reality. A Chatham House 
Report, ISBN 978186203239 2. September 2010.

Stewart, Brian W. (Guest Editors), Rosemary C. Capo, Carl S. Kirby (2015) Preface:

Geochemistry of unconventional shale gas from formation to extraction: Petrogenesis, hydraulic fracturing, and environmental impacts. Applied Geochemistry 60 (2015) 1-2.

Stringfellow, W. T.; Domen, J. K.; Camarillo, M. K.; Sandelin, W. L.; Borglin, S. (2014) Physical, chemical, and biological characteristics of compounds used in hydraulic fracturing. J. Hazard. Mater. 2014, 275, 37-54.

Struchtemeyer, C. G., Morrison, M. D. and Elshahed, M. S. (2012). A critical assessment of the efficacy of biocides used during the hydraulic fracturing process in shale natural gas wells. International Biodeterioration and Biodegradation, 71, 15-21. http://doi.org/10.1016/j.ibiod.2012.01.013

Suárez, A. A. (2012). The Expansion of Unconventional Production of Natural Gas (Tight Gas, Gas Shale and Coal Bed Methane), Advances in Natural Gas Technology, Dr. Hamid Al-Megren (Ed.), InTech, DOI: 10.5772/37404. Available from: https://www.intechopen.com/books/advances-in-natural-gas-technology/the-exp ansion-of-unconventional-production-of-natural-gas-tight-gas-gas-shale-and-co al-bed-methane-

Swarthout, R. F.; Russo, R. S.; Sive, B. C.; Zhou, Y.; Miller, B. M.; Mitchell, B. L.; Horsman, E.; Lipsky, E.; McCabe, D. C.; Baum, E.; Sive, B. C. (2015). Impact of Marcellus Shale natural gas development in southwest Pennsylvania on volatile organic compound emissions and regional air quality. Environ. Sci. Technol., 2015, 49 (5), pp 3175-3184. http://doi.org/10.1021/es504315f

Tan, J. (2014). Shale Gas Potential of the Major Marine Shale Formations in the Upper Yangtze Platform, South China. Von der Fakultät VI - Planen Bauen Umwelt der Technischen Universität Berlin zur Erlangung des akademischen Grades eines Doktor der Naturwissenschaften Dr. rer. nat. Thesis Dissertation. Berlin 2014.

Teichert, C. (1958). Concepts of facies. Bulletin of the American Association of Petroleum Geologists, 42 p. 2718-2744.

Travis C.C. (1978) Mathematical description of adsorption and transport of reactive solutes in soil: A review of selected literature. ORNL-5403. October 1978.

U.S. EIA (Energy Information Administration) (2013) Technically Recoverable Shale Oil and Shale Gas Resources: An Assessmentof 137 Shale Formations in 41 Countries Outside the United States. U.S. Department of Energy, June 2013. 
U.S. EPA. (2017). News Releases from Headquarters. Air and Radiation (OAR), available

https://www.epa.gov/newsreleases/epa-releases-first-ever-standards-cut-methan e-emissions-oil-and-gas-sector

U.S. EPA. (2016). Hydraulic Fracturing for Oil and Gas: Impacts from the Hydraulic Fracturing Water Cycle on Drinking Water Resources in the United States (Final Report). U.S. Environmental Protection Agency, Washington, DC, EPA/600/R-16/236F, 2016).

U.S. EPA. (2015) Assessment of the Potential Impacts of Hydraulic Fracturing for Oil and Gas on Drinking Water Resources (External Review Draft). U.S. Environmental Protection Agency, Washington, DC, EPA/600/R-15/047, 2015. http://cfpub.epa.gov/ncea/hfstudy/recordisplay.cfm?deid=244651

US EPA Technical Panel. (1997). Guiding Principles for Monte-Carlo Analysis. Risk Assessment Forum - U.S. Environmental Protection Agency. EPA/630/R-97/001 (March 1997), 1-35.

Veiguela, M.; Hurtado, A.; Eguilior, S.; Recreo, F.; Roqueñi N.; Loredo, J. (2016) “A risk assessment tool applied to the study of shale gas resources". Science of the Total Environment 571 (2016) 551-560.

Vengosh, A.; Jackson, R. B.; Warner, N.; Darrah T.H.; Kondash A. (2014). A Critical Review of the Risks to Water Resources from Unconventional Shale Gas Development and Hydraulic Fracturing in the United States. Environ. Sci. Technol., 2014, 48 (15), pp 8334-8348.

Vidic, R. D.; Brantley, S. L.; Vandenbossche, J. M.; Yoxtheimer, D.; Abad, J. D. (2013). Impact of shale gas development on regional water quality. Science. 2013 May 17; 340(6134):1235009. doi: 10.1126/science.1235009.

Viscusi, W. K.; Hamilton, J. T.; Dockins, P. C. (1997) Conservative versus Mean Risk Assessments: Implications for Superfund Policies. Journal of Environmental Economics and Management 34, 187-206.

Wang, Guochang and Carr, T.R. (2013) Organic-rich Marcellus Shale lithofacies modeling and distribution pattern analysis in the Appalachian Basin. AAPG Bulletin December 2013, 97 (12).

Wang, Zhongmin and Krupnick, Alan (2013) A Retrospective Review of Shale Gas Development in the United States. What Led to the Boom?. Resources for the Future. Discussion paper. RFF DP 13-12 April 2013.

Warner, N. R., Christie, C. A., Jackson, R. B.; Vengosh, A. (2013). Impacts of shale gas 
wastewater disposal on water quality in Western Pennsylvania. Environmental Science and Technology, 47(20), 11849-11857. http://doi.org/10.1021/es402165b

Warner, N. R.; Jackson, R. B.; Darrah, T. H.; Osborn, S. G.; Down, A.; Zhao, K.; White, A.; Vengosh, A. (2012) "Geochemical evidence for possible natural migration of Marcellus Formation brine to shallow aquifers in Pennsylvania" PNAS vol. 109 no. 30,pp 11961-11966, doi: 10.1073/pnas.1121181109. (May 2012).

Wattenberg, E. V.; Bielicki, J. M.; Suchomel, A. E.; Sweet, J. T.; Vold, E. M.; Ramachandran, G. (2015) Assessment of the Acute and Chronic Health Hazards of Hydraulic Fracturing Fluids. J. Occup. Environ. Hyg. 2015, 12 (9), 611-624.

Waxman, H. A.; Markey, E. J. and DeGette, D. (2011). Chemicals used in hydraulic fracturing. United States House of Representatives. Committee on Energy and Commerce. Minority Staff. April 2011.

Wendt, Anna K.; Arthur, Mike A.; Slingerland, Rudy; Kohl, Daniel; Bracht, Reed; Engelder, Terry (2015). Geochemistry and depositional history of the Union Springs Member, Marcellus Formation in central Pennsylvania American Association of Petroleum Geologists and Society of Exploration Geophysicists. August 2015; 3 (3).

Werner, A.K.; Vink, S.; Watt, K.; Jagals, P. (2015). Environmental health impacts of unconventional natural gas development: A review of the current strength of evidence. Science of The Total Environment Volume 505, 1 February 2015, Pages 1127-1141.

Willmot, C. J. (1981). On the validation of models. Physical Geography, 2,Iss. 2. pp 184-194, 1981.

Wood, R.; Gilbert, P.; Sharmina, M.; Anderson, K. (2011) Shale gas: a provisional assessment of climate change and environmental impacts. A report commissiones by the Cooperative and undertaken by researchers at The Tyndall Centre, University of Manchester. January 2011.

World Energy Council (2011), 'Survey of Energy Resources: Shale Gas - What's New?', World Energy Council, London.

Wright, P.R.; McMahon, P.B.; Mueller, D.K.; Clark M.L. (2012). Groundwater-quality and quality-control data for two monitoring wells near Pavillion, Wyoming, April and May 2012. U.S. Geological Survey Data Series 718, 26 p.

Wrightstone, G. R., 2008, Marcellus Shale: Regional overview from an industry perspective (abs.): AAPG Eastern Section Meeting: 
http://www.papgrocks.org/wrightstone.pdf

Yap, Nonita T. (2016) Unconventional shale gas development: challenges for environmental policy and EA practice. Impact Assessment And Project Appraisal Vol. 34 , Iss. 2, 2016.

Yost, E. E.; Stanek, J. J.; DeWoskin, R. S.; Burgoon, L. D. (2016a) Overview of Chronic Oral Toxicity Values for Chemicals Present in Hydraulic Fracturing fluids, Flowback and Produced Waters. Environ. Sci. Technol. 2016, 50 (9), 4788-4797.

Yost, E. E.; Stanek, J. J.; DeWoskin, R. S.; Burgoon, L. D. (2016b) Estimating the Potential Toxicity of Chemicals Associated with Hydraulic Fracturing Operations Using Quantitative Structure-Activity relationship Modeling. Environ. Sci. Technol. 2016, 50, 7732-7742.

Zhang, Dongxiao and Yang, Tingyun (2015) Environmental impacts of hydraulic fracturing in shale gas development in the United States. Petrol. Explor. Develop., 2015, 42(6): 876-883.

Zielinski, R.E., and McIver, R.D. (1982). Resource and exploration assessment of the oil and gas potential in the Devonian gas shales of the Appalachian Basin: Mound Facility operated by Monsanto Research Corporation for the U.S. Department of Energy, contract No. DE-ACO4-76-DP00053, Report MLM-MU-82-61-0002 DOE/DP/0053-1125, 326 p., 2 appendices.

Zoback, M.; Kitasei, S.; Copithorne B. (2010) "Addressing the Environmental Risks from Shale Gas Development". Worldwatch Institute, Natural gas and sustainable energy initiative. July 2010. 


\section{APPENDIX}

SI Table 8-1: $k_{o c}$ parameters

\begin{tabular}{|c|c|c|c|c|c|c|c|}
\hline Group & Chemicals & $K_{o c}$ & $K_{o c \_a v e r}$ & Group & Chemicals & $K_{o c}$ & $K_{o c \_a v a e r}$ \\
\hline Acetophenone & Acetophenone & 52 & 52 & NAPH & Naphthalene & 1540 & 1540 \\
\hline Benzene & Benzene & 146 & 146 & \multirow{8}{*}{ PAHs-NAPH } & Acenaphthene & 5030 & \multirow{8}{*}{63384} \\
\hline Phenol & Phenol & 148 & 148 & & Acenaphthylene & 5030 & \\
\hline \multirow{6}{*}{ TEX } & Ethylbenzene & 446 & \multirow{6}{*}{366} & & Chrysene & 181000 & \\
\hline & Toluene & 234 & & & Fluoranthene & 55500 & \\
\hline & Xylene, P- & 375 & & & Fluorene & 9160 & \\
\hline & Xylene, m- & 375 & & & Phenanthrene & 16700 & \\
\hline & Xylene, o- & 383 & & & Pyrene & 54300 & \\
\hline & Xylenes & 383 & & & 2-Methylnaphthalene & 1735 & \\
\hline
\end{tabular}




\begin{tabular}{|c|c|c|c|c|c|c|c|}
\hline Group & Chemicals & $K_{o c}$ & $K_{o c \_a v e r}$ & Group & Chemicals & $K_{o c}$ & $K_{o c \_a v a e r}$ \\
\hline \multirow{4}{*}{$\mathrm{TMB}$} & Trimethylbenzene, 1,2,3- & 627 & \multirow{4}{*}{624} & & 7,12-Dimethylbenz(a)anthrace & 28943 & \\
\hline & Trimethylbenzene, 1,2,4- & 614 & & & Benzo(a)anthracene & 28435 & \\
\hline & Trimethylbenzene, 1,3,5- & 602 & & & Benzo(a)pyrene & 51926 & \\
\hline & Isopropylbenzene & 654 & & & Benzo(b)fluoranthene & 51014 & \\
\hline \multirow{8}{*}{ R-Benzene } & n-Butylbenzene & 2340 & \multirow{8}{*}{1738} & & Benzo(ghi)perylene & 125893 & \\
\hline & n-Propylbenzene & 689 & & & Benzo(k)fluoranthene & 182616 & \\
\hline & p-Isopropyltoluene & 1425 & & & Dibenz(a,h)anthracene & 155707 & \\
\hline & sec-Butylbenzene & 3276 & & & Fluoranthene & 9316 & \\
\hline & Styrene & 959 & & & Indeno(1,2,3-cd)pyrene & 115223 & \\
\hline & & & & & & & \\
\hline & & & & & & & \\
\hline & & & & & & & \\
\hline
\end{tabular}


SI Table 8-2 $\rho\left(\mathrm{g} / \mathrm{cm}^{3}\right)$ parameters

\begin{tabular}{|c|c|c|c|c|c|c|c|}
\hline Group & Chemicals & $\rho$ & $\rho_{\text {average }}$ & Group & Chemicals & $\rho$ & $\rho_{\text {average }}$ \\
\hline Acetophenone & Acetophenone & 1.03 & 1.03 & NAPH & Naphthalene & 1.03 & 1.03 \\
\hline Benzene & Benzene & 0.88 & 0.88 & \multirow{11}{*}{ PAHs-NAPH } & Acenaphthene & & \multirow{11}{*}{1.16} \\
\hline Phenol & Phenol & 1.05 & 1.05 & & Acenaphthylene & & \\
\hline \multirow{6}{*}{ TEX } & Ethylbenzene & 0.86 & \multirow{6}{*}{0.86} & & Chrysene & & \\
\hline & Toluene & 0.86 & & & Fluoranthene & & \\
\hline & Xylene, P- & 0.86 & & & Fluorene & & \\
\hline & Xylene, m- & 0.86 & & & Phenanthrene & & \\
\hline & Xylene, o- & 0.86 & & & Pyrene & & \\
\hline & Xylenes & 0.87 & & & 2-Methylnaphthalene & & \\
\hline \multirow{3}{*}{ TMB } & Trimethylbenzene, 1,2,3- & 0.89 & \multirow{3}{*}{0.87} & & 7,12-Dimethylbenz(a)anthrace & & \\
\hline & Trimethylbenzene, 1,2,4- & 0.87 & & & Benzo(a)anthracene & & \\
\hline & Trimethylbenzene, 1,3,5- & 0.86 & & & Benzo(a)pyrene & & \\
\hline
\end{tabular}




\begin{tabular}{|c|c|c|c|c|c|c|c|}
\hline Group & Chemicals & $\rho$ & $\rho_{\text {average }}$ & Group & Chemicals & $\rho$ & $\rho_{\text {average }}$ \\
\hline \multirow{4}{*}{ R-Benzene } & Isopropylbenzene & & \multirow{4}{*}{0.87} & & Benzo(b)fluoranthene & & \\
\hline & n-Propylbenzene & & & & Benzo(k)fluoranthene & & \\
\hline & sec-Butylbenzene & 0.86 & & & Fluoranthene & & \\
\hline & Styrene & 0.9 & & & Indeno(1,2,3-cd)pyrene & & \\
\hline
\end{tabular}


SI Table 8-3: $K_{H}$ parameters

\begin{tabular}{|c|c|c|c|c|c|c|c|}
\hline Group & Chemicals & $\boldsymbol{K}_{H}$ & $K_{H \_a v e r a g e}$ & Group & Chemicals & $\boldsymbol{K}_{H}$ & $K_{H \_ \text {average }}$ \\
\hline Acetophenone & Acetophenone & $4.25 \mathrm{E}-4$ & $4.25 \mathrm{E}-4$ & NAPH & Naphthalene & $1.8 \mathrm{E}-2$ & 1.8E-2 \\
\hline Benzene & Benzene & 0.23 & 0.23 & \multirow{11}{*}{ PAHs-NAPH } & Acenaphthene & & \multirow{11}{*}{$3.95 \mathrm{E}-4$} \\
\hline Phenol & Phenol & $1.36 \mathrm{E}-5$ & $1.36 \mathrm{E}-5$ & & Acenaphthylene & & \\
\hline \multirow{6}{*}{ TEX } & Ethylbenzene & 0.32 & \multirow{6}{*}{0.27} & & Chrysene & & \\
\hline & Toluene & 0.27 & & & Fluoranthene & & \\
\hline & Xylene, P- & 0.28 & & & Fluorene & & \\
\hline & Xylene, m- & 0.29 & & & Phenanthrene & & \\
\hline & Xylene, o- & 0.21 & & & Pyrene & & \\
\hline & Xylenes & 0.27 & & & 2-Methylnaphthalene & & \\
\hline \multirow{3}{*}{$\mathrm{TMB}$} & Trimethylbenzene, 1,2,3- & 0.18 & \multirow{3}{*}{0.26} & & 7,12-Dimethylbenz(a)anthrace & & \\
\hline & Trimethylbenzene, 1,2,4- & 0.25 & & & Benzo(a)anthracene & & \\
\hline & Trimethylbenzene, 1,3,5- & 0.36 & & & Benzo(a)pyrene & & \\
\hline Group & Chemicals & $\boldsymbol{K}_{\boldsymbol{H}}$ & $K_{H \_a v e r a g e}$ & Group & Chemicals & $\boldsymbol{K}_{H}$ & $K_{H \_a v e r a g e}$ \\
\hline
\end{tabular}




\begin{tabular}{|c|c|c|c|}
\hline \multirow{6}{*}{ R-Benzene } & Isopropylbenzene & \multirow{6}{*}{0.5} & Benzo(b)fluoranthene \\
\hline & n-Butylbenzene & & Benzo(ghi)perylene \\
\hline & n-Propylbenzene & & Benzo(k)fluoranthene \\
\hline & p-Isopropyltoluene & & Dibenz(a,h)anthracene \\
\hline & sec-Butylbenzene & & Fluoranthene \\
\hline & Styrene & & Indeno(1,2,3-cd)pyrene \\
\hline
\end{tabular}


SI Table 8-4: $D_{a}\left(\mathrm{~cm}^{2} / \mathrm{s}\right)$ parameters

\begin{tabular}{|c|c|c|c|c|c|c|c|}
\hline Group & Chemicals & $D_{a}$ & $D_{a \_a v e r a g e}$ & Group & Chemicals & $D_{a}$ & $D_{a \_a v e r a g e}$ \\
\hline Acetophenone & Acetophenone & $6.52 \mathrm{E}-2$ & $6.52 \mathrm{E}-2$ & NAPH & Naphthalene & $6.05 \mathrm{E}-2$ & 6.05E-2 \\
\hline Benzene & Benzene & $8.95 \mathrm{E}-2$ & 8.95E-2 & \multirow{11}{*}{ PAHs-NAPH } & Acenaphthene & & \multirow{11}{*}{ 4.47E-2 } \\
\hline Phenol & Phenol & $8.34 \mathrm{E}-2$ & 8.34E-2 & & Acenaphthylene & & \\
\hline \multirow{6}{*}{ TEX } & Ethylbenzene & $6.85 \mathrm{E}-2$ & \multirow{6}{*}{ 6.9E-2 } & & Chrysene & & \\
\hline & Toluene & $6.85 \mathrm{E}-2$ & & & Fluoranthene & & \\
\hline & Xylene, P- & $7.78 \mathrm{E}-2$ & & & Fluorene & & \\
\hline & Xylene, m- & $6.84 \mathrm{E}-2$ & & & Phenanthrene & & \\
\hline & Xylene, o- & $6.84 \mathrm{E}-2$ & & & Pyrene & & \\
\hline & Xylenes & $6.89 \mathrm{E}-2$ & & & 2-Methylnaphthalene & & \\
\hline \multirow{3}{*}{$\mathrm{TMB}$} & Trimethylbenzene, 1,2,3- & $6.13 \mathrm{E}-2$ & \multirow{3}{*}{$6.09 \mathrm{E}-2$} & & 7,12-Dimethylbenz(a)anthrace & & \\
\hline & Trimethylbenzene, 1,2,4- & $6.07 \mathrm{E}-2$ & & & Benzo(a)anthracene & & \\
\hline & Trimethylbenzene, 1,3,5- & $6.02 \mathrm{E}-2$ & & & Benzo(a)pyrene & & \\
\hline
\end{tabular}




\begin{tabular}{|c|c|c|c|c|c|c|c|}
\hline Group & Chemicals & $D_{a}$ & $D_{a \_a v e r a g e}$ & Group & Chemicals & $D_{a}$ & $D_{a \_a v e r a g e}$ \\
\hline \multirow{4}{*}{ R-Benzene } & Isopropylbenzene & & \multirow{4}{*}{ 5.73E-2 } & & Benzo(b)fluoranthene & & \\
\hline & n-Propylbenzene & & & & Benzo(k)fluoranthene & & \\
\hline & sec-Butylbenzene & & & & Fluoranthene & & \\
\hline & Styrene & & & & Indeno(1,2,3-cd)pyrene & & \\
\hline
\end{tabular}


SI Table 8-5: $D_{w}\left(\mathrm{~cm}^{2} / \mathrm{s}\right)$ parameters

\begin{tabular}{|c|c|c|c|c|c|c|c|}
\hline Group & Chemicals & $D_{w}$ & $D_{w \_a v e r a g e}$ & Group & Chemicals & $D_{w}$ & $D_{w \_a v e r a g e}$ \\
\hline Acetophenone & Acetophenone & $8.72 \mathrm{E}-6$ & 8.72E-6 & NAPH & Naphthalene & $8.38 \mathrm{E}-6$ & 8.38E-6 \\
\hline Benzene & Benzene & $1.03 \mathrm{E}-5$ & 1.03E-5 & \multirow{11}{*}{ PAHs-NAPH } & Acenaphthene & & \multirow{11}{*}{ 6.87E-6 } \\
\hline Phenol & Phenol & $1.36 \mathrm{E}-5$ & $1.36 \mathrm{E}-5$ & & Acenaphthylene & & \\
\hline \multirow{6}{*}{ TEX } & Ethylbenzene & $1.03 \mathrm{E}-5$ & \multirow{6}{*}{ 9.7E-6 } & & Chrysene & & \\
\hline & Toluene & $8.46 \mathrm{E}-6$ & & & Fluoranthene & & \\
\hline & Xylene, P- & $9.2 \mathrm{E}-6$ & & & Fluorene & & \\
\hline & Xylene, m- & $8.42 \mathrm{E}-6$ & & & Phenanthrene & & \\
\hline & Xylene, o- & $8.44 \mathrm{E}-6$ & & & Pyrene & & \\
\hline & Xylenes & $8.53 \mathrm{E}-6$ & & & 2-Methylnaphthalene & & \\
\hline \multirow{3}{*}{$\mathrm{TMB}$} & Trimethylbenzene, 1,2,3- & $8.02 \mathrm{E}-6$ & \multirow{3}{*}{ 7.94E-6 } & & 7,12-Dimethylbenz(a)anthrace & & \\
\hline & Trimethylbenzene, 1,2,4- & $7.92 \mathrm{E}-6$ & & & Benzo(a)anthracene & & \\
\hline & Trimethylbenzene, 1,3,5- & $7.84 \mathrm{E}-6$ & & & Benzo(a)pyrene & & \\
\hline Group & Chemicals & $D_{w}$ & $D_{w \_a v e r a g e}$ & Group & Chemicals & $D_{w}$ & Dw_average \\
\hline
\end{tabular}




\begin{tabular}{|c|c|c|c|}
\hline \multirow{6}{*}{ R-Benzene } & Isopropylbenzene & \multirow{6}{*}{$7.46 \mathrm{E}-6$} & Benzo(b)fluoranthene \\
\hline & n-Butylbenzene & & Benzo(ghi)perylene \\
\hline & n-Propylbenzene & & Benzo(k)fluoranthene \\
\hline & p-Isopropyltoluene & & Dibenz(a,h)anthracene \\
\hline & sec-Butylbenzene & & Fluoranthene \\
\hline & Styrene & & Indeno(1,2,3-cd)pyrene \\
\hline
\end{tabular}

